\title{
The Role of Context in the Transformation of Planned Strategy into Implemented Strategy
}

\author{
by \\ Wade R. Rose \\ M.B.A., Queen's University, 1997 \\ M.Sc., Ohio State University, 1986 \\ B.Eng., The Royal Military College of Canada, 1980
}

A thesis submitted to the Faculty of Graduate and Postdoctoral Affairs in partial fulfillment of the requirements for the degree of

Doctor of Philosophy

in

Management

Carleton University

Ottawa, Ontario

(C) 2010, Wade R. Rose 


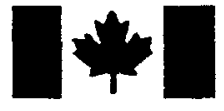

Library and Archives

Canada

Published Heritage

Branch

395 Wellington Street

Ottawa ON K1A ON4

Canada
Bibliotheqque et

Archives Canada

Direction du

Patrimoine de l'édition

395 , rue Wellington

Ottawa ON K1A ON4

Canada
Your file Votre référence
ISBN: $978-0-494-79616-0$
Our file Notre référence
ISBN: $978-0-494-79616-0$
NOTICE:

The author has granted a nonexclusive license allowing Library and Archives Canada to reproduce, publish, archive, preserve, conserve, communicate to the public by telecommunication or on the Internet, loan, distribute and sell theses worldwide, for commercial or noncommercial purposes, in microform, paper, electronic and/or any other formats.

The author retains copyright ownership and moral rights in this thesis. Neither the thesis nor substantial extracts from it may be printed or otherwise reproduced without the author's permission.
AVIS:

L'auteur a accordé une licence non exclusive permettant à la Bibliothèque et Archives Canada de reproduire, publier, archiver, sauvegarder, conserver, transmettre au public par télécommunication ou par l'Internet, prêter, distribuer et vendre des thèses partout dans le monde, à des fins commerciales ou autres, sur support microforme, papier, électronique et/ou autres formats.

L'auteur conserve la propriété du droit d'auteur et des droits moraux qui protège cette thèse. $\mathrm{Ni}$ la thèse ni des extraits substantiels de celle-ci ne doivent être imprimés ou autrement reproduits sans son autorisation.
In compliance with the Canadian Privacy Act some supporting forms may have been removed from this thesis.

While these forms may be included in the document page count, their removal does not represent any loss of content from the thesis.
Conformément à la loi canadienne sur la protection de la vie privée, quelques formulaires secondaires ont été enlevés de cette thèse.

Bien que ces formulaires aient inclus dans la pagination, il n'y aura aucun contenu manquant.

\section{Canadä}




\begin{abstract}
Since the 1970s, there has been an ongoing debate in the literature as to the most effective means of formulating strategy. One camp has touted the merits of formal deliberate strategic planning while the other camp has maintained that strategy simply emerges over time as a firm takes various actions in response to environmental stimuli. Recently, some researchers have recognized the more realistic view that deliberately planned strategies transform during implementation through an emergent strategy formation process.
\end{abstract}

A key gap in the strategy literature is a lack of theory, especially as it relates to the contextual factors which may impact strategy transformation during implementation. In general, the literature has given little consideration to the complex web of internal and external contextual factors which impact a firm at any given time.

This work contributes to the literature by taking a first step toward adding the complexity of context to our understanding of how strategies are formulated and implemented. In 1985, Mintzberg and Waters proposed the concept that intended strategies are transformed into realized strategies during implementation. This research has attempted to identify and test the contextual factors which impact strategy transformation.

An a priori model was initially developed through a review of the literature to identify variables which may impact strategy transformation during implementation. These variables were validated, and new variables added, through a series of interviews with executives. This model was then tested using a quantitative survey which was developed and populated with measures taken from the literature, and added to or modified based on the interviews.

Exploratory factor analysis was used during the data analysis to aid in the development of a Strategy Transformation Model. The model is a step toward our understanding of how strategy transforms during implementation and the factors which most impact this transformation. Further, because of the moderator and mediator interactions between the constructs, it heightens an awareness of the complex and evolving nature of strategy as an implementation proceeds. What becomes clear is that strategy is a living evolving conceptual entity and strategic plans should be living documents.

Flexibility is a central concept in the Strategy Transformation Model. Flexibility inherent in the plans, approach and culture of organizations and leadership teams allows them to react appropriately to the impacts of contextual factors during implementations. Based on the survey, some 
level of strategy transformation is the norm for most organizations. It may be that flexibility is the factor which allows leadership teams to have a level of control over how this transformation proceeds. 


\section{DEDICATION}

This thesis is dedicated to the women in my life: my wife Shirley, my daughters Sara and Amy, and my mother Doris. It is also dedicated to my father Fred. They have been and continue to be the inspiration in my life.

\section{ACKNOWLEDGEMENTS}

I would like to thank Dr. David Cray for his contributions to every portion of this work from initial concept to final product. He was a pleasure to work with and provided excellent guidance throughout.

I am thankful to Dr. Ruth McKay and Dr. Steven Murphy for being part of my thesis committee and providing suggestions which added a great deal to this research.

My thanks to Dr. Ernest Kwan and Dr. Steven Murphy who provided assistance during the data analysis phase which was critical to the quantitative results. 


\section{Table of Contents}

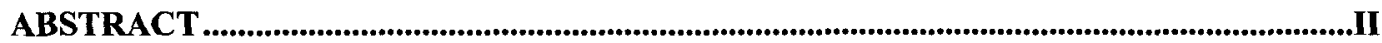

DEDICATION

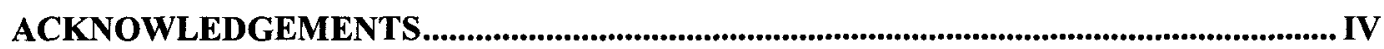

LIST OF FIGURES .............................................................................................................................................

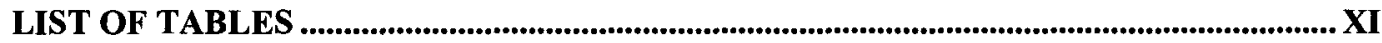

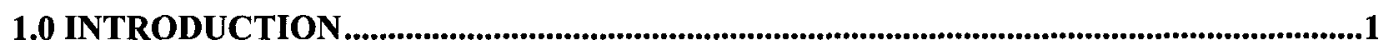

2.0 STRATEGY FORMATION AND STRATEGIC PLANNING …..........................................8

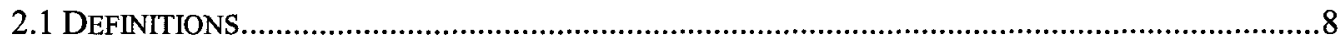

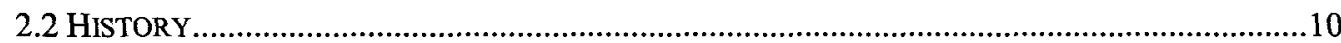

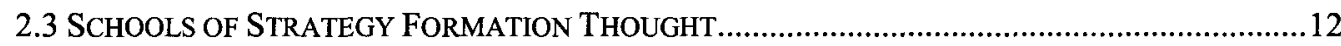

2.4 STRATEGY FoRMATION LIFECYCLE CHARACTERISTICS ....................................................14

3.0 DELIBERATE VERSUS EMERGENT STRATEGY FORMATION..............................17

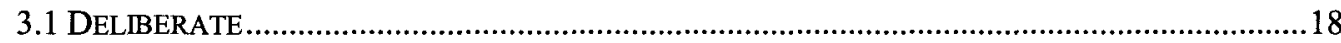

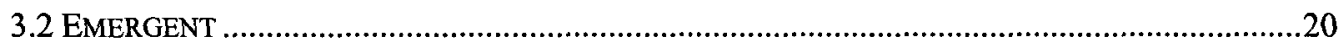

3.3 THE DELIBERATE / EMERGENT STRATEGY FORMATION CONTINUUM ...................................23

3.4 THE DELIBERATE / EMERGENT STRATEGY FORMATION DEBATE ..........................................28

4.0 STRATEGIC PLANNING AND SUBSEQUENT FIRM PERFORMANCE.....................31

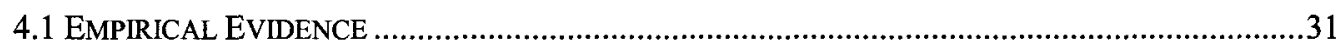

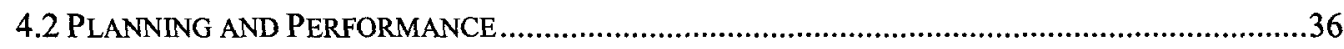

5.0 RESEARCH QUESTION ...............................................................................................................37

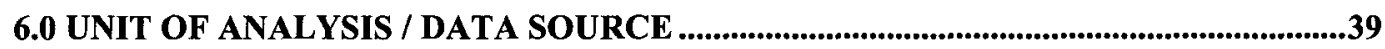

7.0 CONTEXTUAL ISSUES AND HYPOTHESES ...............................................................

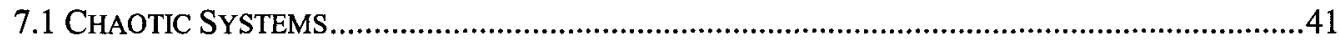


7.2 THE IMPACT OF CONTEXTUAL ISSUES ON STRATEGY FORMATION. .42

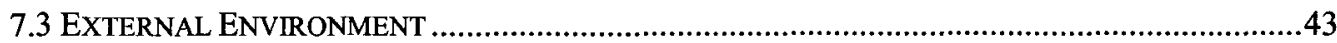

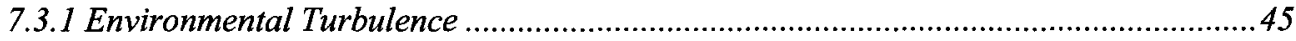

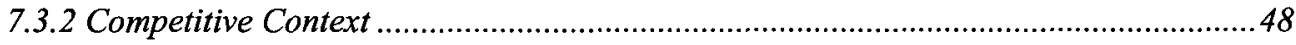

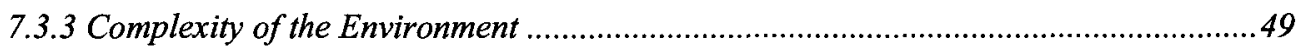

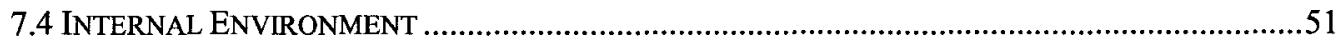

7.4.1 Characteristics of the Leadership Team ...................................................................5

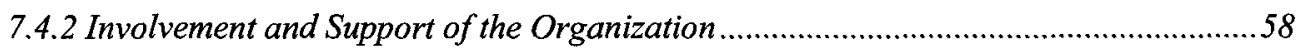

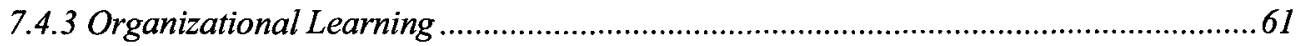

7.4.4 Organizational Learning and Strategy Formation .....................................................6. 65

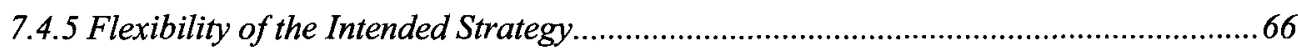

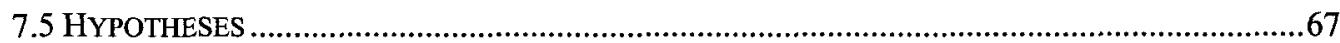

8.0 PROPOSED A PRIORI MODEL....................................................................................69

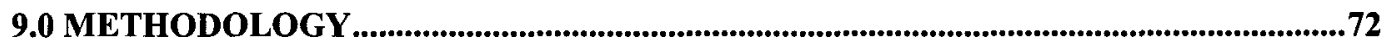

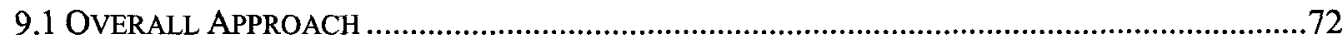

9.2 PHASE 1 - QUALTTATIVE STUDY: INTERVIEWS WITH EXECUTIVES.........................................72

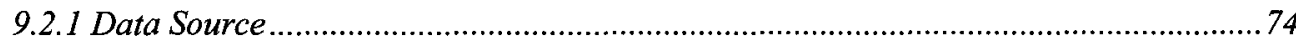

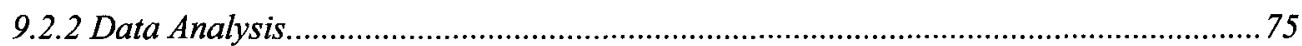

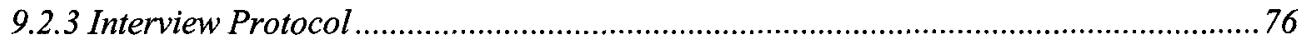

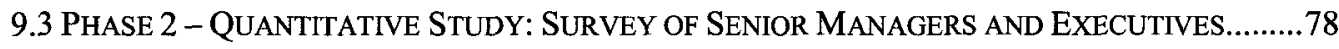

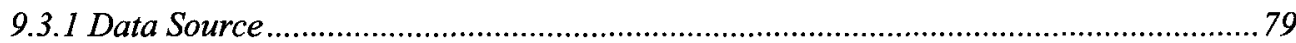

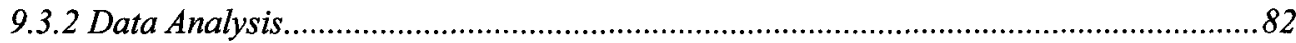

9.3.3 Survey Questions .......................................................................................................8

10.0 RESULTS - QUALITATIVE STUDY INTERVIEWS ..................................................86

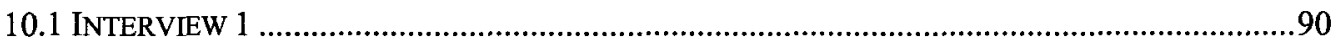

10.1.1 Strategy Example Description ............................................................................90

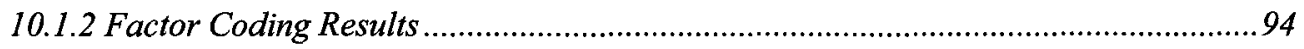




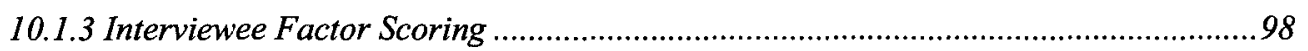

10.1.4 Factor Coding versus Interviewee Factor Scoring...............................................99

10.1.5 Interviewee Strategy Transformation Scoring …...................................................99

10.1.6 Process Issues of Interest ..........................................................................100

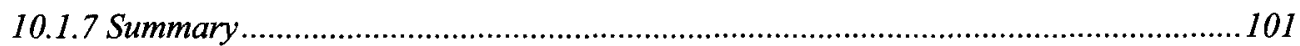

10.2 INTERVIEW 2

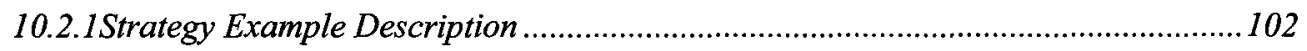

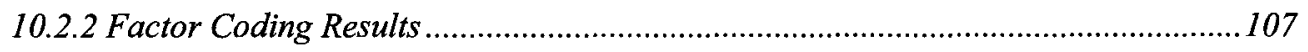

10.2.3 Interviewee Factor Scoring …….................................................................111

10.2.4 Factor Coding versus Interviewee Factor Scoring ............................................112

10.2.5 Interviewee Strategy Transformation Scoring ..................................................112

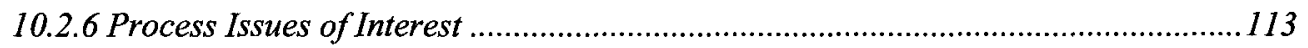

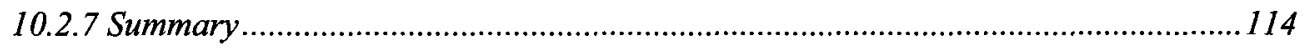

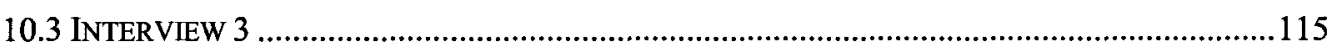

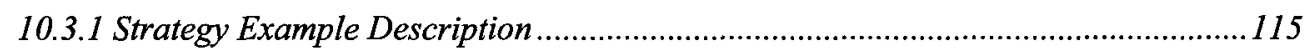

10.3.2 Factor Coding Results .................................................................................117

10.3.3 Interviewee Factor Scoring ...............................................................................121

10.3.4 Factor Coding versus Interviewee Factor Scoring................................................122

10.3.5 Interviewee Strategy Transformation Scoring .......................................................123

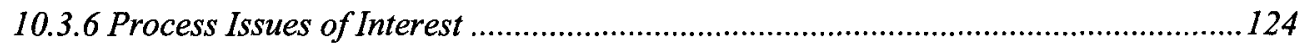

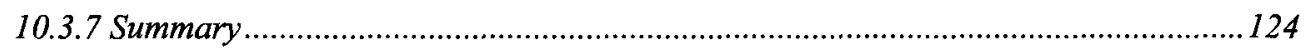

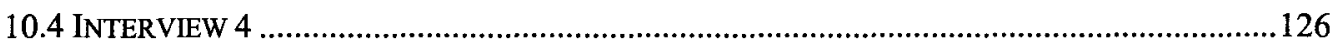

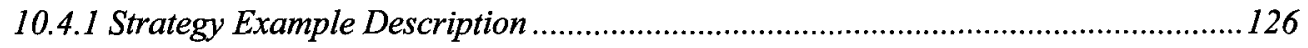

10.4.2 Factor Coding Results ...................................................................................... 130

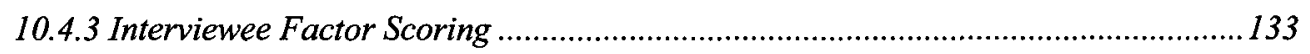

10.4.4 Factor Coding versus Interviewee Factor Scoring............................................... 134

10.4.5 Interviewee Strategy Transformation Scoring ………..........................................135

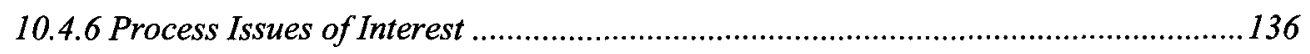


10.4.7 Summary 136

10.5 INTERVIEW 5 137

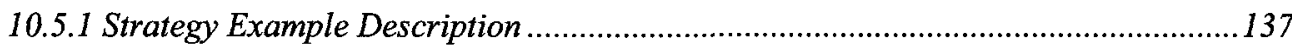

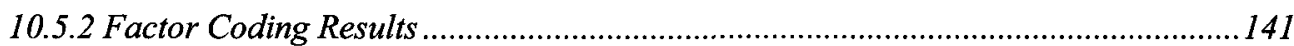

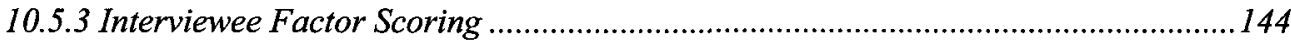

10.5.4 Factor Coding versus Interviewee Factor Scoring..................................................145

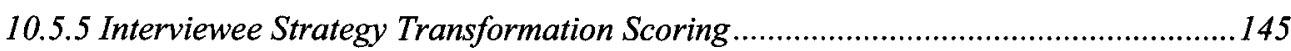

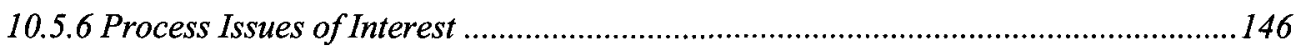

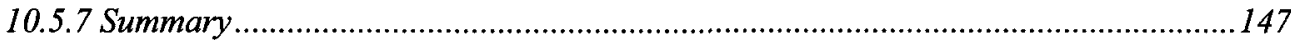

10.6 QUALITATIVE STUDY IMPACT ON QUANTITATIVE STUDY SURVEY INSTRUMENT .............148

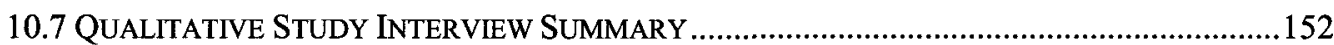

11.0 RESULTS - QUANTITATIVE STUDY SURVEY

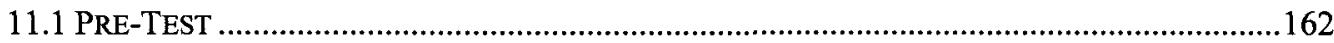

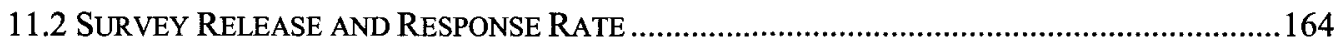

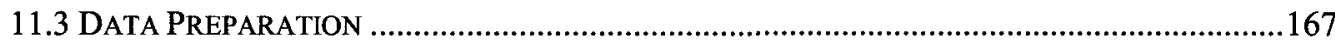

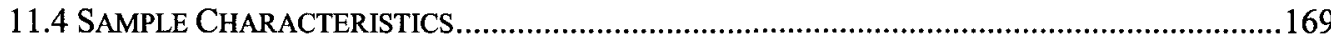

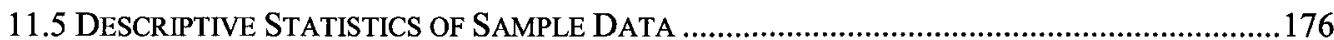

11.5.1 Level of Strategy Transformation ………...........................................................178

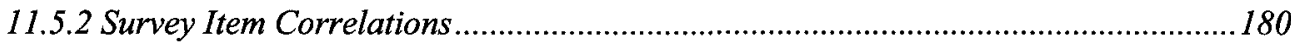

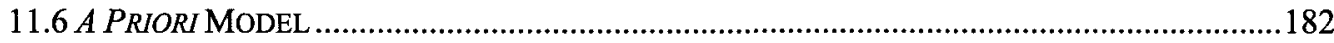

11.6.1 Factor Internal Consistency or Reliability ..........................................................184

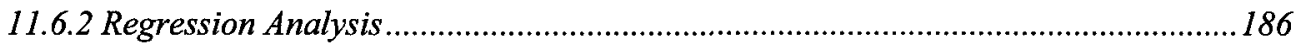

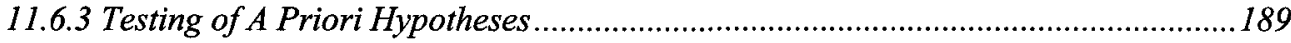

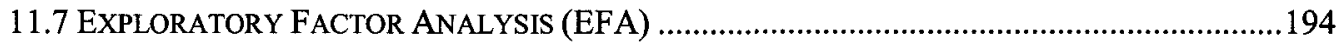

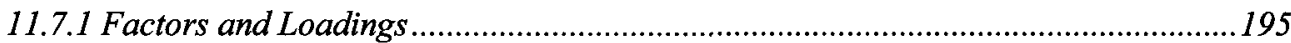

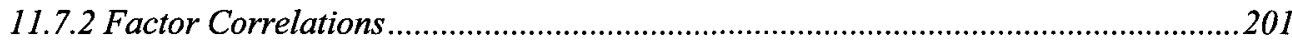

11.8 POST-EFA MODEL - THE STRATEGY TRANSFORMATION MODEL ......................................202

11.8.1 Factor Internal Consistency or Reliability ...........................................................202 
11.8.2 Regression Analysis without Moderators and Mediators

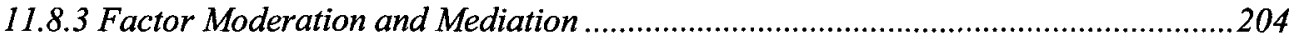

11.8.4 Regression Analysis of Final Strategy Transformation Model ............................208

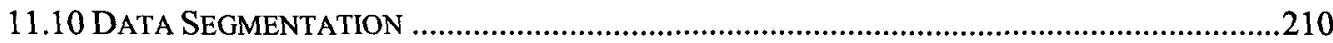

11.11 FACTORS AND ASSOCIATED INDICATORS FOR THE STRATEGY TRANSFORMATION MODEL

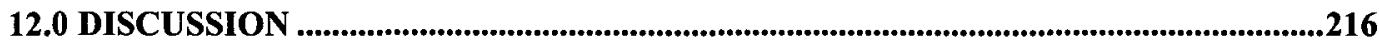

12.1 A PRIORI FACTOR / INDICATOR LOADINGS ....................................................216

12.2 A Priori Model to Final Strategy Transformation Model MaPPING..................218

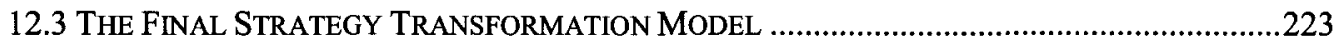

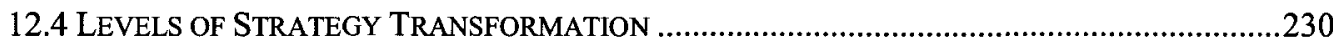

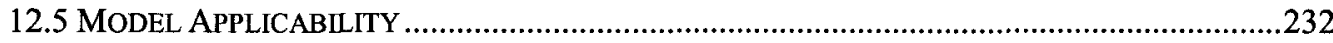

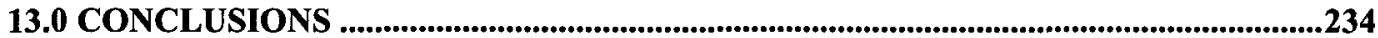

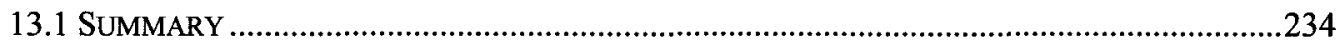

13.2 CONTRIBUTIONS TO THE STRATEGY LITERATURE .............................................238

13.3 IMPLICATIONS FOR PRACTICING MANAGERS ....................................................239

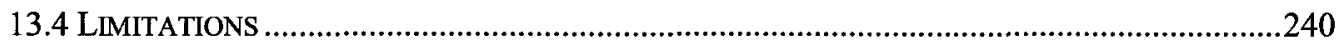

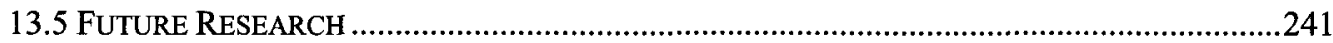

APPENDIX A - INFORMATION SCRIPT FOR INTERVIEW REQUEST ......................244

APPENDIX B - INTERVIEW QUESTIONS ..........................................................246

APPENDIX C - INTERVIEWEE SCORING OF CONTEXTUAL FACTORS ...................248

APPENDIX D - LETTER OF INFORMATION (I.E. COVERING EMAIL FOR SURVEY)

APPENDIX E - SURVEY INSTRUMENT ..............................................................................253

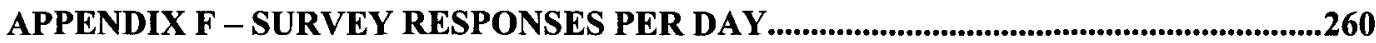


APPENDIX G - DESCRIPTIVE STATISTICS OF SAMPLE DATA IN DESCENDING

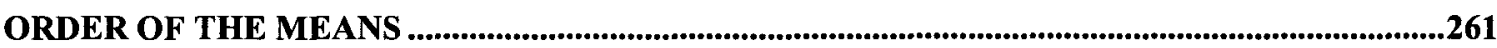

APPENDIX H - SURVEY ITEM CORRELATIONS..................................................................263

APPENDIX I - TABLEPLOT OF NINE FACTOR SOLUTION .........................................264

REFERENCES

\section{LIST OF FIGURES}

Figure 1: Strategy transformation from intended to realized strategy. ......................... 38

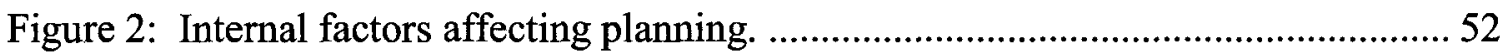

Figure 3: A Priori Strategy Transformation Model - factors taken from the literature. .. 69

Figure 4: Possible impact of moderators and mediators on the transformation of intended

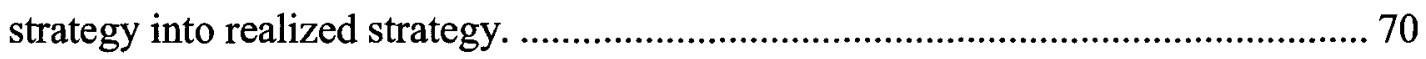

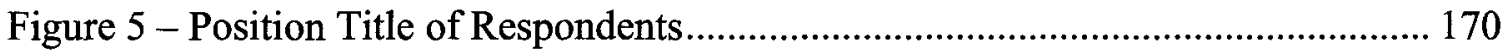

Figure 6 - Experience of Respondents in the Industry Used in their Strategy Example 171

Figure 7 - Size of the Company Used in the Strategy Example in Annual Revenue..... 172

Figure 8 - Headquarters Location of the Company Used in the Strategy Example........ 173

Figure 9 - Ownership of Company Used in the Strategy Example............................ 174

Figure 10 - Industry of Company Used in the Strategy Example.............................. 175

Figure 11 - \% of Primary Goals Achieved as Planned ........................................... 179

Figure 12 - \% of Secondary Goals Achieved as Planned. ......................................... 180

Figure 13 - Level of Agreement that Implementation Process Proceeded Exactly as

Planned 
Figure 14 - Initial Solution Scree Plot.

Figure 15 - Final Strategy Transformation Model

\section{LIST OF TABLES}

Table 1 - Informant Groups and Anticipated Response Rates and Numbers. 81

Table 2 - Factors, Indicators and Sources Used in Survey Question Development......... 84

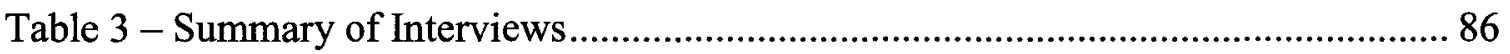

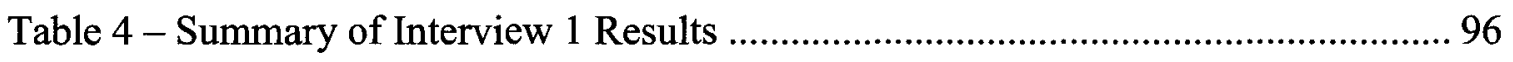

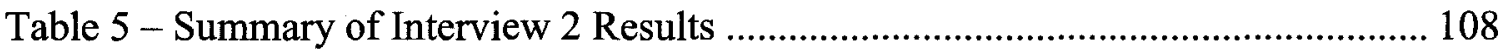

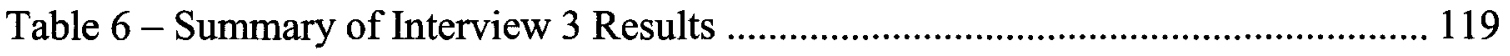

Table 7 - Summary of Interview 4 Results .......................................................... 131

Table 8 - Summary of Interview 5 Results ....................................................... 142

Table 9 - New Variables versus Interview where Indicator was First Mentioned ........ 149

Table 10 - Revised Factors, Indicators and Sources Based on Interview Results ........ 150

Table 11 - Summary of Interview Results - Factor and Indicator Frequency Counts and Frequency Based Ranking from Interview Transcripts ..................................... 153

Table 12 - Summary of Interview Results - Ranking of the Most Important Factors or Indicators from the Interviewee's Ranking on the Contextual Factor Scoring Sheets 
Table 13 - Summary of Interview Results - Transcript Coding Versus Interviewees'

Importance Ranking for Factors and Indicators.................................................... 158

Table 14 - Survey Pre-Test Observations and Corrections ............................................ 162

Table 15 - Survey Response Rate ........................................................................... 166

Table 16 - Descriptive Statistics of Sample Data in Descending Order of the Means .. 177

Table 17 - A Priori Factors and Indicator Loadings ..................................................... 183

Table 18 - Cronbach's Alphas for A Priori Factors ........................................................ 185

Table 19 - Model Summary for A Priori Model Using All Indicators ........................... 186

Table 20 - Regression Details for A Priori Model Using All Indicators ........................ 187

Table 21 - Model Summary for $A$ Priori Model Using All Remaining Indicators......... 188

Table 22 - Regression Details for A Priori Model Using All Remaining Indicators ..... 189

Table 23 - Tests of Sample Adequacy for Factor Analysis........................................... 194

Table 24 - Initial Solution Eigenvalues and Variance Explained .................................. 196

Table 25 - Pattern Matrix for Nine Factors ............................................................... 198

Table 26 - Pattern Matrix for the Nine Factor Solution with Indicator 6 Removed and

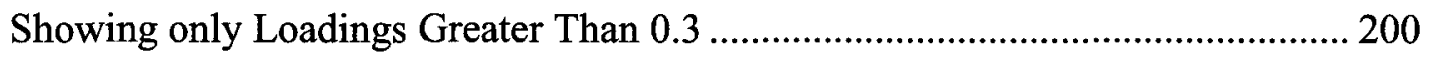

Table 27 - Correlation Table of Factors Used in Final Strategy Transformation Model202

Table 28-Cronbach's Alphas for Strategy Transformation Model Factors.................... 203

Table 29 - Model Summary for the Pre-Moderation/Mediation Model.......................... 204

Table 30 - Regression Details for Pre-Moderation/Mediation Model ............................ 204

Table 31 - Regression Results Showing the Effect of Competitors when Flexibility is

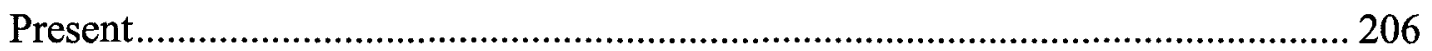


Table 32 - Regression Results Showing the Effect on Competitors when Flexibility is

Removed 207

Table 33 - Model Summary of Final Strategy Transformation Model ........................... 208

Table 34 - Regression Details of Final Strategy Transformation Model ........................ 209

Table 35 - Regression Results Showing the Effects of Each Variable ........................... 210

Table 36 - Model Summary Information for Segmented Data ........................................ 211

Table 37 - Factors and Associated Indicators for the Strategy Transformation Model. 213

Table 38 - A Priori and Final Strategy Transformation Model Factors 219 


\subsection{INTRODUCTION}

'Plans are nothing, planning is everything.' - Dwight Eisenhower

(Blythe \& Zimmerman, 2004).

The organizational strategy formation literature reveals a lack of consensus on a number of key issues critical to understanding this field of academic investigation.

Central to the debate is the question of how strategy can most effectively be formulated, a topic that has been contested since the 1970s (Andrews, 1971; Ansoff, 1991; Mintzberg, 1977; Mintzberg \& Waters, 1985). While much has been written about the deliberate and emergent schools of strategy formation, strategy researchers have not yet reached agreement on their relative merits (Boyd, 1991; Brews \& Hunt, 1999; Greenley, 1994; Holloway, 2004; Miller \& Cardinal, 1994; Schäffer \& Willauer, 2003). As a means of providing empirical support to one side of the debate or the other, several dozen studies (e.g., Andrews et al., 2009; Falshaw, Glaister, \& Tatoglu, 2006; Hopkins \& Hopkins, 1997; Slater, Olson, \& Hult, 2006; Thune \& House, 1970) have tried to quantify the proposed link between strategic planning and organizational performance with mixed results.

A review of the existing strategy formation literature yields two fundamental observations. First, there is a decades-long debate as to whether strategy formation is most effective when it is the result of a deliberate strategic planning process or when strategy is simply allowed to emerge as a result of the decisions and actions of managers over a period of time without the explicit strategic intentions of those decision makers. 
The first side of the debate started as a series of prescriptive strategic planning articles in the 1950s with the numbers increasing through the 1960s and beyond (e.g., Andrews, 1971; H. I. Ansoff, 1964; H. I. Ansoff, 1965; Selznick, 1957; Vancil \& Lorange, 1975). Support for the positive impact of strategic planning has since come from numerous scholars (Armstrong, 1982; Brews \& Hunt, 1999; Grant, 2003; Miller \& Cardinal, 1994; Robinson Jr. \& Pearce II, 1988).

The debate was joined in the 1970's with articles by Henry Mintzberg (e.g., 1972) which questioned the effectiveness of the deliberate strategic planning model and proposed an emergent strategy formation approach in its stead. Deliberate and emergent strategy formation camps formed and a series of increasingly vociferous articles ensued which supported or attacked each of the approaches. Recently, some authors have suggested that it may be more realistic to envision a synthesis whereby deliberately developed strategic plans are modified during their implementation through an emergent strategy formation process. As an indicator of the ongoing prevalence of this debate, the 2008 Academy of Management (AoM) conference in Anaheim, California contained numerous presentation and discussion sessions which referred to the debate as a lead-in to presentations on strategy making in organizations (e.g., sessions 622 The Practice of Strategy: Sensemaking and Evaluation, 974 Resurrecting Strategic Planning, 1343 Strategic Orientation, and 1353 Strategic Planning: Content and Process). In addition, recent journal articles related to strategy often situate their arguments by referring to the deliberate and emergent strategy formation themes (e.g., Glaister \& Hughes, 2008; Liedtka, 2008; Oliver, 2008; Rudd, Greenley, Beatson, \& Lings, 2008; Sminia, 2009; Vilà \& Canales, 2008). 
In an effort to assess the efficacy of the deliberate planning approach, many studies have been carried out to examine any link that may exist between strategic planning and organizational performance. These have been augmented by a series of literature reviews and meta-analyses of the planning-performance studies. The individual studies which include thousands of companies, as well as the literature reviews and metaanalyses, show no consensus for any link between deliberate strategic planning and organizational performance (e.g., Greenley, 1994; Schäffer \& Willauer, 2003). These mixed academic results are at odds with ongoing actions in industry where a very high percentage of companies annually expend the resources necessary to engage in formal strategic planning (Bain, 2003). This would insinuate that company decision makers believe strategic planning contributes to company success.

The second observation concerning the literature relates to the paucity of theoretical development that would explain any linkage between the formation of strategy and subsequent organizational performance. In general, planning-performance studies portray an overly simplistic view of any relationship that may exist between strategic planning and performance. In many studies, a survey simply attempts to gauge the formality of the planning process in order to determine whether deliberate strategic planning is occurring and then tries to relate this finding to firm performance as indicated via various financial measures (Greenley, 1994). It would seem that there is an underlying assumption that contextual factors that impact the strategy between planning activity and eventual implementation results are somehow constant between organizations or not significant to the outcome. A more realistic perception might be that numerous contextual factors have significant effects on strategy and performance; 
however, the importance of internal and external context and the many variables that may impact both the implementation and the performance of the firm are generally ignored (Peng, Sun, Pinkham \& Chen, 2009). Clearly, an economic crisis such as the world experienced 2008 will adversely affect the performance of many firms, whether or not they are carrying out deliberate strategic planning. For example, a 2008 planningperformance study might indicate marginal performance for firms which carried out deliberate strategic planning. An identical study carried out with the same companies in 2006 might have yielded a different conclusion. It is probable that the simplistic model of the planning-performance relationship portrayed in the literature does not reflect the considerable complexity of the relationship and is responsible for many of the mixed results of planning-performance studies. Further, a comprehensive understanding of this process cannot be attained without understanding the impact of internal and external context. This need is not confined to strategy formation research as an increasing number of authors in various management disciplines are now studying the role of context in management theory (Bamberger, 2008).

If the academic literature is meant to elucidate the relationship that may exist between deliberate strategic planning and organizational performance, a more realistic model is required which includes the many contextual variables that affect the performance of the firm during the implementation of a strategic plan. Scattered throughout the literature there is mention of contextual internal and external variables such as organizational factors and market conditions (Ashill, Frederikson, \& Davies, 2003; Blythe \& Zimmerman, 2004; Depperu \& Gnan, 2006; Harrington, Lemak, Reed, \& Kendall, 2004; Miller, Droge, \& Toulouse, 1988). As noted above, an external 
contextual factor such as the general state of the economy may positively or negatively affect the performance of a firm during strategy implementation. An internal contextual factor such as an organization's ability to learn during strategy implementation may interact with the influence of a positive or negative economy to affect firm performance.

Using the variables mentioned in the literature, this thesis presents a model which has been created to provide a more accurate picture of the relationship between deliberate strategy formation and how it is transformed during implementation to become the actual realized strategy that is implemented. The model is an initial step toward addressing the lack of theory to explain the nature of strategy formation and is an extension of a conceptual framework developed by Mintzberg and Waters (1985).

In some respects, this work is an extension of Mintzberg's published theoretical work over the last few decades, and in particular, his models of the often intertwined relationship between deliberate and emergent strategy formation $(1985 ; 1987)$. As such, this research is an attempt to put some contextual meat on the bones of Mintzberg and Waters' (1985) conceptual thoughts relative to how deliberate intended strategy is modified by emergent contextual factors during implementation to become the realized strategy that eventually results in firm performance. It should be noted that in this regard, strategy implementation can be thought of as part of the strategy formation process because the strategy continues to evolve during implementation as emergent aspects arise (Mintzberg, 1977). It is this evolution that transforms intended strategy into realized strategy.

This paper reviews the deliberate and emergent strategy formation methodologies and the ongoing debate over their relative effectiveness. The extant planning versus 
performance empirical results are reviewed and a proposed model presented that may help explain the disparity of previous study conclusions. The model includes contextual factors mentioned in the literature that may influence a strategy during implementation and subsequent organizational performance. The model is presented as a contribution to the state of our knowledge concerning the nature of the planning-performance relationship. Using both qualitative and quantitative methods, the contextual factors will be validated and tested to determine their explanatory capability relative to the transformation of intended into realized strategy. This will contribute to our knowledge and understanding of the intricate dynamics of the planning-performance relationship.

The first step will be a qualitative study designed to ensure that the proposed $a$ priori model is complete and reflects actual practice. A qualitative approach has been chosen to provide the opportunity to identify factors which may not have previously appeared in the literature. This study includes semi-structured interviews with informants at companies in the Ottawa area to gauge whether the most important variables are present in the model and to adjust the model accordingly. Access was gained to these companies through professional and social networks developed through this researcher's prior work experience. The next step is a quantitative study to gain a better understanding of the impact of the identified variables on a deliberate intended strategy (i.e. developed strategic plan) as it transforms into the realized strategy that is actually implemented by the firm. The quantitative study survey instrument has been developed and populated with measures taken from the literature, and added to or modified based on the interviews. The instrument was pre-tested prior to the administration of the survey to the full sample. 
This doctoral thesis endeavours to contribute to theory relative to the deliberate and emergent strategy formation methodologies, and specifically, the factors which transform deliberate (i.e. intended) strategy into realized strategy (i.e. the strategy that is actually implemented). This research will aid the academic community by identifying factors which affect a developed strategic plan and the planning-performance relationship. The intent is also to contribute to managers' understanding of strategy formation and implementation in their complex and dynamic environments. Although the study focuses on the private sector, the results may also be useful to managers in the not-for-profit and government sectors. The paper develops a theoretical foundation for this important facet of strategy research and concludes with suggestions for future research to further inform the intricacy of the relationship between intended and realized strategy. 


\subsection{STRATEGY FORMATION AND STRATEGIC PLANNING}

\subsection{Definitions}

There are numerous definitions of strategy formation and strategic planning in the literature. Some focus on the deliberate planning activity that results in a strategic plan which can then be implemented to attain desired objectives. Other definitions focus on the emergent nature of strategy whereby it evolves as the unique characteristics of an organization and its leadership interact with the complex environment in which the organization finds itself.

Ansoff states that the "widely accepted theory of corporate strategic planning is simple: using a time horizon of several years, top management reassesses the current strategy by looking for opportunities and threats in the environment and by analyzing the company's resources to identify its strengths and weaknesses. Management may draw up several alternative strategic scenarios and appraise them against the long-term objectives of the organization. To begin implementing the selected strategy (or continue a revalidated one), management fleshes it out in terms of the actions to be taken in the near future" (1991 p. 81).

Grinyer and Norborn note that while strategic planning methodologies may differ in details, they

"share basic characteristics. First, corporate objectives are made explicit...Second, responsibility for setting objectives and taking strategic decisions is clearly defined...Third, and related to explicit objectives and clear role definition, the planning process is largely formal...Fourth, the environment of the company is monitored both to signal the need for a review of strategy and to provide information as a basis for choice among alternative strategies...Fifth, an aggressive, change-promoting, management attitude is encouraged" (1977 p. 100).

Mintzberg refers to the creation of "a deliberate, conscious set of guidelines developed in advance of the specific decisions to which they apply. In common terminology, a strategy is a plan." (1977 p. 28). Kudla defines strategic planning as the 
"systemic process of determining the firm's goals and objectives for at least three years into the future and developing the strategies that will govern the acquisition and use of resources to achieve these objectives" (1980 p. 5). Referring more to the structure of the resulting plan, Pearce, Freeman and Robinson define strategic planning as "the process of determining the mission, major objectives, strategies and policies that govern the acquisition and collaboration of resources to achieve organizational aims" (1987 p. 658).

Looking at the more emergent nature of strategy, it can be thought of as "a pattern in a stream of decisions. In others words, when a series of decisions related to some aspect of an organization exhibits some consistency over time, a strategy will be considered to have formed" (Mintzberg, 1977 p. 28). Mintzberg and Waters (1985) later revised this definition to focus on a stream of actions, noting that decisions more closely aligned with intentions rather than the naturally emerging quality of the actions that actually occurred. In other words, an implemented strategy is represented more by the actions taken by the actors than by the intentions represented by their decisions. Mintzberg also noted that "to manage strategy is to craft thought and action, control and learning, stability and change" (1987 p. 73).

Combining the deliberate and emergent aspects leads to a more all-encompassing definition. "Strategy formation is judgemental designing, intuitive visioning, and emergent learning: it is about transformation as well as perpetuation; it must involve individual cognition and social interaction, cooperative as well as conflictive; it has to include analyzing before and programming after as well as negotiation during; and all this must be in response to what may be a demanding environment" (Mintzberg \& Lampel, 1999 p. 27). This definition would be enhanced by adding reference to the 
internal capabilities analysis that is common to the deliberate strategy formation approach.

For the purposes of this paper, the term 'strategy formation' will be used generically to refer to all the various aspects of, and approaches to, making strategy. The term 'strategic planning' will be used to represent the formal deliberate process referred to in broad terms by Ansoff (1991) above. Intended strategy will be defined as a deliberately formulated strategic plan brought about by a planning process in an organization. Realized strategy will be defined as the strategy that was actually implemented by the organization or what the organization actually did (Mintzberg \& Waters, 1985). A realized strategy is an intended strategy that has been transformed during implementation through the emergence and impact of internal and external contextual factors.

\subsection{History}

Although strategic or campaign planning has been used by military leaders for millennia, it first appeared in business literature in the 1950s with the number of journal articles increasing through the 1960s and beyond (e.g., Andrews, 1971; H. I. Ansoff, 1964; H. I. Ansoff, 1965; Mintzberg, 1972; Selznick, 1957; Vancil \& Lorange, 1975). The Harvard Business Review carried a number of articles on long-range planning between 1956 and 1961 (Grant, 2003). The approach quickly gained a foothold in US business with the founding of the American Society of Corporate Planners in 1961 (ASCP website).

While the terminology used in Selznick's 1957 book differs from that used today, the basic premise of a match between internal strengths and weaknesses, and external 
threats and opportunities is present when he states "leaders must take account of (1) the internal state of the policy; the strivings, inhibitions, and competences that exist within the organization, and (2) the external expectations that determine what must be sought or achieved if the institution is to survive" (p. 67). In 1971, Andrews similarly phrased strategy formation as "the intellectual processes of ascertaining what a company might do in terms of environmental opportunity, of deciding what it can do in terms of ability and power, and bringing these two considerations together in optimal equilibrium" (p. 12).

Vancil and Lorange's (1975) article is typical of the prescriptive nature of the literature in the early to mid 1970s. It provides an approach that is "step by step through the three-cycle, long-range planning process" (p. 81). Detailed processes are provided including timelines, documentation requirements, and actions and responsibilities by specific positions. While the authors note that creativity is required and that it cannot be scheduled, they do propose a very specific timeline through which the planning process is to occur.

Mintzberg (1977) took a fundamentally different approach to strategy formation in the 1970s when he proposed that effective strategies cannot be formally planned in advance, suggesting that they emerge as a stream of decisions or actions over a period of time. He referred to the structured strategic planning approach as the design school in a scathing critique of its premises and approach (1990). Much of the research since that time has been devoted to identifying whether strategy formation in companies is formally planned or whether it emerges naturally over time, the effectiveness of the various approaches, and the effect of internal and external context on the method chosen and resultant firm performance. 


\subsection{Schools of Strategy Formation Thought}

Since the 1970s, a discourse has been ongoing in the literature over the most effective approach to strategy formation. Through a review of the literature, Mintzberg and Lampel (1999) identified 10 distinct schools of thought with respect to how strategies are formed. The first three are prescriptive while the last seven are descriptive. These schools of thought are discussed below to provide an overview of the various conceptualizations of strategy formation.

Design School: A Process of Conception. This methodology is taught in both the strategy and marketing academic streams and, in conjunction with the Planning School (described below), is the core of the strategy formation process sold by most management consulting firms and, as such, practiced by most companies. Senior management develops a strategy that best fits an organization's strengths and weaknesses taking into account the opportunities and threats that exist in its external environment. The strategy is then explicitly stated to the organization to aid in the implementation process.

Planning School: A Formal Process. While similar to the Design School, this process differs in that it is generally carried out by staff planners within the organization. It is a formal process that features distinct steps and results in detailed budgets, plans and objectives.

Positioning School: An Analytical Process. Through detailed industry, market and competitive analysis, this school attempts to select the most advantageous generic positioning for the organization. Examples of these generic strategies include cost leadership and differentiation (Porter, 1980). 
Entrepreneurial School: A Visionary Process. The formation of strategy in this school tends to occur in the mind of the leader through intuition or personal vision without detailed analysis or the use of planners. The leader maintains control of the implementation process and communicates only the broad strategy to the organization.

Cognitive School: A Mental Process. In this school, strategy develops as mental maps, frameworks or concepts in the minds of decision makers. These maps can either develop naturally through the individual or shared experiences of the decision makers or, as discussed later in this paper, can be facilitated through means such as scenario-based learning. The maps are then unconsciously referred to by decision makers as they take action in various business situations.

Learning School: An Emergent Process. From this perspective, strategies emerge from anywhere in the organization. As the organization experiences successes and failures, the actors in the organization learn and incorporate lessons into new and evolving strategies. Strategy formation and implementation feed off one another as each moves forward.

Power School: A Process of Negotiation. This view sees strategy formation as the result of internal (micro) and external (macro) power struggles. Strategies emerge and evolve as the internal actors cooperate, negotiate and confront each other, as well as when the organization as a whole works with external partners, competitors, channels and suppliers to engage the market.

Cultural School: A Social Process. This school can be viewed as the opposite of the Power School. While the former focuses on competition, the latter focuses on 
consensus and integration. Some of the literature written about this school raises the issue of how ingrained culture can hinder strategic change in an organization.

Environmental School: A Reactive Process. This school is concerned with the impact of the environment on how strategy is formulated in an organization. As a firm reacts to its external environment, a pattern of actions emerges which can form its strategy. A firm can also be forced into a particular strategy as a means of surviving an environmental shock.

Configuration School: A Process of Transformation. This perspective promotes the idea that the characteristics of a particular organization lead it to a particular school of strategy formation. For example, Mintzberg and Lampel (1999) note that stable bureaucratic organizations might lean toward the Planning School while new organizations might follow the Entrepreneurial School.

Each of these schools represents a distinct view of how strategy is formulated in an organization, but it is the interaction among them that more closely mirrors reality. While a formal process involving detailed planning may occur in a particular firm, the resulting strategy will also reflect the existing cognitive maps of the unique actors, power based negotiations between actors (Kaplan, 2008), the impact of the environment and hopefully, some level of organizational learning.

\subsection{Strategy Formation Lifecycle Characteristics}

Mintzberg notes that strategic change is "rather bumpy and ad hoc, with a complex intermingling of periods of continuity, change, flux, limbo, and so on" (1977 p. 36). Based on his 20 studies that include a magazine, an auto-maker, a government-film agency, and the US involvement in the Vietnam War, he proposes that "two main 
patterns emerge, one superimposed on the other. The first is the life cycle of an overall strategy - its conception, development, decay, and death. ... The second pattern is the cyclical one - periodic waves of change and continuity" (1977 p. 36).

Long periods of stability are interrupted by brief periods of significant change although these stable periods may now be shorter given the accelerated pace of change in the global marketplace. Companies use the periods of stability to fine-tune current strategies but as a company gradually falls out of alignment with its environment, the need for a new strategy develops. The company reacts to formulate a new strategy in an attempt to re-establish stability (Miller, Friesen, \& Mintzberg, 1984). "The real challenge in crafting strategy lies in detecting the subtle discontinuities that may undermine a business in the future. ... the trick is to manage within a given strategic orientation most of the time yet be able to pick out the occasional discontinuity that really matters" (Mintzberg, 1987 p. 74). However, even when change is required, it is often difficult to achieve. Numerous factors including a strong organizational identity can make it difficult to effect strategic change in an organization (Kjaergaard, 2009).

Miller et al. (1984) and Mintzberg (1987) describe the interaction between the internal and external environments of an organization; as the organizational and environmental conditions change, so too does the strategy formation approach. Miller et al. (1984) depict organizations as entities struggling to maintain equilibrium and stability. Perhaps the key to successful strategy formation is, as Mintzberg (1987) suggests, detecting future organization / strategy / environment misalignment before competitors. However, it seems that this would require ongoing deliberate internal and external analysis, and the ability to predict future situations, something that Mintzberg does not 
support in a number of his writings. It may be that varying strategy formation methodologies fall along a continuum and individual points along that continuum may best serve a particular organization depending upon the specific set of circumstances involved. The strategy formation methodology continuum will be discussed below. 


\subsection{DELIBERATE VERSUS EMERGENT STRATEGY FORMATION}

Deliberate and emergent strategy formation processes have been described as science versus art (Parnell \& Lester, 2003), and as opposite ends of a continuum along which the actual strategy making techniques of real firms lie (Boyd \& Reuning-Elliott, 1998; Mintzberg \& Waters, 1985). "The strategy-maker may formulate his strategy through a conscious process before he makes specific decisions; or strategy may form gradually as he makes decisions one by one. In the first case, the strategy determines subsequent decisions ...; in the second, decisions converge into a strategy" (Mintzberg, 1977 p. 29). Although it would seem reasonable to view a situation-dependent mix of these two poles as providing an optimal solution for companies, there has been an ongoing debate for many years between the proponents of each process. As the debate has evolved, the "vivid caricatures presented by each side of the other's conceptualizations of strategy making bear little resemblance to the realities of strategic planning as pursued by large companies" (Grant, 2003 p. 512).

"To describe these as competing perspectives would be an understatement - Mintzberg (1990), for example, ascribes failures as diverse as the Vietnam War and the collapse of Bendix to the design school (grand strategy). Alternatively, the incrementalist school has been dismissed as 'a Shirley McLaine world of New Age mysticism in which rationality is devalued' (Grant, 1995 p. 21). ... However, the bulk of empirical strategy research, and the views of most practitioners (Ginter, Ruck, \& Duncan, $1985)$ remain more closely aligned with the grand strategy school" (Boyd \& Reuning-Elliott, 1998 p. 190).

These two disparate views of how strategy is formulated are discussed below. 


\subsection{Deliberate}

A 2003 survey of US and European firms reported that 89\% employed a strategic planning process (Bain, 2003). In the context of this survey, strategic planning refers to a deliberate analysis and planning approach designed to create a strategic plan which would be used to guide the actions of the firm over an upcoming period. Typically, an internal analysis is carried out to identify the organization's strengths, weaknesses and competencies. An external analysis focuses on opportunities and threats brought about by the current and projected conditions in the market including global, national, economic, customer, competitor, supplier, distributor and partner factors, as well as pertinent factors relative to changes in technology. Strategies are devised to address the internal and external situations in ways that maximize the possibility of success for an organization. These strategies are evaluated by senior management, the preferred strategy is chosen and implementation follows. The choice may be mediated by managerial values and issues of social responsibility (Ansoff, 1991; Mintzberg, 1990).

A deliberate strategy formation methodology is characterized as a planning system with some level of formality whose aim is to devise and implement a plan which will realize the intentions of the organization's leadership (Ansoff, 1991). To be perfectly deliberate, the process must fulfil three criteria: the organization must have precise intentions and have communicated them in detail; the intentions must be common to all components of the organization; and the intentions must have been fulfilled exactly as intended without interference from the environment. This insinuates that the organization must have perfectly predicted the environment or been in control of the 
environment (Mintzberg \& Waters, 1985). By this definition, no process is perfectly deliberate as no organization can perfectly predict the environment.

Mintzberg is quite critical of formal strategic planning, noting that it "repeats itself so often and so mechanically that it desensitizes the organization to real change" and that it "must be recognized for what it is: a means, not to create strategy, but to program a strategy already created" (1987 p. 73). He further states, "show me managers who think they can rely on formal planning to create their strategies, and I'll show you managers who lack intimate knowledge of their businesses or the creativity to do something with it" (1987 p. 74). He emphatically states that environmental prediction is not possible and that the strategy making process cannot be formalized into traditional analyses such as the strengths, weaknesses, opportunities and threats (SWOT) framework. However, the ability to predict during planning is not necessarily a precondition of control during strategy implementation (Wiltbank, Dew, Read, \& Sarasvathy, 2006).

Given the results of the Bain (2003) survey and Ansoff's (1991) perspective on industry's heavy reliance on formal strategic planning as its preferred strategy formation methodology, Mintzberg's (1987) position seems extreme. Bain's (2003) survey demonstrates that deliberate strategy formation is used across industry; it is reasonable to assume that managers feel it is a profitable use of resources or the resources would be deployed in some other way. However, the emergent strategy formation methodology also has its proponents. 


\subsection{Emergent}

To be perfectly emergent, Mintzberg and Waters (1985) state that a strategy must lead to consistent action over a period of time in the absence of intentions by decision makers in the organization. These patterns of action can arise as a result of unconscious tendencies within the organization or by the influence of environmental forces. For example, this process would be present in what Holloway defines as strategically agile organizations, which "are essentially self-organizing systems that progress and succeed through wider use of initiative and self-control with little or no need for intervention from senior management" (2004 p. 472). The process of emergent strategy formation can be seen to a greater or lesser degree in most organizations (Grant, 2003; Mintzberg, 1985).

Holloway (2004) notes that people 'closer to the coalface' are better positioned to make strategic decisions that will achieve business objectives. He cites Entrekin and Court's (2001 p. 14) example of commercial airliners which spend considerable time off their true course during flights yet still achieve their objective of time and place arrival due to the actions of the pilot. However, in this case, Holloway (2004) may be confusing strategy with tactics. While commercial airline traffic patterns are governed by strategies with respect to flight levels and headings based upon tradition, efficiency and safety, the minor weather, comfort and efficiency related course corrections made by a pilot in flight to stay within the parameters of these strategies are simply tactical actions. Holloway (2004) might have been more correct if he had stated that the tactical actions taken by functional experts in organizations to stay within broad mandated strategies do not require senior management intervention. 
Mintzberg (1977) states that slowly, over time, a pattern of actions and/or decisions will emerge which will form a strategy. This strategy emergence results from trial and error and resultant feedback loops. While this may often be the case, it could be argued that many firms could not survive this process, especially those without significant financial reserves finding themselves in difficult market cycles. At the very least, trial and error can be an expensive methodology in terms of time and resources (Ansoff, 1991). However, Ansoff does allow that emergent strategy formation can be successful in environments where change is incremental and slower than organizational response. He sees this being the case in approximately $20 \%$ of firms in developed economies.

Ansoff (1991) argues that making rational choices on possible strategies is especially important in turbulent environments because it focuses the organization on alternatives that are most likely to succeed while saving the effort and time that would have been devoted to alternatives with little hope of success. Mintzberg (1987) takes the view that making long-term rational strategic choices is not possible because managers cannot make reliable environmental predictions.

Mintzberg (1977) states that one of the benefits of an emergent strategy is that it is not explicitly stated. He feels that explicitly stating a strategy can cause the implementing bureaucracy to build up too much momentum, thereby negating the tendency to ponder its actions. He goes as far as to blame the post-1965 United States (US) military escalation in Vietnam on the explicit nature of President Johnson's strategy. He further cautions that changing an explicit strategy once bureaucratic momentum has formed can be extremely difficult (Mintzberg, 1977 p. 32). Rather than 
condemn explicitly stating strategy, another perspective on this situation might be to emphasise the importance of explicitly stating an effective strategy as opposed to an ineffective strategy. Ansoff (1991) notes that explicitly stated strategies need not be inflexible. They can be guidelines that "control erratic deviations from the strategy" (1991 p. 458) while allowing latitude to exploit appropriate opportunities as they arise. Mintzberg (1977) is of the opinion that formal strategic planning leads to mundane strategies while emergent strategies tend to be more creative and innovative. In a 1987 paper, he refers to the process of strategy formation as crafting strategy, using a potter crafting clay as an analogy. Just as the potter may simply wait to see what shape emerges from the clay, Mintzberg (1987) makes the point that strategies can simply form based on the interactions between the firm, its resources, and its environment. While the concept seems valid on the surface, it is a fairly simplistic view of the extremely complex internal and external environment in which the firm must operate. While the analogy may be plausible for a company with one or few employees, it is problematic for organizations with hundreds or thousands of actors. A more appropriate analogy for this situation might be a large sailing vessel. While each of the deck hands might have an intelligent perspective as to the tack that the ship should take, when it should change tack, the amount of sail it should deploy, and how these decisions should evolve as the conditions change, if they all acted independently, the ship would be in a state of confusion. While the Captain would be wise to heed the advice of the experienced sailors on board, he/she would be putting the ship in peril if each were permitted to try various strategies independently. 
Mintzberg uses 3M and Hewlett-Packard as examples of companies where management controls the strategy formation process but leaves the content of the strategies to "people way down in the hierarchy, who are in touch with the situation at hand and have the requisite technical expertise. In a sense, these are organizations peopled with craftsmen, all of whom must be strategists" (1987 p. 71). In practice, it is more likely that similar to other large companies, discretionary dollars spent on research and development, a key strategy lever, are tightly allotted and controlled by management. While ideas are probably solicited from various sources in an organization with a decentralized structure, the strategies are likely decided and controlled by management through the allotment of resources.

While emergent strategies are important aspects of a firm's total strategy formation process, it may be appropriate to view them as acting within the guidelines developed through a formal strategic planning process. That being said, in situations where unforeseen environmental circumstances have a dramatic impact on a firm, the emergent aspects of strategy may define a whole new direction for a firm. Both methodologies play an important role, are complementary and may define the end-points of a strategy formation continuum (Andersen, 2004; Grant, 2003; Harrington, Lemak, Reed, \& Kendall, 2004; Mintzberg \& Waters, 1985).

\subsection{The Deliberate / Emergent Strategy Formation Continuum}

The definitions presented above for perfectly deliberate and emergent strategy formation processes possess characteristics which make their existence unlikely in a real organization. Regarding these processes as the end-points on a continuum, Mintzberg 
and Waters (1985) propose the following eight points along the continuum, starting with the most deliberate and running to the most emergent.

The Planned Strategy. This process is characterised by the leadership of the organization deciding on very specific intentions and courses of action, communicating these intentions in a very detailed and precise fashion, and controlling the implementation to ensure compliance. As the strategy is inflexible, success depends upon the ability to effectively predict or control the environment. Mintzberg and Waters (1985) cite large mining companies, airlines and military campaigns as examples of situations where this process is employed due to the necessity to commit significant resources to the resultant strategy.

The Entrepreneurial Strategy. In this case, one leader, often the owner, has control of an organization and imposes his/her vision. The strategy is formulated by this single person and is not communicated other than through the ongoing decisions and direction provided by this individual. Although a predetermined strategy is present, there is also an emergent quality given that the strategy can evolve easily because it is controlled by only one person. This methodology is found in new and/or small organizations where all the members of the organization are willing to follow the precise direction of the leader. It is reasonable to assume that use of an Entrepreneurial Strategy style would not be effective in a large organization where many different strategy approaches are likely to emerge and the majority of participants in the organization have limited contact with the leader.

The Ideological Strategy. This differs from the Entrepreneurial Strategy in that the vision or ideology is shared by all members of the organization. The ideology is 
articulated and leads to clearly defined intentions. These intentions are formulated and deeply accepted by the components and actors of the organization and are thus very resistant to emergent change. Religious, charitable and some non-governmental agencies can be described as ideological organizations.

The Umbrella Strategy. Mintzberg and Waters (1985) describe this process as deliberately-emergent. The organizational leadership articulates a deliberate vision or set of broad guidelines within which the actors and components of the organization must operate. Within the boundaries or under the umbrella of these deliberate guidelines, different strategies are allowed to emerge within different components of the organization. Mintzberg and Waters cite the US National Aeronautics and Space Administration's (NASA) goal of reaching the moon in the 1960s as an example of an Umbrella Strategy within which many strategies and approaches emerged from the individual departments and scientists at NASA. Variations of this deliberately-emergent approach seem to be used by many multi-division corporations where corporate headquarters provides the umbrella and individual strategies emerge within the divisions.

The Process Strategy. In this approach, organizational leadership controls the process of strategy formation and individual components of the organization define the content of the strategies. For example, a multi-division corporate headquarters can dictate the organizational structure, strategic planning processes, staffing processes and appoint the divisional executives, thereby indirectly controlling the strategy formation process. The design of the system within which strategy is formulated is deliberate, while the strategies of individual divisions are allowed to emerge within the designed system. 
The Unconnected Strategies. These strategies are formulated by individual persons or components of an organization without guidance or direction from organizational leadership. Mintzberg and Waters (1985) use the National Film Board of Canada as an example whereby the individual filmmakers decide their own strategies as to what sort of films they will produce. It should be noted that this methodology is viewed as emergent from the perspective of the Film Board while it can be viewed as either deliberate or emergent from the perspective of the individual filmmaker depending upon the presence or absence of prior deliberate intentions. Unconnected Strategies tend to thrive in organizations such as scientific institutes or hospitals which house collections of experts facing complex environments. If a particular strategy becomes successful for one individual, it can then migrate to other individuals or to the whole organization as a deliberate strategy.

The Consensus Strategy. This process has no deliberate component; it is fundamentally emergent. It occurs when the individuals or components of an organization mutually, without prior intentions, adjust their strategies so that they converge on a particular pattern of actions. This can be an outgrowth of successful Unconnected Strategies. Mintzberg and Waters (1985) note that it can happen in a quick spontaneous fashion as occurred in the 1950s when the National Film Board of Canada produced its first film for television. Without central direction and in less than a year, $60 \%$ of production effort was for television. This example could also have elements of an Imposed Strategy whereby the growth of television in Canada imposed the necessity of making films for television on the filmmakers of the National Film Board of Canada. 
The Imposed Strategy. These strategies are imposed by the external environment with no prior control or input from within an organization. Environmental forces can include markets, national economic factors, natural disasters, technological advances or political influences. The strategy formation process is reactionary and sometimes devoid of alternative choices. While totally Imposed Strategies are rare, the environment provides some level of influence in most situations (e.g. applicable legislation and laws).

In general, deliberate strategies tend to be formulated through a formal process, articulated in a clear and detailed manner, and controlled through implementation. Emergent strategies tend to arise due to the vagaries of the individuals in the organization and the impacts of the external environment. While the eight waypoints described above on the deliberate-emergent continuum represent distinct possibilities, it is the interactions between these methodologies which probably appear in most organizations. In what seems at odds from some of Mintzberg's other writings (see Mintzberg, 1977 and 1987), he and Waters note that "Strategy formation walks on two feet, one deliberate, one emergent.... The relative emphasis may shift from time to time but not the requirement to attend to both sides of this phenomenon" (1985 p. 271). This seems to be a more realistic argument given the prevalence of strategic planning in organizations (Bain, 2003) and the inevitable impact that environmental changes can have on these plans. For example, many companies would have had growth plans in place as part of their deliberate strategies during the summer of 2008. The emergence of the global recession would have had a dramatic impact on these strategies as the last quarter of 2008 began to unfold. 


\subsection{The Deliberate / Emergent Strategy Formation Debate}

The long running debate over the relative effectiveness of deliberate versus emergent strategy formation has served to clarify many of the issues surrounding these two methodologies. As discussed above, the proponents of the two perspectives have emphatically stated their cases and disputed each other's views in a series of papers which have been published over several decades. However, recent studies state the more balanced and realistic view that actual operating organizations must use both deliberate and emergent methodologies in a complementary fashion to strategically manage themselves in an effective manner (Andersen, 2004; Grant, 2003; Harrington, Lemak, Reed, \& Kendall, 2004). This general theme can also be found in the process view of strategy (Chakravarthy \& Doz, 1992) and in Farjoun's (2002) organic perspective.

Considering the internal complexity of any large organization and the multitude of external forces impacting it at any given time, it seems reasonable that both deliberate and emergent methodologies have an important and complementary role to play in strategy formation. If an organization did not formally plan and articulate its strategy, at least in broad strokes, the various actors and components of the organization could act independently and without a shared focus. This could lead to confusion, wasted resources and interactions between actors and organizational components that negatively impact the organization as a whole. Alternatively, if the organization's stated strategy was so rigid that it did not allow the flexibility required to react to changeable external forces, the organization might find itself on a destructive course with no ability to correct itself. 
Although Mintzberg's (1987) example of a potter crafting objects from clay was used as a metaphor for the emergent strategy formation process, it could be argued that the example more aptly relates to deliberate and emergent processes operating in a complementary manner. From a deliberate perspective, the potter made a conscious decision at some point in the past to make and sell pottery versus going into another line of work. The potter must have planned the equipment purchases and infrastructure changes (i.e. building a workshop) and allotted the resources to implement the plan. It is also probable that the strategy was explicitly stated to others at some point in time. Inside this deliberate strategy framework, possibly an Umbrella Strategy (Mintzberg and Waters, 1985), the emergent strategy formation process takes place as described above.

Perhaps this complementary deliberate and emergent approach is really one strategy formation process with two parts. In the first part, an organization deliberately plans its strategy given its internal strengths, weaknesses and competencies, and the external opportunities, threats and forces represented by the environment. This intended strategy is articulated to the organization in enough detail to provide clear guidance to the various actors and components of the organization who will be involved in its implementation. It is often also communicated externally, at least at a high level, to provide signals to external stakeholders. The strategic guidance is structured to provide enough flexibility to allow decision makers to react to environmental changes as they occur throughout the planning period. In part two, the implementation and operation of the strategy is carried out but the strategy is allowed to transform or evolve as new opportunities, threats or environmental forces emerge. At the beginning of the next planning cycle, the baseline strategy that is reviewed to judge its effectiveness is the 
realized strategy that is the product of both the deliberate and emergent aspects of the last cycle. Mintzberg and Waters (1985) refer to this as strategic learning.

Although the executives in a particular organization might not describe their process using these same terms, it is clear from the numerous studies in this subject area that a process containing both deliberate and emergent components is used by many organizations (Grant 2003). An organization's ability to succeed in meeting its strategic goals may be a function of how well the organization is able to learn from the results of these strategy formation cycles. 


\subsection{STRATEGIC PLANNING AND SUBSEQUENT FIRM PERFORMANCE}

Studies of a possible link between the strategy formation methodology utilized and organizational performance present some of the most varied results found in the strategy literature. Some of this disparity may be the result of differing methodologies and a lack of rigour in the execution of the studies (Greenley, 1994). However, the lack of consensus with respect to a link may also be due to the complexity of the relationship and an inability, thus far, to adequately conceptualize the various aspects of the relationship. A number of studies that have sought a link between planning and performance are now discussed.

\subsection{Empirical Evidence}

In a review of 29 studies that specifically investigated the relationship between strategic planning and company performance, Greenley (1994) categorized the papers into three groups. Nine of the studies found no relationship between strategic planning (i.e. the creation of an intended strategy) and company performance. The second group had 12 studies that showed evidence of a relationship, and the third group contained eight studies which not only showed a relationship, but the authors also claimed that companies who carry out strategic planning achieve higher performance than companies which do not strategically plan. While 20 of the 29 studies showed some relationship, Greenley (1994) concludes that no relationship can be surmised because of the methodological differences between the studies, and a general lack of rigour throughout. He further notes that the methodological differences disallow the possibility of a meta-analysis. Some of the issues noted by Greenley (1994) are the lack of a consistent definition for strategic 
planning, a difference in scope whereby some of the studies looked at strategic planning whereas others looked at the broader process of strategic management, a variety of performance measures both quantitative and qualitative, different perceptions of what constitutes formality in planning, the different external environments that existed across the companies, the different internal environmental factors that impacted each company, differences in the industries being sampled, and the varied durations of the studies. Without consistency across studies in these areas, it is difficult to compare them directly. However, this does not invalidate the results of the studies when viewed on an individual basis. It would seem that there is at least some support for a relationship between strategic planning and company performance, given that 20 of the 29 studies provided evidence to support this conclusion.

Brews and Hunt (1999) have noted the significant impact that planning duration has on resultant performance. They postulate that it takes at least four years for the positive impacts of strategic planning to manifest themselves in a specific firm due to the time required to perfect the process in an organization new to strategic planning. Further, an extended period of time is often required for strategic inputs to reach desired ends. If their suggestions are correct, some of the inconsistent results in planning and performance studies could be explained by the varied experience levels of companies with respect to strategic planning, and the possible time lags between implementation and results.

In a meta-analysis of 26 studies, Miller and Cardinal (1994) found that strategic planning positively influences the performance of firms. In discussing the mixed results found by numerous researchers, they note that differences in methodology between 
studies have led to inconsistent findings and the ongoing debate over the value of strategic planning.

Boyd (1991) carried out a meta-analysis of 29 studies whose samples totalled 2,496 organizations. Similar to Greenley (1994), he found disparate results with significant measurement errors. He also noted that the results were questionable due to the small number of firms sampled in some of the studies. However, taking a different stance than Greenley (1994), Boyd (1991) suggests that widespread numerous measurement problems have resulted in findings which undervalue the actual relationship between planning and organizational performance. He suggests that the benefits of strategic planning are underestimated based on the 29 studies in his meta-analysis.

In a study of 112 banks, Hopkins and Hopkins (1997) found that the intensity of the strategic planning effort is directly and positively related to the banks' financial performance. Interestingly, they found the reciprocal also in evidence; greater performance leads to higher levels of strategic planning intensity. This study has an elevated level of credibility because of the large sample size and the fact that the companies were all in the same industry, thereby controlling for some of the external environmental factors.

In a study of 92 companies, Thune and House (1970) found that companies with formal long-range planning consistently outperformed companies using informal planning. The formality of selected companies' planning processes was ascertained through the use of a survey. Performance data consisted of previously published publicly available financial data over seven to 15 years periods (dependent upon the industry). Noting that formal long-range planning is defined as strategic planning in later studies, 
the authors found that the formal planning companies also showed enhanced performance after formal planning was commenced, relative to their states prior to formal planning process implementation.

Falshaw, Glaister and Tatoglu (2006) surveyed 113 companies in the United Kingdom to study whether there was a relationship between formal strategic planning and company performance. However, they did not find evidence of a relationship. They did note that the complexity of the activity, including the many moderating variables, may require a qualitative data gathering approach to allow a better understanding of any possible relationship. This conclusion is significant in that it refers to a general weakness that could be inherent in most of the aforementioned studies. While there have been numerous attempts to find a link between planning and performance, they have been predominately quantitative. Extrapolating from the comments of Falshaw et al. (2006), the inconsistent results may be due to a lack of understanding and theoretical development relative to these two constructs. It has been suggested by several authors that a qualitative approach may provide a more appropriate methodology for theory development and understanding when studying complex relationships and environments (Bradbury \& Lichtenstein, 2000; Lee, Mitchell, \& Sablynski, 1999).

In reviewing the literature, it becomes apparent that although numerous studies have been carried out involving thousands of companies, there is no consistency in the results from either individual studies, literature reviews or meta-analyses (Schäffer \& Willauer, 2003). Many researchers have stated that the inconsistent results are primarily due to the differing methodologies employed and numerous errors in the execution of the research (Greenley, 1994; Miller \& Cardinal, 1994; Boyd \& Reuning-Elliott, 1998). 
Grant notes that "studies relied upon largely superficial characterizations of strategic planning practices based mainly upon questionable data" (2003 p. 492). However, even if more rigour had been applied to more consistent quantitative methodologies, it is questionable whether or not these approaches could adequately characterize such a complex relationship involving a large quantity of dynamic variables in so many firms and industries.

Given the resources expended by a high percentage of firms to carry out strategic planning on an annual basis (Bain, 2003), the fundamental question of whether or not strategic planning leads to positive, tangible results deserves a credible answer. Because of the high percentage of firms engaged in the activity, one can surmise that industry already implicitly believes in a positive relationship between strategic planning and performance. Although designing a sufficiently rigorous and generally accepted research methodology is a significant challenge, this is an area of academic research that warrants the effort. A possible starting point may be recognizing the inherent complexity of the relationship between strategy formation and performance, and designing study methodologies that reflect the significant number of explicit and tacit factors, and the possible chaotic nature of their relationships (Bradbury \& Lichtenstein, 2000). The chaotic nature of the business environment makes the detection of any relationships between the factors much more difficult. However, while these methodologies are unlikely to reflect all of the complex interrelationships inherent in these variables, the resultant research may be a step closer to characterising the real environment in which strategy is formulated and implemented. 
Noting the complexity of the environment defined above, it is understandable that the results of studies simply relating the formality of planning against firm performance can be varied. Numerous variables can affect the planning-performance relationship and their impacts must be accounted for if a study wishes to truly relate how performance is affected by the various aspects of planning.

\subsection{Planning and Performance}

Despite numerous individual studies, qualitative analysis of groups of studies and meta-analyses of selected studies, the literature provides no consensus on the proposed link between planning methodology and subsequent firm performance. A number of researchers point to differing methodologies and a general lack of research rigour to explain the disparity of study results. However, some of the conclusions drawn from qualitative analysis of groups of studies may be too conservative. For example, in his analysis of 29 studies where 20 found a link between planning and performance, Greenley (1994) suggests that no relationship can be implied because of the inconsistent methodologies used in the various studies.

Another explanation for the differing results might be the complexity of the relationship between what is planned (i.e. intended strategy) and what is actually implemented (i.e. realized strategy), and in particular, the number of factors which affect the transformation of one to the other. These factors may include characteristics of the organization and the external environment in which the firm operates. Until an enhanced theoretical understanding of strategy formation is attained, it will be extremely difficult to gain any consistent results from planning-performance studies. 


\subsection{RESEARCH QUESTION}

As noted earlier, this work is an attempt to add a level of detail and quantitative rigour to the Mintzberg and Waters' (1985) concept of intended strategy evolving into realized strategy (Figure 1). In this sense, it is an exploration of "the relationship between leadership plans and intentions and what the organizations actually did. ... the label strategy [is used] for both of these phenomena - one called intended, the other realized" (Mintzberg \& Waters, 1985 p. 257). In Figure 1, unrealized strategy is simply the portion of the strategy which is never realized due to various internal and external considerations. The intended strategy is deliberate and can be the result of a planning process or simply the articulated vision of a leader or leaders. This deliberate or intended strategy then interplays with various emergent aspects that come about due to the vagaries of the internal and external environments to form the realized strategy that is actually implemented by the organization. For example, many companies might have had intended strategies in the fall of 2008 which were predicated on continued global economic growth. With the onset of the global recession, these companies would have taken actions which might have been quite different from their originally intended plans due to the emergence of significant external changes in the economic environment. The combination of a firm's originally intended strategy with the emergent strategies that resulted from its attempts to cope with the economic slowdown would have resulted in its realized strategy. This realized strategy is what the firm actually did. 
Figure 1: Strategy transformation from intended to realized strategy.

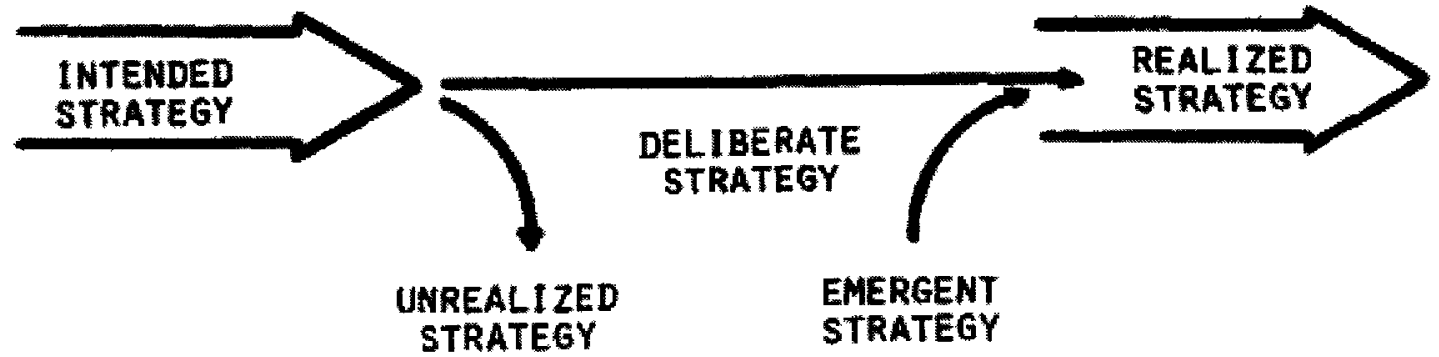

Source: Mintzberg and Waters, 1985.

Although the process view of strategy formation recognizes the change from intended to realized strategy (Sminia, 2009), there has not been any rigorous research into identifying and quantifying the factors which bring about the change. To understand how an implemented or realized strategy evolved from the strategy that leadership initially intended to be implemented, one must understand the contextual factors which impact this evolution. For a commercial company, one might surmise that the impacts would include changes in internal capabilities, competitors' actions, or other changes in the external environment. However, the factors that impact this evolution have thus far not been studied in a rigorous fashion. While the literature contains various researchers' assumptions with respect to what these contextual factors might be, research to identify and quantify these factors is absent from the literature.

Noting this gap in the literature, the research question addressed in this work is: What are the emergent contextual factors which impact deliberate intended strategy during implementation to transform it into realized strategy? Further, what are their relative impacts on the transformation? 


\subsection{UNIT OF ANALYSIS / DATA SOURCE}

The unit of analysis in this work is the individual strategy that was employed by a profit oriented organization at some previous time. The strategies must have reached some level of conclusion to allow questions relative to the level of transformation of the strategy during implementation. Since the strategies cannot be interrogated directly, the required information must be sought from individuals who were directly involved in each strategy and understand the goals, implementation processes and results achieved.

The data source for this research is the individual senior manager (i.e. a manager who has managers as direct reports) or executive who has had experience in formulating and implementing intended strategy as it transforms to become realized strategy. In this way, access can be gained to managers' experiences over numerous companies, industries and timeframes. While a particular manager might be employed by a firm that does not practice the development of intended strategy during the timeframe of this study, that manager may have previously worked for other firms who did practice strategic planning and were involved in the transformation of intended into realized strategy. Even if a particular manager is currently employed by a firm that carries out strategic planning, that manager may have been in roles in other firms that allowed him/her to more closely observe or participate in the evolution to realized strategy. Using the individual senior manager or executive as the data source allows access to these previous experiences so that the manager or executive may choose a strategy example for analysis about which she/he is particularly knowledgeable. By using the individual manager as the data source and the individual strategy as the unit of analysis, it is hoped that a more comprehensive 
utilization of total management experience can be employed as opposed to the narrower approach of focusing only on a manager's current organization. 


\subsection{CONTEXTUAL ISSUES AND HYPOTHESES}

\subsection{Chaotic Systems}

Chaos has been defined as "the behavior of a system whose final state depends so sensitively on the system's precise initial state that the behavior is in effect unpredictable and cannot be distinguished from a random process, even though it is strictly determinate in a mathematical sense" (S\&T Encyclopaedia, 2007). Chaos theory is often used to study complex non-linear dynamic physical systems whose behaviour appears random but is in reality a complex set of non-repeating patterns governed by the non-linear affects of numerous variables and initial conditions. While it is possible to predict the state of the system at a short time into the future, prediction becomes increasingly difficult as the timeframe lengthens (Levy, 1994).

Industries can be thought of as chaotic systems in that they "evolve in a dynamic way over time as a result of complex interactions among firms, government, labor, consumers, financial institutions, and other elements of the environment" (Levy, $1994 \mathrm{p}$. 167). This list could also include domestic and international economies, suppliers, distribution channels, natural and human-made disasters, technological breakthroughs, management teams, individual executives and so on. Some of these elements would characterise the specific conditions of an industry or individual firm at an initial state, while others would define impacts at points in the future. As each impact works its way through the system and changes the states of the other elements, a new set of initial conditions, interactions and states is defined.

Noting the complexity of the system defined above, it is understandable that the results of studies attempting to simplistically relate the formality of planning to firm 
performance can be varied. Numerous emergent contextual variables can affect the planning-performance relationship and their impacts must be accounted for if a study wishes to accurately relate how performance is affected by the various aspects of planning. It is not the intent of this research to study the relationship between planning and performance. However, if this research can shed light on the factors that affect the transition of intended strategy (i.e. planned) into realized strategy (i.e. implemented), future research into planning versus performance may yield more consistent results.

Whether a strategy is deliberate, emergent or a combination of both, it is created and implemented in the context of the external and internal environments of the particular organization. External factors such as environmental turbulence and competitive context impact the methodology utilized and the rapidity of the process (Grant, 2003). The explicit and implicit characteristics of the organization, as well as the characteristics of the individual actors, combine to impact the processes used to formulate and implement strategy. Numerous scholars have highlighted the impact on planning brought about by internal and external context (Ashill, Frederikson, \& Davies, 2003; Blythe \& Zimmerman, 2004; Depperu \& Gnan, 2006; Harrington, Lemak, Reed, \& Kendall, 2004; Miller, Droge, \& Toulouse, 1988). The sections below briefly discuss these issues and suggest how they may impact strategy formation, and the evolution of intended strategy into realized strategy, in organizations.

\subsection{The Impact of Contextual Issues on Strategy Formation}

The choice of strategy formation methodology and how effectively it is carried out does not occur in a vacuum. It is a consequence of numerous external and internal forces affecting an organization. The accelerating pace of change, and the turbulent and 
extremely competitive environment that exists for many businesses may have resulted in an increasing reliance on a process of 'planned emergence' whereby businesses formally plan but retain considerable flexibility to adjust strategies as required to react to their changeable environments (Grant, 2003). A reasonable approach may be for organizations to plot a broad path toward objectives while allowing course adjustments within set guidelines.

The strategy formation methodology utilized by an organization is also impacted by the internal environment of the organization (Boyd \& Reuning-Elliott, 1998; Mintzberg \& Lampel, 1999). Ashill, Frederikson, \& Davies (2003) propose an iceberg as a representation of the many explicit and implicit characteristics of organizations that impact the choice of strategy formation methodology. As with an iceberg, the lower nonvisible levels, including the organization's underlying values and assumptions, have a significant impact on how strategy is formulated and implemented.

\subsection{External Environment}

The already rapid pace of change in the structure of markets and industries is accelerating and "an ability to synthesize the collective impact of a complex set of economic, political, regulatory and social changes, is increasingly at a premium" (Prahalad and Hamel, 1994 p. 9). An ability to predict these impacts and develop strategies to exploit the resultant opportunities could lie at the heart of future success or failure for many firms. However, as the environment becomes more complex and unpredictable, longer planning timeframes become more challenging.

The last few decades have seen numerous industries change radically, with the roots of their evolution buried in regulatory shifts, increased global competition and the 
prevalence of innovative technologies (Prahalad \& Hamel, 1994). While firms

previously had the privilege of deciding whether or not they would compete in global markets, this choice is no longer an option. Off-shore companies are taking the battle to the domestic markets of others with lower prices and a range of quality levels (Blythe \& Zimmerman, 2004). This enhanced competition comes in the form of both traditional sales sites and the ubiquitous nature of the internet. A customer can now compare prices, specifications, warranties and availability from the comfort of an office or home on either a domestic or global level. This in turn has led to an increase in customer expectations which must factor into the strategies of successful firms.

Regulatory and technology changes, and the changing nature of supply and distribution chains, have lowered barriers to entry, as exemplified by the rapid penetration of Dell into the personal computer market (Prahalad and Hamel, 1994). By going direct to the consumer and bypassing traditional distribution channels, Dell effectively restructured the market.

In terms of strategy formation, the rapidly changing environment in which firms must now compete necessitates enhanced creativity and nimbleness in strategy formation and implementation processes. The faster firms can react, or preferably correctly anticipate environmental changes, the higher their probability of success. However, there is always a risk that anticipated environmental changes will not occur as predicted. As with all actions taken by organizations, the skill levels of predictors, planners, decision makers and implementers may have a dramatic impact on success in any particular situation. 


\subsubsection{Environmental Turbulence}

In a study of 113 companies in the United Kingdom, it was found that the more turbulent the environment, the more likely a company was to utilize formal strategic planning (Falshaw et al., 2006). In a study of 185 manufacturing organizations, Andersen (2004) found that in organizations operating in dynamic environments, higher performance is associated with decentralized but formal strategy formation processes. The formal nature of the processes is aligned with deliberate strategy formation while the decentralized nature of the authority structure allows important strategies to emerge from lower level managers. In other words, if lower level managers have the authority to make decisions and take initiatives in response to the changing environment, their actions can become part of a flexible organization's formal yet evolving strategy. In this way, the methodology incorporates both deliberate and emergent strategy making aspects, interacting in a complementary yet complex manner (Andersen, 2004). A similar result was found in a study of 656 firms where simultaneous formal strategic planning and emergent strategy were present in companies situated in unstable environments (Brews and Hunt, 1999).

Harrington et al. (2004) furthered the discussion by looking for a level of fit between strategy formation methodology, the environment and firm performance. Using survey results from 68 firms in 18 industries, the authors sought to determine if a relationship existed between the dynamism of the environment and the company's position along the deliberate - emergent strategy formation continuum. Dynamism was assessed on an industry basis as a standardized measure of the volatility of sales growth over the period from 1995 to 1999 . They noted that in general, the actual strategy 
formation methodology employed by a firm exists between the continuum end-points, and has some mix of both deliberate and emergent components. The emergent components can be either new strategies or changes to previously stated deliberate strategies. The authors found that the more unstable the environment, the more a firm's realized strategy tended to rely on emergent strategy components. They postulated that this was a consequence of managers needing flexibility to adequately respond to environmental dynamism. It might also be said that unstable environments can result in changes to the fundamental premises upon which an intended strategy is built, thereby necessitating the emergence of new strategies with which to cope with these changing parameters. Managers' approach to strategy formation may also reflect the environmental situation in which their firms find themselves (Jennings and Disney, 2006). As such, instability in the environment may cause managers to include an emergent or flexible approach in their overall strategy formulation process.

To understand in more detail how strategic planning proceeds in turbulent environments, Grant (2003) carried out case studies of the 10 leading oil majors as defined by the 1997 Fortune Global 500 list. He then attempted to find similarities in the way these companies formulated strategy. As all 10 companies in this very dynamic environment utilized a formal strategic planning process with an annual planning cycle, he noted that there was a deliberate component to their approach. The planning staffs that facilitated the process were typically made up of high potential individuals drawn from mostly line management roles for three to five year periods. This allows “corporate-level exposure and a 'big-picture' perspective for 'fast track' executives" 
(Grant, 2003 p. 501). Viewed from another perspective, it allows high potential individuals the opportunity to develop wide scope mental models early in their careers. Many of these companies used scenario based planning to formulate strategies (Grant, 2003). They also had stopped trying to predict future values for critical variables in favour of making assumptions about these variables. For example, a company might provide guidance that oil prices were expected to rise over the time period as supply tightened instead of providing specific price per barrel estimates. The corporate headquarters tended to provide broad themes, guidelines and performance targets while allowing the detailed planning to be carried out by executives at the division and business unit levels. Planning horizons were short due to the dynamic nature of the environment, strategic planning sessions were focused on communication and knowledge sharing, and the sessions also functioned as coordination and control vehicles.

"In short, the strategic planning systems of the international majors could be described as processes of 'planned emergence"' (Grant, 2003 p. 513). While the formality of an annual planning process existed in the companies, the processes involved considerable flexibility in the formation of strategies and in the strategies themselves. Further, strategies were allowed to emerge and evolve as the operations proceeded in their changeable environments and within the context of the general strategic guidelines and direction developed during the planning process. This planned emergence approach is consistent with observations taken from complex adaptive systems (Grant, 2003).

The more emergent aspects of strategy formation are particularly important in turbulent environments due to the unpredictable nature of these environments (Parnell and Lester, 2003). As the external environment changes, the organization's strategy must 
also evolve if the organization is to succeed. As such, environmental instability should have a significant impact on the realized strategy of the organization as stated in Hypothesis $1(\mathrm{H} 1)$.

H1: Instability in the external environment is a significant factor in transforming intended strategy into realized strategy. The greater the level of instability, the greater the level of transformation.

\subsubsection{Competitive Context}

Hypercompetition refers to a level of competition from global competitors that is so extreme, it demands a shift in the nature of strategic planning (Blythe and Zimmerman, 2004). Instead of relying on strategy formation techniques aimed at sustained competitive advantage, Blythe and Zimmerman (2004) argue that repeated temporary advantages are more realistic goals with disruption and surprise as the primary tools. The key is to be the first to initiate a change in a market in any particular iteration. They propose a cycle of market disruption, creation of temporary advantage, exploitation of the opportunity, and back to market disruption to create a new advantage. In this environment, flexibility and speed in the strategy formation and implementation processes are essential. As the competitiveness of the environment increases, so does the need for flexibility in the strategy formation process (Blythe and Zimmerman, 2004). This implies the importance of emergent strategy aspects as competitors' actions evolve. 
$\mathrm{H} 2$ : Actions of competitors is a significant factor in transforming intended strategy into realized strategy. The greater the level of competition, the greater the level of transformation.

Depperu and Gnan (2006) tested five factors that may define the competitive context within which a firm formulates its strategy. These are pressure from competitors, demand trends, changes in customer needs, pressure on prices and trends toward sector concentration. In a study of 29 large Italian companies operating through 54 business units, they tried to determine which factors most impacted the firm's strategy formation methodology. They found that demand trends and changes in customer needs explain much of the differences between strategy formation methodologies used by the firms they studied. As such, the rapidity of change of these factors leads to the requirement for flexibility in strategy formation approach by the firms. They conclude that competitive context plays a key role in the method of strategy formation used by a firm.

H3: Changes in customer requirements is a significant factor in transforming intended strategy into realized strategy. The greater the level of change in customer requirements, the greater the level of transformation.

\subsubsection{Complexity of the Environment}

Assuming that business situations can be defined as chaotic or complex non-linear systems, Levy (1994) describes a number of relevant impacts on strategic planning. He notes that as chaotic systems never return to their initial state, managers should not 
assume that their organizations will return to a prior point of equilibrium. Similarly, as new states are not predictable in the long term, strategic planning must allow for a number of possible future scenarios. Strategic planning should focus on developing objectives with guidelines that allow flexibility in exploiting opportunities to attain the objectives. Because chaotic systems can self-organize into more complex systems (Anderson, 1999), organizations must remain nimble and flexible in their strategies. The ability to adapt quickly to environmental changes is also required because seemingly small environmental changes can produce significant downstream effects in chaotic systems. As patterns occurring in subsets of the systems can propagate on a system-wide basis (Anderson, 1999), managers should be observant of emerging patterns and how they might repeat themselves across an industry or economy. Finally, as in chess, it is important that managers see the whole board. Remaining aware that their company is only part of a larger system may aid in understanding the interactions that occur between the system's elements.

The impact of environmental complexity on strategy formation has been studied to some extent. In a study of 115 large manufacturing firms, it was found that firms utilize more flexible planning approaches in the face of more complex operational environments (Kukalis, 1991). Environmental complexity is therefore proposed as one of the emergent factors that has a transformational effect upon intended strategy. This hypothesis differs from $\mathrm{H} 1$ (environmental instability) in that $\mathrm{H} 1$ refers to the unpredictable and changeable nature of particular environments as opposed to the inherent complexity of particular environments referred to in $\mathrm{H} 4$. 
H4: Complexity of the environment is a significant factor in transforming intended strategy into realized strategy. The greater the level of complexity, the greater the level of transformation.

\subsection{Internal Environment}

The internal environment of an organization may play a significant role in determining the strategy formation methodology it is likely to employ (Boyd \& ReuningElliott, 1998; Mintzberg \& Lampel, 1999). Ashill et al. (2003) have proposed a planning model structured around the shape of an iceberg to reflect the internal environment and its effects on planning. While the iceberg model was designed as a representation of strategic marketing planning, its concepts and characteristics are also valid for the strategy formation process of the firm as a whole. It is essentially a visual representation of the factors affecting the planning process. The Figure 2 model is in the shape of a triangle with four layers from top to bottom. The concept centers on the idea that there are apparent and non-apparent factors that affect strategy formation. Just like an iceberg, the visible portion of the whole is small while the larger portion sits invisible below the surface. 
Figure 2: Internal factors affecting planning.

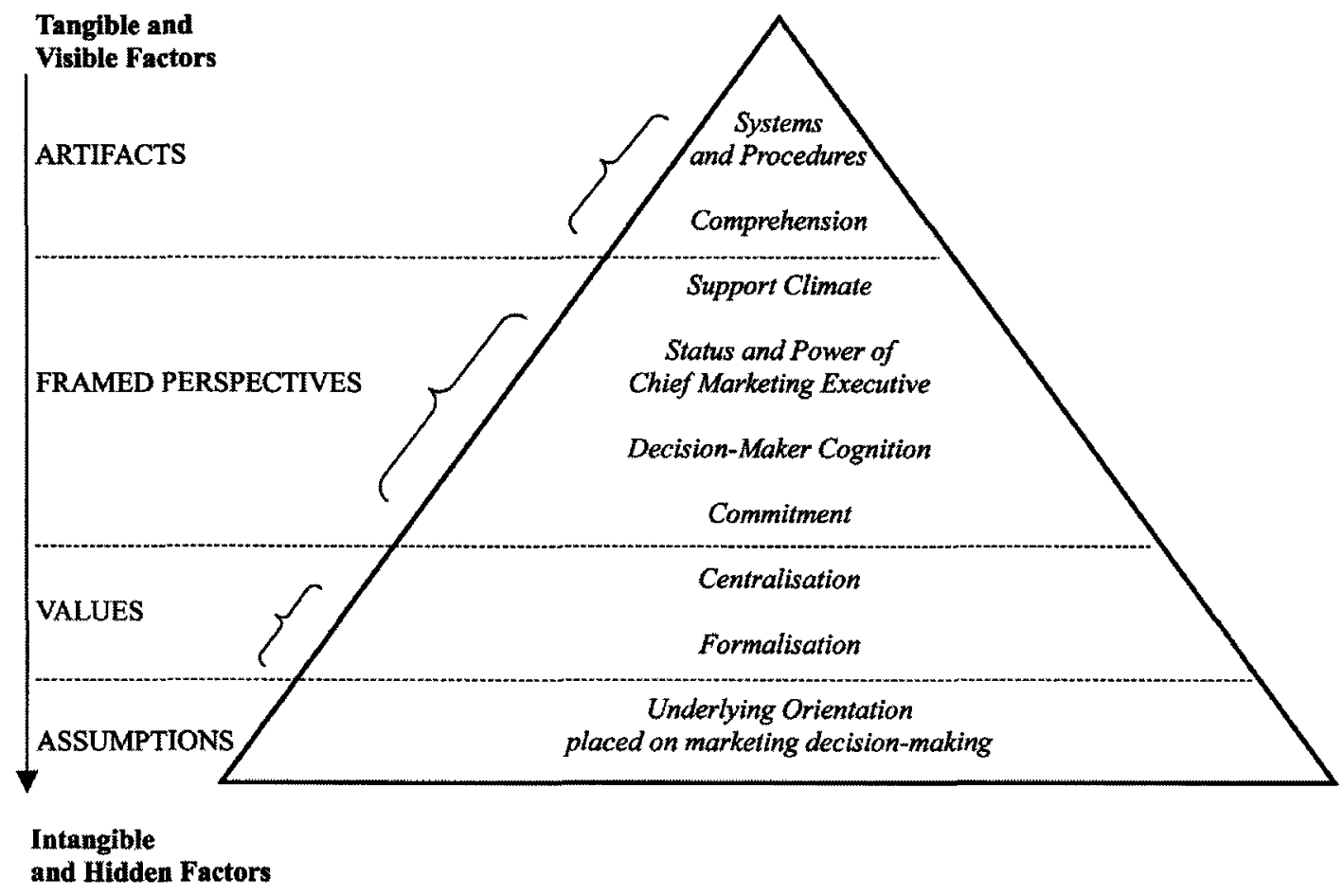

Source: Ashill, Frederikson, \& Davies, 2003.

The uppermost and most visible layer is referred to as artifacts. This layer contains the planning procedures, strategic plan formats and structure, and the firm's understanding of strategy. This portion of the iceberg most closely resembles the traditional strategic planning approach. The authors contend that one of the key problems with past research, is that it has "generally focused on explanations of organisational ... planning, that is, actual planning procedures" (Ashill et al., 2003 p. 454), or in other words, only on this upper layer.

The next layer down is the framed perspectives layer which refers to the level of support for strategic planning in the organization, the relative authority of the senior strategy executive, knowledge of the skill requirements for the process, and the strategic 
leadership provided to the planning process. These are characteristics of the organization and its attitudes toward the strategy formation process. Other parts of the organization will take cues from these framed perspectives as to the level of importance they should lend to the strategic plan.

The values layer has to do with the concepts of centralization and formalization. Centralization refers to whether or not the organization demonstrates its value for the planning process by making a group of key people in the organization responsible for its implementation. Formalization refers to the requirement to rigorously adhere to processes and procedures relative to the activity and the resultant plan. These values signify the importance that the organization places on the process and product.

The assumptions layer is the least visible. It has to do with the underlying assumptions and beliefs of the organization. These may not be documented, or even articulated, but they represent the framework within which decisions are consciously and unconsciously made in the firm.

Each of these layers is a manifestation of the layers below it. The strategy formation process, the intended strategy, and how the organization views both, are functions of these underlying layers. The layers are a chain of concepts, protocols and behaviours that define the strategy formation process and its importance in the firm. It may be appropriate to view the uppermost layer as closely aligning with deliberate strategic planning; however, the lower layers certainly influence this deliberate planning process. The lower layers also represent the more emergent aspects that, in conjunction with the impacts of the external environment, transform the deliberately designed intended strategy into the realized strategy from which the performance results of the 
firm flow. During implementation, these perspectives, values and assumptions combine with external environmental factors to allow the transformation to occur.

This model adds to the understanding of planning in that it recognizes the process, not as a series of steps that are used to develop a plan, but as a manifestation or reflection of the firm's beliefs, values and perspectives. Further, it recognizes that the strategic plan is developed and implemented at many levels of the organization. Mintzberg (1977) also refers to the complex internal characteristics of an organization and how these affect strategy formation. He notes that factors such as "organizational forces (for example, surplus resources, structural arrangements, including extent of bureaucracy, changes in the internal power coalition, organizational age and size, technological systems used) and leadership (new management, desire to grow, etc.)" (1977 p. 40) all play a role.

\subsubsection{Characteristics of the Leadership Team}

While numerous internal organizational factors affect the strategy formation process, the experiences, characteristics and tendencies of the key leaders involved in the process can significantly impact the formation methodology and the transformation from intended to realized strategy. The type of information or data that is used during the process and the personality types of the mangers all affect strategy formation and implementation.

\subsubsection{Tacit Knowledge versus Formal Data}

"Tacit knowledge is previously acquired, hidden knowledge that a person has and draws on, often without realizing it" (Daake, Dawley, \& Anthony, 2004 p. 234). While tacit knowledge is very valuable in helping interpret situations and develop solutions, it 
can also bias the planning process in unpredictable ways depending upon the particular individuals involved and their past experiences.

It is critical that decision makers engaged in strategy formation have "a solid understanding of the business, share a common fact base, and agree on important assumptions" (Kaplan and Beinhocker, 2003 p. 72). Although specifically referring to Boards of Directors, Forbes and Milliken's (1999) assertion about the types of information required for sound strategic decision making is also valid in the context of strategy formation. They state that two types of knowledge are required: the first is functional knowledge about the various aspects of a business including finance, marketing and logistics; the second is detailed knowledge of their specific organization including its management and operations. This type of information can be thought of as formal data. These formal data requirements necessitate the sharing of some level of information at the commencement of the strategy formation process (Daake et al., 2004).

Daake et al. (2004) report on a study of information usage during the strategic planning sessions of a large hospital in the US. Their research question centred on whether or not formal data usage in the strategy formation process could be increased by flooding the participants with formal information. Their answer was an unequivocal 'no'. As an example of the researchers' observations during the actual planning session, the strategic planning team members used informal data sources 128 times while using formal data only 17 times (p. 238). "The transcript analysis indicated that the majority of utterances were opinion, stories, illustrations, analogies and metaphors, and some vague references to regulations and laws based on personal experience" (p. 241). They note that Kotter's (1982) study of a similarly educated and experienced group of general managers 
showed similar results in that tacit knowledge was the primary source of reference in decision making.

One explanation for the results of the hospital study may be bounded rationality whereby people have a limited capacity to process information. As such, the mind cannot retain and process all of the information presented in a particular situation (Simon, 1957 in Daake et al., 2004) so the actors fall back upon the knowledge and experience that they already have stored. Another possibility is that people use their mental maps to filter new information, retaining only the data that fits their current models (Hogarth, 1987 in Daake et al., 2004). This suggests that the prior experiences of the members of the leadership team affect how they view strategic situations and plan formation, and the decisions they make in implementing those plans (Daake et al., 2004). Numerous authors have noted that executives' and managers' characteristics such as personal philosophies, self-interest, personality traits and interpretations of events are linked to strategy formation and implementation (Guth \& MacMillan, 1986; Hambrick \& Fredrickson, 2001; Kotey \& Meredith, 1997; Parnell \& Lester, 2003; Smircich \& Stubbart, 1985; Walsh \& Fahey, 1986). These characteristics may also include the degree of opportunity taking with which leaders may be comfortable (Depperu \& Gnan, 2006). The degree of opportunity taking refers to the readiness of decision makers to quickly exploit new opportunities as they present themselves. The more the tendency toward opportunity taking, the more may be the impact of emergent aspects in the strategy formation process (Mintzberg, 1977), leading to a greater degree of transformation from intended to realized strategy. 


\subsubsection{Leadership Team Understanding and Support of a Strategy}

The impact that the prior experiences of leadership team members can have upon their understanding of relevant issues and strategy formation has been shown (Daake et al., 2004). This has highlighted the importance for strategy formation and implementation of building a shared and detailed understanding among leaders of various aspects of a business, the issues and the external environment (Beinhocker \& Kaplan, 2002). This shared understanding can aid in the development of a coordinated and effective approach to the many changes to the internal and external environments that can occur during the implementation phase of a strategy. However, the lack of a common understanding can lead to ineffective activities as various leaders take non-coordinated and disjointed actions. Either way, the effect can be considerable upon the transformation of intended strategy into realized strategy. Section 7.4.1 references the various applicable leadership team characteristics found in the literature. As some leadership team characteristics would seem to inhibit strategy transformation (e.g. leadership team support of the strategy) while others would seem to facilitate transformation (e.g. tendency toward opportunity taking), H5 does not hypothesize an increase or decrease in the level of transformation. The data analysis will indicate the relative strengths of these two types of characteristics in the literature based a priori model.

H5: The characteristics of the leadership team is a significant factor in transforming intended strategy into realized strategy. 


\subsubsection{Involvement and Support of the Organization}

Despite the best efforts of the leadership team, it is extremely difficult to implement a strategy without the involvement and support of the organization (Mintzberg, 1977; Mintzberg, 1987). Based on prior research, a relationship has also been suggested between an orientation toward change and the existence of deliberate strategic planning in an organization (Boyd \& Reuning-Elliott, 1998). If an organization is overly resistant to change, any change in strategy could be mired in passive or assertive resistance to the point where it is rendered impotent. In the extreme case, this would result in the realized strategy being exactly the same as the status quo. In less extreme cases, it could result in the realized strategy being more closely aligned with the status quo than with the intended strategy. In cases of an orientation toward change, the organization may allow change but be quite involved in the transformation of intended strategy into realized strategy. The impact of the organization on the intended strategy can assert itself through a number of mechanisms.

\subsubsection{Position Bias}

Position bias refers to the tendency of individuals in an organization to pursue the objectives or goals of their position or group instead of the stated goals of the whole organization. This has also been referred to as sub-goal pursuit (Ketokivi \& Castañer, 2004). Sub-goal pursuit can have a detrimental effect on the implementation of an organization's intended strategy by limiting the resources within the organization that are actually striving to attain organizational objectives and goals. It can have a decidedly negative effect in that some of the sub-goals pursued by individuals or groups within the organization may be at odds with the larger goals. For example, scarce resources are 
often allocated to research and development of technologies seen as strategic relative to a firm's competitive position. When these human and financial resources are expended on non-intended technologies by a particular research and development group, the impact on the firm can be significant and unpredictable.

Ketokivi and Castañer (2004) carried out a study to understand if strategic planning can be used as an integrative device to lower the focus on sub-goals by managers within a firm and increase the attention and effort afforded to the objectives of the whole organization. They surveyed three mid-level managers per site at 164 manufacturing plants across three industries and five countries. The managers were asked to evaluate the importance of organizational goals.

Ketokivi and Castañer (2004) note that Pinto, Pinto and Prescott (1993) showed that the development of goals is a significant antecedent to cooperation among crossfunctional groups. Ketokivi and Castañer (2004) then surmised that as goal setting is a component of strategy formation, the planning process itself could possibly be an integrative vehicle for managers and a means of reducing sub-goal pursuit. They argue that allowing mid-level managers to participate in the strategic planning process allows them to have a better understanding of the strategy and objectives, and gives them a sense of ownership of the plan. They propose that goal convergence of managers throughout a firm could have a significant impact on the attainment of the organization's goals.

The study showed evidence for strategic planning acting as an integrative device and increasing goal convergence of managers throughout organizations. This effect was particularly pronounced when the managers both participated in the planning process and the firm communicated the resultant goals and priorities to the whole firm. In other 
words, the affects of participation and communication were complementary and worked to reduce position bias.

The findings of this study provide simple actions that can be implemented quickly by firms to increase organizational focus and effort toward strategic goals and enhance the potential for their attainment. Including mid-level managers in the strategy formation process and communicating subsequent goals and priorities clearly to the whole organization could reduce inter-departmental conflict, increase cooperation and increase effort toward organizational goal attainment.

\subsubsection{Involvement in the 'Act of Planning' and Implementation}

The notion that the 'act of planning' is a critical factor in encouraging an organization to support an intended strategy has been proposed in numerous articles (Falshaw et al., 2006; Greenley, 1994; Parnell \& Lester, 2003). Through a study of 185 manufacturing organizations in North America, Andersen (2004) showed a significant positive relationship between distributed decision authority and performance, especially in turbulent environments and where formal deliberate strategic processes were in evidence. He noted that allowing employees below the executive level to make decisions as the business environment changes enhances an organization's ability to take advantage of the emergent components of a strategy. Another way of stating this might be that it allows the organization to be more actively involved in the transformation from intended to realized strategy and, if lower level managers have been involved in the planning process, they may be more likely to retain the original intent of the intended strategy. 
H6: The involvement of employees below the senior leadership level in the strategy formation process is a significant factor in transforming intended strategy into realized strategy. The greater the level of employee involvement, the lesser the level of transformation.

\subsubsection{Organizational Learning}

As emergent strategies are adopted by an organization and become deliberate in future iterations of strategy formation, the strategy formation process involved is akin to organizational learning (Mintzberg and Waters, 1985). Further, feedback and adaptation is ongoing so that implementation should be viewed as part of the strategy formation

process (Mintzberg, 1977). As decisions are made and results are obtained, analysed and internalized, informal learning is taking place (Mintzberg, 1994) and this enhances the implementation process (Schäffer \& Willauer, 2003). If management is adept enough to recognize successful strategies as they emerge, and flexible enough to adopt and implement them, organizational learning can occur. As organizations are made up of individuals, the ability of these individuals to develop new and shared mental models is a factor in the organization's ability to learn (Schaffer and Willauer, 2003). The process of scenario based learning has been used to accelerate the development of mental models among decision makers in some organizations (De Geus, 1988).

\subsubsection{Mental Models}

Through a review of the practices of 30 companies, Beinhocker and Kaplan have determined that strategic planning can be effective if it has as an objective to "make sure 
that decision makers have a solid understanding of the business, its strategy, and the assumptions behind that strategy, thereby making it possible for executives to respond swiftly to challenges and opportunities as they occur in real time" (2002 p. 51). They propose that to attain this goal, a number of criteria with respect to the strategy formation process must be satisfied. These include: strategy discussions taking place in groups of no more than 10; acknowledging that these intense discussions can take 20 to 30 days spread over numerous sessions for a company with multiple business units; discussions should take place at the business unit sites; strategy dialogue should be held separately from short term debate over budgets and financial targets; considerable environmental analysis should be carried out in preparation for the meetings; and the attainment of strategic objectives should be tied to management compensation.

Schaffer and Willauer note that "based on cognitive and social learning theory, the learning process can be interpreted as a cybernetic feed-back loop aimed at the modification of internal models. In the process, members of an organization modify their interpretation of events. They develop shared understanding and conceptual schemes" (2003 p. 87). The authors argue that changing the internal models or algorithms of decision makers should be a central theme of the strategy formation process.

In a survey of 298 German companies, Schaffer and Willauer (2003) found that learning in the planning process is associated with: the internal complexity and dynamism of the organization, a decentralized structure, and most importantly by the degree of trust among the actors and the amount of information amassed and analysed during the process. The presence of trust allows participants to feel comfortable sharing information and in performing non-conformist actions and behaviours. A higher degree of learning 
leads to more effective plans and implementation. Their results suggest that the size of the company had no effect on the findings.

Perhaps institutional learning is closely aligned with emergent strategy. The strategy might be said to emerge as the mental models of the actors are modified in response to the environment.

\subsubsection{Scenario Based Learning}

If learning or altering the mental models of managers is a significant aspect of strategy formation and organizational success (Schäffer \& Willauer, 2003), the question of how to accelerate new mental model formation or alteration becomes important, especially in the face of a dynamic environment. De Geus (1988) has reported on a methodology used at Shell to accelerate the learning process. Shell developed this approach to planning after surveying 30 companies that had been in continuous operation for at least 75 years. Through studying the experiences of these companies, Shell felt that it was the ability to learn and adapt to environmental changes that separated them from companies that did not survive. Put another way, Shell came to believe that "the ability to learn faster than your competitors may be the only sustainable competitive advantage" (De Geus, 1988 p. 71).

In the event of a crisis, an organization will move quickly to relieve the danger or pain brought about by the situation (De Geus, 1988). The problem is that the organization must first experience the pain and may have only a few reactive options available at the time. The 30 long-lived companies studied by Shell were able to perceive crises in advance, thereby allowing them to react successfully before the presence of 
pain. It is interesting to note that this appears to contradict Mintzberg's (1987) notion that environmental prediction is not possible.

Based upon observations, De Geus (1988) believed that from the onset of a shock or input, it took approximately 12 to 18 months for consistent behavioural changes or learning to take place in an organization. These changes or the alteration of mental models occurred as decision makers interacted with one another both formally and informally over long periods of time. To accelerate this process, Shell introduced a system that ran strategic planning simulations around possible future environmental scenarios. For example, while oil was still priced at approximately $\$ 28$ a barrel in 1984 , the planners at Shell had senior managers plan through a scenario where oil would drop to $\$ 15$ a barrel in 1985 . Despite considerable disbelief and resistance, the planning sessions eventually took place. When oil dropped to $\$ 10$ a barrel in April 1986, senior management had already thought through the impacts and possible solutions, thereby giving the company a decided advantage over its competitors. While one could argue that the planners were simply lucky in predicting the drastic reduction in oil prices, the point of the methodology is that various possible scenarios can be run against a number of probable or improbable futures. In this way, contingency plans can be developed and, more importantly, mental models can be formed.

Military organizations have been using scenario based planning for many years. Further, they carry out mock exercises where the scenarios are run and the developed plans are implemented. Examples include terrorist attacks, airborne bomber attacks, ground force attacks and nuclear events. The exercises are run using real decision makers and assets such as troops and equipment, or decision makers alone playing 
against computer simulations. While most private sector companies do not have the resources available to refine prepared plans through practice implementations, they do have the ability to run the scenarios in strategic planning sessions to allow contingency plans to be developed and cognitive processes in the minds of decision makers to be exercised. This probably occurs already on a limited basis in some firms, but could be viewed as an opportunity for many other organizations to experiment with scenario based planning.

If scenario based contingency planning sounds like 'play', it is exactly that. It allows decision makers to explore new environments that may be different from the ones where their organizations currently find themselves. It allows them to become comfortable with these new environments such that, if their organization suddenly finds itself in such a new environment, the decision makers already have a head-start in learning how to deal with the evolving situation. As such, "good scenarios challenge tunnel vision by instilling a deeper appreciation for the myriad factors that shape the future" (Schoemaker, 1995 p. 31).

Scenario based planning's alternate views of the future lead to alternative strategies and flexibility. As such, the real value of the approach is that it becomes a vehicle for inducing strategic thinking (Grant, 2003). Perhaps another perspective is that it allows emergent strategies to develop without the risk to the organization of actually having to deal with hazardous environments or crises.

\subsubsection{Organizational Learning and Strategy Formation}

The cycle of emergent strategy contributing to the next iteration of deliberate strategy can be viewed as organizational learning (Mintzberg and Waters, 1985). In 
addition, given that organizations are groups of individuals, understanding how individuals learn may be a critical aspect of understanding how the organization as a whole learns. However, organizations have varying levels of learning proficiency (Lichtenthaler, 2009). As with individuals, an organization's ability to quickly learn from past successes and failures may be a key factor in the ongoing ability of the organization to be successful. As such, the higher the degree of learning and sharing of mental models among decisions makers, the higher the probability of effective strategies and implementations (Schaffer and Willauer, 2003). Given the importance of creating and sharing these mental algorithms among decision makers, methods such as scenario based planning should be used where possible to accelerate this learning process. The faster institutional learning can take place, the more an intended strategy is affected during implementation (De Geus, 1988).

H7: The ability of the organization to learn during intended strategy implementation is a significant factor in transforming intended strategy into realized strategy. The greater the ability of the organization to learn, the greater the level of transformation.

\subsubsection{Flexibility of the Intended Strategy}

As noted earlier, the accelerating pace of change and the turbulent and extremely competitive environment that exists for many businesses makes a rigid plan ripe for significant transformation. A more rigid intended strategy does not allow an organization the adaptability to exploit opportunities or pursue innovations as they arise (Miller and 
Cardinal, 1994; Rudd et al., 2008). This has led some firms to rely on a strategy formation process of planned emergence whereby businesses formally plan but retain considerable flexibility to adjust strategies as required to react to their changeable environments (Grant, 2003). An inherently flexible intended strategy allows an organization to plot a broad path toward objectives while allowing course adjustments within set guidelines. As such, an intended strategy would include objectives which were sufficiently broad to allow evolution to occur at the tactical level while transformation of the plan at the strategic level would be reduced.

H8: The inherent flexibility of the intended strategy is a significant factor in transforming intended strategy into realized strategy. The greater the level of flexibility, the lesser the level of transformation.

\subsection{Hypotheses}

The following eight hypotheses will be the focus of the data gathering and analysis in this work:

- H1: Instability in the external environment is a significant factor in transforming intended strategy into realized strategy. The greater the level of instability, the greater the level of transformation.

- H2: Actions of competitors is a significant factor in transforming intended strategy into realized strategy. The greater the level of competition, the greater the level of transformation. 
- H3: Changes in customer requirements is a significant factor in transforming intended strategy into realized strategy. The greater the level of change in customer requirements, the greater the level of transformation.

- H4: Complexity of the environment is a significant factor in transforming intended strategy into realized strategy. The greater the level of complexity, the greater the level of transformation.

- H5: The characteristics of the leadership team is a significant factor in transforming intended strategy into realized strategy.

- H6: The involvement of employees below the senior leadership level in the strategy formation process is a significant factor in transforming intended strategy into realized strategy. The greater the level of employee involvement, the lesser the level of transformation.

- H7: The ability of the organization to learn during intended strategy implementation is a significant factor in transforming intended strategy into realized strategy. The greater the ability of the organization to learn, the greater the level of transformation.

- H8: The inherent flexibility of the intended strategy is a significant factor in transforming intended strategy into realized strategy. The greater the level of flexibility, the lesser the level of transformation. 


\subsection{PROPOSED A PRIORI MODEL}

The model shown in Figure 3 represents intended strategy transforming into realized strategy through the impact of a group of contextual factors. These factors have been gleaned from the literature as the internal and external contextual variables which somehow cause intended strategy to evolve during implementation. However, the mechanisms by which these factors affect intended strategy is not clear. As such, the model simply depicts the factors in a space between the intended and realized strategies through which the implementation proceeds. The purpose of this study is to gain further understanding as to whether these are the actual factors that impact the transformation and the mechanisms by which the impacts of each factor occurs.

Figure 3: A Priori Strategy Transformation Model - factors taken from the literature.

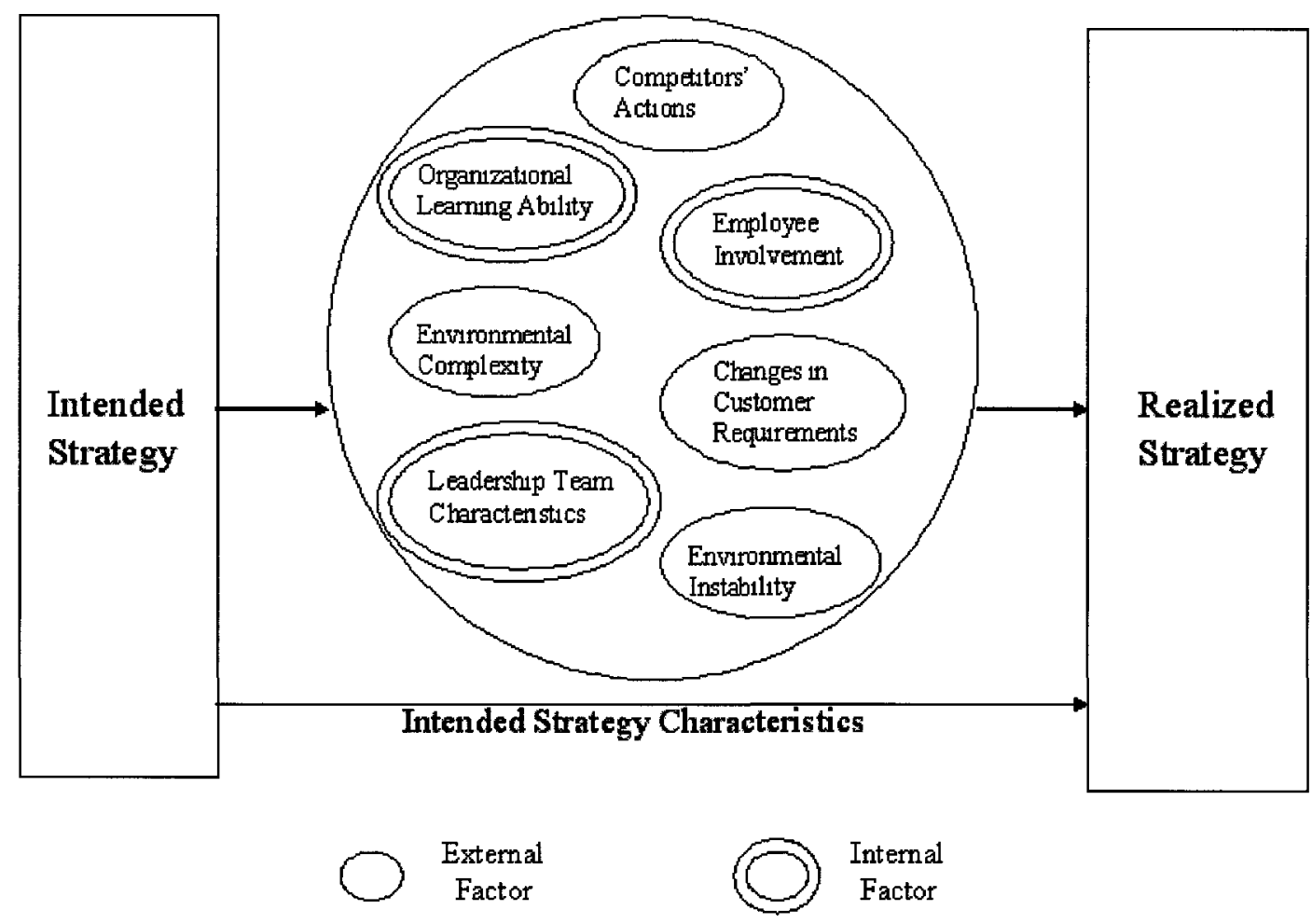


Figure 4 is a conceptual representation of the two ways that these factors may interact to impact the transformation. Some of these factors may act as mediators of the relationship between the independent and dependent variables. Others may be moderators which are variables that affect the level of any relationship between independent and dependent variables. Mediators and moderators can be either continuous or categorical variables; in this study, the factors identified from the literature would all seem to be continuous.

Figure 4: Possible impact of moderators and mediators on the transformation of intended strategy into realized strategy.

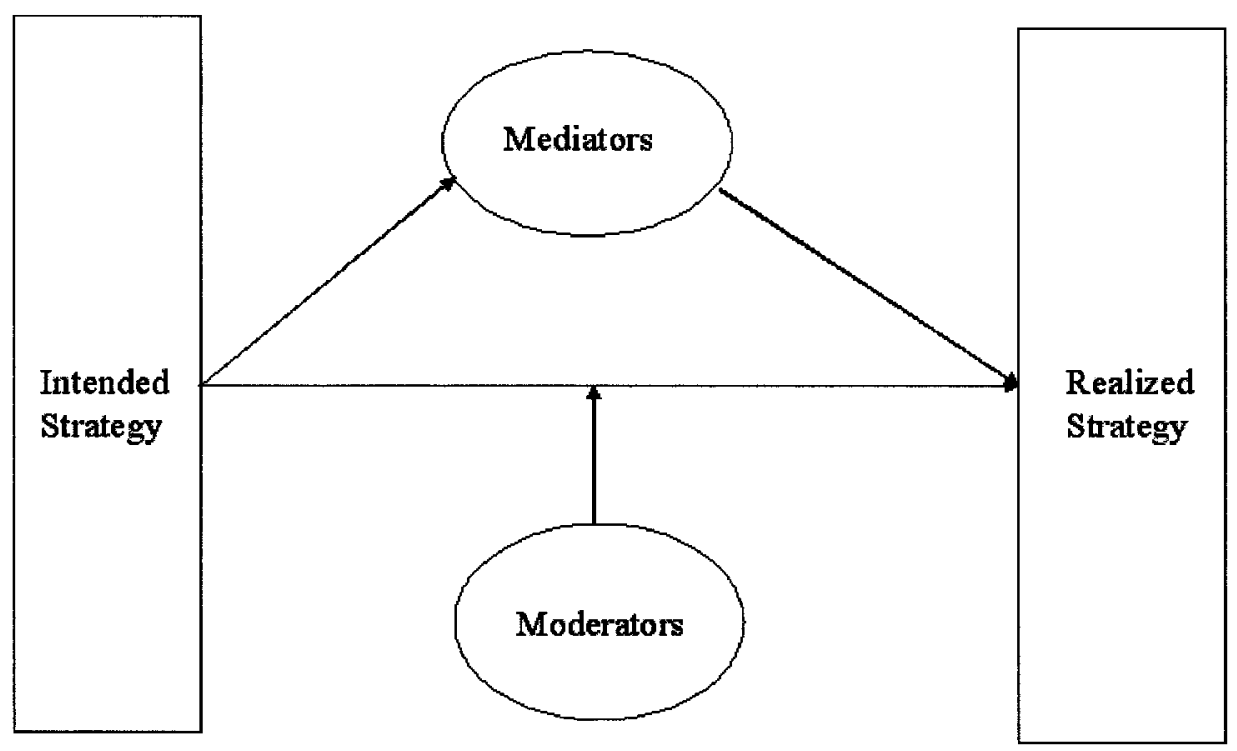

A variable can be determined to be a mediator when it meets the following three criteria: the variance of the independent variable explains the variance of the assumed mediator variable to a significant level; the variance of the assumed mediator variable explains the variance of the dependent variable to a significant level; and when the path through the assumed mediator variable is controlled, the direct relationship between the 
independent variable and the dependent variable is not significant (Baron \& Kenny, 1986).

Moderator variables act upon independent variables such that they moderate any relationship between these variables and a dependent variable. The causal relationship between the independent variables and the dependent variable varies as a function of the moderator. A simple example of a moderator in a medical study might be the level of high blood pressure medication in a subject's blood stream prior to the imposition of a stress upon a subject (e.g. a treadmill stress test). In such a trial, the impact of the induced stress upon the blood pressure increase of the subject would be moderated by the level of medication in the subject's blood stream.

The factors impacting the transformation of intended strategy into realized strategy may be mediators, moderators, neither or a mix of all three. The results of the quantitative phase of this work should identify which factors are mediators and which factors are moderators. 


\subsection{METHODOLOGY}

\subsection{Overall Approach}

Based on the literature, hypotheses have been developed as to the emergent contextual factors which significantly impact the transformation of deliberate intended strategy into realized strategy. Phase 1 of this work is a qualitative study designed to ensure that the framework is complete and reflects actual practice. A qualitative approach has been chosen to provide the opportunity to identify factors which may not have previously appeared in the literature. This section of the study focuses on semistructured interviews with executive informants at companies in the Ottawa area. Based on the results of the qualitative study, the model was modified to include indicators identified during the interviews which are not currently resident in the literature. In so doing, the model is more closely aligned with the contextual environment in which strategy is implemented by actual operating organizations. This in itself is a contribution to theory and makes the testing of that theory in the quantitative phase of this work more significant.

Phase 2 of this work is a quantitative study to gauge how each of the contextual factors in the model contributes to the transformation of intended strategy into realized strategy. A survey instrument was provided to senior managers and executives to gain their perspective on the factors impacting strategy transformation.

\subsection{Phase 1 - Qualitative Study: Interviews with Executives}

If a particular phenomenon is extremely complex and involves both tacit and explicit aspects (Bradbury \& Lichtenstein, 2000), or the study is designed to answer what 
or how-type questions (Lee et al., 1999), a qualitative approach can provide methodologies that accommodate the depth of analysis necessary to provide meaningful results. Further, if the goal is to develop theory relative to a particular phenomenon (Lee et al., 1999), a qualitative approach allows an open ended form of inquiry that permits the researcher the freedom to explore unforeseen avenues, even during the data gathering phase. Although quantitative methods can provide a wealth of important information, the structured data gathering methodologies tend to require assumptions with respect to possible outcomes. In fact, this may be one of the key problems with the quantitative research into strategy formation thus far. Researchers' initial assumptions about this complex problem (and how to operationalize dynamic variables) have necessarily been specific to allow the constructs to be tested using quantitative methods. This approach has not allowed for uncertainty with respect to the assumptions in particular studies, emergent variables and theory in order to better understand this multi-faceted process.

Given the disparity of views and results relative to strategy formation and the complexity of the subject, it is appropriate to start at the beginning in an effort to develop new theory relative to strategy formation and implementation. Weick (1989) describes theory in terms of a set of assertions and assumptions that explain a range of observations. This aligns with Sutton and Staw's (1995) emphasis on the ability of a theory to logically explain phenomena observed in the world, and express the explanation in the form of a causal chain. If this concept of theory is the goal, qualitative methods can provide an appropriate approach. Using open-ended qualitative methods, it is possible to do in-depth observation and analyses to gain a better understanding of the phenomena involved (Snow and Thomas, 1994). This allows the development of theory 
that provides explanations and some level of answer to the 'how and why' questions (Sutton \& Staw, 1995) relative to aspects of the complex relationship that exists between strategy formation and implementation.

\subsubsection{Data Source}

One approach particularly salient to the planning-implementation relationship is a case study format (Lee et al., 1999), using a number of informants with each representing a case. Data can be gathered in a series of semi-structured, in-depth interviews (Miles \& Snow, 1978) with informants who are knowledgeable and experienced in planning and implementing strategy. The interview approach is a critical step in ensuring that the research provides sufficient information to enhance understanding. The questions asked, and probes used to gain greater insight during interviews should be structured to ensure that preconceived notions of the strategy formation-implementation process are minimized on the parts of both the researchers and subjects (Hill et al., 2005).

In this study, the plan was to interview approximately four to ten executives at predominately high tech companies in and around the Ottawa area to gauge whether the most important contextual factors were present in the literature based model. Based on the results, the model was adjusted accordingly. Eisenhardt (1989) recommends a base of four interviews and carrying out additional interviews until the data begins to repeat, indicating that saturation has been reached. As such, a base of four interviews was carried out, with additional interviews occurring until no new factors were being identified which materially affected the transformation of planned strategy into implemented strategy. Once this point was reached, data saturation had occurred and additional interviews would have been very unlikely to yield significant new factors 
(Eisenhardt, 1989). Access was gained to informants through professional and social networks developed through the researcher's prior work experience. These informants were all at the executive level to ensure that they had sufficient experience in strategy formation and implementation to have observed how intended strategy transforms into realized strategy.

The interviews were audio recorded and transcribed to allow subsequent data analysis. The transcripts were written in an exact or non-corrected format (i.e. a naturalized approach) to retain the subtleties of the interviewees' stories (Oliver, Serovich \& Mason, 2005). The interviewer also took notes during the interviews to capture interviewee emphasis and real-time interviewer perceptions which would not have been captured by audio tape.

\subsubsection{Data Analysis}

A tremendous amount of transcription data can be gathered using these qualitative processes. This transcription data and its analysis is a key aspect of qualitative research (Poland, 2002). The data was sifted and reduced to identify themes and patterns which were used as the basis for validating the contextual factors developed from the literature or identifying new factors (Lee et al., 1999). The approach that was utilized involved pattern matching (Yin, 2003) to identify themes both within cases and across cases. The

goal was to identify consistent themes and patterns which could be used to assess the model and modify it as required (Crawford et al., 2008). The methodology iteratively compared the model with the evidence until the model was a solid reflection of the evidence from the informants (Eisenhardt, 1989). 
Specifically, the researcher, immediately following each interview, summarized the key contextual factors which emerged during the interview. This took into account both what the subject said and the emphasis which the subject placed upon the factors (Oliver et al., 2005). The recorded interview was then transcribed to allow the interviewer to perform a detailed analysis of what the subject said. Key words relating to the factors identified in the literature were sought in the transcripts to gauge the impact of each factor on the particular strategy implementation example provided by the informant (Lee et al., 1999). New variables identified by the informants were added to those sought during the analysis of each subsequent interview to gauge their impact across multiple implementation examples.

Additional interviews were carried out until new contextual variables were no longer being identified. The model was then modified by adding variables which proved common across interviews. If particular literature based factors had not been mentioned during the interviews, they would have been retained in the model to ascertain whether they had any support in the survey responses. The model was then ready for quantitative testing as described below.

\subsubsection{Interview Protocol}

The intent of the interviews was to explore, from the interviewees' perspectives, the key variables which contributed to the transformation of intended strategy into realized strategy. Through a detailed examination of a particular strategy implementation cycle chosen by the subject, the variables germane to that implementation were identified and used to validate the factors found in the literature. Further, as new variables were 
identified and appeared across the interviews with the various subjects, they were added to the model prior to the quantitative phase of this work.

During the week before the agreed time for each interview, the researcher contacted the interviewee to give an overview of the intent of the research and request that the subject choose a strategy implementation cycle for the discussion. The researcher emphasized that the chosen implementation cycle must be one with which the subject was intimately involved, both at the planning stage and during the implementation itself. This allowed the subject to ponder the chosen example in advance to ensure that a more complete recollection was available during the interview.

The interview commenced with the researcher restating the goals of the study. As detailed in Appendix B, the interviewee was then asked to recount in detail for the chosen strategy implementation cycle, the planned strategy that was in place prior to the actual implementation. The subject was then asked to describe how the implementation proceeded and, if the results differed from those planned, to describe the differences. The interviewee was asked to discuss how and why any changes occurred.

After the description of the strategy implementation example, the interviewer asked the interviewee to list the most significant factors which impacted the evolution of the strategy throughout the implementation. Probing questions were asked throughout the discussion and factor identification to clarify any vague or discrepant points and to ensure that the researcher had the required information to compare the interview results with the a priori model and modify the model if required.

The interviewee was then asked to rate the eight contextual factors developed from the literature against their importance relative to the example they provided. The 
rating was on a seven-point Likert-type scale running from highly important to highly unimportant. This gave an indication of the relevance of the contextual factors identified in the literature. If new common variables emerged during the interviews, these were added to the list for interviewees to score during subsequent interviews.

If the researcher had additional clarifying questions for a particular subject in the days following a particular interview, the researcher contacted the subject to pose these questions. Using this approach, a clear picture emerged as to the variables which most affected the transformation of intended to realized strategy in the implementation examples provided by the interviewees.

\subsection{Phase 2 - Quantitative Study: Survey of Senior Managers and Executives}

Quantitative methodologies can be utilized to test and calibrate either whole theories or individual aspects of these theories (Lee et al., 1999). In this case, a quantitative approach was used to test and calibrate the a priori model which had been developed from the literature and modified as a consequence of the results of the Phase 1 qualitative study. As such, variables were added to the model based upon common indicators identified and reported across interviews. If particular literature based factors had not been mentioned during the interviews, they would have been retained in the model to ascertain whether they had any support in the survey responses. The survey instrument was pre-tested with five respondents to obtain feedback relative to its ease of use and the efficacy of the questions. Details relative to the pre-test approach and results are presented in section 11.1 . 


\subsubsection{Data Source}

The quantitative study survey instrument was developed and populated with measures taken from the literature where possible, or developed where necessary, based on the literature and interviews. The survey informants were senior managers and executives who had experience in the formation and implementation of strategy. The instrument was pre-tested prior to the full survey as discussed in section 11.1.

Using Stevens' (2002) guidance, approximately 15 survey informants are required per predictive construct to provide a reliable regression equation. As eight factors were retained after the model had been modified based on the results of Phase 1, this required a usable sample of 120 completed surveys. Surveys of executives typically result in very low response rates, with medians as low as half that of managers and employees (Cycyota \& Harrison, 2006). "Of the various methods suggested to increase response rates in other populations, none were found to be effective for executives. However, topical salience and sponsorship by an organization or person in the executive's social networks did bring about response rate increases" (Cycyota \& Harrison, 2006 p. 133). The approach that was taken in this study was to use professional and social networks developed through the researcher's prior work experience to gain the required responses. As strategy formation and implementation is topical for executives, this further enhanced the response rate, especially given the researcher's offer to provide a summary of the results to respondents. This sampling approach represents a trade-off between the generalizability benefits of a truly random sample and the realities of gaining required response rates from executives. 
Snowball sampling, the encouragement of first tier informants to identify or request responses from second tier informants, was utilized as the data gathering technique (Michael, 2006; Welch, 1975). This allowed the social and professional networks of the various first tier informants to be leveraged in the hopes of increasing response rates among senior managers and executives not known by the researcher. Snowball sampling is appropriate when targeting a small, hard to reach population with specific required knowledge, which is embedded within a larger population or screened within a larger population (Michael, 2006; Welch, 1975). This is exactly the case with senior managers and executives. They are relatively few within the population of employees of a given organization and they are effectively screened by executive assistants, administrative assistants and lower level managers. However, their cell phone numbers and direct lines are known to other senior managers and executives, and the names of those in their professional and social networks are de facto passwords for access when given to their assistants. By tapping into a first tier of senior managers and executives, and leveraging their ability to contact their peers, it was possible to gain sufficient survey responses.

A key potential bias which can be introduced when using snowball sampling is the over-sampling of a particular social network or the corresponding under-sampling of another (Welch, 1975). This can lead to an overemphasis in the data on the characteristics of the over-sampled group. To mitigate this possibility, the snowball was started among senior managers and executives from various industries and social networks. 
The survey was emailed to prospective informants, preceded by a phone call to first tier informants from the researcher. This phone call sought to obtain a commitment to respond, and pass along the email with a request to respond to second tier informants. The emails contained a link to the electronic survey; it was felt that this was the most convenient method for the informants to use in answering the survey. During the telephone communication and as part of the email, the informants were asked to forward the email and survey link to at least three additional senior managers or executives and request their participation.

The first tier of informants was formed from a number of professional and social groups. This included ongoing social networks of which the researcher is a member, as well as formal and informal professional associations. These groups, and their second tiers, are listed in Table 1 with their projected response rates and numbers of responses.

Table 1 - Informant Groups and Anticipated Response Rates and Numbers

\begin{tabular}{|c|c|c|}
\hline Informant Group & $\begin{array}{c}\text { Anticipated } \\
\text { Response Rate (\%) }\end{array}$ & $\begin{array}{c}\text { Anticipated } \\
\text { Response Number }\end{array}$ \\
\hline $\begin{array}{l}\text { Researcher Social Network } \\
\text { (30 people X } 1.0 \text { response rate) }\end{array}$ & 100 & 30 \\
\hline $\begin{array}{l}\text { Researcher Social Network } 2^{\text {nd }} \text { Tier } \\
\text { (30 people X } 3 \text { referrals X } 6 \text { response rate) }\end{array}$ & 60 & 54 \\
\hline $\begin{array}{l}\text { Researcher Professional Network } \\
(90 \text { people X } 5 \text { response rate) }\end{array}$ & 50 & 45 \\
\hline $\begin{array}{l}\text { Researcher Professional Network } 2^{\text {nd }} \\
\text { Tier } \\
\text { (45 people X } 2 \text { referrals X .2 response rate) }\end{array}$ & 20 & 18 \\
\hline $\begin{array}{l}\text { Ex-Aerospace Eng (AERE) Officer Social } \\
\text { List } \\
\text { ( } 40 \text { people X . } 5 \text { response rate) }\end{array}$ & 50 & 20 \\
\hline $\begin{array}{l}\text { Ex- AERE Social List } 2^{\text {nd }} \text { Tier } \\
\text { (20 people X } 3 \text { referrals X } .33 \text { response rate) }\end{array}$ & 33 & 20 \\
\hline $\begin{array}{l}\text { Queen's EMBA } 97 \text { Class Social List } \\
\text { (15 people X .7 response rate) }\end{array}$ & 70 & 10 \\
\hline $\begin{array}{l}\text { Queen's EMBA } 972^{\text {nd }} \text { Tier } \\
\text { (10 people X } 3 \text { referrals X } .33 \text { response rate) }\end{array}$ & 33 & 10 \\
\hline Total & & 207 \\
\hline
\end{tabular}




\subsubsection{Data Analysis}

Once the survey instrument shown in Appendix B had been modified based upon the results of the Phase 1 qualitative study, the survey instrument was pre-tested with a small group of executives. The pre-test informants were asked to provide feedback on the survey instructions, the questions and any other aspect of the survey instrument about which they might have suggestions.

After modifying the survey as necessary based upon the pre-test, the survey was sent to potential informants as proposed in Table 1 . The survey was taken on, and the data collected by, a web based survey host. The survey host used was Fluid Surveys, a Canadian web based survey host. As the data was assembled, the first action was to identify usable completed surveys from those which were missing data or otherwise corrupted in some way. This yielded a usable data set.

Although an initial set of factors was assembled based on a literature review and modified by the results of the Phase 1 qualitative study, it was assumed that the data could lead to a more interpretable, and perhaps smaller, number of factors. The analysis used to reduce the data in this way was Exploratory Factor Analysis using the principal components methodology. Essentially this approach can take a highly correlated set of variables (i.e. multi-collinear) and align them with a smaller set of uncorrelated linear combinations or factors (Barth, 2008). However, as the factors were not as interpretable as desired, the analysis was repeated using principal axis factoring to recognize and account for error-related variance including measurement error (Preacher and MacCallum, 2003). The initial use of an orthogonal rotation restricted the factors to be uncorrelated (Preacher \& MacCallum, 2003). The use of an oblique rotation (promax) 
allows the factors to be extracted without this restriction and can yield greater interpretability (Preacher \& MacCallum, 2003). As such, an oblique rotation was used for this factor analysis.

Using Stevens' (2002) guidance, and the SPSS Factor program, the decision as to the number of factors in the final model was made based on a number of perspectives. The Kaiser criterion which chooses factors with eigenvalues greater than 1.0 was utilized; however, factors with eigenvalues close to 1.0 were also considered. A scree plot was utilized which graphically displays the factor eigenvalues against ordinal numbers (i.e. 1 against the highest eigenvalue, 2 against the next highest, etc.). The method suggests retaining the factors on the descending curve before the curve flattens out. The factors were also rotated using the varimax orthogonal rotation in SPSS which allowed the factors to load more heavily on a smaller number of indicators, thereby making the factors more interpretable. An oblique rotation of the factors was also carried out using the promax rotation in SPSS. The promax rotation was the final rotation because it yielded the most interpretable factors.

The next step was regression analysis to determine the level of fit that existed between the level of transformation of intended strategy as the dependent variable, and the contextual factors in the model as the independent variables. As part of this portion of the data analysis, a series of regressions was run using the approach described by Baron and Kenny (1986) to determine if each of the factors operates in a main effects fashion only or if it also operates in a mediator or moderator role. Using the results of the various trial regressions, a regression model was developed which describes relationships 
between the various factors and the transformation of intended strategy into realized strategy.

\subsubsection{Survey Questions}

Survey questions were composed to align with the eight hypotheses based on the literature. The factors and indicators and their sources in the literature for each hypothesis appear in Table 2 while survey questions are detailed in Appendix B. Questions were formatted in the form of a seven-point Likert-type scale from strongly agree to strongly disagree.

Table 2 - Factors, Indicators and Sources Used in Survey Question Development

\begin{tabular}{|c|c|c|}
\hline Factors & Indicators & Source \\
\hline $\begin{array}{l}\text { Environmental instability } \\
\text { - External. }\end{array}$ & $\begin{array}{l}\text { Volatility of sales growth. } \\
\text { Instability of the environment in which the firm operates. } \\
\text { Unpredictability of the environment in which a firm } \\
\text { operates. }\end{array}$ & $\begin{array}{l}\text { Harrington et al., } \\
2004 \\
\text { Jennings and } \\
\text { Disney, 2006 } \\
\text { Grant, 2003; } \\
\text { Parnell and Lester, } \\
2003\end{array}$ \\
\hline $\begin{array}{l}\text { Competitors' actions - } \\
\text { External. }\end{array}$ & $\begin{array}{l}\text { Competitiveness of the environment. } \\
\text { Rate of response of the firm's competitors to changing } \\
\text { market conditions. } \\
\text { Rate of new product introduction by the firm's } \\
\text { competitors. }\end{array}$ & $\begin{array}{l}\text { Blythe and } \\
\text { Zimmerman, } 2004 \\
\text { Blythe and } \\
\text { Zimmerman, } 2004 \\
\text { Kukalis, } 1991\end{array}$ \\
\hline $\begin{array}{l}\text { Changes in customer } \\
\text { requirements - External. }\end{array}$ & $\begin{array}{l}\text { Rate of change of customer needs. } \\
\text { Speed of change in demand trends. } \\
\text { Customer demand for innovation in the firm's market. }\end{array}$ & $\begin{array}{l}\text { Depperu and } \\
\text { Gnan, } 2006 \\
\text { Depperu and } \\
\text { Gnan, } 2006 \\
\text { Kukalis, } 1991 \\
\end{array}$ \\
\hline
\end{tabular}




\begin{tabular}{|c|c|c|}
\hline Factors & Indicators & Source \\
\hline $\begin{array}{l}\text { Environmental } \\
\text { complexity - External. }\end{array}$ & $\begin{array}{l}\text { Complexity of the operating environment of the firm. } \\
\text { Complexity of the firm's relationship with its } \\
\text { distributors, customers and suppliers. } \\
\text { Diversity in the customers and markets served by the } \\
\text { firm. }\end{array}$ & $\begin{array}{l}\text { Kukalis, } 1991 \\
\text { Kukalis, } 1991 \\
\text { Kukalis, } 1991\end{array}$ \\
\hline $\begin{array}{l}\text { Leadership team } \\
\text { characteristics - Internal. }\end{array}$ & $\begin{array}{l}\text { Managers' use of previously acquired experiential } \\
\text { knowledge during strategy implementation. } \\
\text { Managers sharing a detailed and consistent understanding } \\
\text { of the business. } \\
\text { Tendency towards opportunity taking by the firm. } \\
\text { Leadership team support of the strategy. }\end{array}$ & $\begin{array}{l}\text { Daake, Dawley, \& } \\
\text { Anthony, } 2004 \\
\text { Beinhocker \& } \\
\text { Kaplan, } 2002 \\
\\
\text { Depperu \& Gnan, } \\
2006 ; \text { Mintzberg, } \\
1977 \\
\text { Kaplan and } \\
\text { Beinhocker, } 2003\end{array}$ \\
\hline $\begin{array}{l}\text { Employee involvement - } \\
\text { Internal. }\end{array}$ & $\begin{array}{l}\text { Authority of lower level managers to make decisions and } \\
\text { take initiative in response to the changing environment. } \\
\text { Resistance to change of the organization. } \\
\text { Tendency of individuals in an organization to pursue the } \\
\text { objectives or goals of their position or group instead of } \\
\text { the stated goals of the whole organization. } \\
\text { Participation of low and mid-level managers in the } \\
\text { strategic planning process. } \\
\text { Communication by the firm of its strategic goals and } \\
\text { priorities to the whole firm. }\end{array}$ & $\begin{array}{l}\text { Andersen, } 2004 \\
\text { Boyd \& Reuning- } \\
\text { Elliott, } 1998 \\
\text { Ketokivi \& } \\
\text { Castañer, } 2004 \\
\text { Ketokivi \& } \\
\text { Castañer, } 2004 \\
\text { Ketokivi \& } \\
\text { Castañer, 2004 }\end{array}$ \\
\hline $\begin{array}{l}\text { Organization learning } \\
\text { ability - Internal. }\end{array}$ & $\begin{array}{l}\text { Ability of senior managers to quickly develop and share } \\
\text { new perspectives. } \\
\text { Senior management flexibility. } \\
\text { Tendency for the firm to develop contingency plans for } \\
\text { alternate possible futures. }\end{array}$ & $\begin{array}{l}\text { Schaffer and } \\
\text { Willauer, } 2003 \\
\text { Schaffer and } \\
\text { Willauer, 2003 } \\
\text { De Geus, } 1988 \text {; } \\
\text { Schoemaker, 1995 }\end{array}$ \\
\hline $\begin{array}{l}\text { Flexibility of the } \\
\text { intended strategy - } \\
\text { Internal. }\end{array}$ & $\begin{array}{l}\text { Flexibility inherent in the planned strategy } \\
\text { Rigidity of the strategic plan. }\end{array}$ & $\begin{array}{l}\text { Grant, } 2003 \\
\text { Miller and } \\
\text { Cardinal, 1994; } \\
\text { Rudd et al., 2008 }\end{array}$ \\
\hline
\end{tabular}




\subsection{RESULTS - QUALITATIVE STUDY INTERVIEWS}

The qualitative study was comprised of interviews with five executives, four from North American based firms and one from a company headquartered in Europe (see Table 3). The five companies included two from the telecom industry, one from financial management, a major retail chain and a company which provides satellite related wireless services to the defence sector, predominately in the US.

Table 3 - Summary of Interviews

\begin{tabular}{|l|l|l|l|l|}
\hline & Position Level & \multicolumn{1}{|c|}{ Type of Company } & \multicolumn{1}{|c|}{ Industry } & \multicolumn{1}{|c|}{$\begin{array}{l}\text { Length of } \\
\text { Interview }\end{array}$} \\
\hline 1 & Vice President & $\begin{array}{l}\text { European multinational } \\
\text {-public. }\end{array}$ & Telecom & 1 hour 14 minutes \\
\hline 2 & $\begin{array}{l}\text { CEO and } \\
\text { President }\end{array}$ & $\begin{array}{l}\text { North American - } \\
\text { private equity and then } \\
\text { public. }\end{array}$ & $\begin{array}{l}\text { Financial asset } \\
\text { management }\end{array}$ & 1 hour 10 minutes \\
\hline 3 & Director & $\begin{array}{l}\text { North American } \\
\text { multinational - private } \\
\text { equity. }\end{array}$ & $\begin{array}{l}\text { Satellite based } \\
\text { telecom }\end{array}$ & 47 minutes \\
\hline 4 & Director & $\begin{array}{l}\text { North American - } \\
\text { wholly owned } \\
\text { subsidiary of a public } \\
\text { company. }\end{array}$ & Retail chain & 50 minutes \\
\hline 5 & Vice President & $\begin{array}{l}\text { North American } \\
\text { multinational - public. }\end{array}$ & $\begin{array}{l}\text { Satellite services - } \\
\text { defence }\end{array}$ & 53 minutes \\
\hline
\end{tabular}

The interviews ranged from 47 minutes to 1 hour 14 minutes in length and were each an in-depth review of one particular strategic plan, its implementation and results from each executive's professional experience. The executives chose strategy examples of which they were intimately familiar through their direct involvement at both the planning and implementation stages. During each interview, the executive described, in a detailed and distinct fashion, the plan, its implementation and the results. The interviewee was then asked to summarize his experience by listing the factors which most 
impacted any changes between the original strategic plan and what was actually implemented.

The interviewee was then given a Contextual Factor Scoring Sheet (Appendix C) upon which to score listed contextual variables as to their importance relative to the transformation of strategy in the example they provided. The scoring sheet used a seven point Likert-scale from 'Completely Unimportant' to 'Highly Important'. The listed factors came from the literature, as outlined in section 7.0, as well as any new factors or indicators which arose during the interviews. As new factors or indicators were added during any particular interview, they were kept on the list for the next interviewed executive to score. The score sheet also contained three questions related to the degree of change that occurred to the strategy during implementation. The last question on the score sheet asked the interviewee to go back to where the contextual factors were scored, and rank all those they listed in the most important scored category from 1 to $n$.

Tables 4 through 8 display the results of the interviews. The second column in each table displays the frequency with which each factor or indicator was mentioned during the particular interview. The frequency of mention is the parameter that has been utilized as a proxy for the importance of the particular variable to the strategy example being reviewed (Weston et al., 2001). This follows from the logic that the more times the interviewee returns to a particular variable in describing its effect on strategy transformation, the more importance the interviewee assigns to that variable. This approach was validated by the alignment of the coding results with the results of the ranking by interviewees of the most important variables. The factors or constructs were specified a priori through a review of the literature (see Section 7.0). As noted by 
Eisenhardt (1989), if the analysis of the data shows these preselected constructs to be significant, any emergent theory will have a more solid empirical base. The list of factors and indicators became the codebook against which the 238 double spaced pages of transcripts were analysed and the codebook was updated to include a new factor or indicator each time one was discovered in a particular transcript (Weston et al., 2001). The coding was carried out by the lone researcher involved in this work. Multiple coders were not considered necessary because the coding results were not being used to test a theory. The results of the coding were only being used to validate the presence of the factors in the literature based a priori model and to add any new factors or indicators which appeared during the interviews.

At the start of the coding process, each transcript was read and coloured highlighters were used to identify three types of text for further analysis: text containing noteworthy process or situational issues; text containing important facts pertinent to this strategy example; and text referring to contextual variables which had an impact on the transformation of strategy documented in the example. This third type of text would be the portions of the narrative which would be coded (i.e. coding text). This highlighting process was repeated on the same transcript copies to validate consistency. The next step was an analysis of the coding text to label the text with the appropriate variable name each time a contextual variable was mentioned that impacted the transformation of strategy. A single counted mention of any variable was defined as a mention of the variable, separated from the last time it was mentioned by at least one sentence which referred to a different thought or issue. For example, if a particular variable was mentioned in three successive sentences, this was defined as one mention. In practice, 
this usually meant that each mention of any variable was separated from the last time it was mentioned by at least one paragraph. This variable identification / coding process was repeated to judge and ensure consistency. The number of mentions for each variable was then tallied and recorded.

The third column in Tables 4 through 8 denotes the factors and indicators that were highlighted by the interviewee when asked to summarize those that were particularly significant to their strategy's transformation. The final column in each of Tables 4 through 8 lists the importance ranking of the factors and indicators given by the interviewee on the Contextual Factor Scoring Sheet. Table 11 summarizes the interview coding results and ranks the factors and indicators based upon their combined frequency of mention from the five interview transcripts.

At the beginning of each of the sections below which is titled to introduce one of the interviews (e.g. 10.1 Interview 1 and 10.2 Interview 2), there is a sub-section which comprises a description of that interview. In each of these descriptive narratives, some non-material details relative to the companies and their strategies / implementations have been deliberately written in a manner designed to protect the anonymity of the sources. In addition, the reader will note that a large number of quotes, many which are lengthy, have been used. This provides the reader a flavour of the language used in the interviews and allows the interviewees to tell their stories in their own words. To facilitate this approach, a naturalized approach to transcription was used (Schegloff 1997), that is to say each transcript is an exact depiction of what the interviewee said (e.g. grammar is not corrected, etc.). These quotes will be provided from a first person perspective. In other 
words, they will not be introduced as quotes (i.e. such as "the interviewee said" or "the executive stated") but will simply be woven into the narratives.

\subsection{Interview 1}

\subsubsection{Strategy Example Description}

The first interviewee (Interviewee 1) was a Vice President in the Canadian division of a multibillion dollar European multinational telecom company (Company A) listed on a major North American Stock Exchange. The company had a matrix structure such that this executive and his employees were part of the Canadian division from an administrative perspective but reported directly to a line of business headquartered in Europe from an operational perspective. The strategy was the focus for the European line of business and involved the development of an industry infrastructure piece of telecom equipment with a potential annual market of $\$ 6$ billion. Company A was forecasting capture of $25 \%-30 \%$ of the available market. By the spring of 2001, at the height of the "tech boom", Company A had invested approximately $\$ 1.1$ billion in the development of this particular piece of equipment with a significant portion of the research and development (R\&D) work being done in Canada. The marketing estimates relative to the \$6 billion market were based on discussions held between Company A's representatives and telecom services providers in Canada (e.g. Bell Canada), the US (e.g. AT\&T), Europe and parts of Asia.

The strategy involved educating potential customers in advance about the new equipment and its R\&D timeline, and starting a two to three year sales build-up by providing prized customers with their first pieces of equipment at substantial discounts to seed the market. However, not everyone in Company A was convinced that the market 
for the new product would be as large as projected. As the Canadian division was an acquisition for Company A, it seemed to Interviewee 1 that the European line of business did not always share all pertinent information at certain points. This lack of communication (Ketokivi \& Castañer, 2004) may have led to some of the issues that followed.

"To my way of thinking, the whole thing was a little bit loose in that it was predicated on the market being $\$ 6$ billion ... this was of course at the height of the high tech boom where there seemed to be no end in sight for the requirement of additional bandwidth ... Biggest issue we had with it, or certainly I had with it, was where did the 6 billion [number] come from in the first place ... When I looked at the total volume of committed sales in terms of pieces of equipment ... it actually didn't seem like it was that many. ... Not only myself but others in the company had this little niggling feeling this can't keep doubling forever, you know, it has got to plateau out sometime. ... So the projections that it would continue to grow and get to that $\$ 6$ billion market and increase beyond that seemed a little bit out of whack. Although, in my position I didn't have access to the raw data that the analysts were using" (Interviewee 1).

The plan was ambitious from the outset from both an R\&D and a marketing perspective. While this was not unusual in the high tech world due to the pace of technological change and the desire to be first into any particular market with a new product, "people knew or ought to have known that the timelines were very ambitious and did not allow for any slippage of any sort. So that was probably the first problem we had" (Interviewee 1). However, even with R\&D's slipping timelines, Company A did not take substantive action but assumed that the problem would rectify itself. As a consequence, none of the program or marketing schedules were changed, indicating a level of rigidity in the plan and its implementation (Miller and Cardinal, 1994; Rudd et al., 2008). 
"If we work harder we can catch up. If one could picture a bunch of ostriches standing around with their heads in the sand. You know, the plan is the plan is the plan. ... But the cumulative effect of numerous setbacks just weren't recognised. This is a facetious example, but you could be six months behind on the day before something was to be delivered and you're still telling people that you were going to deliver it because that was the schedule date.... The marketing end was still telling customers all the way through that there would be deliveries at a certain time. ... It quickly started to unravel for a host of good reasons but none the less we held true to the plan because that's what ... senior members of [Company A] had told the CEOs of these major telecom companies would happen. They went around and chatted with these guys, you know their fellow multi-millionaires at the heads of these corporations. They would say we were producing it, it would be here at a certain date and I guess these other guys believed them" (Interview 1).

One of the interesting facets of a matrix structured organization is the sometime mismatch between line of business revenue projections and administrative organization expenditure responsibilities. While the European line of business headquarters held to their revenue projections, the Chief Executive Officer (CEO) of the Canadian division of Company A began to modify his projections because he was responsible for payroll for the Canadian division based on these numbers. This resulted in the beginnings of an adversarial relationship between the European line of business and the Canadian division. This sort of situation can make consistency of action during implementation difficult (Beinhocker \& Kaplan, 2002).

"The next thing that happened was you know the orders weren't appearing as rapidly as our marketing analysis folks had told us ... Some of the companies knew we were having some difficulty in the R\&D because there was a steady stream of their representatives back and forth as we were developing this piece of equipment. I'd be surprised if any of them knew the extent to which it had slipped because we certainly weren't telling them that level of detail. ... But it was about that point in time as well where the entire market started to soften ... This was now getting into summer 2001/fall 2001. Overall revenue streams were slipping, bandwidth was no longer growing at an exponential rate the way it had for the last couple of years, so I think these companies themselves were starting to take a look at how much of this really big expensive equipment were they 
going to need. The big companies with deep pockets ... did buy some, but the numbers ... were starting to fall by the wayside and the small companies just couldn't raise the capital because they couldn't substantiate the revenue projections required to purchase this equipment " (Interview 1).

Despite the softening of the market and a review of the marketing assumptions,

there were only slight adjustments made to the $\$ 6$ billion market projection.

"But true to form ... [Company A] wasn't going to let this stand in the way. We decided that some of the emerging markets, India and perhaps South America were probably on the edge of having their own boom ... there was about to be a phone in every Chinese home which would dwarf our market, as well as in India. South America, Argentina, Brazil, Chile were also poised to boom and Mexico to a certain extent ... so the revenue projection was modified a little bit in terms of you know when we would hit the $\$ 6$ billion ... The new projections were more assumption based, we didn't really have good connections with the telecoms or the main telecom groups in those countries. ... So it was done more on casual conversation rather than in-depth conversation. But by God, [the European line of business] was not going to fail. It was going to meet its revenue projections. ... I think it was a number of senior guys in [the European line of business], to use the euphemism, covering their own asses and being able to report back up to [the Company A corporate] CEO that this was still a good thing to be pouring hundreds of millions into ... each year for the R\&D and not to worry he was going to get his money back out" (Interviewee 1).

The Canadian division CEO started to look into this more closely.

"I remember him asking a question very clearly, who did you talk to in those companies that gave you the indication that they were going to actually be buying this equipment. Well when you really delved into that ... it was our marketing guys, who were former techies, talking to techies in other companies. ... It turned out to be more you know we would go to the director of technical advancement at Bell and he'd say that's really neat, we could use a hundred of those. Nobody went, again, as I said, to his finance people to say can you afford to buy a hundred of those even with, even in the previous year with what you thought your revenue projections would be. We didn't talk to the right people and it became pretty clear as our CEO in Canada started to look into this that our original projections were bogus to begin with let alone the fact that the entire market was softening ... So he actually took it up with, of course, the head of [the European line of business] who I guess, in simplest terms, told him that he didn't have his facts correct. ... Eventually he took it up with the 
head of [Company A], the big CEO. And the decision was made, they didn't actually mothball the entire operation, but the decision was made to get rid of probably about $80 \%$ of the people" (Interviewee 1 ).

While this amounted to approximately 250 personnel in Canada, Company A laid off over 20,000 people world-wide. Some of this reduction was related to this program but it was mostly due to the tech collapse.

"So it was part of every project, the search for the guilty, punishment of the innocent soon to follow. So they viewed us as just not working hard enough, of sowing some discontent within the company about the validity of this project, for even asking questions about what the projections were based on" (Interviewee 1).

In the end, sales projections fell to almost zero and Interviewee 1 summed up the end-state of the strategy as "failure" (Interviewee 1). This is consistent with volatility of sales being an indicator of significant transformation of a strategy (Harrington et al., 2004). In terms of whether Company A went through a formal process to document some obvious lessons learned, the answer was:

"No, absolutely not. ... I think if they had truly looked at lessons learned and who had failed then some very senior people would have had to publicly admit that they had failed, that some senior people who had been friends for years would have had to have been offered up. They would have had to have been canned because they made some fundamentally bad decisions over a long period of time that had cost the company hundreds of millions. ... So we essentially refused to accept reality. I think too many people had too much personal time and effort invested in it to turn around and say you know, we screwed up" (Interviewee 1).

\subsubsection{Factor Coding Results}

In terms of the most frequently mentioned factor or indicator, Interviewee 1 mentioned the feasibility of the intended strategy eight times (see Table 4). This variable was not previously included in the model as it did not emerge from the literature; 
however, in terms of contextual variables which might have an impact on the results of a strategic plan, it would seem reasonable that the inherent realism or feasibility of the plan itself would be a key item. As a consequence, feasibility of the intended plan was added to the list of factors and indicators to be scored by interviewees. While one could imagine feasibility having a direct relationship with the transformation of intended into realized strategy, in the case of this narrative, feasibility takes on an interesting role in its interaction with the external environment. If the tech market had continued to grow during the introduction period for this piece of telecom equipment, it is possible that the strategy might not have transformed at so significant a level and Company A may have achieved its projected revenue targets. In that case, the intended strategy might have been viewed as being feasible. However, the dramatic drop in the tech market during the pertinent period for this strategy led to the plan becoming increasingly unfeasible. Therefore, it was the interaction between this variable and external environmental factors which led to its impact on strategy transformation. 
Table 4 - Summary of Interview 1 Results

\begin{tabular}{|l|c|c|c|}
\hline Factors / Indicators & $\begin{array}{c}\text { Transcript Coding } \\
\text { (number of times } \\
\text { referred to in } \\
\text { transcript) }\end{array}$ & $\begin{array}{c}\text { Factors / } \\
\text { Indicators } \\
\text { Mentioned in } \\
\text { Interviewee } \\
\text { Summary }\end{array}$ & $\begin{array}{c}\text { Interviewee } \\
\text { Ranking of Most } \\
\text { Important Factors } \\
\text { / Indicators }\end{array}$ \\
\hline $\begin{array}{l}\text { Environmental } \\
\text { instability. }\end{array}$ & 5 & $\checkmark$ & $4^{\text {th }}$ \\
\hline $\begin{array}{l}\text { Competitors' } \\
\text { actions. }\end{array}$ & 1 & $\checkmark$ & \\
\hline $\begin{array}{l}\text { Changes in customer } \\
\text { requirements. }\end{array}$ & 5 & & $3^{\text {rd }}$ \\
\hline $\begin{array}{l}\text { Environmental } \\
\text { complexity. }\end{array}$ & 0 & $\checkmark$ & $5^{\text {th }}$ \\
\hline $\begin{array}{l}\text { Leadership team } \\
\text { characteristics. }\end{array}$ & 5 & $\checkmark$ & $6^{\text {th }}$ \\
\hline $\begin{array}{l}\text { Employee } \\
\text { involvement. }\end{array}$ & 3 & $\checkmark$ & $2^{\text {nd }}$ \\
\hline $\begin{array}{l}\text { Organizational } \\
\text { learning ability. }\end{array}$ & 5 & $\checkmark$ & $1^{\text {st }}$ \\
\hline $\begin{array}{l}\text { Flexibility of the } \\
\text { intended strategy. }\end{array}$ & 5 & & \\
\hline $\begin{array}{l}\text { Feasibility of the } \\
\text { intended strategy. }\end{array}$ & 8 & & \\
\hline $\begin{array}{l}\text { Ambitiousness of } \\
\text { the intended } \\
\text { strategy. * }\end{array}$ & 2 & & \\
\hline
\end{tabular}

* New indicator from this interview.

Five factors were mentioned five times in the transcript. These were the external factors environmental instability and changes in customer requirements, and the internal factors leadership team characteristics, organizational learning ability and flexibility of the intended strategy.

In this case, there does not seem to be simple main effects impacts from the instability of the environment and changes in customer requirements factors. As indicated by Interviewee 1, the tech market collapse was the key reason for much of the lowering of customer demand for the equipment. However, changing customer requirements in this case is a more complex issue because Company A did not seem to 
have an objective idea of what the demand really was during the planning cycle. So it may not be that customer demand actually changed but that perceived customer demand changed. Once again, the interaction with environmental instability plays a role because even though customer demand seemed to be based to a significant degree on optimistic assumptions, these assumptions may have proven correct in an environment where bandwidth demand had continued to grow at a dramatic rate.

The internal factors of leadership team characteristics, organizational learning ability and flexibility of the intended strategy also displayed significant interactions with the external environment. However, in this case, the interactions were negative. The inaction of the leadership team and the organization's inability to learn led to a lack of appropriate reaction to changes in the external environment and the inability of the plan to transform in a positive way, thereby preventing Company A from being more successful with this strategy. Further, the lack of flexibility in the original plan may have contributed to Company A's dogged adherence to the plan despite all the contrary evidence regarding its feasibility.

Although only mentioned twice, the ambitiousness of the intended strategy was the second new variable mentioned by Interviewee 1 . This variable was not previously included in the model as it did not emerge from the literature. Even if the plan had proved feasible through a continuing rise in the market's bandwidth requirements, it would still have to be considered ambitious given the tight R\&D timelines, and aggressive revenue and market share targets. Even without the tech market collapse, the ambitiousness of this strategy may have led to considerable transformation of the strategy if the implementation had continued. 


\subsubsection{Interviewee Factor Scoring}

As noted earlier, at the end of the interview, each interviewee was given a Contextual Factor Scoring Sheet upon which to score listed contextual factors as to their importance relative to the transformation of strategy in the example they provided. The scoring sheet used a seven point Likert-scale from 'Completely Unimportant' to 'Highly Important'. The interviewee was then asked to rank all those they listed in their most important category from 1 to $n$. The fourth column of Table 4 displays the results for Interviewee 1.

In terms of importance to the transformation of the strategy, Interviewee 1 rated the feasibility of the intended strategy as the most important variable. This was consistent with the frequency of its mention in the transcript. However, the variables ranked from two to six all had the same number of mentions in the transcript. Each variable was mentioned five times in the narrative. These variables, in order of Interviewee 1's ranking from two to six, were: flexibility of the intended strategy; changes in customer requirements; environmental instability; leadership team characteristics; and organizational learning ability.

Only the third and fourth ranked variables are external while the other four are internal. While this ranking is indicative of only Interviewee 1's perspective, it indicates a significant level of importance given to the internal characteristics of the organization. The second highest ranking was given to flexibility of the intended strategy; therefore, the two top ranked variables were related to characteristics of the original strategy itself. The third and fourth were factors related to the external environment, and the fifth and 
sixth were related to characteristics of the organization that would inform its reaction to the external environmental inputs.

\subsubsection{Factor Coding versus Interviewee Factor Scoring}

Based on both the transcript coding and Interviewee 1's ranking of the most important variables relative to the transformation of strategy in the example, the most important variable from the strategy example in Interview 1 is the feasibility of the intended strategy. This seems appropriate given that the strategy became unfeasible in

the environment of the tech market collapse. While the next five ranked variables all had the same number of mentions in the transcript, this frequency of mention was second only to feasibility of the intended strategy. Interviewee 1 ranked all of these six variables as highly important and the six variables were also the top six mentioned variables in the coding. Therefore, there was a level of consistency in the way Interviewee 1 related the narrative relative to the way he scored the variables as to their importance.

\subsubsection{Interviewee Strategy Transformation Scoring}

Interviewee 1 scored the level of transformation of the strategy in the example as follows:

- Primary goals implemented and achieved as originally planned: $0-25 \%$.

- Secondary goals implemented and achieved as originally planned: $0-25 \%$.

- "The actions that formed the process of implementing the strategy were carried out exactly as planned": Strongly Disagree.

These scores are consistent with the narrative of Interviewee 1's strategy example. Given the coding of the transcript and the way Interviewee 1 scored the variables relative 
to their importance for the example, one might say that the strategy transformed significantly due to the unfeasibility of the plan, exacerbated by the instability of the environment and the resultant change in customer requirements. Further, the organization's leadership was unable to react in an effective way and the organization was not capable of learning rapidly enough to lead to a positive transformation of the strategy.

\subsubsection{Process Issues of Interest}

There are two interesting process issues from this strategy example which may be common in some organizations and prevent strategy from transforming in a positive way. First, there is the issue of various levels of management ignoring the mounting problems with the implementation despite the dire consequences of such inaction. While the transcript is clear that $R \& D$ timeline slippage was both significant and apparent, technical program schedules were not changed. Marketing schedules and targets were also not changed, nor were financial targets at the line of business level. Even if the tech market collapse had not happened, it is possible that this strategy may not have succeeded in the way that it was planned. The result of the missed timelines and targets, and failure to make appropriate adjustments, would have been very unhappy customers and potential damage to Company A's credibility. This may have affected their eventual market share.

The second interesting process issue is the lack of a lessons learned process to review the numerous problems with this strategy and its implementation. Interviewee 1's belief is that no attempt was made to learn from this implementation scenario because it would have led to embarrassment on the parts of some very senior leaders in Company A. If this assessment is correct, it may indicate the potential for repeated errors on future 
strategies. This example involved a failed strategy with an implementation expenditure of over a billion dollars. Company A's unwillingness to learn from the experience could potentially mean more costly mistakes in the future.

\subsubsection{Summary}

The Interview 1 strategy implementation resulted in a dramatic strategy transformation. Unfortunately, this transformation was almost completely negative in that Company A was unable to achieve a significant percentage of its primary or secondary goals.

Interviewee 1 related the narrative in a manner which provided consistency between the transcript coding and his scoring of the most important variables relative to transformation of the strategy. In order of importance, the first two related to characteristics of the intended strategy, the next two involved the environmental factors of instability and changing customer requirements, and the last two related to characteristics of the leadership team and organization which prevented it from transforming the strategy in a way that might have led to a more positive outcome.

Interview 1 added two variables to the literature based model. The first is feasibility of the intended strategy. The second is ambitiousness of the intended strategy. In this example at least, characteristics of the original intended strategy played a pivotal role in the transformation. These two variables were added to the Contextual Factor Scoring Sheet for interviews 2 through 5. 


\subsection{Interview 2}

\subsubsection{Strategy Example Description}

Company $B$ is a North American financial asset management firm. It manages the financial assets of members of a professional network; this network is also the private equity owner of the firm. The second interviewee (Interviewee 2) was the President and Chief Executive Officer (CEO) of an investment management firm (Company b) set up, and initially wholly owned, by Company B. Later, Company b had split ownership between Company B and two additional equity owners, then went public on a major North American Stock Exchange and was subsequently acquired by another public company listed on a major North American Stock Exchange.

Prior to the setup of Company $b$, Company B:

"hired investment management firms to manage a lot of the mutual funds that we provided to our [owners / clients]. And we wrote rather large checks, and they were always on a percentage of assets, so it was completely variable. And our concept was, why don't we try to keep some of that money in-house. And so we decided that one of the ways to do that would be to start our own investment management firm" (Interviewee 2).

The new company would create and manage its own mutual funds.

"You've already got the customer lined up, which would be essentially the parent company. It's now just a question of, do we build or do we buy a small investment management firm in order to carry out the investment management function" (Interviewee 2).

The new company would also allow Company B to pursue another objective.

"As we met with success in a number of areas, we saw the need to expand our potential market in some way in order to allow the company to grow for the long term. And that was to market to the general public in one capacity or another" (Interviewee 2). 
Company B developed a strategy to acquire an existing firm. However, a contingency plan was also developed to build an investment management firm in the event a suitable acquisition opportunity did not present itself. This tendency to develop contingency plans is an indicator of Company B's organizational learning abilities (De Geus, 1988; Schoemaker, 1995). The strategy was to be implemented over a five year period whereby at the five year point,

"we would have an investment management firm with a good track record ... was completely self-sufficient ... spinning off profits and managing $10 \%$ of the equity assets and $100 \%$ of the fixed income assets within the parent company" (Interviewee 2).

"Our first thought was okay, let's go and try to buy a small firm and we did a search with a small advisory firm ... went out and combed the waterfront to talk to small shops ... we could see that ... clearly the crown jewel is the equity investment management skill set. Fixed income, it's such a narrow band; the good guys versus the guys you think are lousy. It's minuscule; it's half a percentage point" (Interviewee 2).

Because small equity management firms typically specialize in only equity, Company B decided that it would have to get its fixed income talent separately. Therefore, it hired two fixed income asset managers, one for money markets and one focused on the bond markets.

"We drew money from our outside management firms and brought it inhouse and gave it to these guys to manage the assets and you know, there was some good quarters and some bad quarters but for the most part, we were quite pleased with our achievement because we were saving a lot of money on the fees" (Interviewee 2).

The search for an equity management firm continued until Company B eventually found a suitable acquisition target and negotiated a deal in principle. However, the agreement was never fully executed, an indicator of the unpredictability of the environment in which Company B operated (Grant, 2003; Parnell and Lester, 2003). 
"So we did the search and came up with a potential bride but the bride got cold feet at the altar and so we were left with having spent oh, probably a year on that exercise maybe more, with nothing. ... One of the partners got cold feet at the end and the other partner didn't want to proceed unless he had a willing group behind him and so that deal fell apart essentially at the altar. So that frustrated the senior people at [Company B] and the decision was made to build instead of buy" (Interviewee 2).

Company B started a search for credible and experienced equity managers.

However, because Company B was located in a city without a robust financial sector, it was difficult to find suitable people in the area where the company had its offices. Finally, Company B decided that Company $b$ would open an office in a particular city where other equity investment management firms were located and keep an office where it was already situated to house existing management and the fixed income personnel. In doing so, Company B displayed an ability to quickly react to unforeseen environmental inputs while still moving toward the attainment of its key goals (Schaffer and Willauer, 2003).

"[The second hiring problem was that] nobody knew us and we were a start up and we weren't a typical start up where a majority equity position was going to be owned by the key people in the firm. [Company B] wanted to own this and so the agreement was that over time we would let the professionals, the investment professionals, own 30\% and [Company B] was going to own $70 \%$, but you had to allow for room to grow, so up front they only had a three year plan for $10 \%$ " (Interviewee 2).

However, despite the challenges, Company B eventually hired two equity management professionals. The two equity managers started operations but were very quickly under intense scrutiny from senior management at Company B with respect to their performance.

"Their numbers were OK but [because it takes about four years to establish credibility] they weren't going to be able to sell anything for four years anyways. ... and with the six month and nine month numbers they had, if you extrapolated four years, we weren't going to get anybody 
excited in the outside world. ... We looked at the fact, even if they did perform, we still had three and a half years or so to continue to wait and the top two guys at the parent company, the CEO and the COO were ... looking to retire. And they were looking to make their mark and they really weren't prepared to wait for four years to see if maybe this thing worked out.... And so they were keen to go back to [the acquisition plan]" (Interviewee 2).

About that time, Company B, through word of mouth, heard about a firm made up of two equity managers with a great track record who were very interested in coming up with a long term succession plan for themselves.

"We got into negotiations with that firm. ... So sat down with [them and] things went swimmingly, we negotiated a deal with them, and I kept pinching myself. And people kept asking me what's going to go wrong, like have you hit that wall where somebody says, well that's not exactly the deal I thought we made. ... Then we got the lawyers deeply involved to try and put together the whole raft of agreements. Nobody ever waivered in terms of what they had already agreed upon, no one ever tried to pretend that that wasn't what they had agreed upon. So the strategy unfolded quite smoothly at that point" (Interviewee 2).

Company B acquired approximately two-thirds of the acquired company, but the plan was for Company B to eventually buy out the remaining equity from the original owners. The problem was that this eventual expenditure was tied to the value of Company b.

"We were enormously successful bottom line and top line. And so the cost of buying these guys was astronomical because it was going up all the time. And the [Company B] CEO was leaving and he wanted to leave a positive legacy, he didn't want to leave the next CEO this big buy-out bill. ... So the way to skin both cats was to say if we take this thing public, these guys now have public shares so they don't need our buyout so we'll make sure that disappears. Two, [Company B] will sell half of its shares in the public offering so they'll get this whack of cash, which will be the legacy, essentially the foundation of [Company B] for many years, essentially a trust that they can draw on. ... The investment bankers thought we could sell this thing, we had to do a few things because we were really a very tightly held subsidiary in terms of very many administrative and operational things in [Company B]. As a public company you had to have a lot more independence from your major 
shareholder so we had to engage a whole lot of activities. ... We took the company public and people bought our shares so it was an enormous success and [Company B] got its money. [The original owners of Company b] sold their shares so they got another whack of dough" (Interviewee 2).

As a consequence of Company $\mathrm{b}$ becoming a public company, it now had to formally buy certain services that it had been using from Company B (e.g. information technology systems usage and support) or pursue the more costly option of creating groups to supply its own services or buying them from other third parties. Because the markets were continuing to rise, Company $b$ was very successful but there was a sense that if there was a downturn in the markets, Company b's value could drop significantly. Company B's leadership support for the original strategy started to deteriorate, leading to a significant transformation in the strategy (Kaplan and Beinhocker, 2003).

"The CEO of the parent company [did retire], the new CEO came along and he's the guy who really wanted [to discontinue] all of these services and yeah, you are sort of covering your fair share but you are a pain ... and we are not really factoring in [the cost of Company B] management time. ... The new CEO didn't have any equity in terms of saying you know, I grew this baby. ... The new guy sort of said, I didn't grow this baby ... I'd just like to put this into a positive piece of history ... and then could we sell this thing completely and double up on the nest egg" (Interviewee 2).

After a lot of discussion, it was decided to try to find a large investment management firm who would be willing to acquire Company b. Eventually, Company b was acquired by such a firm. Although Company B netted very significant cash reserves from the implementation of its strategy, it essentially ended up back at its original starting point. The strategy had evolved dramatically and Company B did not attain its objectives of reducing the fees it pays to outside investment firms or creating the opportunity to market to the general public. 


\subsubsection{Factor Coding Results}

The factor which was most mentioned in this interview was organizational learning ability with a frequency of 19 (see Table 5). The organizational learning factor has three indicators: the tendency for the firm to develop contingency plans for alternate possible futures; the ability of senior managers to quickly develop and share new perspectives; and senior management flexibility. Company B developed the buy and build scenarios in its original strategic plan thereby allowing it to move between these options as circumstances dictated. Because the executives had thought through these scenarios in advance (De Geus, 1988), it allowed them to exercise the options without undue delay or internal tension. Interviewee 2's narrative indicated that the organization made changes to the strategy as the implementation proceeded in order to make the best decisions, from their perspective, for each situation as it arose. This displays the ability of the executive team to create and share these new perspectives in real time. Finally, senior management flexibility was demonstrated through the transformation of the strategy to include an option which resulted in Company $b$ going public. This does not indicate that it was a good or bad decision, but only that management was able to change course to pursue what they perceived to be the most appropriate alternative at the time. 
Table 5 - Summary of Interview 2 Results

\begin{tabular}{|l|c|c|c|}
\hline Factors / Indicators & $\begin{array}{c}\text { Transcript Coding } \\
\text { (number of times } \\
\text { referred to in } \\
\text { transcript) }\end{array}$ & $\begin{array}{c}\text { Factors / } \\
\text { Indicators } \\
\text { Mentioned in } \\
\text { Interviewee } \\
\text { Summary }\end{array}$ & $\begin{array}{c}\text { Interviewee } \\
\text { Ranking of Most } \\
\text { Important Factors } \\
\text { / Indicators }\end{array}$ \\
\hline $\begin{array}{l}\text { Environmental } \\
\text { instability. }\end{array}$ & 6 & $\checkmark$ & $3^{\text {rd }}$ \\
\hline $\begin{array}{l}\text { Competitors' } \\
\text { actions. }\end{array}$ & 0 & & \\
\hline $\begin{array}{l}\text { Changes in customer } \\
\text { requirements. }\end{array}$ & 0 & $\checkmark$ & $2^{\text {nd }}$ \\
\hline $\begin{array}{l}\text { Environmental } \\
\text { complexity. }\end{array}$ & 13 & $\checkmark$ & \\
\hline $\begin{array}{l}\text { Leadership team } \\
\text { characteristics. }\end{array}$ & 6 & $\checkmark$ & $1^{\text {st }}$ \\
\hline $\begin{array}{l}\text { Employee } \\
\text { involvement. }\end{array}$ & 0 & & \\
\hline $\begin{array}{l}\text { Organizational } \\
\text { learning ability. }\end{array}$ & 19 & $\checkmark$ & $4^{\text {th }}$ \\
\hline $\begin{array}{l}\text { Flexibility of the } \\
\text { intended strategy. }\end{array}$ & 4 & $\checkmark$ & $5^{\text {th }}$ \\
\hline $\begin{array}{l}\text { Feasibility of the } \\
\text { intended strategy. }\end{array}$ & 3 & $\checkmark$ & \\
\hline $\begin{array}{l}\text { Ambitiousness of } \\
\text { the intended } \\
\text { strategy. }\end{array}$ & 0 & & \\
\hline $\begin{array}{l}\text { Availability of } \\
\text { Resources. * }\end{array}$ & 6 & & \\
\hline $\begin{array}{l}\text { Changes in key } \\
\text { personnel. * }\end{array}$ & 5 & & \\
\hline
\end{tabular}

* New indicator from this interview.

The second highest frequency variable was environmental complexity with a

coding score of 13 . This factor may be related to organizational learning in this narrative because without the complexity of the environment, the organization's learning ability might not have had the opportunity to show itself. The complexity of the environment may have also led to Company B's inability to predict events over the timeframe of the implementation which may have contributed to the level of transformation seen in this narrative. Despite Company B's experience in this industry, it did not foresee the 
difficulty it might have in finding an investment management firm to acquire nor the scarcity of available equity investment talent needed for its build scenario.

The third most mentioned factors and indicators each had a frequency of six. These are leadership team characteristics, environmental instability and availability of resources. In this narrative, it is possible that leadership team characteristics are closely aligned with organizational learning, especially with respect to the leadership team characteristics' indicator related to opportunity taking by the firm. It may be that it was the characteristics of the leadership team which allowed the organization to learn at the pace indicated in the narrative. As such, these two factors appear to be related in this particular example.

Environmental instability impacted Company B's strategy transformation in an interesting fashion. It was not the actual instability of the environment but perceived possible future instability that caused Company B to re-evaluate the financial viability of Company b. Company b had continued to be successful as it lessened its dependence on Company B despite escalating costs associated with its having to acquire support services at higher rates in the market. However, there was a fear that if the market experienced a downturn, lower Company $\mathrm{b}$ revenue might threaten profit levels. This was one of the issues that led to Company $\mathrm{b}$ being sold to a large investment management firm. Therefore, it may not just be the real impact of various factors that leads to strategy transformation. The perception that these factors might have an impact in the future may be enough to cause a strategy to transform. Given the difficulty that firms have in accurately predicting future conditions during intended strategy development, one may 
assume that prediction would be just as tenuous during the strategy implementation process. This may introduce another level of complexity to strategy transformation. The third factor or indicator with a frequency of six is availability of resources. This is a new indicator first introduced in this interview which did not appear in the literature based model. While the resources referred to in this narrative are human resources, this indicator could just as well relate to financial or other types of resources needed by a firm in another instance of strategy implementation. In the case of highly intellectually capable human resources such as seen in this narrative, the availability of a small number may determine the ability to implement a particular strategy. They can therefore have a significant impact on the transformation of strategy.

Changes in key personnel is a new indicator which was introduced in this narrative. It scored a frequency of five as a result of the significance of the change of the $\mathrm{CEO}$ and $\mathrm{COO}$. Both the original $\mathrm{CEO}$ and $\mathrm{COO}$, and the new $\mathrm{CEO}$ played material roles in the transformation of this strategy. In particular, the original individuals pushed for a buy option due to their limited time remaining in Company B, and the original CEO decided to take Company $\mathrm{b}$ public to recoup significant cash to be used as his legacy to Company B. The new CEO eventually decided to allow Company $b$ to be acquired by another company, something that was the antithesis of the intended strategy.

Flexibility of the intended strategy and feasibility of the intended strategy were mentioned four and three times respectively. While these two indicators were not among the more significant factors or indicators in this scenario, their presence may be indicative of the importance of the intended strategy in all implementations. The intended strategy 
is the starting point for any transformation and its characteristics may therefore have some level of impact on most realized strategies.

\subsubsection{Interviewee Factor Scoring}

In terms of importance to the transformation of the strategy, Interviewee 2 rated an internal factor, organizational learning ability, as the most important variable. The choices for the second and third most important variables were environmental complexity and environmental instability respectively. Both of these factors are related to the external environment and would seem to be related to organizational learning ability. It seems that it may have been the organization's ability to learn that allowed it to cope with the complex and unstable environment in which it found itself. While each of these variables is important, it may be that their real significance lies in the interaction between the three.

Interviewee 2's fourth and fifth most important variables were feasibility of the intended strategy and availability of resources. Neither of these indicators was found in the strategy formulation literature with feasibility of the intended strategy being added in the first interview and availability of resources being added in Interview 2. As noted previously, it seems reasonable to posit that characteristics of the intended strategy will have an impact on most strategy transformations just as it did in this example. It is interesting to note that in this narrative, the availability of such a small number of human resources played such a significant role in the strategy transformation of such a large firm. When resources are readily available, they often seem to have little impact on strategy transformation but when there is a deficit of a particular resource, it can have a significant impact. 


\subsubsection{Factor Coding versus Interviewee Factor Scoring}

As shown in Table 5, Interviewee 2's scoring of factors or indicators aligns perfectly with the results of the transcript coding for the first, second, third and fifth rankings but deviates for the fourth ranking. While Interviewee 2 ranked feasibility of the intended strategy fourth, it was mentioned only three times in the transcript. Based solely on the coding results, one might have expected Interviewee 2 to rank leadership team characteristics as fourth given that it was mentioned six times in the transcript. Changes in key personnel was mentioned five times and flexibility of the intended strategy was mentioned four times, so each of these might have been considered a more probable choice for a fourth rank than feasibility of the intended strategy.

However, leadership team characteristics, flexibility of the intended strategy and changes in key personnel were all scored by Interviewee 2 as only one importance level less than feasibility of the intended strategy. While there is an inconsistency in the ranking of the fourth most important variable relative to the transformation of strategy in this example, this variable and the three others that Interviewee 2 might have chosen all scored close to one another in his rankings.

\subsubsection{Interviewee Strategy Transformation Scoring}

Interviewee 2 scored the level of transformation of the strategy in the example as follows:

- Primary goals implemented and achieved as originally planned: $51-75 \%$.

- Secondary goals implemented and achieved as originally planned: $51-75 \%$.

- "The actions that formed the process of implementing the strategy were carried out exactly as planned": Somewhat Disagree. 
The scores for the achievement of the primary and secondary goals may be considered generally consistent with the narrative of Interviewee 2's strategy example in that the establishment of Company $\mathrm{b}$ was achieved and the strategy resulted in significant financial gains for Company B. However, a more specific accounting of Company B's goals might render the opinion that the goals were achieved to a degree much less than $50 \%$ because in the end, Company B was still paying high fees to outside firms and it was not in a position to market to the public. Based on the coding of the transcript and the way Interviewee 2 scored the variables relative to their importance for the example, the transformation that occurred seemed to be a function of the changeable and complex environment in which Company B was doing business and the ability of the organization to learn quickly and adapt to the challenges and opportunities that presented themselves. In addition, this example displayed the impact that a few key people can have on a strategy. In the case of the old and new CEOs, they changed the strategy directly during the implementation. In the case of the equity investment managers, their scarcity and their unwillingness to relocate also caused material change to the strategy.

\subsubsection{Process Issues of Interest}

The use of metaphor by Interviewee 2 not only served to clarify his narrative, but also gave him a sense that he was explaining the story in an understandable way. $\mathrm{He}$ struggled with a way to properly describe the failure of the first acquisition attempt by Company B. Once he started to describe it as a situation similar to a bride leaving a groom at the altar, he was much more comfortable with his belief that the interviewer had an in-depth understanding of the situation. This metaphor continued later in the narrative when he described the new CEO's perspective on Company $b$ as that of a parent who had 
or had not created a baby. In other words, the new CEO would feel or not feel responsible for the new company in the same way parents would or would not feel responsible for a child dependent upon whether or not the child was their own.

During the interview, it seemed that Interviewee 2's struggle to describe the situations was not related to the objective details involved. Rather, it was more related to his attempt to portray the emotional elements of the situations. When the first acquisition attempt failed, there was a sense of failure in Company B, not just on an objective level, but on an emotional level. While senior leaders and organizations in general are often viewed by the press and public as operating in an objective or logical manner, this may not always be the case. The emotional reactions of decision makers may be responsible for some percentage of decisions and resultant transformation of strategy.

\subsubsection{Summary}

Company B's strategy implementation proceeded through a series of significant changes that were not foreseen during the original strategy planning process. While Company B was quite successful in gaining considerable financial assets, it did not attain its goals, over the long term, of structurally reducing fee payments to outside firms or sustaining a vehicle that would allow it to market to the public.

Interviewee 2's narrative was spoken in a manner which resulted in consistency between the transcript coding and his scoring of the most important variables relative to transformation of the strategy. The one deviation was his ranking of the fourth most important variable, feasibility of the intended strategy. However, the other variables which might have been ranked fourth, being consistent with the coding results, were 
scored on the next level of importance below his ranked variables, so he did view them as important variables relative to their impact on the transformation of the strategy.

Interview 2 added two variables to the literature based model: changes in key personnel and availability of resources. The frequency of mention in the narrative for these variables tied availability of resources for third most mentioned and placed changes in key personnel as the fourth most mentioned.

\subsection{Interview 3}

\subsubsection{Strategy Example Description}

Interviewee 3 is the Director of Planning and Marketing at a North American satellite based telecom firm (Company $\mathrm{C}$ ) owned by private equity. The firm was acquired by the private equity concerns within the last few years, and as part of the acquisition, a smaller satellite firm was merged with Company C. After the acquisition and merger, Company $\mathrm{C}$ pursued a strategic plan with a five year time horizon. The goals were: organizing the firm to fit the business; increasing satellite utilization and resultant revenue; reducing costs; and increasing company size through merger and acquisition (M\&A) activity. However, government foreign ownership restrictions make M\&A activity very difficult in this industry.

"In terms of bringing the two companies together ... we basically sat with a clean sheet of paper and designed the org structure that we thought we needed to support that business and then implemented that org structure. ... we've made some tweaks to it since we implemented pieces of it and got things settled and lived it for a while ... there was friction in the system, it wasn't really working great in some areas. So we reorganized and adjusted as we went along. ... Not major restructuring and not restructuring in the sense of terminating employees, restructuring in the sense of moving groups and functions within organizations.... And moving responsibilities around and just refining the processes. And that, that's all gone very well. Again, when we set the plan and we set the org 
structure that we felt was the right org structure, right up front we said we know we didn't get it right. We don't know where we got it wrong, but we know it's not $100 \%$ correct ... So we had planned up front knowing, and let everyone know, all the employees know ... we know we are going to come back and reorganize and we've done that" (Interviewee 3).

In 2009 , as a consequence of the recession, several of the large automotive manufactures scaled back or terminated their contracts with Company $\mathrm{C}$ as a means of reducing their own costs. The most significant loss of business involved the maintenance of remote sites for General Motors (GM) at approximately 9000 locations across the US. This volatility of sales growth was an indicator of the instability of the market in 2009 (Harrington et al., 2004).

"Huge piece of business and brought a lot of scale and allowed us to leverage that scale to do other things for other companies. So Ford, Verizon, other customers, we were able to serve and able to keep prices down because we had the scale of GM. You lose GM, you lose the scale and a lot of that scale is achieved with infrastructure. ... Also, all this maintenance was done through field service reps, so third party independent contractors. When you can offer them fairly regular business, you can get good prices out of them. When you can only offer them a piece of business once in a while, not so much the good price. So our costs start to go up, revenue goes down, so we decided to exit out of the ... remote maintenance business. ... So that's the down side of revenue, on the up side of revenue, for some of the international satellites we were able to increase, increase sell factor, increase the utilization of those satellites and again, I think that was largely due to market conditions. In South America, there is an under-supply of satellites. There is a lot of demand in Brazil and Columbia in particular for world broadband. So they are trying, they have realized the need to bring internet access to the rural communities and satellite in those countries is the way to do it. So there has been a lot of demand from those countries to roll out these services. And there's not been a lot of supply in years prior since the meltdown of South America in the ' 90 's, there's not been a lot of new satellites going in, new investment going in and because it's such a long planning cycle, it's a three year, two and a half to three year build, for satellite programs to get them built and launched it takes a long time to connect. ... The beams on South America are getting sold out because there is nothing else. So good, good revenue opportunity there for us, the beams on those satellites are very full" (Interviewee 3 ). 
In addition to positive and negative revenue impacts which come from economic shocks (Grant, 2003) or customer changes (Depperu and Gnan, 2006), a complex business such as satellite based telecom can often have technical issues which impact its service and revenue (Kukalis, 1991). When these problems are hardware related and occur on orbiting satellites, there is usually no way to make repairs.

"With [satellite name] there is an issue with that satellite's bus manufactured by [company name] that results in power degradation over time. So we are dealing with [satellite name] which was originally a North and South America satellite. We have shut off the North America payload, replaced it with another North America satellite and its power is slowly degrading over time. ... And on [satellite name] ... one of its solar arrays didn't deploy. So it's got a much shorter, shorter life and less capacity than originally designed" (Interviewee 3 ).

Government regulations are also an issue for a satellite based telecom company which impacts its strategies. In this case, Company $\mathrm{C}$ is dealing with its national government on foreign ownership restrictions and the government's reluctance to allow operation on certain frequency spectrums. This is an interesting challenge for Company $\mathrm{C}$ in that each of the national governments with which it deals has different regulations pertaining to frequency spectrum exploitation.

Up to this point in the roll-out of its five year strategic plan, Interviewee 3 feels that Company $\mathrm{C}$ is meeting more than $75 \%$ of its goals, albeit with a process that has not proceeded as envisioned in the original plan.

\subsubsection{Factor Coding Results}

The factor which had the highest frequency of mention was changes in customer requirements which appeared seven times in the transcript (see Table 6). The loss of the GM business was a significant issue with respect to Company C's revenue. It also played 
a role in causing Company C's costs to rise as it lost the scale of a major account. However, the increasing demand of Company C's South American customers helped offset its automotive sector losses. Between the positive and negative changes in customer requirements for Company $\mathrm{C}$, it is reasonable that this factor would be prominent in the strategy transformation for this company. One of the factors which received three mentions in the narrative was environmental instability. As this variable played a role in Company C's customers changing their requirements, it would seem that there is some form of interaction between the two variables. Environmental complexity received two mentions and it too may have had some interaction with changing customer requirements. 
Table 6 - Summary of Interview 3 Results

\begin{tabular}{|l|c|c|c|}
\hline Factors / Indicators & $\begin{array}{c}\text { Transcript Coding } \\
\text { (number of times } \\
\text { referred to in } \\
\text { transcript) }\end{array}$ & $\begin{array}{c}\text { Factors / } \\
\text { Indicators } \\
\text { Mentioned in } \\
\text { Interviewee } \\
\text { Summary }\end{array}$ & $\begin{array}{c}\text { Interviewee } \\
\text { Ranking of Most } \\
\text { Important Factors } \\
\text { / Indicators }\end{array}$ \\
\hline $\begin{array}{l}\text { Environmental } \\
\text { instability. }\end{array}$ & 3 & $\checkmark$ & \\
\hline $\begin{array}{l}\text { Competitors' } \\
\text { actions. }\end{array}$ & 0 & $\checkmark$ & \\
\hline $\begin{array}{l}\text { Changes in customer } \\
\text { requirements. }\end{array}$ & 7 & $\checkmark$ & $1^{\text {st }}$ \\
\hline $\begin{array}{l}\text { Environmental } \\
\text { complexity. }\end{array}$ & 2 & $\checkmark$ & \\
\hline $\begin{array}{l}\text { Leadership team } \\
\text { characteristics. }\end{array}$ & 3 & $\checkmark$ & $3^{\text {rd }}$ \\
\hline $\begin{array}{l}\text { Employee } \\
\text { involvement. }\end{array}$ & 2 & $\checkmark$ & \\
\hline $\begin{array}{l}\text { Organizational } \\
\text { learning ability. }\end{array}$ & 2 & & \\
\hline $\begin{array}{l}\text { Flexibility of the } \\
\text { intended strategy. }\end{array}$ & 3 & & \\
\hline $\begin{array}{l}\text { Feasibility of the } \\
\text { intended strategy. }\end{array}$ & 0 & & \\
\hline $\begin{array}{l}\text { Ambitiousness of } \\
\text { the intended } \\
\text { strategy. }\end{array}$ & 0 & & \\
\hline $\begin{array}{l}\text { Availability of } \\
\text { Resources. }\end{array}$ & 0 & & \\
\hline $\begin{array}{l}\text { Changes in key } \\
\text { personnel. }\end{array}$ & 1 & & \\
\hline $\begin{array}{l}\text { Government } \\
\text { regulatory } \\
\text { requirements. }\end{array}$ & 5 & & \\
\hline
\end{tabular}

* New indicator from this interview.

The Government regulatory requirements factor was mentioned five times in this interview which places it as the second most mentioned variable. This variable did not appear in the literature based model nor did it appear in the transcripts of interviews 1 or 2. However, for Company $\mathrm{C}$, this variable is significant in that this company operates in a highly regulated environment at both the national and international levels. The 
deployment of satellites and the usage of particular frequency bands are highly scrutinized by governments and international bodies such as the United Nations. Company $\mathrm{C}$ must operate within the regulatory frameworks provided by these bodies and, like other such companies, it lobbies these governing bodies to change regulatory requirements which restrict its strategic options. In the case of Company $\mathrm{C}$, it had objectives in its strategic plan which required changes to particular national regulations. As these regulations have not as yet changed, its strategy has changed accordingly.

There are three variables which each received three mentions in the transcript: environmental instability; leadership team characteristics; and flexibility of the intended strategy. Environmental instability may have interacted with each of the other two variables. Leadership team characteristics are mentioned in the context of how Company $\mathrm{C}$ dealt with issues such as the loss of the automotive business and the merger with the smaller satellite company. Flexibility of the intended strategy was also mentioned as a variable that allowed Company $\mathrm{C}$ to cope with unexpected circumstances such as a need for more service in South America and technical issues with orbiting satellites. As noted previously, it seems that it is the interactions between variables that often result in the transformations that occur to the original strategies. While the five interviews do not provide enough data to definitely explore these interactions, the relationships between these variables will be explored in the analysis of the quantitative survey data. However, it can be posited that there seems to be a give and take relationship between the characteristics of the external environment, and the flexibility that results from the combination of the characteristics of the internal environment and the intended plan. It may be that while almost all strategies transform, it is the flexibility in the internal 
environment that impacts whether the transformation leads to a positive or negative result, and how disruptive the transformation is or is perceived to be.

Environmental complexity, employee involvement and organizational learning ability were all mentioned twice, and changes in key personnel was mentioned once in the transcript. Based on the frequency of mention by Interviewee 3, these variables did not play a major role in strategy transformation at Company C. However, given the importance that the interactions among variables seems to have in this scenario, they may have played an important role in their impact on other variables which in turn influenced changes to the strategy.

\subsubsection{Interviewee Factor Scoring}

Interviewee 3 scored only three variables as highly important relative to the transformation of strategy in this example. The highest ranking went to changes in customer requirements. This is consistent with the emphasis that was placed upon it in the narrative. Given the sensitivity of GM's product to the erosion of consumer confidence brought about by the recession, the change in GM's needs was a resultant follow-on. The negative automotive sector changes and the positive changes to customer requirements that Company $\mathrm{C}$ experienced in its South American market both impacted the transformation of its strategy.

The second and third highest ranked variables were flexibility of the intended strategy and leadership team characteristics respectively. While the highest ranked variable is external, the second and third are both internal and represent Company C's response to an external situation that was out of its control. As customer requirements changed, the leadership team reacted in ways which it felt were most beneficial to 
Company $\mathrm{C}$ in this difficult situation. Company $\mathrm{C}$ was also fortunate enough to have built flexibility into its strategy so that the leadership team was able to react without completely abandoning its strategy.

\subsubsection{Factor Coding versus Interviewee Factor Scoring}

As displayed in Table 6, changes in customer requirements was both the most mentioned variable in the transcript and the highest ranked variable by Interviewee 3 in terms of its importance relative to strategy transformation in this narrative. It is clear that this external variable had a significant impact upon Company $\mathrm{C}$ during the implementation of its strategy.

The second most mentioned variable was government regulatory requirements; however, this variable was not scored by Interviewee 3 as highly important and therefore not ranked. Government regulatory requirements was scored as important, but only those variables listed as highly important were ranked. In a follow-on conversation with Interviewee 3 , the researcher asked why government regulatory requirements was not listed as highly important despite the five times it was mentioned by Interviewee 3 during the interview. Interviewee 3 responded that it was probably because government regulatory requirements is a challenge that Company $\mathrm{C}$ deals with all the time. In other words, it is a constant force that continually changes their strategies because the strategies often have an embedded assumption, or perhaps a hope, that certain regulations will change. When Interviewee 3 chose which variables would be listed as most important, variables were selected which were more unique to this particular scenario.

The next most mentioned variables in the transcript had a frequency of three mentions and there were three of these. Two of these variables were ranked as second 
and third most important by Interviewee 3: flexibility of the intended strategy as second and leadership team characteristics as third. While these two variables showed good consistency between the coding and Interviewee 3's ranking of the most important variables, the third variable with three mentions, environmental instability, was not listed as highly important. When queried on this inconsistency, Interviewee 3 stated that it may have been because environmental instability led to the changes in customer requirements and during his scoring of the variables, he was most focused on the variables that seemed to be impacting Company $\mathrm{C}$ directly.

\subsubsection{Interviewee Strategy Transformation Scoring}

Interviewee 3 scored the level of transformation of the strategy in the example as follows:

- Primary goals implemented and achieved as originally planned: $76-100 \%$.

- Secondary goals implemented and achieved as originally planned: $76-100 \%$.

- "The actions that formed the process of implementing the strategy were carried out exactly as planned": Somewhat Agree.

The achievement scores for the primary and secondary goals may be considered generally consistent with the narrative of Interviewee 3's strategy example in that they achieved their goals of cutting costs, integrating the new company as part of the acquisition, increasing satellite usage and increasing revenue. However, the path Company $\mathrm{C}$ took to achieve its goals had some additional curves relative to the path envisioned during the original planning process. This is reflected in Interviewee 3's partial agreement to the assertion that the implementation process proceeded exactly as planned. 
Of the five interviews, Company C's strategy was the least dramatic. There was no billion dollar development program or start-up of a new company in a highly complex environment. In essence, Company C's strategy was to stabilize itself after being acquired by a new ownership group and grow revenues. It may therefore be reasonable or somewhat expected that the attainment of its goals was a more achievable result.

\subsubsection{Process Issues of Interest}

While most companies focus their efforts on their customers and competitors in the knowledge that their competitors must operate within the same basic legal and regulatory framework as themselves, companies in highly regulated industries are somewhat different. These companies must make discussions of various national and international governing bodies a staple of their strategy formulation activities. For example, because there are so few companies in the satellite telecom industry, their individual national regulatory frameworks can have a significant impact upon their competitiveness as they challenge the world market. Finding ways to influence bureaucrats and their political masters toward a more attractive competitive environment can be both costly and frustrating. Company $\mathrm{C}$ has what it sees as very reasonable requests for regulatory change but it has so far been unsuccessful in its efforts to obtain them. This desire for regulatory change is a central plank of its ongoing strategy and one which it believes will determine the level of its ongoing success.

\subsubsection{Summary}

Company $\mathrm{C}$ implemented its strategy and achieved its goals to a high degree, albeit not in the precise manner that it expected. This strategy was not overly ambitious 
which perhaps explains the lower level of transformation that occurred relative to other strategies discussed during the interviews.

Interviewee 3's narrative was related in a manner which resulted in a medium level of consistency between the transcript coding and his scoring of the most important variables relative to transformation of the strategy. There were two deviations, one whereby he did not list government regulatory requirements as highly important despite mentioning it the second highest number of times in the narrative. He explained this by saying that because it is an ever-present issue for Company $\mathrm{C}$, he did not focus on it as much as the unique variables for this strategy example. The other deviation related to not listing environmental instability as highly important despite it receiving the third most number of mentions in the narrative. He noted that this was probably because it was a variable that led to the impact of another variable. In other words, although environmental instability may have led to changes in customer requirements, it was the changes in customer requirements that were most apparent to Company $\mathrm{C}$ during the implementation.

Interview 3 added one variable to the literature based model: government regulatory requirements. The frequency of mention in the narrative for this variable was second highest with five mentions. While this variable will probably not be as important to many companies as it is to companies in highly regulated industries, it is a variable that impacts all companies to one degree or another. 


\subsection{Interview 4}

\subsubsection{Strategy Example Description}

Company $\mathrm{D}$ is a North American major retail chain that is a wholly owned subsidiary of a company listed on a major North American Stock Exchange. Due to the highly human resource intensive nature of distribution centres in this industry, Company D devised a strategy to automate a major distribution centre in its network. This new centre was needed to mitigate capacity challenges in the network and the green-field nature of its creation allowed the opportunity for Company D to implement an automated site. It should be noted that this automated distribution centre is only the second of its kind in the industry in North America. Therefore, this was a very bold strategic move given the capital investments required and the lack of a track record for the equipment in the industry.

Interviewee 4 is the Director of Projects and Process for Company D and the individual responsible for the detailed planning and implementation of the strategy. $\mathrm{He}$ noted the large number of variables that had to be taken into account during the planning phase, indicating the complexity of the environment in which the company was operating (Kukalis, 1991).

"We had to take a look at what we wanted to do. What was the overall strategy, so yes we are at capacity but what do we want to do, call it, I hate using the term, when we grow up. We knew that $30 \%$ of our volume was DSD [direct store delivery] driven. So direct store delivery, we knew, that was one of the elements, did we want to bring that in house or not. We needed to understand our growth against the competitors. What did we truly think our growth would be - organic growth just within same stores and new business, or new stores? So we looked at all that, came up with what we thought would be the end state so that we could evaluate what we needed. And we went through many, many permutations. I think we went through 60 models. ... Probably a year down the line as we were going 
through with our partner, with [automated equipment company], we were taking a look at the facility and how large it needed to be ... and our growth projections were in my humble opinion, a little bit too aggressive. ... Because it was automated, we really didn't know what would be the cost of such a facility" (Interviewee 4).

After analysing approximately 60 permutations of the operational model, Company D settled on three possible futures (De Geus, 1988; Schoemaker, 1995) which were presented to senior executive management. After considerable debate at the highest levels of Company D, it was decided to centralize specific product departments in this facility for the entire network. One of the main issues was that Company D was not just focused on urban centres like some of its competitors. While the company's revenue from rural areas was continuing to grow, servicing these small remote stores was an operational challenge. However, Interviewee 4 noted that the productivity of the automated machinery is the same for both small and large stores, so Company D believed that it gained a competitive advantage through servicing the small remote stores in an automated fashion.

"We had our strategy, we had our growth formulas ... we certainly did our due diligence looking at various companies that offered automation. ... We had a team that ... visited both types of automation. At the end of the day, [automation equipment company] was really the only one that had been able to build pallets through an automated process ... using COMs, case order machines, that's actually the machine that builds the pallets.... We gave them all our data, they reviewed almost 6 to 8 months of detailed data and came up with, based on the growth and everything else, came up with a model. This model was in essence very large. Right now our facility, the one in the video you saw today, is a $16 \mathrm{COM}$ model. What [automation equipment company] initially proposed was a $24 \mathrm{COM}$ model. ... And we had fully automated repack areas which they call a DPS, dynamic picking system. ... Needless to say that the cost of this was significant to the degree that it was really a, you know, it would break the deal. It was just so high" (Interviewee 4). 
Company D reviewed the design assumptions and was forced to conclude that its growth assumptions were too high. They adjusted the growth curve by almost half and had the automation equipment provider remodel the data. The result was a design using $16 \mathrm{COMs}$ instead of the original $24 \mathrm{COMs}$. This ability to admit earlier errors and adjust the plan during the implementation indicated a strong level of leadership flexibility (Schaffer and Willauer, 2003), and a detailed understanding of the business (Beinhocker \& Kaplan, 2002). However, the company did not want to have to expand the facility in the event that additional capacity was needed in the future, especially since it was much less costly to build an extra 100,000 to 200,000 square feet of floor space during the initial construction than to add it on later. It was therefore decided to embed the contingency (De Geus, 1988; Schoemaker, 1995) of adding more COMs in the future by constructing the building to its original planned size of over 500,000 square feet. At roughly the same point in time, it was decided to cancel another type of automation (i.e.

Direct Pack) for a particular product line due to sales declines across the industry.

"So throughout that time ... we assessed many of the risks you know, especially our vendor risks and our store risks. But there were certainly many other risks that were identified. Risk of ... the building, risk of the supply of material ... so many of those things were all factored in. Eventually, as the building was getting built, some of those risks fell and we closed them off because they were no longer risks. The risk of people ... that is probably one of the big ones. ... With a project of this size, it was important that we had you know, continuity of the project team and that was certainly something that we acknowledged and we needed to do. ... Our ramp up of our hiring of people took longer than we expected just because we were looking for the quality people ... certainly something that I didn't anticipate but certainly the right thing to do. ... As I said earlier, it's about making sure the project of this duration if you had players that change it would be a significant setback in a project. So we made sure we certainly had redundancy in certain roles and we made sure that there were enough people just in case one won the million dollars and took off. From that point of view that went well. I would say just the hiring piece was our struggle. Especially human resources of course that 
is the key role and we went through three human resource managers in three weeks. They'd get hired and they'd leave. I don't know why and all valid reasons and things like that, it was like the perfect storm. But certainly that was the one that was the toughest one. ... We really managed through the risk, through the project governance. There were some check points on a weekly basis, there were check points on a monthly basis and a complete project governance around it" (Interviewee 4).

With respect to any impact of the recession, Company D acknowledged that this had an effect on current and projected volumes. Interviewee 4 noted that this was also true for its competitors, one of which had major issues which resulted in its supply chain fragmenting to the point where it was in the national press for having stores with empty shelves. This competitor's reaction to changing market conditions was to reduce prices, thereby impacting Company D's strategy (Blythe and Zimmerman, 2004) through the resultant impact on projected revenues.

"About 18 months prior to the ramp up date, we chose that date and we said that's when we are going to open up our facility and we are going to ship our first case. Eighteen months prior and we hit that date. So certainly [automaton equipment company] had an amazing team. ... But we certainly managed it very well and you know, the project plan was very meticulous probably three thousand lines and everything from every component of the business. Certainly when it came to the transition of the ramp up / ramp down, the key there was putting teams in place and we had a team in place for that. We went to the business, to all our stakeholders and said this is our intention on the ramp up / ramp down, anybody have any major concerns? Certainly some were raised and made it to the risk logs. Mitigated, understood, mitigated and things like that. ...

[Automation equipment company] typically said the ramp up should take you 27,28 weeks. ... We went back to them, no, too long. We felt confident that we can do it in less time. So we actually went with a 17 week ramp up. Which they said they were very cautious and it did make it into many of the steering committee updates that there is a lot of risk with going this way. Three weeks into the ramp up, we accelerated the ramp up by another two weeks" (Interviewee 4).

Although Company D views the strategy as a success, it is now in the process of comparing its original strategic plan with what actually happened, thereby facilitating 
organizational learning (Schaffer and Willauer, 2003). As it considers automating other distribution facilities, it wants to ensure that it understands what could have been done more effectively and how this might be accomplished.

\subsubsection{Factor Coding Results}

In coding the transcript of Interview 4, the most frequently mentioned variable was environmental instability; it had a frequency of mention of 10 (see Table 7). There were a number of issues which Company $D$ had to face that arose as a result of changes in the market relative to the circumstances upon which it had based its original assumptions. The initial rationale for building the new facility was because the company was running out of capacity to handle the demand from its customers. However, over the period of the implementation, the global recession had an impact on its markets; people simply had less money to spend so demand declined. In addition, there was one particular product line whose demand was dramatically dropping all across the industry. Finally, a previously infrequent format for shipping and displaying product started to gain prominence during the implementation. This particular format did not provide an opportunity for automated pallet assembly. 
Table 7 - Summary of Interview 4 Results

\begin{tabular}{|l|c|c|c|}
\hline Factors / Indicators & $\begin{array}{c}\text { Transcript Coding } \\
\text { (number of times } \\
\text { referred to in } \\
\text { transcript) }\end{array}$ & $\begin{array}{c}\text { Factors / } \\
\text { Indicators } \\
\text { Mentioned in } \\
\text { Interviewee } \\
\text { Summary }\end{array}$ & $\begin{array}{c}\text { Interviewee } \\
\text { Ranking of Most } \\
\text { Important Factors } \\
\text { / Indicators }\end{array}$ \\
\hline $\begin{array}{l}\text { Environmental } \\
\text { instability. }\end{array}$ & 10 & $\checkmark$ & \\
\hline $\begin{array}{l}\text { Competitors' } \\
\text { actions. }\end{array}$ & 9 & $\checkmark$ & $2^{\text {nd }}$ \\
\hline $\begin{array}{l}\text { Changes in customer } \\
\text { requirements. }\end{array}$ & 0 & $\checkmark$ & \\
\hline $\begin{array}{l}\text { Environmental } \\
\text { complexity. }\end{array}$ & 3 & & \\
\hline $\begin{array}{l}\text { Leadership team } \\
\text { characteristics. }\end{array}$ & 2 & $\checkmark$ & \\
\hline $\begin{array}{l}\text { Employee } \\
\text { involvement. }\end{array}$ & 1 & $\checkmark$ & \\
\hline $\begin{array}{l}\text { Organizational } \\
\text { learning ability. }\end{array}$ & 9 & & \\
\hline $\begin{array}{l}\text { Flexibility of the } \\
\text { intended strategy. }\end{array}$ & 8 & & \\
\hline $\begin{array}{l}\text { Feasibility of the } \\
\text { intended strategy. }\end{array}$ & 0 & & \\
\hline $\begin{array}{l}\text { Ambitiousness of } \\
\text { the intended } \\
\text { strategy. }\end{array}$ & 2 & & \\
\hline $\begin{array}{l}\text { Availability of } \\
\text { Resources. }\end{array}$ & 5 & & \\
\hline $\begin{array}{l}\text { Changes in key } \\
\text { personnel. }\end{array}$ & 3 & & \\
\hline $\begin{array}{l}\text { Government } \\
\text { regulatory } \\
\text { requirements. }\end{array}$ & 1 & & \\
\hline
\end{tabular}

There were a number of issues related to competitors which impacted Company D and its strategy. These were spoken of by Interviewee 4 both in terms of environmental instability and competitors' actions. As such, competitors' actions was the second most mentioned variable with a count of nine. This occurred when one of the major competitors in the industry began reducing prices across all its products. Company D did 
not react immediately and therefore lost, for a period of time, market share. Company D also had to react to the arrival of a significant new entrant in its market as well as the introduction of competing products in several retail chains which had not previously carried these products. This also had the effect of reducing the need for additional capacity in the network.

Organizational learning ability was tied with competitors' actions for the second most mentioned variable with a count of nine. Interviewee 4 noted that as the environment changed or competitors' took unanticipated actions, Company D was able to learn quickly and make necessary changes. He also noted that the risk management process remained integral to the project framework throughout the project. As issues arose, risks were quantified and mitigations planned and executed. Interviewee 4 also stated that the flexibility built into the strategy from the outset helped Company D learn and overcome challenges. Flexibility of the intended strategy was third most mentioned with a count of eight. He noted that it was not just an issue of contingency plans being built into the strategy, but more of a mindset in the project team and in the members of the governance council that allowed for flexibility. It may be that working through 60 permutations of the operating model during the planning stage allowed for a wider range of cognitive schema in the minds of decision makers. While it was not Company D's intent to adopt a scenario based planning approach to its strategy formulation, the result of the detailed review of so many different models or scenarios may have resulted in the benefits of scenario based planning for this strategy.

The fourth most mentioned variable was availability of resources with a frequency of five. This referred to Company D's challenges in finding a match between 
the qualities it was looking for in its new staff and the people available for it to hire. Interviewee 4 also noted the challenge of finding and retaining an appropriate human resources manager for the project. This led to the fifth most mentioned variable being changes in key personnel with a count of three. Interviewee 4 referred to the interaction between the challenge of finding appropriate staff resources and the challenge of keeping a human resources manager to search for the appropriate staff as the "perfect storm".

Environmental complexity was mentioned three times and therefore tied changes in key personnel as the fifth most mentioned. Ambitiousness of the intended strategy and leadership team characteristics were each mentioned twice. Employee involvement and government regulatory requirements were only mentioned once each.

\subsubsection{Interviewee Factor Scoring}

Interviewee 4 scored only two variables as highly important relative to the transformation of strategy in this example. The highest ranking went to flexibility of the intended strategy. As noted above, this flexibility seemed to present itself in the speed of reaction by Company $\mathrm{D}$ to external impacts. Company $\mathrm{D}$ spent considerable time during the strategy planning stage discussing various versions of the future environment in which the new distribution network would have to operate. This may have resulted in flexibility of the intended strategy being more in the minds of the decision makers than in the project documentation.

Competitors' actions was ranked by Interviewee 4 as the second most important variable. Given the entrance of new competitors in the market and the price reduction strategy of a key player in the existing market, Company D had to re-evaluate its strategy and make material changes. The actions taken by its competitors resulted in a significant 
change to the capacity assumptions upon which it had based the need for its new strategy. This external variable interacted with the internal flexibility variable to result in the transformation of the strategy discussed in this narrative.

\subsubsection{Factor Coding versus Interviewee Factor Scoring}

The four highest mentioned variables documented from the coding had counts of 10, nine, nine and eight (see Table 7). These were environmental instability, competitors' actions, organizational learning ability, and flexibility of the intended strategy respectively. The remaining variables had counts of five or less. The number one ranked variable by the interviewee was flexibility of the intended strategy. As noted above, Interviewee 4 spoke of flexibility of the intended strategy in terms of its interaction with organizational learning ability. While flexibility of the intended strategy is not the highest frequency variable from the coding, it has a combined count of 17 with organizational learning ability. This combined count is high and may have been why Interviewee 4 ranked flexibility as the most important variable.

Interviewee 4 ranked competitors' actions as the number two most important variable. However, similar to the two variables discussed above, Interviewee 4 spoke of competitors' actions in terms of its interaction with instability of the environment. These two variables had a combined count of 19 . If one accepts the rationale for how Interviewee 4 could have been thinking of these variables in terms of their interactions, it still could be argued that Interviewee 4's ranking should be reversed to give the number one ranking to the variables with the combined coding score of 19 . However, given that the difference in coding scores for the two sets of variables is only 2 , and that these four variables are all mentioned at a much higher frequency than the other variables in the list, 
Interviewee 4 does display a reasonable level of consistency between the way he related the narrative and the way he ranked the variables in terms of importance.

\subsubsection{Interviewee Strategy Transformation Scoring}

Interviewee 4 scored the level of transformation of the strategy in the example as follows:

- Primary goals implemented and achieved as originally planned: $76-100 \%$.

- Secondary goals implemented and achieved as originally planned: $76-100 \%$.

- "The actions that formed the process of implementing the strategy were carried out exactly as planned": Agree.

The achievement scores for the primary and secondary goals may be considered generally consistent with the narrative of Interviewee 3's strategy example. As such, they achieved their goals of increasing their network's capacity, starting up the new facility on time, implementing the automation without experiencing any issues on start-up that jeopardized the network, and using automation to increase the effectiveness of support to their rural outlets.

The course toward these objectives was relatively stable with the exception of capacity design changes relative to the final equipping of the facility. Interviewee 4's assertion that the process of strategy implementation proceeded exactly as planned is understandable. While changes were made relative to how the facility would be equipped, the process seems to have been executed as originally planned. 


\subsubsection{Process Issues of Interest}

Company $\mathrm{D}$ is currently engaged in a detailed audit of how the strategy was implemented versus how it was originally planned. This effort is designed to allow them to make required changes before the green-field start-up of new automated facilities is attempted. This is in stark contrast to Company A's refusal to carry out a lessons learned activity relative to its failed multibillion dollar $\mathrm{R} \& \mathrm{D}$ and marketing project. While this is just speculation on the part of this researcher, it may have something to do with the difference of industry between the two companies. Company $\mathrm{A}$ is in the cutting edge portion of the high tech sector where a culture of risk taking, extremely high margins and winner-take-all (or at least most) is accepted. The industry is populated with flashy executives whose names are often in the headlines.

By contrast, Company D is in a very conservative industry and is a company that grew out of a family owned business. The volumes are high and the margins are low, and strategic moves tend to resemble tortoise-like movements instead of the hare-like leaps that are often seen in the high tech sector. Therefore, perhaps it should not be a surprise that Company D would scrutinize its performance before moving on to its next strategy.

\subsubsection{Summary}

Company D implemented its strategy, achieved its goals and proceeded with its strategy in a manner that was reasonably similar to its original plan. The strategy did transform by way of reaction to its external environment, but only in ways that allowed it to continue toward its preset goals.

Interviewee 4's narrative was related in a manner which resulted in a reasonable level of consistency between the transcript coding and his scoring of the most important 
variables relative to transformation of the strategy. While there was not an exact match between his ranking of two variables as most important, and the frequency of mention in the narrative of those variables, he seemed to relate the narrative in a way that focused on the interaction between two variables for each of his two ranking picks.

Interviewee 4 ranked flexibility of the intended strategy as the most important variable but related the story in a way that focused on the interaction of this variable with organizational learning abilities. His ranking of competitors' actions as the number two most important variable seemed to focus on the interaction between competitors' actions with environmental instability. While the one versus two ranking still seemed to be reversed relative to the combined count of each of these sets of variables, the counts are quite close and these four variables are all mentioned at a much higher frequency than any other variables.

Interviewee 4 did not add any new variables to the literature based model. However, with the exception of feasibility of the intended strategy, all four of the other new variables from Interviews $1-3$ were mentioned in this narrative.

\subsection{Interview 5}

\subsubsection{Strategy Example Description}

Interviewee 5 is the Vice President of Business Development and Strategy for a North American firm (Company E) which provides satellite related wireless services to the defence sector, predominately in the US. Company $\mathrm{E}$ is a public company listed on a major North American Stock Exchange.

In the Iraqi theatre of operations, during operation Iraqi Freedom, Company E developed a force protection personnel recovery infrastructure. This capability was used 
by soldiers embedded in small teams with the Iraqi military whose role was to transfer knowledge and technology to the indigenous military to enable it to effectively police its own state.

"This was the long term strategy of the top US military as an exit plan for the US out of Iraq. So it was a very high profile program but on the other side, because of where these soldiers were going to be placed, they were going to be outside of the typical military environment, what we call outside the wire and far past the forward operating bases and literally living in small remote villages and mud huts with Iraqi nationals. These people were classified as ... very high risk of isolation or capture. And because of this we had to make sure that every possible technology was afforded to these individuals to help them signal when they were isolated or detained" (Interviewee 5).

The intent of the technology was to provide the soldier with a 911 type panic button capability that would work globally and in any environment. When a soldier becomes isolated, detained, lost or on the verge of capture, s/he presses the panic button to send a signal off satellites to a ground receiving station and on to a mission control or rescue coordination centre. This emergent strategy was initially the result of opportunity taking (Depperu \& Gnan, 2006; Mintzberg, 1977) on the part of Company E. The system had been in operation for about three years, and because of the success of the program, the US Army was planning to transition the program from a rapid fielding of off-the-shelf technology to a US Department of Defense (DOD) program of record.

"Which means that they were going to look at it as long term, build a ten to twenty year plan on the evolution of the technology ... what it really meant to us was the Army was going to... instead of using commercial off-the-shelf equipment wanted to take a step back from the technology, identify capability and production documentation which is the requirements for the entire program from the Joint Forces perspective. Not just Army but Navy, Air Force and Marines. And then look at what are all the requirements if we were to develop this technology from scratch. And what we read into this is that it meant that the Army was going to develop a military set of the technology instead of using 
commercial technology. So the [Company E] piece of this to date had been providing all the infrastructure but we had no stake in the actual devices that were being fielded. The devices that were fielded were literally commercial off-the-shelf devices that you could get from any Cabela's or Bass World kind of stuff and it was unclassified, overt transmissions but it seemed to be quite effective" (Interviewee 5).

The technology had been successfully deployed in Iraq and many lives saved as a result of its effectiveness. The next step would be building in authentication codes, encrypted voice and data capability, harsh environmental tolerance standards and other requirements which would make it a military piece of equipment. However, transitioning a field based operational necessity procurement to an official DOD program with military equipment specifications and multi-year funding also meant adding a significant layer of bureaucratic involvement and the full weight of the US military procurement rules and regulations.

"It was a good program, it was a high margin program for us but it was only a few million dollars here and there. And what we were looking at is a program that was ramping up to potentially represent hundreds of millions of dollars over the next decade. And the idea was how could we position [Company E] to be the program prime ... as it was while it was a very tiny program.... The plan, which was based on all the information that we had ... said that the US military were going to move very quickly on this ... so we therefore needed to move very quickly on it too. So our plan was, we need to invest immediately in this technology, we needed to execute an $R \& D$ spend that started the first of January $20[X X]$ to be ready for a June product introduction in $20[\mathrm{XX}]$ for start fielding of equipment in summer $20[\mathrm{XX}]$ with an eighteen month roll out ... to field the first about 140,000 units" (Interviewee 5).

Company E again displayed its tendency toward opportunity taking (Depperu \& Gnan, 2006; Mintzberg, 1977) by accelerating its involvement in the program. It found a partner for a joint development effort on part of the technology and both companies started to spend R\&D funds quickly for a program that they believed would be imminently announced. Over time, each company spent in the vicinity of \$2 million on 
R\&D and marketing related activities. As of 2010 , no official request for proposal has

been released nor has the contract been awarded. However, the strategy successfully

transformed through the senior management flexibility (Schaffer and Willauer, 2003)

displayed by Company E and the leadership team's use of its previously acquired

experiential knowledge (Daake, Dawley, \& Anthony, 2004) with respect to military

contracting. As a consequence of its flexibility and experience, Company $\mathrm{E}$ built in

contingencies from the outset which allowed the strategy to transform in a positive

manner (De Geus, 1988; Schoemaker, 1995).

"So I guess, the strategy in the end did not work out because of the fact that we really couldn't ... there's a number of elements within the strategy that were outside of our control, that were necessary for success. ... We've moved off of trying to sell it only to the US Army and have sold this product into places like the Emirates Air Force, the Brazilian Air Force, the Turkish military and so on. ... So we've been able to recover costs but it isn't the home run that we had been hoping for at the time.... We had the foresight to look at the time when we were building the plan, what are the contingencies that we could do, and what happens if this plan weren't to happen. ... Now for our current year's plan for instance we are looking at taking the technology into a personal tracking device that is used for corporate executives and, and corporate duty of care applications.... There is also a potential market with some of the private militaries like the Aegis, Triple Canopy, Blackwater type of private security companies operating in places like Iraq and Afghanistan. Which is an obvious market and that's going to be well served by the technology. The other markets that we are looking at are the government workers, the aid workers who are not necessarily in war zones but are in some, some remote areas. There's for instance in Canada and the remote areas of Northern Canada, there is legislation for lone-worker's safety. In places like the United Kingdom there's legislation on corporate safety in remote areas. So there is a lot of what we call corporate duty of care emerging market where the technology that we had invested in for the US military now has applicability in the civilian world far beyond the reaches of what was ever envisioned in the, in the US military. So it turns out that we have what I think to be some intellectual property that was developed on this that is going to position us very well for new business growth in 2010" (Interviewee 5). 
Company $\mathrm{E}$ is also interested in government / private partnerships in places like the Philippines, Indonesia and India where there are hundreds of thousands of small fishing boats that have no radio capabilities whatsoever. While the original strategy did not work out as planned, Company $\mathrm{E}$ now has intellectual property and operational experience in an area which may lead to sizeable new markets.

\subsubsection{Factor Coding Results}

In the interview 5 transcript, the coding revealed the number one mentioned variable to be flexibility of the intended strategy with a count of 18 (see Table 8). This variable had more than double the number of mentions than did the second highest frequency variable, indicating the import of this variable to Interviewee 5 relative to his narrative. The manner in which Interviewee 5 spoke about this variable indicated that he was referring to flexibility in a number of different ways. First, he noted that the way the strategy was woven into Company E's financial plans allowed for considerable flexibility in how the implementation would evolve, especially with respect to timeline. This may have been due to Company E's experience with government procurement or a generally conservative culture in the company. Either way, it allowed the strategy to evolve without materially and negatively impacting the company. 
Table 8 - Summary of Interview 5 Results

\begin{tabular}{|l|c|c|c|}
\hline Factors / Indicators & $\begin{array}{c}\text { Transcript Coding } \\
\text { (number of times } \\
\text { referred to in } \\
\text { transcript) }\end{array}$ & $\begin{array}{c}\text { Factors / } \\
\text { Indicators } \\
\text { Mentioned in } \\
\text { Interviewee } \\
\text { Summary }\end{array}$ & $\begin{array}{c}\text { Interviewee } \\
\text { Ranking of Most } \\
\text { Important Factors } \\
\text { / Indicators }\end{array}$ \\
\hline $\begin{array}{l}\text { Environmental } \\
\text { instability. }\end{array}$ & 2 & $\checkmark$ & \\
\hline $\begin{array}{l}\text { Competitors' } \\
\text { actions. }\end{array}$ & 0 & & \\
\hline $\begin{array}{l}\text { Changes in customer } \\
\text { requirements. }\end{array}$ & 3 & & \\
\hline $\begin{array}{l}\text { Environmental } \\
\text { complexity. }\end{array}$ & 0 & & \\
\hline $\begin{array}{l}\text { Leadership team } \\
\text { characteristics. }\end{array}$ & 6 & & \\
\hline $\begin{array}{l}\text { Employee } \\
\text { involvement. }\end{array}$ & 0 & $\checkmark$ & $1^{\text {st }}$ \\
\hline $\begin{array}{l}\text { Organizational } \\
\text { learning ability. }\end{array}$ & 2 & & \\
\hline $\begin{array}{l}\text { Flexibility of the } \\
\text { intended strategy. }\end{array}$ & 18 & & \\
\hline $\begin{array}{l}\text { Feasibility of the } \\
\text { intended strategy. }\end{array}$ & 7 & & \\
\hline $\begin{array}{l}\text { Ambitiousness of } \\
\text { the intended } \\
\text { strategy. }\end{array}$ & 0 & & \\
\hline $\begin{array}{l}\text { Availability of } \\
\text { Resources. }\end{array}$ & 0 & & \\
\hline $\begin{array}{l}\text { Changes in key } \\
\text { personnel. }\end{array}$ & 0 & & \\
\hline $\begin{array}{l}\text { Government } \\
\text { regulatory } \\
\text { requirements. }\end{array}$ & 4 & & \\
\hline
\end{tabular}

Interviewee 5 also spoke about the flexibility the company was seeking in terms of its proprietary technology. Interviewee 5 noted that when the company decided to fund the R\&D program for this opportunity, it was not just on the basis of the DOD procurement. During the planning discussions, Company E executives decided that the 
technology had numerous applications over and above the DOD program, and it was on this combined opportunity basis that the R\&D funding allocation was made.

Perhaps it is a function of Company E's experience waiting for government procurement programs to materialize, but Interviewee 5 stressed that there is always a level of flexibility in Company E's strategies. He noted that the strategy parameters in Company $\mathrm{E}$ are always flexible against the assumption that the strategy will probably change during its implementation.

The variable with the second highest frequency of mention was feasibility of the intended strategy with a count of seven. Interviewee 5 acknowledged that one of the primary goals of the strategy was to put Company $\mathrm{E}$ in a position to receive a solesourced contract, in other words a contract for which they would not have to compete. In most cases, it is extremely difficult for western governments to sole-source a contract because of the perception of bias or preferential treatment toward the receiving contractor. The sole-source approach did not prove feasible and led to a significant transformation of the strategy both in terms of process and timeline.

The third highest frequency variable was leadership team characteristics with a count of six. This variable was closely tied to flexibility in the way Interviewee 5 related the narrative. In other words, it is the characteristics of the leadership team that led to Company E's flexibility in the way it plans and implements its strategies.

Government regulatory requirements had a frequency of four and played a role in this strategy transformation in that it was these requirements that did not allow Company $E$ to attain its goal of winning a sole-sourced contract. It is interesting that Company E's strategy was focused on the government taking actions that would prove difficult from a 
public relations and regulatory perspective. Company E's strategy had to be flexible enough to transform so that it could still reach some of its strategy objectives. The variable with the next highest count was changes in customer requirements with a frequency of three. It was government regulatory requirements that caused the customer's requirements to change toward a competitive procurement program.

Environmental instability and organizational learning abilities both coded with a count of two. While these two variables impacted the strategy, they did not have the significant transformative influence on this strategy as did the higher frequency variables.

\subsubsection{Interviewee Factor Scoring}

Interviewee 5 scored only two variables as highly important relative to the transformation of Company E's strategy. The number one ranked variable was flexibility of the intended strategy. As noted above, and from Interviewee 5's perspective, flexibility referred to the way the company structured its financials relative to the strategy's outcome, the general approach taken by Company $E$ in terms of developing technology, and the flexibility Company E consistently tried to build into its strategies. Flexibility is clearly a prominent aspect of Company E's overall approach to strategy.

The second highest ranked variable was feasibility of the intended strategy. In this narrative, one of the primary goals of the company was not feasible, even though it seemed feasible from the perspective of the company at the time the strategy was put together. Although Company E believed that the government intended to sole-source this contract, this was not a realistic option for either DOD or the company. However, because of the flexible approach taken by Company $\mathrm{E}$ to its strategy and implementation, the strategy was able to transform in a way that led to a profitable venture. 


\subsubsection{Factor Coding versus Interviewee Factor Scoring}

As shown in Table 8, the manner in which Interviewee 5 told his story was consistent with the way he ranked the variables relative to their impact on the transformation of Company E's strategy. The highest ranked variable, flexibility of the intended strategy, was also the variable that had the highest frequency of mention in the transcript with a count of 18 .

The variable with the second highest coding count was feasibility of the intended strategy with a count of 7 . Interviewee 5 ranked this variable as the second most important variable relative to the strategy's transformation.

\subsubsection{Interviewee Strategy Transformation Scoring}

Interviewee 5 scored the level of transformation of the strategy in the example as follows:

- Primary goals implemented and achieved as originally planned: $0-25 \%$.

- Secondary goals implemented and achieved as originally planned: $76-100 \%$.

- "The actions that formed the process of implementing the strategy were carried out exactly as planned": Disagree.

The achievement scores for the primary and secondary goals are consistent with the narrative of Interviewee 5's strategy example. Their primary goals revolved around winning a sole-sourced contract from DOD and acting as the prime contractor for the program. These goals were not met and leave Company $\mathrm{E}$ in a position where it may, at some point in the future, opt to submit a competitive bid for the program. A competitive bid process will require considerably more funding from Company $\mathrm{E}$ than would a sole- 
source bid and the company will potentially have to accept lower margins, even if it does win the program, as price may be a key parameter in the evaluation process.

Company E's secondary goals involved developing this technology to create a commercially viable product and marketing it to a number of potential markets. These goals have been realized and the product is now marketed to private sector customers, foreign governments and public / private partnerships. By taking a flexible approach to this strategy and its implementation, Company E allowed the strategy to transform in a positive way for the company.

The path taken by Company $\mathrm{E}$ during the implementation was quite different than envisioned when the strategy was developed. The original plan was to launch the products and services with a single major customer and branch out to other markets by leveraging this initial success. When the launch customer scenario failed to materialize, Company E smoothly changed its strategy to move into its secondary markets sooner than originally planned. Because the R\&D had already been done, the program took on a marketing focus and continued to move forward.

\subsubsection{Process Issues of Interest}

Company $\mathrm{E}$ is predominately a defence contractor and therefore focuses on a single client, DOD. This has a number of effects on the company from its structure to the way it markets its products to the approach it takes to strategy. In terms of structure, the Board of Directors at Company $\mathrm{E}$ is populated by former general officers and undersecretary ranked individuals. This probably contributes to the continued focus of Company E on DOD and may also have other effects on the company which have not been studied. 
The marketing approach taken by defence contractors tends toward a focus on customer intimacy which is facilitated by the small number of primary customers that are involved. The larger defence contractors employ Washington lobby firms to influence DOD toward their agendas. They also tend to employ numerous ex-military personnel to exploit the contacts made over their careers to gain information on upcoming programs or acquisition processes.

A positive benefit of often delayed government procurement programs may be the flexibility that defence contractors develop to survive in this environment. Company E's flexibility allowed its strategy to transform and become successful even though it proceeded in a way that was not previously envisioned.

\subsubsection{Summary}

Company E planned a flexible strategy that allowed the strategy to transform in a positive way despite the unpredictable manner in which the market evolved. As a result, it achieved its financial goals for the strategy, albeit due to revenues from a much greater focus on secondary markets.

Interviewee 5's narrative was related in a manner which resulted in a high level of consistency between the transcript coding and his scoring of the most important variables relative to transformation of the strategy. Interviewee 5 ranked flexibility of the intended strategy as the most important variable and it was also the variable with the highest frequency of mention in the transcript coding. This variable might be considered to have an even higher count, from a conceptual perspective, as the narrative was related in a manner that interwove flexibility with the characteristics of the leadership team that made the flexibility possible. 
Interviewee 5's ranking of feasibility of the intended strategy as the second most important variable was consistent with its position as the variable with the second highest coding count. Other than government regulatory requirements, the other variables were not the focus of significant attention in the narrative. Interviewee 5 did not add any new variables to the literature based model.

\subsection{Qualitative Study Impact on Quantitative Study Survey Instrument}

The interview portion of this research was undertaken to allow the use of openended qualitative methods to facilitate in-depth observation and analyses to gain a better understanding of the phenomenon involved (Lee et al., 1999). In this case, the phenomenon being studied is the transformation of intended strategy that occurs to produce realized strategy. A literature based model was developed based on the strategy formulation and implementation research that has been published to date. This qualitative study was not executed to test the literature based model. Rather, its role was to validate the factors included based on the literature, and to find additional factors and indicators which might be appropriate to add to the model prior to quantitative testing of the model.

As displayed in Table 9, five new variables have been taken from the interviews for addition to the model. Two new variables came from Interview 1, two came from Interview 2 and one came from Interview 3. All of these added variables were mentioned to some extent in interviews that took place after they were first included. 
Table 9 - New Variables versus Interview where Indicator was First Mentioned

\begin{tabular}{|l|c|c|c|c|c|}
\hline New Indicator & \multicolumn{5}{|c|}{ Interview where New Indicators were First Mentioned } \\
\hline & 1 & 2 & 3 & 4 & 5 \\
\hline $\begin{array}{l}\text { Feasibility of } \\
\text { the intended } \\
\text { strategy }\end{array}$ & $\checkmark$ & & & & \\
\hline $\begin{array}{l}\text { Ambitiousness } \\
\text { of the intended } \\
\text { strategy }\end{array}$ & $\checkmark$ & $\checkmark$ & & & \\
\hline $\begin{array}{l}\text { Availability of } \\
\text { Resources }\end{array}$ & & $\checkmark$ & & & \\
\hline $\begin{array}{l}\text { Changes in key } \\
\text { personnel }\end{array}$ & & & & & \\
\hline $\begin{array}{l}\text { Government } \\
\text { regulatory } \\
\text { requirements }\end{array}$ & & & & & \\
\hline
\end{tabular}

Each of the five new variables has been added to the model as seen in Table 10 . Each variable has been listed as an indicator rather than a separate factor because each one seemed to fit with one of the existing factors in the model. Feasibility of the intended strategy and ambitiousness of the intended strategy have been added as indicators for characteristics of the intended strategy. It should be noted that this factor was originally named flexibility of the intended strategy; however, with the addition of the two new indicators, the broader title of characteristics of the intended strategy has been adopted. Availability of resources has been added as an indicator for environmental instability because the interviewees discussed this indicator with respect to the interaction between the company and its external environment. At some points in time, resources are readily available from the external environment while at other times, for various reasons, they are more difficult to obtain. Changes in key personnel has been added as an indicator for leadership team characteristics. In other words, if a key person leaves or a new one is added, it can change the characteristics of the leadership team. Government regulatory 
requirements has been added as an indicator for environmental complexity. While all companies must deal with some form of government regulatory framework, companies in highly regulated industries are forced to deal with an added level of complexity as they face the competitive market. Exploratory factor analysis will be carried out as part of the analysis of the quantitative data, and dependent upon the resultant loadings, the final relationship between factors and their underlying indicators will be decided.

The Appendix E survey instrument has been modified based on the results of the interviews. As such, each of the five new indicators is represented by a new item in the quantitative survey instrument. Table 10 displays the factors and indicators of the $a$ priori model that were tested using the Appendix E survey instrument.

\section{Table 10 - Revised Factors, Indicators and Sources Based on Interview Results}

Note: The Factor 8 wording change and the new indicators are in bold.

\begin{tabular}{|c|c|c|}
\hline Factors & Indicators & Source \\
\hline $\begin{array}{l}\text { Environmental instability } \\
\text { - External. }\end{array}$ & $\begin{array}{l}\text { Volatility of sales growth. } \\
\text { Instability of the environment in which the firm operates. } \\
\text { Unpredictability of the environment in which a firm } \\
\text { operates. } \\
\text { Unavailability of resources. }\end{array}$ & $\begin{array}{l}\text { Harrington et al., } \\
2004 \\
\text { Jennings and } \\
\text { Disney, } 2006 \\
\text { Grant, 2003; } \\
\text { Parnell and Lester, } \\
2003 \\
\text { Interview } 2\end{array}$ \\
\hline $\begin{array}{l}\text { Competitors' actions - } \\
\text { External. }\end{array}$ & $\begin{array}{l}\text { Competitiveness of the environment. } \\
\text { Rate of response of the firm's competitors to changing } \\
\text { market conditions. } \\
\text { Rate of new product introduction by the firm's } \\
\text { competitors. }\end{array}$ & $\begin{array}{l}\text { Blythe and } \\
\text { Zimmerman, } 2004 \\
\text { Blythe and } \\
\text { Zimmerman, } 2004 \\
\text { Kukalis, } 1991\end{array}$ \\
\hline $\begin{array}{l}\text { Changes in customer } \\
\text { requirements - External. }\end{array}$ & $\begin{array}{l}\text { Rate of change of customer needs. } \\
\text { Speed of change in demand trends. } \\
\text { Customer demand for innovation in the firm's market. }\end{array}$ & $\begin{array}{l}\text { Depperu and } \\
\text { Gnan, } 2006 \\
\text { Depperu and } \\
\text { Gnan, } 2006 \\
\text { Kukalis, } 1991\end{array}$ \\
\hline
\end{tabular}




\begin{tabular}{|c|c|c|}
\hline Factors & Indicators & Source \\
\hline $\begin{array}{l}\text { Environmental } \\
\text { complexity- External. }\end{array}$ & $\begin{array}{l}\text { Complexity of the operating environment of the firm. } \\
\text { Complexity of the firm's relationship with its } \\
\text { distributors, customers and suppliers. } \\
\text { Diversity in the customers and markets served by the } \\
\text { firm. } \\
\text { Government regulatory requirements. }\end{array}$ & $\begin{array}{l}\text { Kukalis, } 1991 \\
\text { Kukalis, } 1991 \\
\text { Kukalis, } 1991 \\
\text { Interview } 3\end{array}$ \\
\hline $\begin{array}{l}\text { Leadership team } \\
\text { characteristics - Internal. }\end{array}$ & $\begin{array}{l}\text { Managers' use of previously acquired experiential } \\
\text { knowledge during strategy implementation. } \\
\text { Managers sharing a detailed and consistent understanding } \\
\text { of the business. } \\
\text { Tendency towards opportunity taking by the firm. } \\
\text { Leadership team support of the strategy. } \\
\text { Changes in key personnel. }\end{array}$ & $\begin{array}{l}\text { Daake, Dawley, \& } \\
\text { Anthony, 2004 } \\
\text { Beinhocker \& } \\
\text { Kaplan, 2002 } \\
\text { Depperu \& Gnan, } \\
\text { 2006; Mintzberg, } \\
1977 \\
\text { Kaplan and } \\
\text { Beinhocker, 2003 } \\
\text { Interview 2 }\end{array}$ \\
\hline $\begin{array}{l}\text { Employee involvement - } \\
\text { Internal. }\end{array}$ & $\begin{array}{l}\text { Authority of lower level managers to make decisions and } \\
\text { take initiative in response to the changing environment. } \\
\text { Resistance to change in the organization. } \\
\text { Tendency of individuals in an organization to pursue the } \\
\text { objectives or goals of their position or group instead of } \\
\text { the stated goals of the whole organization. } \\
\text { Participation of low and mid-level managers in the } \\
\text { strategic planning process. } \\
\text { Communication by the firm of its strategic goals and } \\
\text { priorities to the whole firm. }\end{array}$ & $\begin{array}{l}\text { Andersen, } 2004 \\
\text { Boyd \& Reuning- } \\
\text { Elliott, } 1998 \\
\text { Ketokivi \& } \\
\text { Castañer, 2004 } \\
\text { Ketokivi \& } \\
\text { Castañer, } 2004 \\
\text { Ketokivi \& } \\
\text { Castañer, } 2004\end{array}$ \\
\hline $\begin{array}{l}\text { Organization learning } \\
\text { ability - Internal. }\end{array}$ & $\begin{array}{l}\text { Ability of senior managers to quickly develop and share } \\
\text { new perspectives. } \\
\text { Senior management flexibility. } \\
\text { Tendency for the firm to develop contingency plans for } \\
\text { alternate possible futures. }\end{array}$ & $\begin{array}{l}\text { Schaffer and } \\
\text { Willauer, } 2003 \\
\text { Schaffer and } \\
\text { Willauer, } 2003 \\
\text { De Geus, 1988; } \\
\text { Schoemaker, } 1995\end{array}$ \\
\hline
\end{tabular}




\begin{tabular}{|l|l|l|}
\hline $\begin{array}{l}\text { Characteristics of the } \\
\text { intended strategy - } \\
\text { Internal. }\end{array}$ & $\begin{array}{l}\text { Flexibility inherent in the planned strategy } \\
\text { Rigidity of the planned strategy. }\end{array}$ & $\begin{array}{l}\text { Grant, 2003 } \\
\text { Miller and } \\
\text { Cardinal, 1994; } \\
\text { Rudd et al., 2008 } \\
\end{array}$ \\
& $\begin{array}{l}\text { Feasibility of the planned strategy. } \\
\text { Interview 1 } \\
\text { Ambitiousness of the planned strategy. }\end{array}$ & Interview 1 \\
\hline
\end{tabular}

\subsection{Qualitative Study Interview Summary}

The transcript coding results from the five interviews are summarized in Table 11. The counts for each variable are listed in the columns under the interview number and summed in the total column. The scores are ranked in the column on the right based on the total number of mentions across the interviews, with the highest number of mentions receiving the highest ranking. It should be noted that three of the variables were not added until after Interview 1, and one variable was not added until Interview 3. Because the added variables from the interviews are indicators, the Table 11, 12 and 13 counts refer to both factors and indicators. While this approach would not be used for a statistically valid calculation, it is used here simply to illustrate the subjective relative importance given to the variables by the interviewees. As the five added indicators were not counted until after they were first referred to in an interview, this could generate a perception that these variables might not have had the same chance of being mentioned across all interviews as the other variables. However, if the three variables discovered in Interviews 2 and 3 had been pertinent to prior interviews, then they would have been discovered and the mentions counted in prior interviews. Thus, all variables had the same opportunity to be mentioned and counted in all interviews. 
Table 11 - Summary of Interview Results - Factor and Indicator Frequency Counts and Frequency Based Ranking from Interview Transcripts

\begin{tabular}{|c|c|c|c|c|c|c|c|}
\hline \multirow[t]{2}{*}{$\begin{array}{l}\text { Factors / } \\
\text { Indicators }\end{array}$} & \multicolumn{7}{|c|}{$\begin{array}{l}\text { Transcript Coding (number of times factor or indicator referred } \\
\text { to in transcript) for each Interview, Total and Numeric Rank }\end{array}$} \\
\hline & 1 & 2 & 3 & 4 & 5 & Total & Rank \\
\hline $\begin{array}{l}\text { Flexibility of the } \\
\text { intended } \\
\text { strategy }\end{array}$ & 5 & 4 & 3 & 8 & 18 & 38 & $1^{\text {st }}$ \\
\hline $\begin{array}{l}\text { Organizational } \\
\text { learning ability }\end{array}$ & 5 & 19 & 2 & 9 & 2 & 37 & $2^{\text {nd }}$ \\
\hline $\begin{array}{l}\text { Environmental } \\
\text { instability }\end{array}$ & 5 & 6 & 3 & 10 & 2 & 26 & $3^{\text {rd }}$ \\
\hline $\begin{array}{l}\text { Leadership team } \\
\text { characteristics }\end{array}$ & 5 & 6 & 3 & 2 & 6 & 22 & $4^{\text {th }}$ \\
\hline $\begin{array}{l}\text { Environmental } \\
\text { complexity }\end{array}$ & 0 & 13 & 2 & 3 & 0 & 18 & $\mathrm{~T}-5^{\text {th }}$ \\
\hline $\begin{array}{l}\text { Feasibility of the } \\
\text { intended } \\
\text { strategy* }\end{array}$ & 8 & 3 & 0 & 0 & 7 & 18 & $\mathrm{~T}-5^{\text {th }}$ \\
\hline $\begin{array}{l}\text { Changes in } \\
\text { customer } \\
\text { requirements }\end{array}$ & 5 & 0 & 7 & 0 & 3 & 15 & $6^{\text {th }}$ \\
\hline $\begin{array}{l}\text { Availability of } \\
\text { Resources* }\end{array}$ & 0 & 6 & 0 & 5 & 0 & 11 & $7^{\text {th }}$ \\
\hline $\begin{array}{l}\text { Competitors' } \\
\text { actions }\end{array}$ & 1 & 0 & 0 & 9 & 0 & 10 & $T-8^{t h}$ \\
\hline $\begin{array}{l}\text { Government } \\
\text { regulatory } \\
\text { requirements* }\end{array}$ & 0 & 0 & 5 & 1 & 4 & 10 & $T-8^{t h}$ \\
\hline $\begin{array}{l}\text { Changes in key } \\
\text { personnel* }\end{array}$ & 0 & 5 & 1 & 3 & 0 & 9 & $9^{\text {th }}$ \\
\hline $\begin{array}{l}\text { Employee } \\
\text { involvement }\end{array}$ & 3 & 0 & 2 & 1 & 0 & 6 & $10^{\text {th }}$ \\
\hline $\begin{array}{l}\text { Ambitiousness } \\
\text { of the intended } \\
\text { strategy* }\end{array}$ & 2 & 0 & 0 & 2 & 0 & 4 & $11^{\text {th }}$ \\
\hline
\end{tabular}

* New indicator from the interviews.

Table 11 demonstrates that all of the literature based factors were validated in the interviews. The highest ranked variable is flexibility of the intended strategy with a combined count of 38 . This aligns with the five narratives in that flexibility played a role 
in each one. Sometimes the role was negative when flexibility was not present and strategies were not allowed to transform to align with external circumstances. Sometimes the role was positive in the manner it allowed strategies to evolve toward desired results. In the case of Company $A$ and its billion dollar R\&D effort, a lack of flexibility prevented the company from adjusting to a very unstable environment. While such an adjustment might not have salvaged the strategy, it may have limited the damage.

The second highest ranked variable was organizational learning ability with a combined frequency of 37 . These two highest ranked variables have much higher counts than any of the other variables with the next highest having 11 fewer mentions. During interviews 2 through 4, flexibility and organizational learning were often spoken of in terms of how they leveraged one another. For example, in the case of Company B, the flexible approach taken to its Company b strategy and Company B's ability to learn quickly, allowed the strategy to transform in a manner that led to considerable financial success.

The fourth ranked variable is leadership team characteristics with a combined count of 22. This variable was also spoken of in the interviews in terms of its relationship to flexibility. Interviewee 5 attributed the inherent flexibility with which Company E approached strategy to characteristics of Company E's leadership team. These three variables ranked as first, second and fourth (i.e. flexibility, organizational learning and leadership team characteristics) are all internal variables.

The third highest ranked variable in terms of mentions in the transcripts is environmental instability with a combined count of 26 . One of the variables tied for a ranking of fifth is environmental complexity, an external variable, with a combined count 
of 18. These two external variables in the third and fifth positions may represent some of the forces which require actions and reactions related to the internal variables of flexibility and learning, fostered by leadership team characteristics, which make these actions and reactions either positive or negative.

Feasibility of the intended strategy is the other variable tied for fifth with a combined count of 18 . The sixth highest ranked variable is changes in customer requirements with a combined count of 15 . Feasibility of the intended strategy is an internal variable while changes in customer requirements is external. Therefore, in the top six rankings, noting that there are two variables tied for fifth, there are three external variables and four internal variables. After the sixth ranked variable, the number of mentions falls off quickly.

Table 12 uses the ranking of variables by the interviewees found in Tables $4-8$ and assigns a numerical value to allow the rankings to be summed across the interviews and an overall ranking to be attained. Because the highest number of variables scored as their most important, and therefore ranked, by any one interviewee was six (Interviewee 1), the points have been assigned as one through six. A ranking of sixth will net a variable a score of one, a ranking of fifth will net a variable a score of two, and so on, with a first ranking netting the variable a score of six. The scores are totalled in the second column from the right in Table 12 and the scores are ranked in the far right column.

The top two ranked variables are internal, these being flexibility of the intended strategy and feasibility of the intended strategy respectively. These are followed by an external variable, changes in customer requirements at third and another external 
variable, environmental instability tied for fourth. The other variable tied for fourth and the fifth variable are both internal, organizational learning ability and leadership team characteristics respectively.

Table 12 - Summary of Interview Results - Ranking of the Most Important Factors or Indicators from the Interviewee's Ranking on the Contextual Factor Scoring Sheets

\begin{tabular}{|c|c|c|c|c|c|c|c|}
\hline & \multicolumn{7}{|c|}{$\begin{array}{c}\text { Interviewees' Ranking of Most Important Factors or Indicators } \\
\text { (Scored as } 1^{\text {st }}=6 \text { points, } 2^{\text {nd }}=5 \text { points, } \ldots 6^{\text {th }}=1 \text { point) and Numeric } \\
\text { Rank }\end{array}$} \\
\hline & 1 & 2 & 3 & 4 & 5 & Score & Rank \\
\hline $\begin{array}{l}\text { Flexibility of the } \\
\text { intended } \\
\text { strategy }\end{array}$ & $2^{\text {nd }}$ & & $2^{\text {nd }}$ & $1^{\mathrm{st}}$ & $1^{\text {st }}$ & 22 & $1^{\text {st }}$ \\
\hline $\begin{array}{l}\text { Feasibility of } \\
\text { the intended } \\
\text { strategy } *\end{array}$ & $1^{\text {st }}$ & $4^{\text {th }}$ & & & $2^{\text {nd }}$ & 14 & $2^{\text {nd }}$ \\
\hline $\begin{array}{l}\text { Changes in } \\
\text { customer } \\
\text { requirements }\end{array}$ & $3^{\text {rd }}$ & & $1^{\text {st }}$ & & & 10 & $3^{\text {rd }}$ \\
\hline $\begin{array}{l}\text { Environmental } \\
\text { instability }\end{array}$ & $4^{\text {th }}$ & $3^{\text {rd }}$ & & & & 7 & $T-4^{\text {th }}$ \\
\hline $\begin{array}{l}\text { Organizational } \\
\text { learning ability }\end{array}$ & $6^{\text {th }}$ & $1^{\text {st }}$ & & & & 7 & $\mathrm{~T}-4^{\text {th }}$ \\
\hline $\begin{array}{l}\text { Leadership team } \\
\text { characteristics }\end{array}$ & $5^{\text {th }}$ & & $3^{\text {rd }}$ & & & 6 & $5^{\text {th }}$ \\
\hline $\begin{array}{l}\text { Competitors' } \\
\text { actions }\end{array}$ & & & & $2^{\text {nd }}$ & & 5 & $T-6^{\text {th }}$ \\
\hline $\begin{array}{l}\text { Environmental } \\
\text { complexity }\end{array}$ & & $2^{\text {nd }}$ & & & & 5 & $T-6^{\text {th }}$ \\
\hline $\begin{array}{l}\text { Availability of } \\
\text { Resources * }\end{array}$ & & $5^{\text {th }}$ & & & & 2 & $7^{\text {th }}$ \\
\hline $\begin{array}{l}\text { Ambitiousness } \\
\text { of the intended } \\
\text { strategy } *\end{array}$ & & & & & & & \\
\hline $\begin{array}{l}\text { Changes in key } \\
\text { personnel * }\end{array}$ & & & & & & & \\
\hline $\begin{array}{l}\text { Employee } \\
\text { involvement }\end{array}$ & & & & & & & \\
\hline $\begin{array}{l}\text { Government } \\
\text { regulatory } \\
\text { requirements * }\end{array}$ & & & & & & & \\
\hline
\end{tabular}

* New indicator from the interviews. 
Table 13 is a side-by-side comparison of the transcript coding ranking from Table 11 and the Table 12 ranking of the interviewees' most important variables. The Table 11 and Table 12 rankings are a summation of the scores from across all five interviews. From both the transcript coding and the interviewees' ranking, flexibility of the intended strategy is the most important variable relative to its impact on the transformation of strategy. This is not surprising given the prominence of this variable in all five strategy narratives, from either a positive or negative perspective. It also shows a strong level of consistency between the way the interviewees told their stories and the way they judged the variable's relative importance from the list of all the factors and indicators. However, as noted in the individual interview write-ups, the interviewees spoke of flexibility from a holistic perspective. They spoke of flexibility of the leadership team, flexibility being built into the strategies, flexibility resulting from the organizations' learning abilities and flexibility being applied during the implementations. It may be that the appropriate application of internal flexibility in reaction to external environmental stimuli has a significant impact on the success or failure of a realized strategy.

The five highest rankings in each of the Table 13 lists include seven discreet variables due to ties. Five of the variables appear in both lists showing a high level of consistency between the transcripts and the interviewees' ranking of the variables. The two variables which only appear in one list are changes in customer requirements which is ranked sixth in the transcript coding and environmental complexity which is tied for sixth in the interviewees' ranking. After flexibility, the remaining four variables which appear in both top five rankings are: organizational learning ability; feasibility of the intended strategy; environmental instability; and leadership team characteristics. 
Table 13 - Summary of Interview Results - Transcript Coding Versus Interviewees' Importance Ranking for Factors and Indicators

\begin{tabular}{|c|c|c|c|c|}
\hline \multirow[t]{2}{*}{$\begin{array}{l}\text { Factors / } \\
\text { Indicators }\end{array}$} & \multicolumn{2}{|c|}{$\begin{array}{l}\text { Transcript Coding (number } \\
\text { of times factor or indicator } \\
\text { referred to in transcripts) } \\
\text { for all Interviews and } \\
\text { Numeric Rank } \\
\end{array}$} & \multicolumn{2}{|c|}{$\begin{array}{c}\text { Interviewees' Ranking of Most } \\
\text { Important Factors or Indicators } \\
\text { (Scored as } 1^{\text {st }}=6 \text { points, } 2^{\text {nd }}=5 \\
\text { points, } \ldots 6^{\text {th }}=1 \text { point) and } \\
\text { Numeric Rank }\end{array}$} \\
\hline & Total & Rank & Total & Rank \\
\hline $\begin{array}{l}\text { Flexibility of } \\
\text { the intended } \\
\text { strategy }\end{array}$ & 38 & $1^{\text {st }}$ & 22 & $1^{\text {st }}$ \\
\hline $\begin{array}{l}\text { Organizational } \\
\text { learning ability }\end{array}$ & 37 & $2^{\text {nd }}$ & 7 & $\mathrm{~T}-4^{\text {th }}$ \\
\hline $\begin{array}{l}\text { Environmental } \\
\text { instability }\end{array}$ & 26 & $3^{\mathrm{rd}}$ & 7 & $\mathrm{~T}-4^{\text {th }}$ \\
\hline $\begin{array}{l}\text { Leadership } \\
\text { team } \\
\text { characteristics }\end{array}$ & 22 & $4^{\text {th }}$ & 6 & $5^{\text {th }}$ \\
\hline $\begin{array}{l}\text { Feasibility of } \\
\text { the intended } \\
\text { strategy* }\end{array}$ & 18 & $\mathrm{~T}-5^{\text {th }}$ & 14 & $2^{\text {nd }}$ \\
\hline $\begin{array}{l}\text { Environmental } \\
\text { complexity }\end{array}$ & 18 & $\mathrm{~T}-5^{\text {th }}$ & 5 & $T-6^{\text {th }}$ \\
\hline $\begin{array}{l}\text { Changes in } \\
\text { customer } \\
\text { requirements }\end{array}$ & 15 & $6^{\text {th }}$ & 10 & $3^{\text {rd }}$ \\
\hline $\begin{array}{l}\text { Availability of } \\
\text { Resources * }\end{array}$ & 11 & $7^{\text {th }}$ & 2 & $7^{\text {th }}$ \\
\hline $\begin{array}{l}\text { Competitors' } \\
\text { actions }\end{array}$ & 10 & $\mathrm{~T}-8^{\text {th }}$ & 5 & $\mathrm{~T}-6^{\text {th }}$ \\
\hline $\begin{array}{l}\text { Government } \\
\text { regulatory } \\
\text { requirements * }\end{array}$ & 10 & $T-8^{\text {th }}$ & & \\
\hline $\begin{array}{l}\text { Changes in key } \\
\text { personnel * }\end{array}$ & 9 & $9^{\text {th }}$ & & \\
\hline $\begin{array}{l}\text { Employee } \\
\text { involvement }\end{array}$ & 6 & $10^{\text {th }}$ & & \\
\hline $\begin{array}{l}\text { Ambitiousness } \\
\text { of the intended } \\
\text { strategy * }\end{array}$ & 4 & $11^{\text {th }}$ & & \\
\hline
\end{tabular}

* New indicator from the interviews. 
The four internal variables which appear in the top five rankings are all in both Table 13 lists. These variables are flexibility of the intended strategy, feasibility of the intended strategy, organizational learning ability and leadership team characteristics. Using either method of calculating the rankings, and based on this small sample of interviews, these variables appear to be the most important internal variables relative to the transformation of strategy. From an external variable perspective, only environmental instability appears in the top five rankings in both lists. Changes in customer requirements is in only the interviewee ranking list and environmental complexity is in only the transcript coding list. While not quantified, the interaction between the variables was clear from the interviews. The external variables caused reactions inside the companies which were influenced by the internal variables. This complex interaction is exemplified by the evolution of feasibility of the intended strategy that can occur during implementation. A strategy might be quite feasible when first planned but may become unfeasible due to shifts in an unstable environment at some point during an implementation. In addition, there seemed to be interplay between the internal variables such as how leadership team characteristics affect organizational learning abilities. This was also apparent in the external context such as how environmental instability affected changes in customer requirements. The relationships among the variables becomes clearer through the analytical analysis of the survey data during the quantitative phase of this research.

As noted above, it seems to be the evolving relationship between the internal and external variables during the implementation that results in the transformation of strategy in these interview narratives. While the sample is small, the results do seem to point to 
the importance of leadership teams building flexibility into their strategies, culture and implementations. Further, the importance of leaders fostering a culture of organizational learning also seems to be highlighted, as does the importance of having a feasible intended strategy. One of the themes that emerges from this small sample qualitative study is that while almost all strategies transform, flexibility in the internal environment may have an important impact on whether the transformation leads to a positive or negative result.

Modern business environments all seem to be both complex and unstable to some degree and these variables can often lead to changes in the requirements of customers. If this is a reasonable assumption, then leadership teams will consistently have to cope with the variability of these external variables. If these interview narratives are any indication, it may be prudent for more business leadership teams to pursue flexibility and organizational learning ability as key cultural goals for their organizations. In businesses where these are not key goals, it may be an issue of limited cognitive schema on the part of existing leadership or an overly rigid internal organizational culture. It simply may not occur to all leaders that this level of flexibility is preferable to the dogged following of intended strategies.

As noted in Table 9, five new variables resulted from the first three interviews while no new variables were encountered in interviews four and five. Eisenhardt (1989) recommends a base of four interviews and carrying out additional interviews until the data begins to repeat, indicating that saturation has been reached. In this case, no new variables became available in Interview 4; however, a fifth interview was carried out to be sure that data saturation had been reached. As there were also no new factors or 
indicators in Interview 5, it was concluded that five interviews were sufficient for this segment of the study. 


\subsection{RESULTS - QUANTITATIVE STUDY SURVEY}

\subsection{Pre-Test}

A survey pre-test was conducted using five participants. Each received an email as would a respondent to the live survey. Each pre-test participant was asked to provide comments on the relevance, clarity and adequacy of the covering email and the survey preamble, as well as the clarity of the survey questions. They were also asked to comment on the ease of use and any technical issues with the web site hosting the survey. Finally, the pre-test respondents were asked to provide any other comments they would like to make, especially with respect to anything they found confusing or irritating, or something that might cause a subject to not respond to the survey. As a check on the effectiveness of the changes, modifications were made prior to Respondent 5's review. This provided a check on the final version of the survey and gave the researcher confidence as to how the survey would be perceived by respondents to the actual survey.

The observations and responses are listed in Table 14.

Table 14 - Survey Pre-Test Observations and Corrections

\begin{tabular}{|c|c|c|}
\hline Pre-test Respondent & Observation & Response \\
\hline Respondent 1 - S.R. & $\begin{array}{l}\text { Repetition in survey } \\
\text { preamble from covering } \\
\text { email. } \\
\text { - Wording of question } 34 \\
\text { confusing. } \\
\text { - Suggestion for wording } \\
\text { of question } 42 \text {. }\end{array}$ & $\begin{array}{l}\text { - Repetition removed } \\
\text { - Wording modified / } \\
\text { clarified. } \\
\text { - Wording modified. }\end{array}$ \\
\hline
\end{tabular}




\begin{tabular}{|c|c|c|}
\hline Pre-test Respondent & Observation & Response \\
\hline Respondent 2 - C.J. & $\begin{array}{l}\text { - Repetition in survey } \\
\text { preamble from covering } \\
\text { email. } \\
\text { - Wording of question } 34 \\
\text { confusing. } \\
\text { - Concern about } \\
\text { attribution of names or } \\
\text { email addresses to } \\
\text { respondents. } \\
\text { - Requested addition of } \\
\text { 'Logistics' in industry } \\
\text { list. } \\
\end{array}$ & $\begin{array}{l}\text { - Same as for respondent } \\
1 . \\
\text { - Same as for respondent } \\
1 . \\
\text { - Concern addressed in } \\
\text { covering email. } \\
\text { - 'Logistics' added to } \\
\text { industry list. } \\
\end{array}$ \\
\hline Respondent $3-$ S.H. & $\begin{array}{l}\text { Repetition in survey } \\
\text { preamble from covering } \\
\text { email. } \\
\text { - This respondent did not } \\
\text { understand how to } \\
\text { correctly complete } \\
\text { questions 1-31. } \\
\text { - Email address for } \\
\text { summary results requests } \\
\text { should be hyperlinked. } \\
\text { - Covering email too } \\
\text { lengthy because it } \\
\text { contains unnecessary } \\
\text { information (e.g. } \\
\text { reference to ethics } \\
\text { committee). } \\
\text { - Comment box too small. } \\
\text { - Requested addition of } \\
\text { 'Engineering' in industry } \\
\text { list. }\end{array}$ & $\begin{array}{l}\text { - Same as for respondent } \\
1 . \\
\text { - A paragraph was added } \\
\text { to the header of the } \\
\text { survey with explicit } \\
\text { instructions for questions } \\
1-31 . \\
\text { - Hyperlink added. } \\
\text { - No change made. } \\
\text { Information in the } \\
\text { covering email is the } \\
\text { minimum required by } \\
\text { Carleton University } \\
\text { guidelines. } \\
\text { - Comment box enlarged. } \\
\text { 'Engineering' added to } \\
\text { industry list. }\end{array}$ \\
\hline
\end{tabular}




\begin{tabular}{|c|c|c|}
\hline Pre-test Respondent & Observation & Response \\
\hline Respondent 4 - I.M. & $\begin{array}{l}\text { - Respondent missed the } \\
\text { summary results request } \\
\text { instructions at the end of } \\
\text { the survey. } \\
\text { - Survey link in covering } \\
\text { email did not operate. } \\
\text { - Email address for } \\
\text { summary results requests } \\
\text { should be hyperlinked. } \\
\text { - Survey takes only } 10 \\
\text { minutes versus } 15 \\
\text { minutes mentioned in } \\
\text { covering email. }\end{array}$ & $\begin{array}{l}\text { - Instructions' font size } \\
\text { enlarged. } \\
\text { - Survey link repaired. } \\
\text { - Same as for respondent } \\
\text { 3. } \\
\text { - Covering email changed } \\
\text { to read '10 minutes' after } \\
\text { consultation with the } \\
\text { other pre-test } \\
\text { respondents. }\end{array}$ \\
\hline $\begin{array}{l}\text { Respondent } 5-\text { J.F. } \\
\text { (changes from Respondents } \\
1 \text { through } 4 \text { were made } \\
\text { prior to Respondent } 5 \text { 's } \\
\text { review) }\end{array}$ & $\begin{array}{l}\text { Respondent suggested no } \\
\text { changes. } \\
\text { Without prompting, the } \\
\text { respondent commented } \\
\text { very favourably about } \\
\text { the instructional } \\
\text { paragraph added as a } \\
\text { consequence of } \\
\text { respondent } 3 \text {. }\end{array}$ & $\begin{array}{l}\text { - No changes made. } \\
\text { - No change made. }\end{array}$ \\
\hline
\end{tabular}

\subsection{Survey Release and Response Rate}

The survey was released on 22 January 2010 and remained active on the web host for 50 days. The initial intent was to keep the survey active for 30 days but just prior to the planned closure date, two issues arose. First, an opportunity presented itself on day 26 for the survey to be sent to a number of South American business people by a visiting professor at Carleton University whose permanent home is in Brazil. In addition, one of the first tier social network respondents had been away from work for personal reasons and indicated on day 28 that he had just sent the survey on to 15 people in his network. 
In both these cases, the recipients needed time to respond; therefore, the survey response window was extended by 20 days.

The responses per day over the 50 days are detailed in Appendix F. Approximately $73 \%$ of the responses were received in the first 15 days, with responses over the remaining 35 days being zero, one or two per day. Due to a slowing of the response receipts starting on day 9 , a reminder was sent out to the first tier social and professional networks. This resulted in 23 responses being received between days 13 and 14. It is interesting to note that although, presumably, most of the first tier social and professional network recipients intended to respond to the survey, many of them still needed to be prompted before they took the action necessary to respond.

Due to the nature of snowball sampling, there was no way for the researcher to know exactly how many potential recipients received the survey email from colleagues in various first tier social and professional networks. However, approximations can be estimated based on unsolicited communications received by the researcher from various recipients and the emails sent by respondents requesting the offered summary of the study's results. Table 15 summarizes the response rate data estimates based upon various communications received by the researcher. The exception is the first tier social network response rate which is an accurate figure as the researcher received confirmation from all recipients in that first tier network. This response rate was an expected $100 \%$ as the researcher has a personal relationship with each recipient. 
Table 15 - Survey Response Rate

\begin{tabular}{|l|c|c|c|}
\hline Data Source & Recipients & Responses & $\begin{array}{c}\text { Response } \\
\text { Rate }\end{array}$ \\
\hline First Tier & 26 & 26 & $100 \%$ \\
\hline $\begin{array}{l}\text { Researcher } \\
\text { Social Network }\end{array}$ & 78 & 49 & $63 \%$ \\
\hline $\begin{array}{l}\text { Various } \\
\text { Professional } \\
\text { Networks }\end{array}$ & 37 & 6 & $16 \%$ \\
\hline \multicolumn{1}{|c|}{ Random } & $\mathbf{1 4 1}$ & $\mathbf{8 1}$ & $\mathbf{5 7 \%}$ \\
\hline First Tier Totals & $\mathbf{1 0 4}$ & $\mathbf{7 5}$ & $\mathbf{7 2 \%}$ \\
\hline $\begin{array}{l}\text { First Tier Without } \\
\text { Random Sample }\end{array}$ & $\mathbf{1 1 7}$ & $\mathbf{8 0}$ & $\mathbf{6 8 \%}$ \\
\hline & & $\mathbf{1 6 1}$ & $\mathbf{6 2 \%}$ \\
\hline Second Tier & $\mathbf{2 5 8}$ & & \\
\hline & & & \\
\hline Total & & & \\
\hline
\end{tabular}

The first tier professional network response rate was approximately $63 \%$ with about 49 responses received from the 78 recipients. This rate is between the $50 \%$ and $70 \%$ estimated in Table 1 for the various first tier professional networks.

The first tier random data source in Table 15 refers to a small random sample initiated due to the slowing of the response receipts starting on day 9. These recipients were randomly chosen from the list of member companies on the OCRI (Ottawa Centre for Research and Innovation) website. The only selection criterion was the provision of an email address for a company executive on the company's website. The response rate for these 37 survey invitations was predictably low at $16 \%$ or six responses.

The second tier response rate of approximately $68 \%$ is higher than the Table 1 second tier estimated rates of $20 \%$ to $60 \%$. This is probably due to the nature of the relationships that exist between the first tier respondents and the recipients to whom they forwarded the survey invitations. Based on conversations held between the researcher 
and various first tier respondents, the first tier respondents tended to send the survey only to individuals with whom they had a close relationship. Therefore, the response rate was higher than anticipated.

The overall estimated response rate of $62 \%$ can be considered to be extremely high given the senior manager and executive target group for the survey (Cycyota \& Harrison, 2006). This is a function of the snowball sampling technique (Michael, 2006; Welch, 1975) and the impact of the social and professional relationships that exist between the researcher and the first tier respondents, and between the first tier and second tier respondents (Cycyota \& Harrison, 2006). Given the high executive response rate in this study, researchers may want to consider the snowball sampling technique in future studies where executives are the target respondents.

\subsection{Data Preparation}

The 161 responses contained a number with missing data. To maintain the integrity of the sample, it was decided to delete any response that had more than one missing data point. As such, the following seven responses were deleted due to missing data: numbers $21,25,64,71,106,119$ and 154 . Response number 24 was also deleted as the respondent answered all 31 model-related independent variable questions with the same answer. Further, the comments provided by the respondent indicated a lack of understanding as to what the questions were actually asking.

With respect to the 34 model-related questions, there were six respondents who missed one question each; these were respondents' number 20, 54, 56, 96, 117 and 139. Questions 20, 24, 27 and 28 had one empty cell each while question 22 had two empty cells. In each of these cases, the response was retained but a value was put into the cell 
equal to the arithmetic average of the other 152 answers (151 answers in the case of question 22) for that question (Stevens, 2002). This arithmetic average was rounded to the nearest whole number to facilitate recoding the data for SPSS analysis (discussed below). Filling the six empty cells in this way changed the averages for the five questions by small amounts which ranged from 0.0003 to 0.0014 , on response averages of 3.954 to 4.895 respectively. In percentage terms, the change range was from $0.008 \%$ to $0.03 \%$. This involved only five questions and the small changes in the averages for each question were considered acceptable.

Question 41 asked the respondent to input the number of years s/he had worked in the industry used in his/her example. Four respondents answered with either a "+" sign or the word "plus" after the number of years (i.e. $20+$ or 15 plus). These additions were removed to leave just the number to allow arithmetic calculations to proceed.

Respondent 79 did not complete question 40 as to whether the company was publicly or privately owned. As the company's revenue was over $\$ 10$ billion annually, it was assumed that the company was public.

Respondent 114 did not complete question 37 which asked in which country the company's headquarters was located. Because the respondent was the CEO and the company's annual revenue was less than $\$ 10$ million, it was assumed that the headquarters was in the same country as the respondent's position (question 38), that being Canada. After all of these changes, there were 153 usable responses.

Prior to SPSS analysis, the model-related data was re-coded so that in each case, a higher number on the applicable Likert-type scale indicated a higher degree of transformation. This was done to allow the question averages to be more intuitively 
interpretable. Therefore, for questions $1-31$, the independent variable related questions, the numbers one through seven were reversed (i.e. one becomes seven, two becomes six etc.). For questions 32 and 33, dependent variable related questions, the numbers one through four were reversed. Question 34 was already in the required configuration.

\subsection{Sample Characteristics}

Survey questions 35 through 41 asked for descriptive information relative to the respondent, company and industry used in the respondent's strategy implementation example. The results defined a sample that spanned the senior manager and executive ranks through publicly and privately owned companies over five continents and at least 26 industries. 
Figure 5 displays the position titles of the respondents including senior managers, the various executive levels, and consultants. A small number of consultants who had direct experience working with executive teams on strategy formulation and implementation completed the survey. This was considered acceptable in that they were acting as de facto executive team members during these assignments. The largest group of respondents were vice presidents at 34 or $22.2 \%$ of the 153 total usable responses. The group of executive respondents who were fully responsible for the companies or divisions who were implementing the strategies numbered 50 or $32.7 \%$ of all respondents. This group included general managers, presidents, CEOs and company owners.

\section{Figure 5 - Position Title of Respondents}

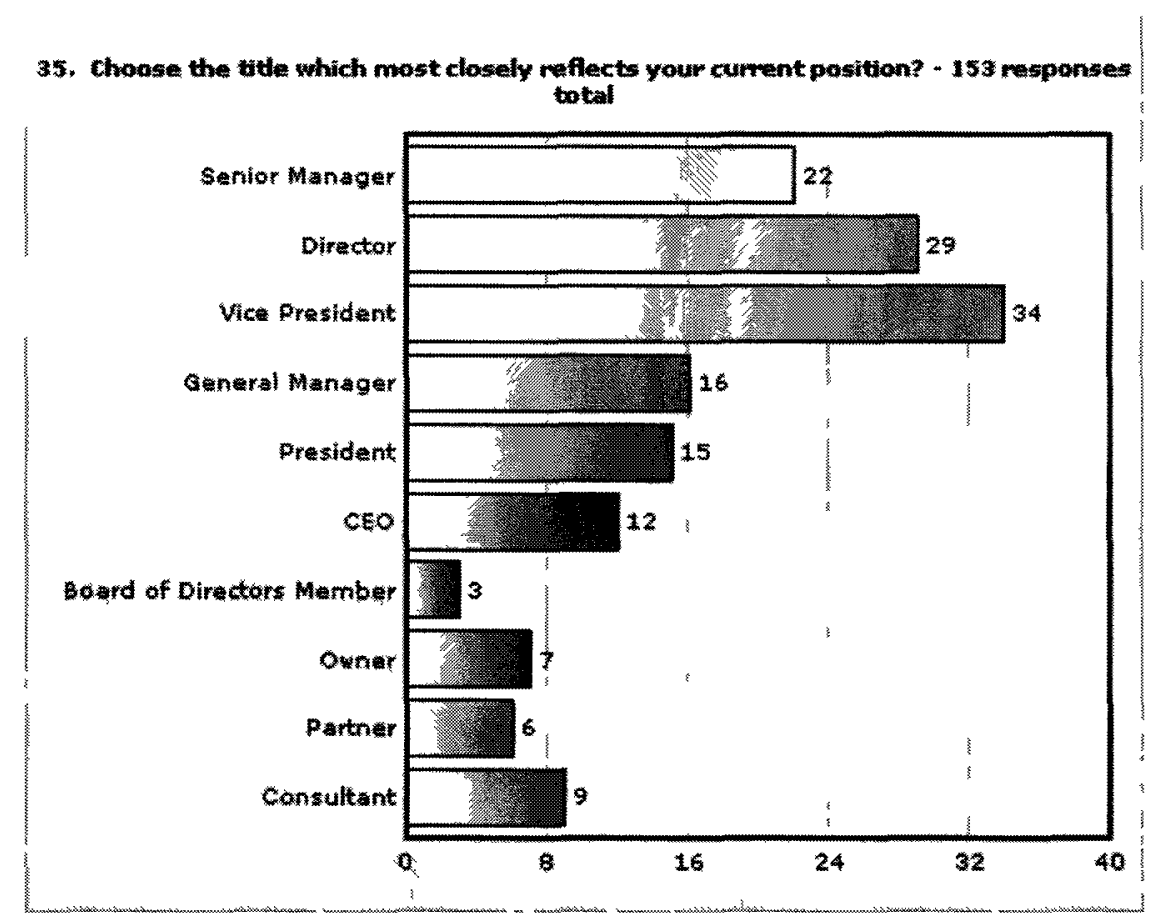


The experience levels of the respondents are displayed in the Figure 6 histogram. In Figure 6, the five on the horizontal axis indicates the number of respondents with one to five years of experience, while the ten indicates the number of respondents with six to ten years of experience, and so on. The mean experience of all respondents in the industry used in their strategy examples is 18.4 years with a standard deviation of 9.3 years. Therefore, $68.3 \%$ of all respondents had between 9.1 and 27.7 years of experience in their industries. This high level of experience in their industries adds to the credibility of the responses in that the respondents had the experience to understand the impacts of the environments in which the companies operated.

Figure 6 - Experience of Respondents in the Industry Used in their Strategy Example

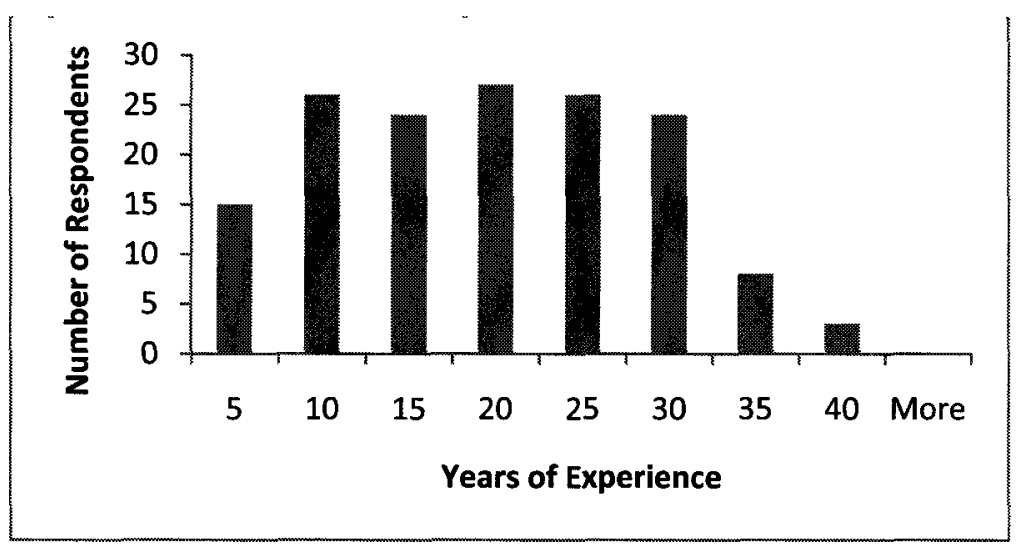


Figure 7 shows the size of the companies used in the strategy examples. While 42 (27.5\%) were smaller companies with annual revenue under $\$ 10$ million, 37 (24.2\%) were very large companies with annual revenue over $\$ 1$ billion. A total of 55 (35.9\%) companies had annual revenue between $\$ 50$ million and $\$ 1$ billion. The sample is representative of a wide range of company sizes including 15 (9.8\%) with annual revenue over $\$ 10$ billion.

\section{Figure 7 - Size of the Company Used in the Strategy Example in Annual} Revenue

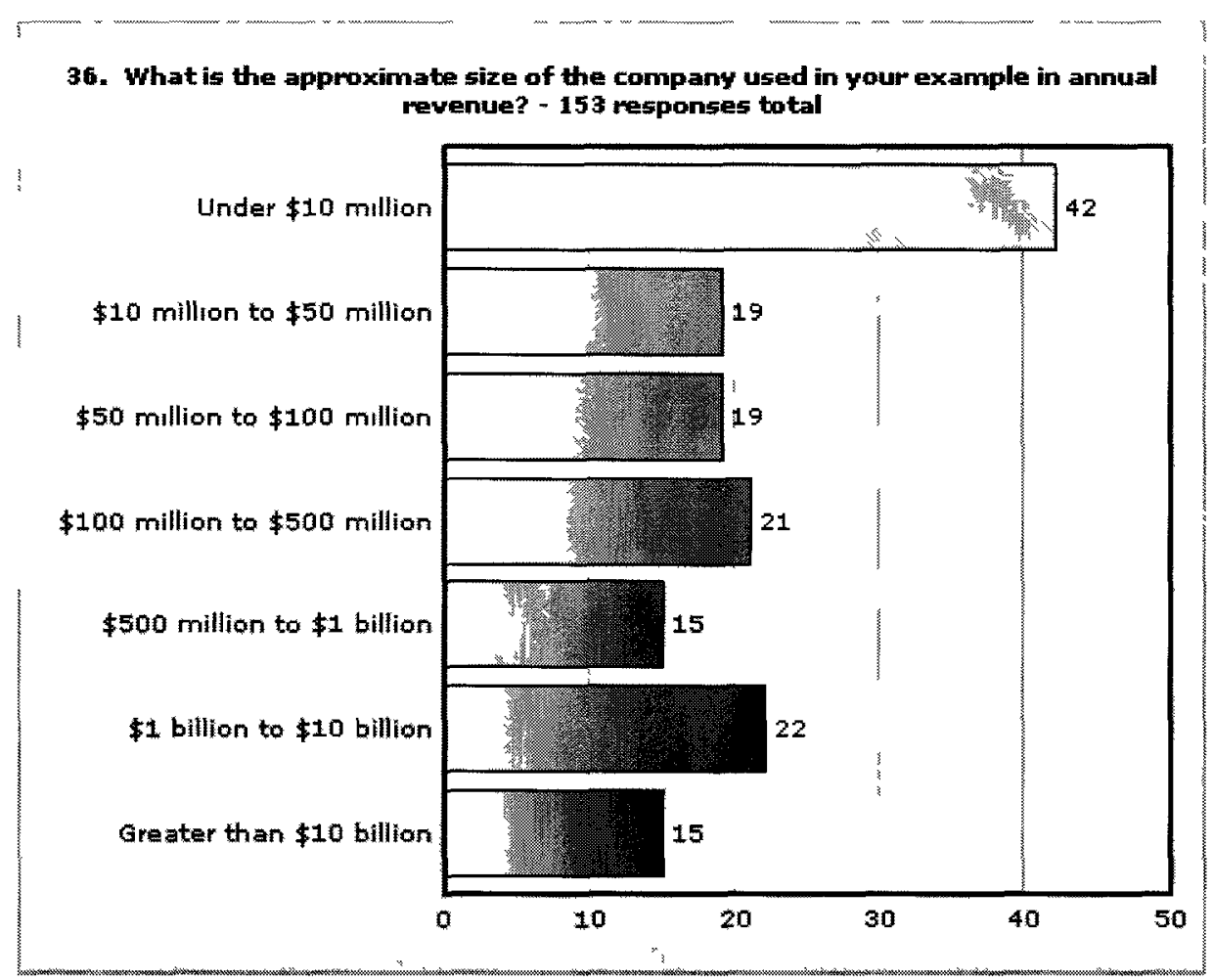


The headquarters locations of the companies used in the strategy examples are displayed in Figure 8. While the majority of companies were headquartered in Canada (99 companies, 64.7\%), the remaining 54 (35.3\%) companies were from four other continents. These included 23 (15\%) from the United States and $19(12.4 \%)$ from Asia.

Not included in Figure 8 are the locations of the positions of the respondents. While all five continents were represented, these numbers showed a slightly higher number in Canada, relative to headquarters locations, with 112 (73.2\%). The United States had locations where $10(6.5 \%)$ respondents were located, while Asia had 20 $(13.1 \%)$.

Figure 8 - Headquarters Location of the Company Used in the Strategy Example

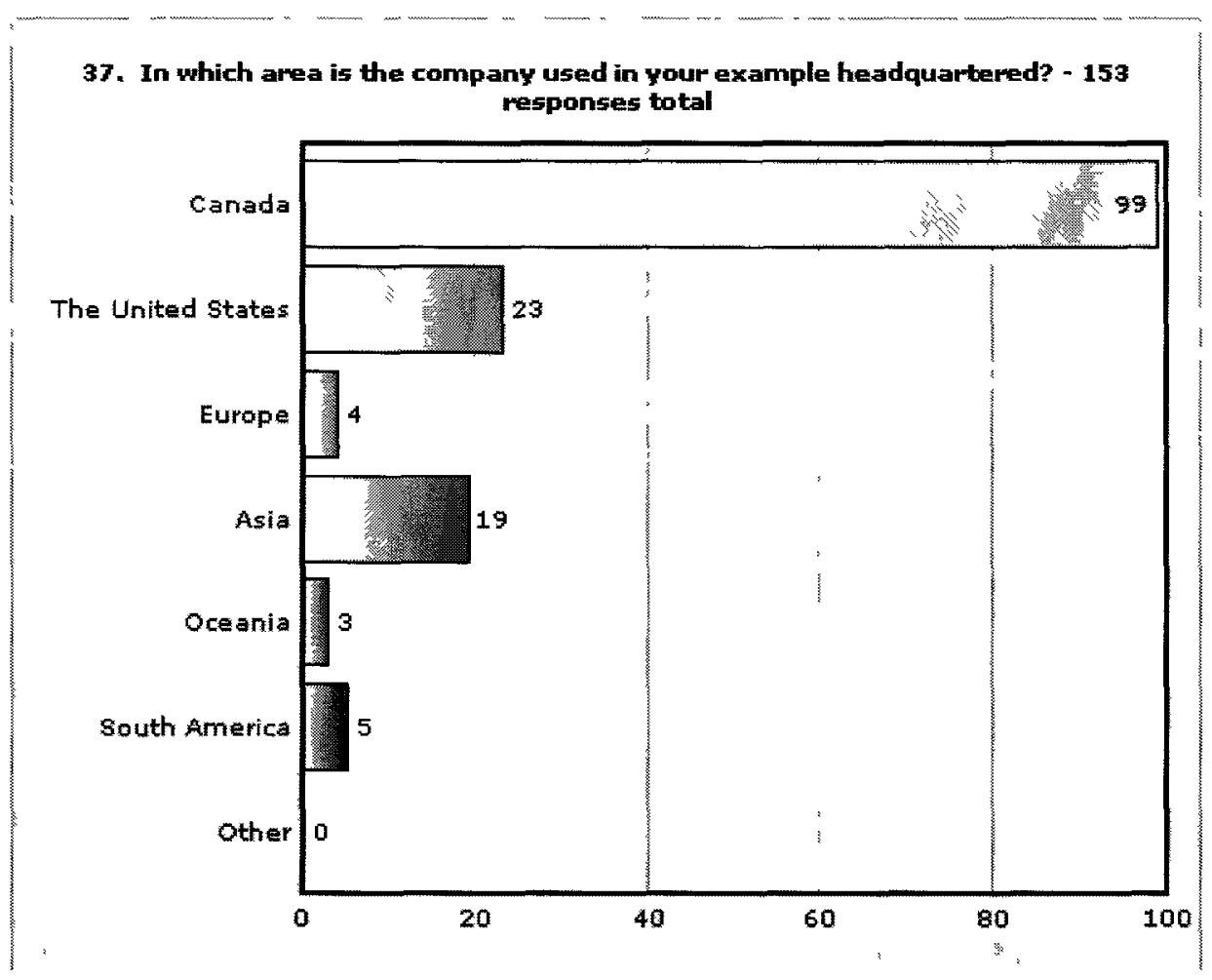


Figure 9 shows the public versus private ownership status of the companies used in the strategy examples. Eighty-two (53.6\%) of the companies were privately owned while $71(46.4 \%)$ were public entities owned by shareholders. Company size was strongly associated with ownership status with 39 of the $82(47.6 \%)$ private companies having annual revenue under $\$ 10$ million. Private companies with annual revenues up to $\$ 100$ million included 59 of the $82(72 \%)$ companies. Of the publicly owned companies, 14 of the $71(19.7 \%)$ companies had annual revenues over $\$ 10$ billion while 50 of the 71 (70.4\%) companies had annual revenues over $\$ 100$ million.

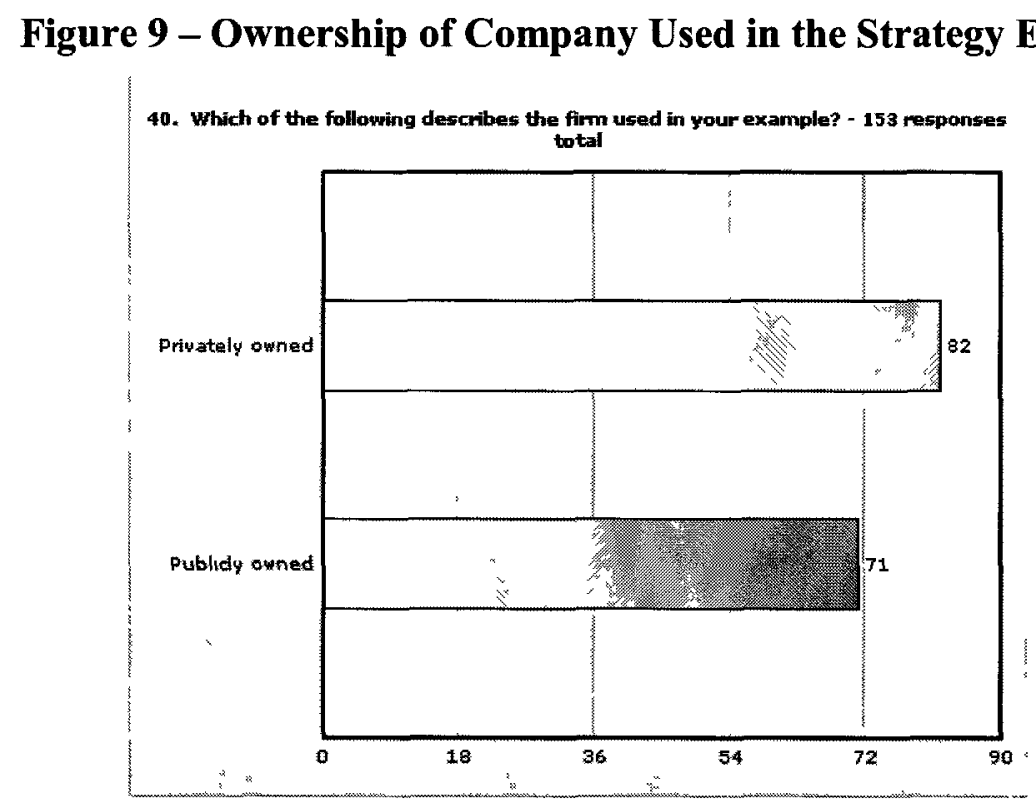

The sample detailed in Figure 10 included companies from numerous industries with the largest representations being from the financial sector with 22 out of 153 companies (14.4\%), defence with $19(12.4 \%)$, telecom with $17(11.1 \%)$ and general manufacturing with $16(10.5 \%)$. The number of defence and telecom companies (36 companies, $23.5 \%$ ) is probably indicative of the Ottawa location where many of the first tier respondents were located. However, because over $75 \%$ of the sample does not come 
from these Ottawa-heavy sectors, the sample should not have a large bias toward the Ottawa region. This is also demonstrated by the geographic distribution of the companies displayed in Figure 8.

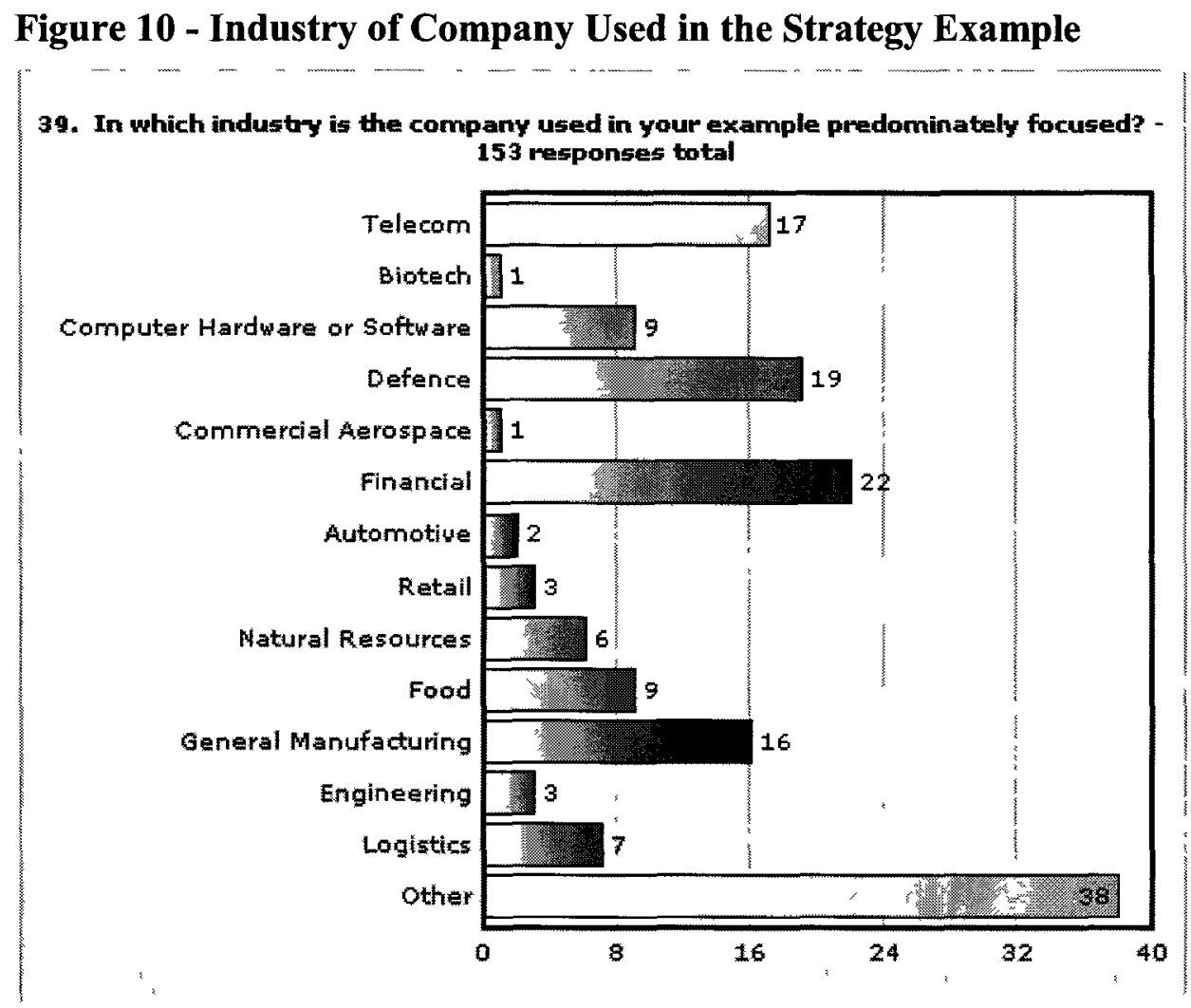

Due to space constraints, it was not possible to provide answer options in the survey for all industries resulting in 38 respondents utilizing the 'other' category (see Figure 10). However, information did become available to identify many of these 'other' industries. Based on emails received by the researcher from various respondents, the 'other' category included the following industries: construction, construction materials, import/export, pharmaceuticals, petrochemical, mining, green technology, plastics, chemical, tourism, law firms and real estate. Therefore, in total, at least 26 industries are represented in the sample. 


\subsection{Descriptive Statistics of Sample Data}

Appendix $\mathrm{G}$ contains the descriptive statistics including the items' means for all survey items. Table 16 displays statistical information with respect to the individual items in the survey for only the five highest and five lowest means. The data is arranged in Table 16 in descending order of the items' means. The data has been re-coded from the original survey configuration such that the highest means indicate that the respondents thought that these items led to the highest level of difference between the organization's original strategic plan and what was actually implemented. In other words, the items that led to the highest levels of transformation had the highest means, and the items that led to the lowest levels of transformation had the lowest means. 
Table 16 - Descriptive Statistics of Sample Data in Descending Order of the Means

\section{Descriptive Statistics}

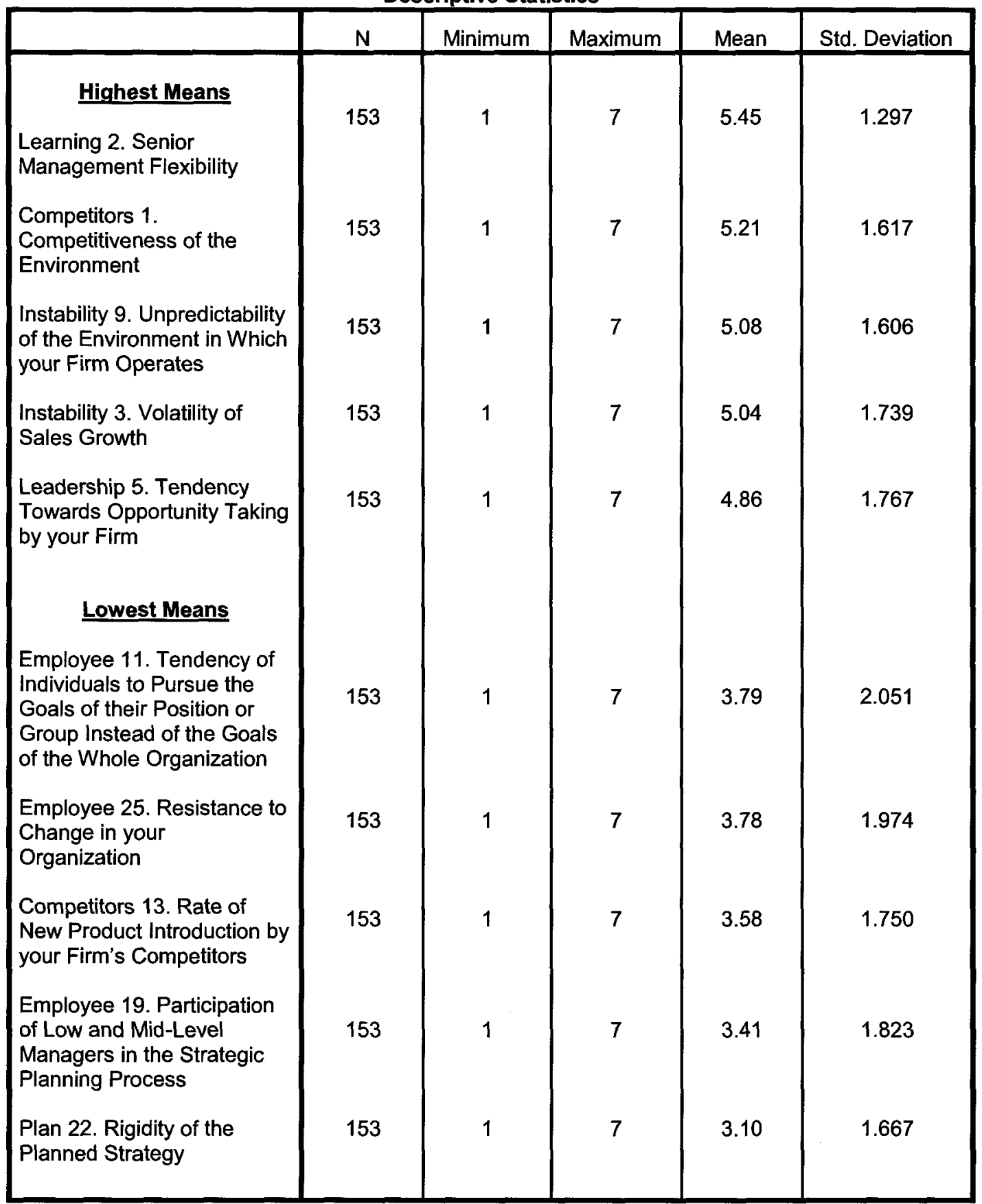

The item with the most transformative impact was senior management flexibility with a mean of 5.45 out of possible 7.0 over the 153 responses. This item was followed by three external environmental items: competitiveness of the environment, 
unpredictability of the environment and volatility of sales growth. The fifth most transformative item is another which indicates a level of flexibility on the part of management: tendency toward opportunity taking. These five items tell a story of the interplay between management and the impacts of the external environment. Specifically, the story focuses on the transformation of strategy brought about by management actions as it reacts to external environmental impacts.

The five items with the least transformative impact include three which are related to the actions of employees below the senior management level: sub-goal pursuit, resistance to change and participation of low and mid-level managers in the strategic planning process. The other two items are the rate of new product introduction by competitors and the rigidity of the planned strategy. The story which seems to be told by these items is the low level of strategy transformation impact of employee actions and involvement. However, it must be noted that the survey respondents were at the senior manager and executive levels. Therefore, it is possible that these items may have been underestimated because the respondents were at a higher level.

\subsubsection{Level of Strategy Transformation}

The level of strategy transformation reported by each survey respondent was measured by three items. Items 32 and 33 measured the levels to which the primary and secondary goals of the strategic plan were achieved as originally planned. Item 34 measured the level to which the process of implementing the strategy was implemented exactly as planned. 
A mean score of 2.05 for question 32 indicates that only $73.8 \%$ of the primary goals of the respondents' organizations were achieved as planned. Therefore, approximately one quarter of the primary goals were not achieved as planned.

Figure 11 displays responses in quartiles of achievement. Of note is that $9.8 \%$ of organizations achieved one quarter or less of their primary goals and only $31.4 \%$ achieved more than three-quarters of their primary goals. Further, $26 \%$ of organizations achieved half or less of their primary goals.

\section{Figure 11 - \% of Primary Goals Achieved as Planned}

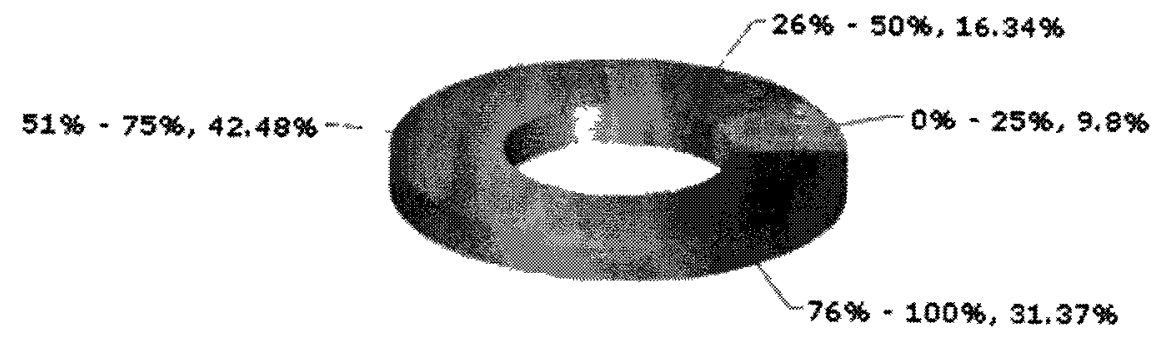

A mean score of 2.30 for question 33 indicates that only $67.5 \%$ of the secondary goals of the respondents' organizations were achieved as planned. Therefore, approximately one third of the secondary goals were not achieved as planned.

Figure 12 shows that $11.8 \%$ of organizations achieved one quarter or less of their secondary goals and only $22.2 \%$ achieved more than three-quarters of their secondary goals. Further, $40.5 \%$ of organizations achieved half or less of their secondary goals. 
Figure 12 - \% of Secondary Goals Achieved as Planned.

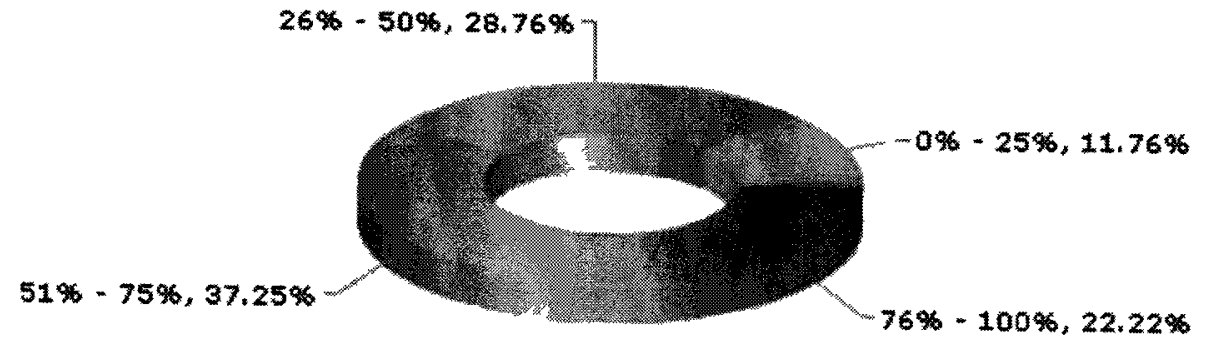

A mean score of 4.22 for question 34 indicates that the average response was neutral to somewhat disagree relative to the respondents' organizations implementation process proceeding exactly as planned. As displayed in Figure 13, 33.3\% of respondents either disagreed or strongly disagreed that their implementation processes proceeded exactly as planned. When somewhat disagree is added, the three levels of disagreement with the implementation process proceeding exactly as planned climbs to $48.4 \%$ or almost half of respondents. Less than half of respondents $(48.4 \%)$ have some level of agreement that the implementation process proceeded exactly as planned.

\section{Figure 13 - Level of Agreement that Implementation Process Proceeded Exactly as Planned}

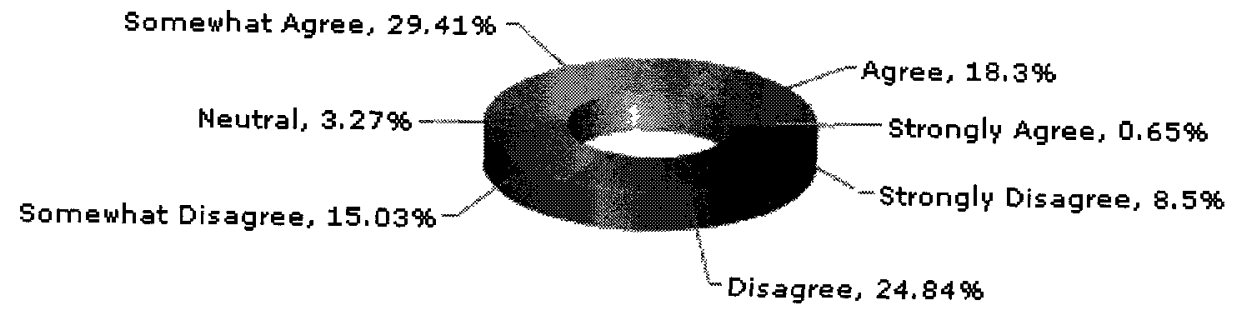

\subsubsection{Survey Item Correlations}

Appendix H shows the correlations between the survey items. There are numerous correlations present between items at both the .05 and .01 significance levels. However, only four of the correlations are above .6 with the largest being .706 . Further, 
these items are not being used as predictors in the model's regression equations. They are simply indicators which will be used as part of the operational definitions of the latent variables or factors. The operational definitions of the factors in the a priori model were taken from the literature or came from the interviews in the qualitative study. The operational definitions of the factors (i.e. indicator allocations) in the final Strategy Transformation Model (section 11.8) were decided upon using exploratory factor analysis (EFA) techniques.

In building the a priori model, the indicators were taken from the literature and associated with a priori factors based upon a combination of assertions in the literature and the judgement of this researcher. As discussed in Chapter 10, five additional indicators were added as a consequence of the qualitative interview results and associated with a priori factors based upon the judgement of the researcher. However, as noted in Chapter 7, the factors and indicators gleaned from the literature were not based upon a series of rigorous studies into the transformation of strategy that occurs during implementation. This is because the literature does not contain such studies. For the most part, the factors and indicators were taken from the numerous planning versus performance studies that have been published. Further, the factors and indicators were usually proposed as part of the discussion sections of the papers as the authors attempted to explain their findings. As such, and because of the exploratory nature of this research, a level of correlation among these items is not unexpected.

The post-EFA final Strategy Transformation Model is made up of a group of latent variables or factors which have acceptable loadings upon various indicators or 
items from the survey. A correlation table is presented in section 11.7 which shows the correlations between these factors.

\subsection{A Priori Model}

An a priori model of the transformation of planned (i.e. intended) strategy into implemented (i.e. realized) strategy is displayed in Figure 3. The factors and indicators were taken from the literature as the internal and external contextual variables which somehow cause intended strategy to evolve during implementation. Table 17 displays the factor to indicator loadings for the a priori model. The a priori factors are listed across the top of Table 17 while the indicators are listed down the side. The indicator short forms portray the a priori factor that the indicator was associated with when the model was built from the literature, and the number after the short form is the item number from the survey (e.g. Comp 13 is an indicator associated with the a priori factor 'Competitors' and is the $13^{\text {th }}$ question in the survey). 
Table 17 - A Priori Factors and Indicator Loadings

\begin{tabular}{|c|c|c|c|c|c|c|c|c|c|}
\hline \multirow[b]{2}{*}{$\begin{array}{l}\text { Survey } \\
\text { Items }\end{array}$} & \multicolumn{9}{|c|}{$A$ Priori Factors } \\
\hline & $\begin{array}{c}\text { Compettors } \\
\text { (Comp) }\end{array}$ & $\begin{array}{l}\text { Envronmental } \\
\text { Instablitity } \\
\text { (Instab) }\end{array}$ & $\begin{array}{c}\text { Customers } \\
\text { (Cust) }\end{array}$ & $\begin{array}{c}\text { Environmental } \\
\text { Complexity } \\
\text { (Cplx) }\end{array}$ & $\begin{array}{l}\text { Leadership } \\
\text { (Ldr) }\end{array}$ & $\begin{array}{c}\text { Employees } \\
\text { (Emply) }\end{array}$ & $\begin{array}{l}\text { Learning } \\
(\mathrm{Lm})\end{array}$ & $\begin{array}{c}\text { Plan } \\
\text { Charactersttics } \\
\text { (Plan) }\end{array}$ & $\begin{array}{l}\text { Transformation } \\
\text { Factor } \\
\text { (Trans) }\end{array}$ \\
\hline Comp 13 & .809 & & & & & & & & \\
\hline Comp 24 & .806 & & & & & & & & \\
\hline Comp 1 & .731 & & & & & & & & \\
\hline Instab 9 & & .749 & & & & & & & \\
\hline Instab 17 & & .738 & & & & & & & \\
\hline Instab 3 & & .565 & & & & & & & \\
\hline Instab 30 & & .382 & & & & & & & \\
\hline Cust 20 & & & .901 & & & & & & \\
\hline Cust 10 & & & .860 & & & & & & \\
\hline Cust 15 & & & .837 & & & & & & \\
\hline Cplx 26 & & & & .728 & & & & & \\
\hline Cplx 6 & & & & .701 & & & & & \\
\hline Cplx 18 & & & & .680 & & & & & \\
\hline Cplx 28 & & & & .564 & & & & & \\
\hline Ldr 16 & & & & & .783 & & & & \\
\hline Ldr 7 & & & & & .773 & & & & \\
\hline Ldr 23 & & & & & .768 & & & & \\
\hline Ldr 5 & & & & & .288 & & & & \\
\hline Ldr 31 & & & & & .093 & & & & \\
\hline Emply 19 & & & & & & .716 & & & \\
\hline Emply 8 & & & & & & .714 & & & \\
\hline Emply 4 & & & & & & .711 & & & \\
\hline Empl 25 & & & & & & .682 & & & \\
\hline Emply 11 & & & & & & .641 & & & \\
\hline $\operatorname{Lrn} 21$ & & & & & & & .753 & & \\
\hline $\operatorname{Lrn} 12$ & & & & & & & .739 & & \\
\hline $\operatorname{Lm} 2$ & & & & & & & .732 & & \\
\hline Plan 27 & & & & & & & & .791 & \\
\hline Plan 29 & & & & & & & & .790 & \\
\hline Plan 22 & & & & & & & & .611 & \\
\hline Plan 14 & & & & & & & & .027 & \\
\hline Trans 32 & & & & & & & & & .896 \\
\hline Trans 33 & & & & & & & & & .860 \\
\hline Trans 34 & & & & & & & & & .711 \\
\hline
\end{tabular}


Table 17 shows the eight explanatory factors and the dependent factor with their loadings on the applicable indicators. It should be noted that this table is not the result of factor analysis. Each factor was built using only the survey items associated with it in the a priori model. In the case of each factor, SPSS PASW Statistics 18 was used to calculate the loadings for the applicable indicators only. This was done to allow the $a$ priori model to be specifically tested.

Most of the loadings are reasonably strong with a few notable exceptions. The leadership factor loading on the Ldr 5 indicator is only .288 and on the Ldr 31 indicator is only .093. The plan factor loading on the Plan 14 indicator is only .027. As a consequence of EFA, these indicators were relocated to other factors as discussed in Section 12.2. When the dependent factor was regressed on the explanatory factors, the model was run with these indications included and again with these indicators removed as discussed below.

\subsubsection{Factor Internal Consistency or Reliability}

Cronbach's alpha is a measure of the reliability or internal consistency of a set of items as it provides an indication of whether the group of items is measuring a single latent construct (Cronbach, 1951). A higher alpha indicates higher internal consistency among the items representing a given construct. In relation to survey data, the acceptable level of Cronbach's alpha has risen over the years from an alpha of .6, originally considered acceptable (Nunnally, 1967), to the currently favoured .7 (Nunnally, 1978). However, for preliminary research theorizing the probable underlying measures of a latent variable, an alpha of .5 or .6 can be considered acceptable (Shay \& Baack, 2004). 
Table 18 lists the Cronbach's alphas for the factors in the a priori model. The alphas for the leadership and plan factors are calculated both with and without indicators Ldr 5, Ldr 31 and Plan 14 as discussed above. The first point to note is that the level of the alpha does not seem to be related to the number of underlying indicators. For example, customers has an alpha of .832 with only three indicators while leadership has an alpha of .517 with five indicators. Similarly, Peterson (1994) found no significant evidence of a relationship between the size of the alpha and the number of underlying indicators in his meta-analysis of studies which calculated Cronbach's alphas.

Table 18 - Cronbach's Alphas for $\boldsymbol{A}$ Priori Factors

\begin{tabular}{|l|c|c|}
\hline \multicolumn{1}{|c|}{$\boldsymbol{A}$ Priori Factor } & Number of Indicators & Cronbach's Alpha \\
\hline Competitors & 3 & .684 \\
\hline Environmental Instability & 4 & .452 \\
\hline Customers & 3 & .832 \\
\hline $\begin{array}{l}\text { Environmental } \\
\text { Complexity }\end{array}$ & 4 & .588 \\
\hline Leadership & 5 & .517 \\
\hline $\begin{array}{l}\text { Leadership without } \\
\text { indicators Ldr 5 and Ldr } \\
31 \text { (Leadership 4 factor) }\end{array}$ & 3 & .686 \\
\hline Employees & 5 & .728 \\
\hline Learning & 3 & .583 \\
\hline Plan Characteristics & 4 & .435 \\
\hline $\begin{array}{l}\text { Plan Characteristics } \\
\text { without indicator Plan 14 } \\
\text { (Plan 2 factor) }\end{array}$ & 3 & .571 \\
\hline Transformation Factor & 3 & .686 \\
\hline
\end{tabular}

Five of the nine alphas in Table 18 which include all indicators are lower than a .6 cut-off. These are environmental instability, environmental complexity, leadership, learning and plan characteristics. Given the lack of theory in the literature upon which to base these factors and indicators, this is not unexpected. However, environmental complexity and learning are close to .6 at .588 and .583 respectively. In addition, when 
the low loading indicators are removed from leadership (i.e. Ldr 5 and Ldr 31) and plan (i.e. Plan 14), the alpha for leadership increases from .517 to .686 and for plan from .453 to .571 . This brings the leadership factor above .6 and the plan factor near .6 .

While regression analysis was employed to test the a priori model, it is noted that the factor to indicator associations for several of these factors are not optimal. As such, EFA was used to associate the indicators with a new set of latent variables to build the final Strategy Transformation Model.

\subsubsection{Regression Analysis}

Using SPSS, the a priori dependent factor (i.e. transformation factor) was regressed against the eight a priori independent factors. The results are shown in Tables 19 and 20. Table 19 shows an R Square of .212 which indicates that $21.2 \%$ of the variance of the transformation factor can be explained by the a priori independent factors in their current configuration.

Table 19 - Model Summary for $\boldsymbol{A}$ Priori Model Using All Indicators

\begin{tabular}{|l|r|r|r|c|}
\hline Model & $\mathrm{R}$ & $\mathrm{R}$ Square & $\begin{array}{c}\text { Adjusted } \mathrm{R} \\
\text { Square }\end{array}$ & $\begin{array}{c}\text { Std. Error of the } \\
\text { Estimate }\end{array}$ \\
\hline 1 & $.460^{\mathrm{a}}$ & .212 & .168 & .91203295 \\
\hline
\end{tabular}

a. Predictors: (Constant), Plan Factor, Learning Factor, Instability Factor, Employee Factor, Customer Factor, Competitor Factor, Leadership Factor, Complexity Factor

As shown in Table 20, of the eight independent variables, only the complexity, leadership and plan factors are significant with p-values less than .05 . As opposed to the complexity and plan factors, the coefficient for the leadership factor is negative indicating that the mean impact of the survey items associated with the operational definition of this factor will lessen the transformation of strategy in a given situation. As displayed in Table 10, the leadership factor indicators which may impede the 
transformation of strategy, or work to maintain the intended strategy, are managers sharing a detailed and consistent understanding of the business and leadership team support for the strategy. The regression results suggest that the most influential factor with respect to strategy transformation is the plan factor with a Standardized Beta (SB) of .318. This is followed by the complexity factor with a SB of .230 and the leadership factor with a SB of -.218 .

Table 20 - Regression Details for $A$ Priori Model Using All Indicators Coefficients $^{\mathrm{a}}$

\begin{tabular}{|c|c|c|c|c|c|c|}
\hline \multirow{2}{*}{\multicolumn{2}{|c|}{ Model }} & \multicolumn{2}{|c|}{ Unstandardized Coefficients } & $\begin{array}{c}\text { Standardized } \\
\text { Coefficients }\end{array}$ & \multirow[b]{2}{*}{$t$} & \multirow[b]{2}{*}{ Sig. } \\
\hline & & B & Std. Error & Beta & & \\
\hline \multirow[t]{9}{*}{1} & (Constant) & $8.553 \mathrm{E}-17$ & .074 & & .000 & 1.000 \\
\hline & Competitor Factor & .068 & .094 & .068 & .724 & .470 \\
\hline & Instability Factor & .098 & .090 & .098 & 1.085 & .280 \\
\hline & Customer Factor & -.103 & .096 & -.103 & -1.080 & .282 \\
\hline & Complexity Factor & .230 & .109 & .230 & 2.103 & .037 \\
\hline & Leadership Factor & -.218 & .102 & -.218 & -2.137 & .034 \\
\hline & Employee Factor & -.030 & .099 & -.030 & -.300 & .765 \\
\hline & Learning Factor & .011 & .090 & .011 & .118 & .906 \\
\hline & Plan Factor & .318 & .087 & .318 & 3.660 & .000 \\
\hline
\end{tabular}

a. Dependent Variable: Transform Factor

As noted in section 11.6, several of the loadings of a priori factors on the indicators were quite low. The following indicators were removed and the regression rerun: the leadership factor indicators $\operatorname{Ldr} 5(.288)$ and Ldr $31(.093)$; and the plan factor indicator Plan 14 (.027). The results are shown in Tables 21 and 22. Table 21 shows an $\mathrm{R}$ Square of .221 which indicates that $22.1 \%$ of the variance of the transformation factor can be explained by the a priori independent factors in this configuration. By removing these three indicators, the R Square increased by a non-material $0.9 \%$. 
Table 21 - Model Summary for $\boldsymbol{A}$ Priori Model Using All Remaining Indicators

\begin{tabular}{|c|c|c|c|c|}
\hline Model & $\mathrm{R}$ & $\mathrm{R}$ Square & $\begin{array}{c}\text { Adjusted } \mathrm{R} \\
\text { Square }\end{array}$ & $\begin{array}{c}\text { Std. Error of the } \\
\text { Estimate }\end{array}$ \\
\hline 1 & $.470^{\mathrm{a}}$ & .221 & .178 & .90675178 \\
\hline
\end{tabular}

a. Predictors: (Constant), Instability Factor, Leadership 4 Factor, Customer Factor, Plan 2 Factor, Learning Factor, Employee Factor, Competitor Factor, Complexity Factor

As displayed in Table 22, similar to the Table 20 regression, of the eight independent variables, only the complexity, leadership and plan factors are significant with p-values less than .05 . The complexity and plan p-values remained nearly the same but the p-value for the leadership factor reduced from .034 (Table 20) to .014 (Table 22). The coefficient for the leadership factor increased from -.218 (Table 20) to -.240 (Table 22). The coefficient for the leadership factor remained negative indicating that the mean impact of the survey items associated with the operational definition of this factor will lessen the transformation of strategy in a given situation. The most influential factor with respect to strategy transformation remained the plan factor with a SB of .318. This is followed by the leadership factor with a SB of -.240 and the complexity factor with a SB of .227. The significance of these factors seems reasonable in that they represent the starting point of the strategy (i.e. plan) as well as the influence of the external environment (i.e. complexity) and the actions of the internal leadership of the firm. 
Table 22 - Regression Details for $\boldsymbol{A}$ Priori Model Using All Remaining Indicators

\begin{tabular}{|c|c|c|c|c|c|c|}
\hline \multicolumn{7}{|c|}{ Coefficients $^{\mathrm{a}}$} \\
\hline \multirow{2}{*}{\multicolumn{2}{|c|}{ Model }} & \multicolumn{2}{|c|}{ Unstandardized Coefficients } & \multirow{2}{*}{$\begin{array}{c}\begin{array}{c}\text { Standardized } \\
\text { Coefficients }\end{array} \\
\text { Beta }\end{array}$} & \multirow[b]{2}{*}{$\mathrm{t}$} & \multirow[b]{2}{*}{ Sig. } \\
\hline & & $\mathrm{B}$ & Std. Error & & & \\
\hline \multirow[t]{9}{*}{1} & (Constant) & $6.097 \mathrm{E}-17$ & .073 & & .000 & 1.000 \\
\hline & Competitor Factor & .064 & .093 & .064 & .691 & .491 \\
\hline & Customer Factor & -.103 & .095 & -.103 & -1.080 & .282 \\
\hline & Complexity Factor & .227 & .109 & .227 & 2.089 & .038 \\
\hline & Employee Factor & -.021 & .097 & -.021 & -.217 & .829 \\
\hline & Learning Factor & .013 & .088 & .013 & .153 & .879 \\
\hline & Plan 2 Factor & .318 & .085 & .318 & 3.719 & .000 \\
\hline & Leadership 4 Factor & -.240 & .096 & -.240 & -2.495 & .014 \\
\hline & Instability Factor & .093 & .090 & .093 & 1.040 & .300 \\
\hline
\end{tabular}

a. Dependent Variable: Transform Factor

Given the preliminary nature of this work, an $\mathrm{R}$ Square of 0.221 provides an interesting finding in that over $20 \%$ of the variance of the strategy transformation factor can be explained. Strategy formulation and implementation processes can be considered to be quite complex given the myriad human and environmental inputs that occur at all points in the processes. Therefore, the ability to explain $20 \%$ of the variance of the strategy transformation factor is considered acceptable. However, the ability to explain a greater proportion of variance may be available through a different combination of the indicators taken from the literature and the interviews. Combining the indicators in a different way to reveal a different set of latent constructs will be undertaken through the use of exploratory factor analysis (section 11.7).

\subsubsection{Testing of A Priori Hypotheses}

The eight hypotheses listed below made up the a priori model. Each hypothesis is followed by its test result based on the Table 22 regression results. Of the six hypotheses which hypothesized a directional relationship, five were supported by the 
analysis. One Beta was in a direction opposite to that hypothesized. Three of the hypothesized factors were found to be significant with p-values less than .05 . Of these three, one had a hypothesized directional relationship while the other two did not hypothesize a direction. These three factors also had the highest SBs, so therefore the greatest impact upon the dependent variable. As noted above, these three factors represent portions of the internal and external environments of the firm, and the starting point of strategy transformation, the intended strategy.

- H1: Instability in the external environment is a significant factor in transforming intended strategy into realized strategy. The greater the level of instability, the greater the level of transformation. The positive Beta is in the hypothesized direction but the result is not significant $(p=.300)$.

- H2: Actions of competitors is a significant factor in transforming intended strategy into realized strategy. The greater the level of competition, the greater the level of transformation. The positive Beta is in the hypothesized direction but the result is not significant $(p=.491)$.

- H3: Changes in customer requirements is a significant factor in transforming intended strategy into realized strategy. The greater the level of change in customer requirements, the greater the level of transformation. The negative Beta indicates a relationship in the opposite direction from that hypothesized and the result is not significant $(p=\mathbf{2 8 2})$. This factor is made up of three indicators: rate of change of customer needs; speed of change in demand trends; and customer demand for innovation. While the result is not statistically significant, the negative Beta implies that the greater the level of change in customer requirements, the 
lesser the level of transformation. This seems counter-intuitive but it may be due to the long term influence of changing customer requirements on firms over many strategy formulation iterations. A possible explanation may be that the more the level of customers' actions in a market, the more a firm in that market may have been conditioned to build flexibility into its strategy from the outset. As such, the impact of customers' actions may take place when the intended strategy is first being developed. In addition, the non-significant $\mathrm{p}$-value may indicate that firms do not specifically focus on their customers in terms of changing their strategies during implementations. Perhaps the actions of a firm's customers are perceived through the actions of competitors or the general external environment. As discussed more fully in Section 12.3, examples of this possibility are exemplified in Interviews 2 and 4 .

- H4: Complexity of the environment is a significant factor in transforming intended strategy into realized strategy. The greater the level of complexity, the greater the level of transformation. The positive Beta is in the hypothesized direction and the result is significant $(\mathrm{p}=. \mathbf{0 3 8})$.

- H5: The characteristics of the leadership team is a significant factor in transforming intended strategy into realized strategy. The Beta indicates a relationship and the result is significant $(p=.014)$. However, the direction of the impact of this factor was not hypothesized. The negative Beta indicates that the greater the level of leadership actions, the lesser the level of transformation. The direction of this factor's impact was not hypothesized because there were indicators which would seem to have both impeded 
transformation (e.g. leadership team support for the strategy) and aided transformation (e.g. tendency toward opportunity taking by the firm). The negative Beta signifies that the indicators in the leadership actions factor which would impede transformation have a greater influence than those which would aid transformation.

- H6: The involvement of employees below the senior leadership level in the strategy formation process is a significant factor in transforming intended strategy into realized strategy. The greater the level of employee involvement, the lesser the level of transformation. The negative Beta is in the hypothesized direction but the result is not significant $(p=.829)$. The non-significance of this factor may be due to the executive level respondents' perspective of the impact of employees. If lower level employees were to take the survey, it is possible that the result might be different. Alternatively, it may simply indicate that employees below the senior management level do not have a significant impact on strategy transformation.

- H7: The ability of the organization to learn during intended strategy implementation is a significant factor in transforming intended strategy into realized strategy. The greater the ability of the organization to learn, the greater the level of transformation. The positive Beta is in the hypothesized direction but the result is not significant $(p=.879)$.

- H8: This factor was originally: "The inherent flexibility of the intended strategy is a significant factor in transforming intended strategy into realized strategy. The greater the level of flexibility, the lesser the level of transformation." However, H8 was changed after the qualitative study (i.e. before the survey) to be: "The 
characteristics of the intended strategy is a significant factor in transforming intended strategy into realized strategy". The change was made due to the addition of two new indicators which arose during the interviews. These indicators are feasibility and ambitiousness of the planned strategy. When these two indicators were added to the intended strategy factor, the factor became more than just a measure of flexibility. Therefore, the factor was broadened to include these two additional characteristics of the planned strategy. The Beta indicates a relationship and the result is significant $(p=.000)$. However, the direction of the impact of this revised factor $\mathrm{H} 8$ was not hypothesized. The positive Beta indicates that the greater the level of this factor, the greater the level of transformation. The direction of this factor's impact was not hypothesized because there were indicators which would seem to have both impeded transformation (e.g. flexibility inherent in the planned strategy) and aided transformation (e.g. ambitiousness of the planned strategy). The positive Beta signifies that the indicators in the characteristics of the intended strategy factor which would aid transformation have a greater influence than those which would impede transformation.

While the a priori factors and hypotheses provided a starting point for the analysis, these factors and their underlying collections of indicators were based solely on the judgement of the researcher after review of the literature. The results above indicate some level of explanatory capability through the regression; however, an alternative combination of the indicators could possibly provide more capable results. As such, exploratory factor analysis was planned as the next step in the analysis. 


\subsection{Exploratory Factor Analysis (EFA)}

A test of the adequacy of the sample was carried out with the Table 23 results provided by SPSS. The Kaiser-Meyer-Olkin statistic of . 769 indicates that factor analysis will provide reliable factors and is therefore appropriate for this sample (Hutcheson \& Sofroniou, 1999). Bartlett's Test of Sphericity has a p-value less than .05. Therefore, the null hypothesis that the correlation matrix is an identity matrix is rejected and factor analysis is appropriate for the data (Hutcheson \& Sofroniou, 1999).

Table 23 - Tests of Sample Adequacy for Factor Analysis KMO and Bartlett's Test

\begin{tabular}{|lr|r|}
\hline $\begin{array}{l}\text { Kaiser-Meyer-Olkin Measure of Sampling Adequacy. } \\
\text { Bartlett's Test of Sphericity }\end{array}$ & Approx. Chi-Square & .769 \\
& df & 5617.483 \\
& Sig. & .000 \\
\hline
\end{tabular}

EFA was initially executed using principal components analysis (PCA) and an orthogonal rotation. However, this process yielded factors which were not interpretable, including a dependent factor which had explanatory indicators mixed with the dependent indicators. Preacher and MacCallum (2003) note that this is a common problem with PCA which has been recognized for decades (Thurston, 1935; Wolfle, 1940). It relates to PCA's inability to recognize and account for error-related variance including measurement error. However, principal axis factoring does take measurement error into account and has therefore been used in the factor analysis discussed below.

The initial use of an orthogonal rotation restricted the factors to be uncorrelated (Preacher \& MacCallum, 2003). The use of an oblique rotation (Promax) allows the factors to be extracted without this restriction and can yield greater interpretability 
(Preacher \& MacCallum, 2003). As such, an oblique rotation was used for this factor analysis.

\subsubsection{Factors and Loadings}

The initial EFA solution provided by SPSS displayed the Table 24 list of eigenvalues and variation explained, and the Figure 14 Scree Plot. Three criteria were used to decide how many factors to retain (Stevens, 2002):

- The Kaiser Rule which recommends retaining factors which have eigenvalues greater than one;

- The number of factors present in the steep vertical descent of a Scree Plot; and

- The most important criterion is that the factors must be interpretable based upon the indicators of which they are composed.

As seen in Table 24, the Kaiser Rule would indicate that nine factors would be appropriate. Nine factors would explain $63.377 \%$ of the variance and the ninth factor explains over $3 \%$ of the variance as do the eighth and seventh factors. It would therefore seem reasonable to retain the ninth factor. The factor to indicator ratio $(\mathrm{Q} / \mathrm{P})$ with nine factors is $<.3$ so this number of factors is credible from the $\mathrm{Q} / \mathrm{P}$ ratio perspective (Stevens, 2002). 
Table 24 - Initial Solution Eigenvalues and Variance Explained

\begin{tabular}{|c|c|c|c|c|c|c|c|}
\hline \multirow[t]{2}{*}{ Factor } & \multicolumn{3}{|c|}{ Initial Eigenvalues } & \multicolumn{3}{|c|}{ Extraction Sums of Squared Loadings } & $\begin{array}{l}\text { Rotation Sums } \\
\text { of Squared } \\
\text { Loadings }^{\mathrm{a}} \\
\end{array}$ \\
\hline & Total & $\%$ of Variance & Cumulative \% & Total & $\%$ of Variance & Cumulative \% & Total \\
\hline 1 & 7.012 & 20.623 & 20.623 & 6.543 & 19.245 & 19.245 & 4.027 \\
\hline 2 & 3.412 & 10.036 & 30.659 & 2.976 & 8.754 & 27.999 & 3.509 \\
\hline 3 & 2.714 & 7.983 & 38.642 & 2.290 & 6.736 & 34.735 & 4.127 \\
\hline 4 & 1.845 & 5.425 & 44.068 & 1.416 & 4.164 & 38.899 & 2.803 \\
\hline 5 & 1.637 & 4.814 & 48.882 & 1.141 & 3.355 & 42.254 & 3.409 \\
\hline 6 & 1.341 & 3.944 & 52.826 & .946 & 2.782 & 45.036 & 2.786 \\
\hline 7 & 1.301 & 3.826 & 56.651 & .851 & 2.502 & 47.538 & 3.276 \\
\hline 8 & 1.221 & 3.591 & 60.243 & .674 & 1.982 & 49.520 & 2.679 \\
\hline 9 & 1.066 & 3.134 & 63.377 & .611 & 1.797 & 51.317 & .920 \\
\hline 10 & .997 & 2.934 & 66.311 & & & & \\
\hline 11 & .953 & 2.802 & 69.112 & & & & \\
\hline 12 & .908 & 2.671 & 71.784 & & & & \\
\hline 13 & .781 & 2.298 & 74.082 & & & & \\
\hline 14 & .737 & 2.168 & 76.250 & & & & \\
\hline 15 & .689 & 2.027 & 78.277 & & & & \\
\hline 16 & .661 & 1.945 & 80.222 & & & & \\
\hline 17 & .607 & 1.785 & 82.007 & & & & \\
\hline 18 & .590 & 1.737 & 83.744 & & & & \\
\hline 19 & .563 & 1.655 & 85.399 & & & & \\
\hline 20 & .522 & 1.535 & 86.934 & & & & \\
\hline 21 & .501 & 1.474 & 88.408 & & & & \\
\hline 22 & .485 & 1.427 & 89.834 & & & & \\
\hline 23 & .433 & 1.273 & 91.107 & & & & \\
\hline 24 & .415 & 1.221 & 92.328 & & & & \\
\hline 25 & .404 & 1.189 & 93.518 & & & & \\
\hline 26 & .348 & 1.022 & 94.540 & & & & \\
\hline 27 & .312 & .918 & 95.459 & & & & \\
\hline 28 & .293 & .862 & 96.321 & & & & \\
\hline 29 & .269 & .792 & 97.113 & & & & \\
\hline 30 & .242 & .713 & 97.826 & & & & \\
\hline 31 & .212 & .624 & 98.450 & & & & \\
\hline 32 & .202 & .593 & 99.044 & & & & \\
\hline 33 & .177 & .519 & 99.563 & & & & \\
\hline 34 & .149 & .437 & 100.000 & & & & \\
\hline
\end{tabular}

Extraction Method: Principal Axis Factoring.

a. When factors are correlated, sums of squared loadings cannot be added to obtain a total variance. 
The Figure 14 Scree Plot indicates that five or six factors should be retained.

Based on the Scree plot, factor extractions were run which retained five and six factors and interpretation was attempted. In both cases, the results yielded factors with associated indicators which did not allow clear interpretation.

Figure 14 - Initial Solution Scree Plot

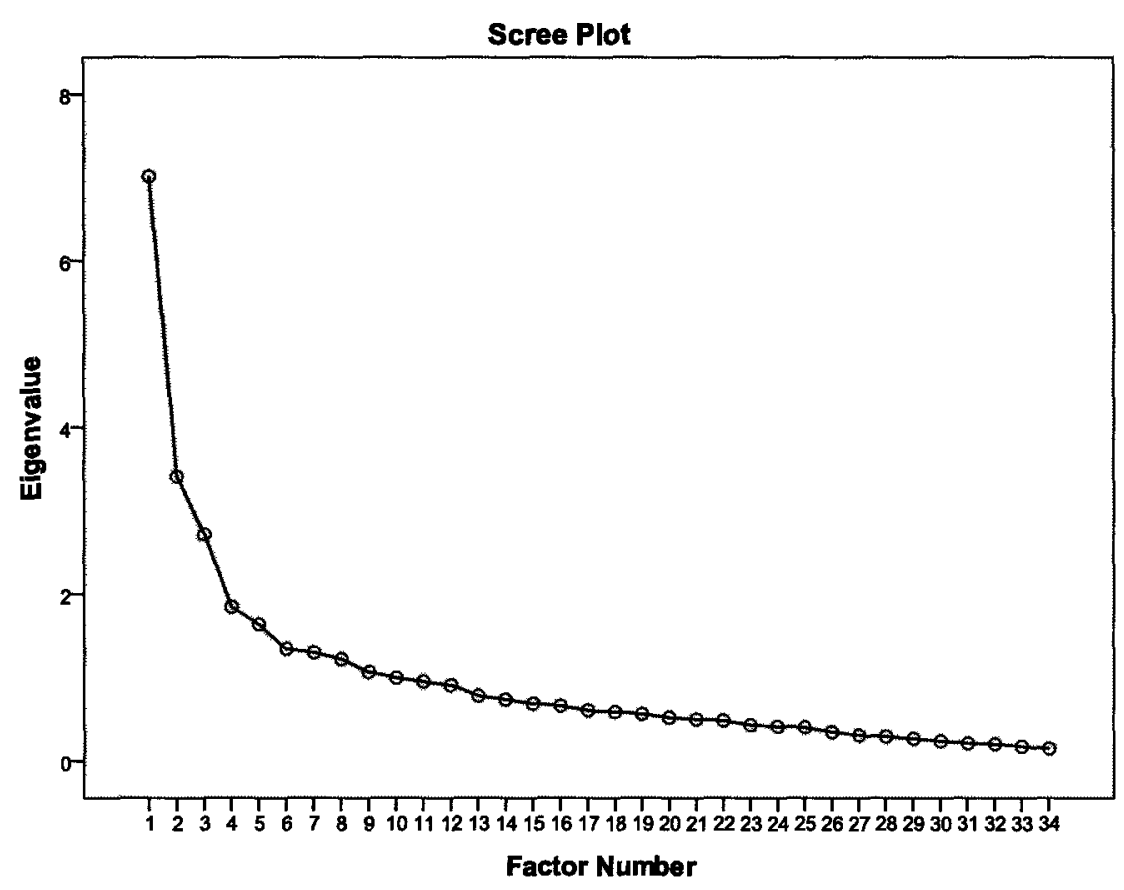

The factor extraction for nine factors using principal axis factoring and a Promax (i.e. oblique) rotation is seen in the Table 25 pattern matrix. The matrix provides nine interpretable factors; however, the ninth factor has only one indicator. Also, indicator 'complexity 6' (i.e. an indicator for the a priori complexity factor and question number 6 on the survey) has an approximately equal level of loading on several factors or no discrimination relative to several factors and was therefore removed. This lack of discrimination can be readily seen in a more pictorial way in the Tableplot diagram (Kwan, 2009) found in Appendix I. 
Table 25 - Pattern Matrix for Nine Factors

\begin{tabular}{|c|c|c|c|c|c|c|c|c|c|}
\hline & \multicolumn{9}{|c|}{ Factor } \\
\hline & 1 & 2 & 3 & 4 & 5 & 6 & 7 & 8 & 9 \\
\hline Employee8 & .909 & .057 & -.169 & .007 & -.080 & -.027 & .004 & -.055 & .245 \\
\hline Leadership7 & .762 & -.007 & -.017 & .069 & -.050 & .146 & -.054 & -.097 & .011 \\
\hline Leadership16 & .681 & -.092 & .030 & -.116 & .084 & -.120 & -.093 & .179 & .021 \\
\hline Employee19 & .679 & .161 & .113 & -.115 & .069 & -.074 & -.130 & -.054 & -.036 \\
\hline Leadership23 & .432 & -.050 & .001 & -.028 & .211 & .025 & -.036 & .173 & -.414 \\
\hline Complexity18 & .304 & .123 & .208 & .024 & .026 & .063 & .164 & .037 & .122 \\
\hline Employee11 & .100 & .719 & -.120 & .112 & -.064 & .136 & .051 & -.130 & -.081 \\
\hline Leadership31 & -.108 & .665 & .162 & .059 & .061 & -.122 & -.068 & .130 & -.001 \\
\hline Employee25 & .164 & .641 & -.128 & .043 & -.083 & .070 & .152 & .071 & -.045 \\
\hline Instability 30 & -.223 & .537 & -.083 & -.004 & .026 & -.108 & .098 & .405 & .050 \\
\hline Employee4 & .361 & .401 & .062 & -.112 & .209 & -.160 & .056 & -.130 & .132 \\
\hline Plan22 & .295 & .369 & .118 & -.107 & -.303 & .085 & -.070 & .166 & -.056 \\
\hline Customer20 & -.048 & -.058 & .878 & -.084 & -.030 & .029 & .118 & -.007 & -.130 \\
\hline Customer 10 & -.061 & -.017 & .733 & .010 & .020 & .170 & -.032 & -.058 & .133 \\
\hline Customer 15 & .058 & -.029 & .700 & .122 & .079 & -.180 & .199 & -.051 & .004 \\
\hline Complexity 28 & -.008 & .209 & .255 & -.048 & .128 & -.079 & .084 & .029 & -.072 \\
\hline Transform 32 & -.009 & -.009 & .022 & .926 & .049 & -.071 & -.091 & -.007 & .080 \\
\hline Transform 33 & -.099 & .105 & -.042 & .763 & .048 & .020 & .016 & -.017 & .065 \\
\hline Transform 34 & -.121 & .159 & .026 & .432 & .008 & -.073 & -.091 & .173 & .042 \\
\hline Plan 14 & -.085 & .037 & .139 & -.044 & .704 & -.001 & -.129 & -.047 & -.109 \\
\hline Learning12 & -.050 & -.060 & .022 & .077 & .601 & .193 & -.047 & -.039 & -.046 \\
\hline Learning2 & .089 & .024 & -.048 & .121 & .554 & -.091 & .188 & -.133 & -.194 \\
\hline Learning21 & .310 & -.150 & -.046 & -.122 & .451 & .091 & .024 & .083 & .009 \\
\hline Leadership5 & .161 & -.057 & -.095 & .160 & .352 & -.066 & .049 & .119 & .249 \\
\hline Instability 17 & -.018 & .019 & -.012 & -.090 & .025 & .893 & .006 & -.070 & .094 \\
\hline Instability9 & -.028 & -.064 & .121 & -.018 & .131 & .415 & -.079 & .197 & .207 \\
\hline Complexity 26 & -.001 & .198 & .053 & .119 & .071 & .364 & .160 & .135 & -.195 \\
\hline Complexity 6 & .120 & .259 & .248 & .168 & .051 & .262 & -.226 & -.013 & .089 \\
\hline Competitors 13 & -.174 & .148 & .140 & -.101 & -.017 & -.097 & .819 & -.033 & .165 \\
\hline Competitors 24 & -.053 & -.061 & .251 & -.027 & -.083 & .150 & .539 & .007 & .120 \\
\hline Competitors 1 & .022 & -.109 & -.082 & -.026 & .192 & .270 & .345 & .154 & .232 \\
\hline Plan29 & -.139 & .371 & -.136 & -.087 & .066 & .110 & -.042 & .697 & -.071 \\
\hline Plan27 & .324 & -.155 & .100 & .251 & -.216 & -.130 & .032 & .653 & -.078 \\
\hline Instability3 & .128 & -.056 & .004 & .093 & -.110 & .137 & .200 & -.069 & .520 \\
\hline
\end{tabular}

Extraction Method: Principal Axis Factoring.

Rotation Method: Promax with Kaiser Normalization.

a. Rotation converged in 11 iterations.

A nine factor solution was generated after the removal of the 'complexity 6'

indicator. Total variation explained increased from $63.377 \%$ (Table 25) over the nine

factors to $64.163 \%$ with this solution. Table 26 is the pattern matrix for the nine factor 
solution showing only loadings greater than .3 and with indicator 'complexity 6 ' removed. The ninth factor is not readily interpretable. As this is the most important criterion for factor retention (Stevens, 2002), this factor was considered for rejection; however, indicators 'instability 3' and 'leadership 23' which make up the ninth factor were retained because they show loadings on other factors. Trial regressions were run using all eight independent factors versus without the 'Remaining Items' (i.e. ninth) factor and on the basis of the results, this factor was not used in the final model. However, as noted above, indicators 'instability 3' and 'leadership 23' were retained. 
Table 26 - Pattern Matrix for the Nine Factor Solution with Indicator 6 Removed and Showing only Loadings Greater Than 0.3

\begin{tabular}{|c|c|c|c|c|c|c|c|c|c|}
\hline & \multicolumn{9}{|c|}{ Factor } \\
\hline & Managers & Employees & Customers & Transformation & Flexibulty & $\begin{array}{l}\text { External } \\
\text { Environ }\end{array}$ & Compettiors & Plan & $\begin{array}{c}\text { Remaining } \\
\text { Items }\end{array}$ \\
\hline Employee8 & .930 & & & & & & & & \\
\hline Leadership7 & .777 & & & & & & & & \\
\hline Leadership16 & .685 & & & & & & & & \\
\hline Employee19 & .671 & & & & & & & & \\
\hline Complexity18 & .328 & & & & & & & & \\
\hline Employee11 & & .712 & & & & & & & \\
\hline Leadership31 & & .674 & & & & & & & \\
\hline Employee25 & & .626 & & & & & & & \\
\hline Instability 30 & & .509 & & & & & & .391 & \\
\hline Employee4 & .353 & .388 & & & & & & & \\
\hline Plan22 & & .353 & & & -.312 & & & & \\
\hline Customer20 & & & .902 & & & & & & \\
\hline Customer10 & & & .752 & & & & & & \\
\hline Customer15 & & & .640 & & & & & & \\
\hline Complexity28 & & & & & & & & & \\
\hline Transform32 & & & & .892 & & & & & \\
\hline Transform33 & & & & .759 & & & & & \\
\hline Transform34 & & & & .495 & & & & & \\
\hline Plan14 & & & & & .695 & & & & \\
\hline Learning12 & & & & & .605 & & & & \\
\hline Learning2 & & & & & .568 & & & & \\
\hline Learning21 & .317 & & & & .462 & & & & \\
\hline Leadership 5 & & & & & .352 & & & & \\
\hline Instability17 & & & & & & .877 & & & \\
\hline Instability9 & & & & & & .413 & & & \\
\hline Complexity26 & & & & & & .352 & & & \\
\hline $\begin{array}{l}\text { Competitors1 } \\
3\end{array}$ & & & & & & & .885 & & \\
\hline $\begin{array}{l}\text { Competitors2 } \\
4\end{array}$ & & & & & & & .578 & & \\
\hline Competitors 1 & & & & & & & .331 & & \\
\hline Plan29 & & .358 & & & & & & .712 & \\
\hline Plan27 & .305 & & & & & & & .666 & \\
\hline Instability 3 & & & & & & & & & .512 \\
\hline Leadership23 & .416 & & & & & & & & -.418 \\
\hline
\end{tabular}

Extraction Method: Principal Axis Factoring.

Rotation Method: Promax with Kaiser Normalization.

a. Rotation converged in 11 iterations. 


\subsubsection{Factor Correlations}

The Table 27 correlation table displays the factors which are used in the final Strategy Transformation Model. Most of the factors share some level of correlation with each other at either the .01 or .05 significance levels which adds to the credibility of using an oblique rotation during factor analysis (Preacher \& MacCallum, 2003). However, the correlations are not overly large, with 14 out of 28 being less than .3 . Only four are above .5 with all being below .6. Further, even if the correlations were larger, they would only affect the regression results if the dependent variable was regressed against each variable individually. When the dependent variable is regressed against all the independent variables at once, the correlations will not adversely affect the regression results (Gujarati \& Porter, 2009).

It should be noted that the dependent variable, transformation, is correlated significantly with all variables except flexibility, managers and customers. This is the first indication that a moderation effect may be at play with one or more of these three variables (Baron \& Kenny, 1986). 
Table 27 - Correlation Table of Factors Used in Final Strategy Transformation Model

\begin{tabular}{|c|c|c|c|c|c|c|c|c|}
\hline & Managers & Employees & Customers & $\begin{array}{l}\text { Transfor- } \\
\text { mation }\end{array}$ & Flexibility & $\begin{array}{c}\text { External } \\
\text { Environment }\end{array}$ & Competitors & $\begin{array}{c}\text { Intended } \\
\text { Plan }\end{array}$ \\
\hline Managers & 1 & & & & & & & \\
\hline Employees & $\begin{array}{l}.199 * \\
.014\end{array}$ & 1 & & & & & & \\
\hline Customers & $\begin{array}{c}.249 * * \\
.002\end{array}$ & $\begin{array}{c}.268^{* * *} \\
.001\end{array}$ & 1 & & & & & \\
\hline Transformation & $\begin{array}{l}0.03 \\
.714\end{array}$ & $\begin{array}{c}.271^{* *} \\
.001\end{array}$ & $\begin{array}{c}0.101 \\
.215\end{array}$ & 1 & & & & \\
\hline Flexibility & $\begin{array}{c}.358 * * \\
.000\end{array}$ & $\begin{array}{c}.252^{* *} \\
.002\end{array}$ & $\begin{array}{c}.532 * * \\
.000\end{array}$ & $\begin{array}{c}0.039 \\
.628\end{array}$ & 1 & & & \\
\hline $\begin{array}{l}\text { External } \\
\text { Environment }\end{array}$ & $\begin{array}{l}0.152 \\
.060\end{array}$ & $\begin{array}{l}.189 * \\
.019\end{array}$ & $\begin{array}{c}.330 * * \\
.000\end{array}$ & $\begin{array}{c}.353 * * \\
.000\end{array}$ & $\begin{array}{l}.207^{*} \\
.010\end{array}$ & 1 & & \\
\hline Competitors & $\begin{array}{c}.462^{* * *} \\
.000\end{array}$ & $\begin{array}{c}.315^{* *} \\
.000\end{array}$ & $\begin{array}{c}.556^{* *} \\
.000\end{array}$ & $\begin{array}{c}.379 * * \\
.000\end{array}$ & $\begin{array}{c}.518^{* * *} \\
.000\end{array}$ & $\begin{array}{c}.501 * * \\
.000\end{array}$ & 1 & \\
\hline $\begin{array}{l}\text { Intended } \\
\text { Plan }\end{array}$ & $\begin{array}{c}.258 * * \\
.001\end{array}$ & $\begin{array}{c}.250^{* *} \\
.002\end{array}$ & $\begin{array}{c}.328 * * \\
.000\end{array}$ & $\begin{array}{c}.478 * * \\
.000\end{array}$ & $\begin{array}{c}.307 * * \\
.000\end{array}$ & $\begin{array}{c}.277^{* *} \\
.001\end{array}$ & $\begin{array}{c}.330 * * \\
.000\end{array}$ & 1 \\
\hline
\end{tabular}

*. Correlation is significant at the 0.05 level ( 2 -tailed).

**. Correlation is significant at the 0.01 level (2-tailed).

\subsection{Post-EFA Model - The Strategy Transformation Model}

The EFA analysis conducted in section 11.7 yielded a set of latent constructs

which contribute to the transformation of intended strategy into realized strategy during strategy implementation. This section of the paper displays the results of the analysis which was carried out to determine the level of transformation of strategy which can be attributed to these constructs and any relationships which may exist between the constructs.

\subsubsection{Factor Internal Consistency or Reliability}

Table 28 lists the Cronbach's alphas for the factors in the Strategy Transformation Model. The managers, employees and customers factors are all above .7 and are 
therefore considered acceptable by current standards for either exploratory or follow-on research (Nunnally, 1978). Of the remaining five factors, flexibility, competitors and transformation are all near .7 with the lowest being .683 . The remaining two factors, external environment and plan, are above .6 and are considered acceptable given the exploratory nature of this research (Shay \& Baack, 2004). As such, all of the Strategy Transformation Model factors portray a single underlying construct to an acceptable level.

Table 28-Cronbach's Alphas for Strategy Transformation Model Factors

\begin{tabular}{|l|c|c|}
\hline \multicolumn{1}{|c|}{ Factor } & Number of Indicators & Cronbach's Alpha \\
\hline Managers & 5 & .792 \\
\hline Employees & 6 & .757 \\
\hline Customers & 4 & .766 \\
\hline Flexibility & 5 & .683 \\
\hline External Environment & 3 & .634 \\
\hline Competitors & 3 & .684 \\
\hline Plan & 2 & .604 \\
\hline Transformation Factor & 3 & .686 \\
\hline
\end{tabular}

\subsubsection{Regression Analysis without Moderators and Mediators}

Using SPSS, the dependent factor (i.e. transformation factor) was regressed against the seven independent factors. The results are shown in Tables 29 and 30 . Table 29 shows an R Square of .430 which indicates that $43 \%$ of the variance of the transformation factor can be explained by the independent factors in the premoderation/mediation model. 
Table 29 - Model Summary for the Pre-Moderation/Mediation Model

\begin{tabular}{|c|c|c|c|c|}
\hline Model & $\mathrm{R}$ & $\mathrm{R}$ Square & $\begin{array}{c}\text { Adjusted } \mathrm{R} \\
\text { Square }\end{array}$ & $\begin{array}{c}\text { Std. Error of the } \\
\text { Estimate }\end{array}$ \\
\hline 1 & $.655^{\mathrm{a}}$ & .430 & .402 & .71321312 \\
\hline
\end{tabular}

a. Predictors: (Constant), Intended Plan, Employees, Managers,

Environmental Instability, Flexibility, Customers, Competitors

In Table 30, all of the factors are significant with the exception of the external

environment factor ( $\mathrm{p}$-value $=.1$ ). Managers, competitors and intended plan are

significant at the .01 level (i.e. p-value $<.01$ ) with customers and flexibility very close to that level with p-values of .010 and .013 respectively.

Table 30 - Regression Details for Pre-Moderation/Mediation Model

\begin{tabular}{|c|c|c|c|c|c|c|}
\hline \multirow{2}{*}{\multicolumn{2}{|c|}{ Model }} & \multicolumn{2}{|c|}{ Unstandardized Coefficients } & \multirow{2}{*}{$\begin{array}{c}\begin{array}{c}\text { Standardized } \\
\text { Coefficients }\end{array} \\
\text { Beta }\end{array}$} & \multirow[b]{2}{*}{$t$} & \multirow[b]{2}{*}{ Sig. } \\
\hline & & $B$ & Std. Error & & & \\
\hline \multirow[t]{8}{*}{1} & (Constant) & $9.660 \mathrm{E}-17$ & .058 & & .000 & 1.000 \\
\hline & Managers & -.209 & .071 & -.214 & -2.944 & .004 \\
\hline & Employees & .146 & .068 & .145 & 2.156 & .033 \\
\hline & Customers & -.208 & .080 & -.213 & -2.604 & .010 \\
\hline & Flexibility & -.209 & .083 & -.200 & -2.502 & .013 \\
\hline & External Environment & .126 & .076 & .123 & 1.654 & .100 \\
\hline & Competitors & .458 & .097 & .444 & 4.734 & .000 \\
\hline & Intended Plan & .461 & .072 & .448 & 6.415 & .000 \\
\hline
\end{tabular}

a. Dependent Variable: Transformation

\subsubsection{Factor Moderation and Mediation}

The pre-moderation/mediation model $\mathrm{R}$ Square value of .43 does not take moderation level relationships into account. Recalling the Figure 3 a priori model, this lack of knowledge with respect to any relationships that exist between the factors was depicted pictorially by the factors existing together in a bubble in the space between the intended and realized strategies through which the implementation proceeds. Baron and Kenny's (1986) definitive process for determining the presence of moderators and 
mediators will be employed to ascertain whether relationships exist between the model's variables.

To determine the presence of moderation, the dependent variable $(\mathrm{Y})$ is regressed on the suspected moderator $(Z)$, the associated independent variable $(X)$ and the product of these two variables (i.e. $\mathrm{Y}=\mathrm{X}+\mathrm{Z}+\mathrm{XZ}$ ). Moderation is revealed by $\mathrm{XZ}$ showing a significant effect (Baron \& Kenny, 1986).

As noted in Section 11.7.2, there is some indication that flexibility may be a moderator. As such, flexibility was tested against the remaining variables for moderation effects. Flexibility was shown to moderate the effects of the managers factor $(p=.024)$ and the employees factor $(\mathrm{p}=.052)$. While .052 is slightly higher than .05 , a $\mathrm{p}$-value of only 2-thousands higher than the cut-off is considered to be within reasonable bounds.

To ensure that other moderating relationships were not missed, the Baron and Kenny (1986) test was performed using combinations of all the remaining variables. During this analysis, a moderating relationship was discovered between the external environment and competitors factors. The indicators which made up the external environment factor were the instability, unpredictability and complexity of the environment. Since it would be unreasonable to assume that competitors' actions could moderate the totality of the external environment defined in this way, competitors did not seem to be the moderator. However, the impacts of the external environment would be capable of moderating the actions of competitors. Interview 4 provided an example of this moderating relationship whereby the recession which began in 2008 moderated the actions of the competitors of the retail firm, resulting in a significant change in Company 
D's strategy. Therefore, the external environment was designated as the moderator in this relationship.

A mediator is a variable that accounts for some level of the effect that exists between an independent variable and dependent variable. Baron and Kenny (1986) define three tests to determine the presence of a mediator. First, the mediator is regressed on the independent variable resulting in a significant effect. Second, the dependent variable is regressed on the independent variable resulting in a significant effect. Third, the dependent variable is regressed on the independent variable and the mediator, with the mediator showing a significant effect. If a potential mediator passes these tests, its existence can be confirmed by a decrease in the effect of the associated independent variable when the mediator is removed. The only variable combination that passed all three tests was flexibility which acts as a mediator for competitors. The existence of flexibility as a mediator is confirmed in Tables 31 and 32 . Note that when flexibility is present, the competitors factor has an effect of $13.4 \%$ (Table 31 ). However, when

flexibility is removed, the effect of competitors drops to $10.7 \%$ (Table 32).

\section{Table 31 - Regression Results Showing the Effect of Competitors when Flexibility is Present}

Dependent Variable:Transformation
\begin{tabular}{|l|c|c|c|c|c|c|}
\hline Source & $\begin{array}{c}\text { Type III Sum of } \\
\text { Squares }\end{array}$ & df & Mean Square & F & Sig. & $\begin{array}{c}\text { Partial Eta } \\
\text { Squared }\end{array}$ \\
\hline Corrected Model & $55.533^{\mathrm{a}}$ & 7 & 7.933 & 15.596 & .000 & .430 \\
Intercept & .000 & 1 & .000 & .000 & 1.000 & .000 \\
Managers & 4.409 & 1 & 4.409 & 8.668 & .004 & .056 \\
Employees & 2.365 & 1 & 2.365 & 4.649 & .033 & .031 \\
Customers & 3.449 & 1 & 3.449 & 6.780 & .010 & .045 \\
Flexibility & 3.184 & 1 & 3.184 & 6.260 & .013 & .041 \\
External Environ & 1.391 & 1 & 1.391 & 2.734 & .100 & .019 \\
\hline Competitors & 11.402 & 1 & 11.402 & $\mathbf{2 2 . 4 1 4}$ & .000 & .134 \\
\hline IntendedPlan & 20.931 & 1 & 20.931 & 41.149 & .000 & .221 \\
Error & 73.758 & 145 & .509 & & & \\
Total & 129.291 & 153 & & & & \\
Corrected Total & 129.291 & 152 & & & & \\
\hline
\end{tabular}

a. R Squared $=.430$ (Adjusted R Squared $=.402$ ) 


\section{Table 32 - Regression Results Showing the Effect on Competitors when Flexibility is Removed}

Dependent Variable:Transformation
\begin{tabular}{|l|c|c|c|c|c|c|}
\hline Source & $\begin{array}{c}\text { Type III Sum of } \\
\text { Squares }\end{array}$ & df & Mean Square & F & Sig. & $\begin{array}{c}\text { Partial Eta } \\
\text { Squared }\end{array}$ \\
\hline Corrected Model & $52.349^{\mathrm{a}}$ & 6 & 8.725 & 16.556 & .000 & .405 \\
Intercept & .000 & 1 & .000 & .000 & 1.000 & .000 \\
Managers & 5.660 & 1 & 5.660 & 10.740 & .001 & .069 \\
Employees & 2.081 & 1 & 2.081 & 3.949 & .049 & .026 \\
Customers & 6.718 & 1 & 6.718 & 12.747 & .000 & .080 \\
External Environ & 1.874 & 1 & 1.874 & 3.556 & .061 & .024 \\
\hline Competitors & 9.259 & 1 & 9.259 & 17.570 & .000 & .107 \\
\hline IntendedPlan & 19.535 & 1 & 19.535 & 37.067 & .000 & .202 \\
Error & 76.942 & 146 & .527 & & & \\
Total & 129.291 & 153 & & & & \\
Corrected Total & 129.291 & 152 & & & & \\
\hline
\end{tabular}

a. R Squared $=.405$ (Adjusted $\mathrm{R}$ Squared $=.380$ )

Baron and Kenny note that "mediators explain how external physical events take on internal psychological significance" (1986 p. 1176). This definition fits well the relationship between flexibility and competitors. The external physical actions of competitors take on internal psychological significance through internal organizational reactions which are a function of the flexibility of the organization. This inter-company interaction has been likened to the co-evolution of species by some researchers in that the actions of a firm's competitors can have an impact on the evolution of a firm and vice versa (Ganco \& Agarwal, 2009). In this case, the reaction or evolution of the firm relative to competitors' actions is a function of the mediation of those actions by the flexibility of the organization. By way of example, a competitor's external physical action might be the introduction of an innovative new product to a firm's marketplace. This action is then passed through the mediator of the firm's flexibility in influencing the reaction of the firm or the transformation of the firm's strategy. In reaction, a firm with a low level of flexibility may not develop new perspectives or look at the opportunities arising from the competitor's actions. In this case, the internal psychological significance 
would be low. However, a firm with a high level of flexibility may have a flexible intended strategy which allows them to quickly develop and share new perspectives and exploit opportunities which present themselves through this situation. If so, the competitor's action would lead to a high level of internal psychological significance. This situation was exemplified in Interview 4 whereby Company D's competitors took actions which flowed through the mediating effect of the flexibility of the firm and led to changes in the firm's strategy. In this case, the physical actions of the competitors took on a high level of internal psychological significance as the firm re-evaluated its basic assumptions relative to growth and adjusted its strategy accordingly.

\subsubsection{Regression Analysis of Final Strategy Transformation Model}

The dependent factor (i.e. transformation factor) was regressed against the ten independent factors, including the three product variables which represent the moderation influences (e.g. FlexibilityXXManagers indicates the moderating interaction of the flexibility factor on the managers factor). The results are shown in Tables 33 and 34. Table 33 shows an $\mathrm{R}$ Square of .446 which indicates that $44.6 \%$ of the variance of the transformation factor can be explained by the independent factors in the Strategy Transformation Model.

Table 33 - Model Summary of Final Strategy Transformation Model

\begin{tabular}{|c|c|c|c|c|}
\hline Model & $\mathrm{R}$ & $\mathrm{R}$ Square & $\begin{array}{c}\text { Adjusted R } \\
\text { Square }\end{array}$ & $\begin{array}{c}\text { Std. Error of the } \\
\text { Estimate }\end{array}$ \\
\hline 1 & $.668^{\mathrm{a}}$ & .446 & .407 & .71013124 \\
\hline
\end{tabular}

a. Predictors: (Constant), Environlnstability XXCompetitors, Intended Plan, FlexibilityXXEmployees, FlexibilityXXManagers, Managers, Employees, Environmental Instability, Customers, Flexibility, Competitors 
In Table 34, all of the factors are significant with the exception of the customers factor $(\mathrm{p}$-value $=.08)$ and the three moderation interaction variables. Flexibility, competitors and intended plan are significant at the .01 level (i.e. p-value $<.01$ ) with managers very close to that level with a p-value of .010. Managers' actions, customers' actions and flexibility all have negative coefficients indicating that as these variables increase, the level of transformation of the applicable strategy decreases.

Table 34 - Regression Details of Final Strategy Transformation Model

\begin{tabular}{|c|c|c|c|c|c|c|}
\hline \multirow{2}{*}{\multicolumn{2}{|c|}{ Model }} & \multicolumn{2}{|c|}{ Unstandardized Coefficients } & \multirow{2}{*}{$\begin{array}{c}\text { Standardized } \\
\text { Coefficients } \\
\text { Beta }\end{array}$} & \multirow[b]{2}{*}{ t } & \multirow[b]{2}{*}{ Sig. } \\
\hline & & $\mathrm{B}$ & Std. Error & & & \\
\hline \multirow[t]{11}{*}{1} & (Constant) & .003 & .066 & & .051 & .959 \\
\hline & Managers & -.204 & .078 & -.208 & -2.615 & .010 \\
\hline & Employees & 152 & .073 & .151 & 2.073 & .040 \\
\hline & Customers & -.152 & .086 & -.156 & -1.762 & .080 \\
\hline & Flexibility & -.252 & .090 & -.242 & -2.810 & .006 \\
\hline & External Environ & .161 & .082 & 157 & 1.962 & .052 \\
\hline & Competitors & 432 & 099 & 419 & 4.378 & .000 \\
\hline & Intended Plan & .421 & .075 & 409 & 5.636 & .000 \\
\hline & FlexibilityXXManagers & -.065 & .075 & -.067 & -.871 & .385 \\
\hline & FlexibilityXXEmployees & -.106 & .073 & -.102 & -1.452 & .149 \\
\hline & ExtEnviron $X X$ Competitors & .094 & .071 & .103 & 1.324 & .188 \\
\hline
\end{tabular}

a. Dependent Variable: Transformation

Table 35 shows the level of effect of each of the variables. The highest effect comes from the characteristics of the intended plan at $18.3 \%$. Competitors' actions have a high level of effect at $11.9 \%$. Managers' actions and flexibility also have a strong effect at approximately $5 \%$ each. Flexibility has an added effect through its moderating and mediating influences on managers, employees and competitors. These Strategy Transformation Model regression results are discussed in Section 12.3. 
Table 35 - Regression Results Showing the Effects of Each Variable

Tests of Between-Subjects Effects

Dependent Variable:Transformation

\begin{tabular}{|c|c|c|c|c|c|c|}
\hline Source & $\begin{array}{l}\text { Type III Sum } \\
\text { of Squares }\end{array}$ & df & Mean Square & $F$ & Sig. & $\begin{array}{l}\text { Partial Eta } \\
\text { Squared }\end{array}$ \\
\hline Corrected Model & $57.682^{\mathrm{a}}$ & 10 & 5.768 & 11.438 & .000 & .446 \\
\hline Intercept & .001 & 1 & .001 & .003 & .959 & .000 \\
\hline Managers & 3.449 & 1 & 3.449 & 6.839 & .010 & .046 \\
\hline Employees & 2.167 & 1 & 2.167 & 4.297 & .040 & .029 \\
\hline Customers & 1.566 & 1 & 1.566 & 3.106 & .080 & .021 \\
\hline Flexibility & 3.982 & 1 & 3.982 & 7.897 & .006 & .053 \\
\hline External Environ & 1.941 & 1 & 1.941 & 3.849 & .052 & .026 \\
\hline Competitors & 9.666 & 1 & 9.666 & 19.168 & .000 & .119 \\
\hline IntendedPlan & 16.021 & 1 & 16.021 & 31.769 & .000 & .183 \\
\hline Flexibility XXManagers & .382 & 1 & .382 & .758 & .385 & .005 \\
\hline FlexibilityXXEmployees & 1.063 & 1 & 1.063 & 2.107 & .149 & .015 \\
\hline $\begin{array}{l}\text { Ext } \\
\text { EnvironXXCompetitors }\end{array}$ & .884 & 1 & .884 & 1.754 & .188 & .012 \\
\hline Error & 71.609 & 142 & & & & \\
\hline Total & 129.291 & 153 & & & & \\
\hline Corrected Total & 129.291 & 152 & & & & \\
\hline
\end{tabular}

a. $\mathrm{R}$ Squared $=.446$ (Adjusted R Squared $=.407$ )

\subsection{Data Segmentation}

The 153 usable responses to the survey contained questions which allowed the sample to be sub-divided along a number of lines. For example, question 40 asked respondents to report if the company used in the example was a publicly or privately owned company. Using these responses, a number of regressions of the Strategy Transformation Model were run while controlling for various descriptive variables. The results of the regressions with segmented data are displayed in Table 36. 
Table 36 - Model Summary Information for Segmented Data

\begin{tabular}{|c|c|c|c|c|c|}
\hline Data Set & $\mathbf{N}$ & $\mathbf{R}^{2}$ & $\begin{array}{c}\text { Adjusted } \\
\mathbf{R}^{2} \\
\end{array}$ & Significance & $\begin{array}{c}\mathrm{R}^{2} \text { Different? } \\
\text { Significance }\end{array}$ \\
\hline $\begin{array}{l}\text { Full Data Set } \\
\text { Company } \\
\text { Ownership }\end{array}$ & 153 & 0.446 & 0.407 & 0.000 & \multirow{7}{*}{$\begin{array}{c}<50 \mathrm{M} \text { vs }>100 \mathrm{M} \\
.215\end{array}$} \\
\hline Public & 71 & 0.606 & 0.541 & 0.000 & \\
\hline Private & 82 & 0.386 & 0.299 & 0.000 & \\
\hline $\begin{array}{l}\text { Company Size } \\
\text { (Annual } \\
\text { Revenue) }\end{array}$ & & & & & \\
\hline$\leq \$ 50$ million & 61 & 0.382 & 0.259 & 0.004 & \\
\hline$\leq \$ 100$ million & 80 & 0.451 & 0.371 & 0.000 & \\
\hline $\begin{array}{l}\geq \$ 100 \text { million } \\
\text { Headquarters } \\
\text { Location }\end{array}$ & 73 & 0.542 & 0.468 & 0.000 & \\
\hline Canada & 99 & 0.489 & 0.431 & 0.000 & \multirow[t]{2}{*}{.682} \\
\hline $\begin{array}{l}\text { Outside Canada } \\
\text { Industry }\end{array}$ & 54 & 0.437 & 0.307 & 0.003 & \\
\hline $\begin{array}{l}\text { Industry } \\
\text { Financial }\end{array}$ & 22 & 0.774 & 0.568 & 0.020 & \multirow[t]{2}{*}{.881} \\
\hline Defence & 19 & 0.794 & 0.534 & 0.062 & \\
\hline $\begin{array}{l}\text { Respondent } \\
\text { Experience }\end{array}$ & & & & & \multirow{3}{*}{.219} \\
\hline$\leq 18$ years (mean) & 75 & 0.401 & 0.307 & 0.000 & \\
\hline$>18$ years $($ mean) & 78 & 0.547 & 0.479 & 0.000 & \\
\hline
\end{tabular}

Of the various data segmentation regression results shown in Table 36, the only difference in R Squares that is close to a $95 \%$ confidence level that the R Squares are really different is for public versus private companies with a p-value of .057 (see Table 36 final column). Therefore, although the remaining paragraphs in this section discuss the R Squares in Table 36 for the various data segments, it should be noted that there is less than $95 \%$ confidence that these $\mathrm{R}$ Squares are truly different.

When results for publicly owned companies are compared with those for privately owned companies, public companies have a higher R Square (.606) or potentially better model fit than private companies (.386). Company size R Squares show that the model tends to fit the data better as the size of the company in annual revenue increases. 
Section 11.4 noted that company size was strongly associated with ownership status with 39 of the $82(47.6 \%)$ private companies having annual revenue under $\$ 10$ million. Fourteen of the $71(19.7 \%)$ publicly owned companies had annual revenues over $\$ 10$ billion while 50 of the 71 (70.4\%) companies had annual revenues over $\$ 100$ million. The inference is that the model fits better for larger companies.

The segmented data for company headquarters location shows a similar $\mathrm{R}$ Square or model fit for the 54 companies outside and 99 companies within Canada. This would suggest that the model may have a level of applicability across national boundaries.

Because there were a large number of options for the industry survey item, the number of responses for each industry is low. However, the regressions were run for the two industries which had the largest number of responses: financial with 22 responses and defence with 19 responses. Both industries showed a better model fit statistic than the fit for the full data set (i.e. R Squares of .774 and .794 versus .446); however, the sample sizes are quite small. Further, while financial was significant at .020 , defence was just below a significant level at .062 .

Finally, model fit was compared against respondents' experience. The average years of experience for the respondents was 18.4 years. The $\mathrm{R}$ Square for respondents with less than or equal to 18 years experience was .401 or less than the full data set statistic. The R Square for respondents with greater than 18 years experience was .547 which was larger than the statistic for the less experienced group and larger than the statistic for the whole data set. The inferences of the applicability of the model to the various data segments are discussed in Section 12.5. 


\subsection{Factors and Associated Indicators for the Strategy Transformation Model}

Table 37 lists the final Strategy Transformation Model factors and associated indicators or survey items. These associations come from the results of EFA.

Table 37 - Factors and Associated Indicators for the Strategy Transformation Model

\begin{tabular}{|c|c|}
\hline Factor & Indicators \\
\hline \begin{tabular}{|l} 
Managers' Actions \\
\end{tabular} & $\begin{array}{l}\text { Communication by the firm of its strategic } \\
\text { goals and priorities to the whole firm. } \\
\text { Leadership team support of the strategy. } \\
\text { Managers sharing a detailed and consistent } \\
\text { understanding of the business. } \\
\text { Participation of low and mid-level } \\
\text { managers in the strategic planning process. } \\
\text { Diversity in the customers and markets } \\
\text { served by the firm. }\end{array}$ \\
\hline \begin{tabular}{|l|} 
Employees' Actions \\
\end{tabular} & $\begin{array}{l}\text { Tendency of individuals in an organization } \\
\text { to pursue the objectives or goals of their } \\
\text { position or group instead of the stated goals } \\
\text { of the whole organization. } \\
\text { Changes in key personnel. } \\
\text { Resistance to change of the organization. } \\
\text { Unavailability of resources. } \\
\text { Authority of lower level managers to make } \\
\text { decisions and take initiative in response to } \\
\text { the changing environment. } \\
\text { Rigidity of the planned strategy. }\end{array}$ \\
\hline
\end{tabular}




\begin{tabular}{|l|l|}
\hline \multicolumn{1}{|c|}{ Factor } & \multicolumn{1}{c|}{ Indicators } \\
\hline Customers' Actions & Rate of change of customer needs. \\
Speed of change in demand trends. \\
Customer demand for innovation in the \\
firm's market. \\
Government regulatory requirements.
\end{tabular}




\begin{tabular}{|l|l|}
\hline \multicolumn{1}{|c|}{ Factor } & \multicolumn{1}{c|}{ Indicators } \\
\hline Strategy Transformation & $\begin{array}{l}\text { Level that the primary goals of the strategic } \\
\text { plan were implemented and achieved as } \\
\text { originally planned. }\end{array}$ \\
& $\begin{array}{l}\text { Level that the secondary goals of the } \\
\text { strategic plan were implemented and } \\
\text { achieved as originally planned. } \\
\text { Level that the process of implementing the } \\
\text { strategy was carried out exactly as planned. }\end{array}$ \\
\hline
\end{tabular}




\subsection{DISCUSSION}

\subsection{A Priori Factor / Indicator Loadings}

The first step in this research was to develop an a priori model of strategy transformation based upon the factors and underlying indicators present in the literature. The indicators were associated with underlying factors based upon the evidence and assertions found in published papers as well as the best judgement of this researcher. Interviews were then conducted with executives to validate the factors and to determine if other indicators should be included which had not been found in the strategy research. Based upon the interviews, five additional indicators were added to the model and these were associated with particular factors by the researcher. Table 17 (Section 11.6) shows the loadings of the a priori factors on the associated indicators. As should be expected based upon the exploratory nature of this research, several of the indicators are not significantly loaded. Each of these low loading indicators is discussed below.

Environmental instability 30 (loading .382 ) related to the unavailability of resources. This indicator was associated with the external environment in the a priori model because resources such as capital, people and raw materials are generally found in the environment external to the firm. In the final model, as a result of factor analysis, this indicator was loaded most highly by issues related to employees (loading .509). It may be that the question was interpreted by respondents to mean unavailability of human resources. In future studies, this indicator could be broken into several more specific indicators such as unavailability of human resources, unavailability of capital, unavailability of raw materials and additional indicators which relate to other types of necessary resources. 
Leadership 5 (loading .288) assessed the impact on strategy transformation of the tendency toward opportunity taking by the firm. It was associated with leadership because the decisions related to opportunity taking by the firm were assumed to be a leadership function. In the final model, Leadership 5 moved to the flexibility factor with a loading of .352 . While still not a high level of loading, this indicator seemed to naturally fit with other indicators related to the flexibility inherent in the firm. The indicators underlying the flexibility factor are related to various characteristics or actions of the firm's leadership (see Table 37).

Leadership 31 (loading .093) related to changes in key personnel. This factor was related to leadership because it was assumed, based on the strategy examples in the interviews, that these key personnel would generally be in leadership roles. In the final model, Leadership 31 was associated with the employees factor (loading .674) indicating that the applicable key personnel could be in various employment roles throughout the organization. While most of the examples which arose in the interviews related to senior leadership (e.g. the CEO in Interview 2), there was an example in Interview 4 of the impact of a change in human resources manager. In retrospect, the employees factor is a better location for this factor given that the key person in question could be the CEO, but it could also be a particular software designer, technical librarian or salesperson.

Plan 14 (loading .027) questioned the impact of the flexibility inherent in the planned strategy on strategy transformation. Because it was focused on a characteristic of the planned strategy, it was placed in the plan characteristics factor in the a priori model. In the final model, this indicator was associated with the flexibility factor (loading .695). This may indicate that the flexibility built into the strategy is more than 
simply a characteristic of the plan itself. It may be that the level of flexibility built into the plan is a function of the flexibility inherent in the mindset and culture of the firm and its leadership. As such, this indicator is more closely aligned with other indicators that underlie a factor which seeks to assess the overall flexibility of the firm.

Of the four indicators which experienced low loadings in the a priori model, two were indicators which were added based upon the results of the interviews. These indicators were aligned with factors based solely upon the judgement of this researcher. The use of factor analysis for the final Strategy Transformation Model provided more appropriate factor associations for these indicators.

\subsection{A Priori Model to Final Strategy Transformation Model Mapping}

The differences between the a priori model and the final Strategy Transformation Model include both new factors and the re-alignment of indicators. Section 12.1 discussed the movement of indicators which had particularly low loadings in the a priori model. However, a number of other indicators were also re-aligned in the final model.

The a priori or literature based model had eight independent factors while the Strategy Transformation Model has seven, with both having one dependent factor. The dependent factor and its indicators stayed the same in both models. Table 38 lists the factors for the two models with the factors in the left column transforming into the factors in the right column on a row by row basis. The bullets in the right column specifically refer to changes relative to the a priori factors in the left column. The Strategy Transformation Model factors in the right column were developed through the use of factor analysis techniques. 
Table 38 - $A$ Priori and Final Strategy Transformation Model Factors

\begin{tabular}{|c|c|}
\hline A Priori Factors & $\begin{array}{l}\text { Strategy Transformation Model Factors noting } \\
\text { changes relative to the a priori factors / indicators }\end{array}$ \\
\hline Competitors' Actions & $\begin{array}{l}\text { Competitors' Actions } \\
\text { - No change. }\end{array}$ \\
\hline $\begin{array}{l}\text { Changes in Customer } \\
\text { Requirements }\end{array}$ & $\begin{array}{l}\text { Customers Actions } \\
\text { - Added: } \\
\text { o Government regulatory requirements. }\end{array}$ \\
\hline $\begin{array}{l}\text { Characteristics of the Intended } \\
\text { Strategy }\end{array}$ & $\begin{array}{l}\text { Characteristics of the Intended Plan } \\
\text { - Removed: } \\
\circ \text { Flexibility inherent in the planned } \\
\text { strategy. } \\
\circ \text { Rigidity of the planned strategy. }\end{array}$ \\
\hline Employee Involvement & $\begin{array}{l}\text { Employees Actions } \\
\text { - Added: } \\
\circ \text { Changes in key personnel. } \\
\circ \text { Unavailability of resources. } \\
\circ \text { Rigidity of the planned strategy. } \\
\text { - Removed: } \\
\circ \text { Participation of low and mid-level } \\
\text { managers in the strategic planning } \\
\text { process. } \\
\circ \text { Communication by the firm of its } \\
\text { strategic goals and priorities to the } \\
\text { whole firm. }\end{array}$ \\
\hline Organizational Learning Ability & 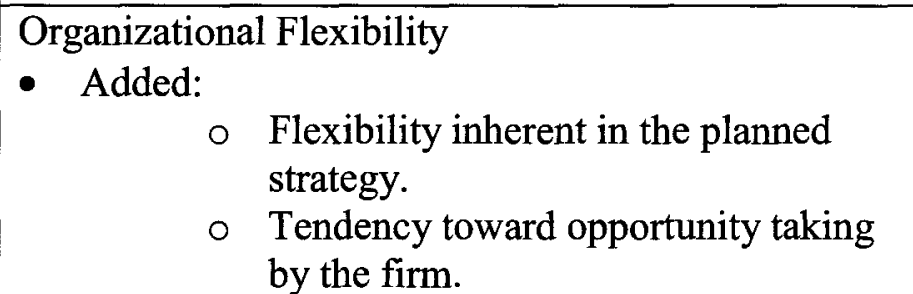 \\
\hline
\end{tabular}




\begin{tabular}{|c|c|}
\hline A Priori Factors & $\begin{array}{l}\text { Strategy Transformation Model Factors noting } \\
\text { changes relative to the a priori factors / indicators }\end{array}$ \\
\hline Leadership Team Characteristics & $\begin{array}{ll}\text { Managers' Actions } \\
\text { - Added: }\end{array}$ \\
\hline $\begin{array}{l}\text { Environmental Complexity } \\
\text { (two separate factors) }\end{array}$ & 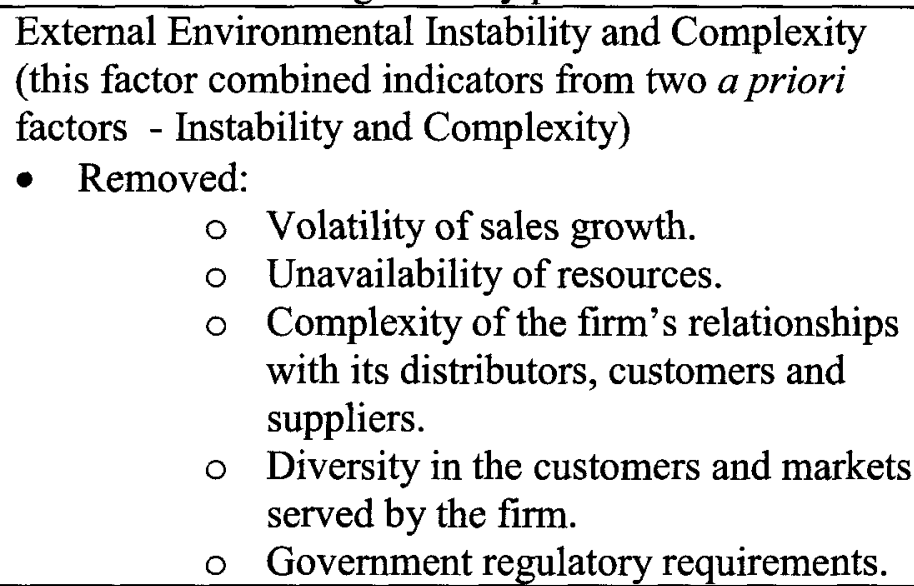 \\
\hline Strategy Transformation & $\begin{array}{l}\text { Strategy Transformation } \\
\text { - No change. }\end{array}$ \\
\hline \multicolumn{2}{|c|}{$\begin{array}{l}\text { Additional Changes } \\
\text { - Due to non-specificity of loading from any individual factor, complexity of the firm's } \\
\text { relationships with its distributors, customers and suppliers was not included in the } \\
\text { final model. } \\
\text { Two indicators made up a possible factor in the final model but the indicators could } \\
\text { not be interpreted as underlying a single factor. The two indicators were retained in } \\
\text { the model as contributors to the other factors but were not entered separately into the } \\
\text { regression. These two indicators are: volatility of sales growth; and managers' use of } \\
\text { previously acquired experiential knowledge during strategy implementation. }\end{array}$} \\
\hline
\end{tabular}


As seen in Table 38, the factor relating to competitors retained the same indicators in both models. The customers factor received one additional indicator - government regulatory requirements. This indicator moved from the a priori environmental complexity factor and seems to indicate that the government was thought of as a customer by some respondents while other respondents may have interpreted government regulation as it specifically pertained to the actions of their firms' customers. For example, in Interview 5 the defence firm's customer was the US government while in Interview 3, the satellite telecom company's customers' actions were regulated by various government bodies.

The a priori factor related to characteristics of the intended strategy was renamed to characteristics of the intended plan. The name was changed to reflect that the factor included elements of the intended strategy and the implementation plan. For example, a particular strategy might be feasible (e.g. increase market penetration in Asia) while the implementation plan might make the strategy unattainable due to its specific choices of milestones, resources or process. The plan factor lost the indicator related to flexibility of the planned strategy as it moved to the organizational flexibility factor. As such, it is part of the overall flexibility portrayed by this factor. Rigidity of the planned strategy moved to employee actions. As seen in Table 34, employee actions has a positive Beta indicating that the greater the level of employee actions, the greater the level of transformation of the strategy (e.g. indicators include resistance to change and sub-goal pursuit). This could also be said for the rigidity indicator which had a predictable negative loading (-.312) from the flexibility factor. 
The employee actions factor added the changes to key personnel and unavailability of resources indicators as discussed in section 12.1. Employee actions lost the indicators related to: participation of low and mid-level managers in the strategic planning process; and communication by the firm of its strategic goals and priorities to the whole firm. Both of these indicators moved to the managers' actions factor which seems logical given that they are both actions specifically under the control of managers.

The a priori organizational learning factor was renamed organizational flexibility given the addition of two indicators: flexibility inherent in the planned strategy; and tendency toward opportunity taking by the firm. These two indicators broadened the factor beyond learning to the more encompassing factor related to the overall flexibility of the firm.

The a priori leadership team characteristics factor was renamed managers' actions in recognition of the inclusion of the low and mid-level managers indicator and the fact that leadership in the firm can come from various levels of managers i.e. not just the senior leadership level. The diversity in the customers and markets served by the firm indicator was also added. This indicator portrays a key activity of management, that being the choice of markets and customers to be targeted. The indicator related to managers' use of previously acquired experiential knowledge during strategy implementation was removed. This indicator was one of the two indicators which made up an eighth factor which was not used in the final model due to its non-interpretable nature. However, this indicator and volatility of sales growth were retained in the final model because of their loadings on other factors. 
The a priori factors relating to instability and complexity of the external environment were combined into one factor during factor analysis but a number of the indicators from the two a priori factors moved to different final model factors. All of the removed indicators have already been discussed in the paragraphs above. The final factor included three indicators: instability; unpredictability; and complexity of the external environment.

\subsection{The Final Strategy Transformation Model}

The Strategy Transformation Model is depicted in Figure 15 and shows both the factors and their interactions with one another. The factor with the greatest impact on transformation is competitors with a SB of .419 (the SB is shown in the bracket near the arrowhead). This SB is positive indicating that as the actions underlying the competitors factor increase, the level of strategy transformation also increases. The predicted actions of competitors are fundamental to the formulation of strategic plans; however, since particular competitors may not be sure themselves of their future actions, it is extremely difficult for a monitoring firm to predict them. This can lead to shifts in a firm's strategy as competitors change their approaches to a market. As competition increases, strategic shifts can become more rapid and profound (Blythe and Zimmerman, 2004). As noted in Section 7.3.2, high levels of competition make flexibility and speed in the strategy formation and implementation processes essential. 
Figure 15 - Final Strategy Transformation Model

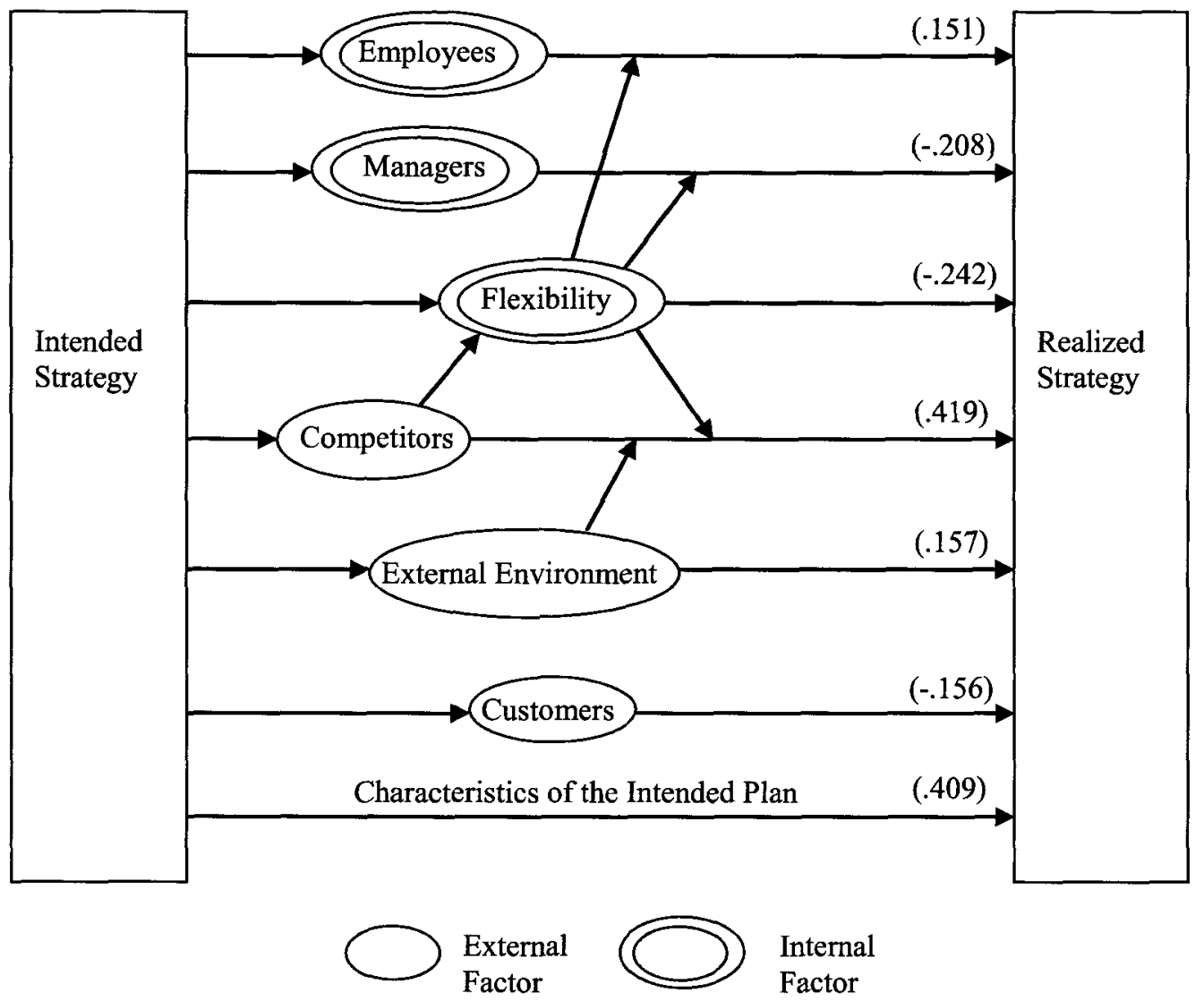

Figure 15 shows that the competitors' actions factor interacts with both flexibility and the external environment. Flexibility mediates the impact of competitors such that the impact of competitors' actions on strategy transformation is greater when flexibility is present (see Tables 31 and 32). The external environment moderates competitors' actions as these actions change due to the environment in which these competitors must function. For example, in an expanding and profitable market such as that experienced by the high tech sector in the late 1990 s and early 2000 s, competitors might be more prone to invest in new product introduction and marketing, thereby making the market more competitive. However, a more unstable, unpredictable and complex environment may make firms more conservative, thereby resulting in a less competitive market. 
Interviewee 4 noted the moderating impact of the external environment on his firm's competitors' actions (i.e. lowered prices) which resulted in a change in Company D's strategy. These competitors' actions were mediated by Company D's flexibility in their impact on Company D's strategy.

The second highest SB belongs to characteristics of the intended plan at .409 . Hence, the more ambitious or unfeasible the plan, the more its impact on the transformation of strategy (see Interview 1). This factor did not display mediation or moderation interactions with any of the other factors.

Flexibility has the third highest SB at -.242 which indicates that the higher the level of flexibility the lesser the level of strategy transformation. The more flexible the firm's management and the general culture of the organization, the more an organization has the adaptability to exploit opportunities or pursue innovations as they arise (Miller and Cardinal, 1994; Rudd et al., 2008). This can allow a firm to tale a 'planned emergence' approach whereby it develops strategic plans but retains considerable flexibility to adjust strategies as required to react to changeable conditions (Grant, 2003). A flexible intended strategy allows an organization to pursue objectives which are sufficiently broad to allow change to occur at the tactical level while transformation of the plan at the strategic level is minimized.

Flexibility also has interaction effects with three other factors. As discussed above, it mediates the impact of competitors' actions. It also moderates the impacts of managers' actions (fourth highest SB) and employees' actions (sixth highest SB). In the case of managers (SB of -.208), actions such as communications of the strategy to the firm, leadership support of the strategy, and sharing a detailed understanding of the 
business among themselves decreases the level of transformation of strategy.

Remembering that a decrease in the transformation of strategy means a higher level of goal attainment, it seems reasonable that greater communication of the strategy in the firm, more leadership support of the strategy and a higher level of understanding of the business by managers would lead to higher strategic goal attainment. These sorts of actions, and participation of lower level managers in the strategy formulation process (Falshaw et al., 2006; Greenley, 1994; Parnell \& Lester, 2003), also lead to more effective strategies being developed and implemented (Schaffer and Willauer, 2003). Flexibility moderates this factor such that the more flexible the organization, the more these managers' actions are allowed to apply, thereby reducing the transformation of strategy.

Flexibility moderates employees' actions (SB of .152). As defined in the model, these actions include resistance to change, sub-goal pursuit and unavailability of resources. Because of the positive coefficient, the higher the level of employees' actions, the higher the level of strategy transformation. Flexibility moderates this factor such that a more flexible organization (e.g. one that allows more participation of employees in the planning process) may have less organizational resistance to change and less tendency among the employees to pursuit goals which conflict with the strategic goals of the whole organization (Ketokivi \& Castañer, 2004).

The fifth highest SB is external environmental instability and complexity at .161. The positive coefficient indicates that instability, unpredictability and complexity of the environment lead to higher levels of strategy transformation. As Levy (1994) might state it, the more chaotic the environment, the more may be the need for the strategy to 
transform during implementation to remain viable. In general, firms in more unstable environments tend to have more emergent strategies (Harrington et al., 2004) and therefore see more strategy transformation. Studies have found that such firms tend to employ a mix of deliberate and emergent strategies (Andersen, 2004; Brews and Hunt, 1999; Grant, 2003) which may be an acknowledgement that strategy transformation will occur.

The customers' actions factor is the seventh highest SB (-.152) but it should be noted that this is the only individual factor which does not have a significant $p$-value (.080). Therefore, this factor has the lowest impact on the transformation of strategy from a standardized beta perspective and in any case, it may not be statistically relevant. This result was foreshadowed during the qualitative analysis when changes in customer requirements did not appear as one of the top five most important factors across the interviews from a transcript coding perspective (see Table 11). Changes in customer requirements did appear to be moderated by the external environment in both Interviews 1 and 3. However, this moderation effect did not appear in the quantitative analysis presented in Section 11.8.3.

The negative coefficient for the customers' actions factor indicates that the higher the level of customers' actions such as changes in customer needs or demand trends, the lesser the level of strategy transformation; this would seem to be counter-intuitive. However, a possible explanation may be that the more the level of customers' actions in a market, the more flexibility is built into the strategy of a firm from the outset. As such, the impact of customers' actions may take place when the intended strategy is first being developed. In addition, the low beta and significance levels may indicate that firms do 
not specifically focus on their customers in terms of changing their strategies during implementation. Perhaps the actions of a firm's customers are perceived through the actions of competitors or the general external environment. For example, Interview 2 viewed customers' actions in terms of a perceived possible future downturn in the general market. In Interview 4, Company D reacted to the actions of customers not directly, but because of their impact on competitors' actions. In these cases, customers' actions were partially viewed through the lens of environmental instability or competitors' actions. The customers' actions SB is in conflict with the findings of Depperu and Gnan (2006). They found that demand trends and changes in customer needs explain much of the difference between strategy formation methodologies (i.e. deliberate versus emergent) used by the firms they studied. However, they studied only 29 firms in one country (Italy). Perhaps their findings represent something that pertains specifically to this one country.

The most important factor in the model seems to be the impact of flexibility. Although flexibility's SB as a single main effect is only third highest, it also impacts the transformation of strategy through three additional factors. It is a mediator for competitors' actions which has the highest main effect impact of any single factor. Flexibility is also a moderator for both managers' actions and employees' actions. Therefore, flexibility has an impact on strategy transformation along four different paths. It should be noted that the definition of flexibility resulting from the indicators aligned with it during EFA yields a broad concept that touches many facets of an organization. It is perhaps this broad internal scope that makes it such an influential factor. In the final Strategy Transformation Model, flexibility is comprised of the following components: 
- Flexibility inherent in the planned strategy;

- Tendency for the firm to develop contingency plans for alternate possible futures;

- Senior management flexibility;

- Ability of senior managers to quickly develop and share new perspectives; and

- Tendency towards opportunity taking by the firm.

The impact of the flexibility factor seen in the quantitative survey results aligns with the qualitative interview results. Flexibility was found to be the most important variable relative to its impact on the transformation of strategy from the perspectives of both the transcript coding and the interviewees' rankings. The second highest ranked variable from a coding perspective was organizational learning. In the post-EFA model, all three of the indicators from the a priori organizational learning factor moved to the flexibility factor. These rankings are in-sync with the prominence of flexibility and organizational learning in all five of the interviewees' narratives. In the interviews, flexibility was spoken of from a holistic perspective. The interviewees spoke of flexibility of the leadership team, flexibility being built into the strategies, flexibility resulting from the organizations' learning abilities and flexibility being applied during the implementations.

As noted numerous times in the qualitative study results (chapter 10), it seems that it is the interactions between factors that often leads to strategy transformation. The five interviews provided numerous examples of these interactions and the quantitative survey data analysis shows the interactions through moderation and mediation effects. There seems to be a give and take relationship between the characteristics of the external environment, and the flexibility that results from the combination of the characteristics of 
the internal environment and the intended plan. Further, these characteristics of the external environment need not be real. As demonstrated in Interview 2, they can also simply be perceptions of the external environment on the parts of decision makers and still elicit the same internal responses. As subjectively observed in the five interviews, and quantitatively shown in Section 11.5.1, it seems that most strategies transform to some degree. Further, the quantitative data suggests that the level of flexibility inherent in the internal environment of a particular organization influences whether the transformation leads to a positive or negative result. The negative SB (i.e. -.242) of flexibility indicates that the more flexibility is present, the less transformation occurs. By the operational definition of transformation in this study, less transformation means a higher level of attainment of the strategic goals set by the firm.

If some level of strategy transformation is the norm for most organizations, this would imply that strategies are 'living evolving conceptual entities' and strategic plans must be living documents. This is in contrast to the static nature of the documents that are compiled on a once-a-year basis by many firms. Further, as evinced by the results of both the qualitative and quantitative results of this study, the concept of a snapshot-intime strategic planning process as practiced by many firms should be changed if these firms are to gain the advantages possible by implementing a more dynamic and flexible approach.

\subsection{Levels of Strategy Transformation}

Although Mintzberg and Waters highlighted the evolution of intended to realized strategy (1985) and Mintzberg carried out case studies of organizations such as the Canadian National Film Board, Volkswagenwerk and the US Department of Defense 
during the Vietnam War $(1977 ; 1979)$, his research on the evolution of strategy has tended to focus on timeframes of 20 to 30 years. The data from the qualitative interviews in this study has provided evidence that significant strategy transformation can occur over much shorter periods, even as little as one to three years. Further, dramatic strategy transformations seem to be quite common.

The transformation of strategy measured by the survey relied on three survey items. These measured the level of achievement of the primary and secondary goals of the strategy, and the extent to which the strategy implementation process proceeded exactly as planned. Figures 11,12 and 13 display the results of these survey items and tell a story of considerable strategy transformation.

In terms of the achievement of primary goals, $26 \%$ of organizations achieved half or less. Further, $40.5 \%$ of organizations achieved half or less of their secondary goals. Only $31.4 \%$ of organizations achieved more than three-quarters of their primary goals while only $22.2 \%$ achieved more than three-quarters of their secondary goals. Finally, when it came to organizations that achieved less than one quarter of their goals, this pertained to $9.8 \%$ and $11.8 \%$ of organizations for primary and secondary goals respectively.

These numbers indicate that organizations are experiencing dramatic strategy transformation in terms of the percentage of their strategic objectives they are achieving. In terms of implementation, $48.4 \%$, or approximately half of organizations have some level of disagreement with the notion that their strategy implementation processes are proceeding exactly as planned. It is probable that practicing managers are not aware of the generally low level of strategic goal attainment and process fulfillment across 
industry. Further, it raises the question of the relationship between executive bonus payout and the attainment of strategic goals. Despite $26 \%$ and $40.5 \%$ of organizations achieving half or less of their primary and secondary goals respectively, it is probable that the percentage of executives not receiving bonus payouts is somewhat less.

Overall, the evidence indicates that the strategies of organizations are not being realized as intended. This pertains to the attainment of objectives and the processes of strategy implementation. Therefore, the evidence suggests that some level of strategy transformation is the norm in the types of for-profit organizations represented in this research.

\subsection{Model Applicability}

Section 11.10 and Table 36 show the results of regressions of the Strategy Transformation Model which were run while controlling for various descriptive variables such as company ownership and revenue. The data showed different levels of model fit for different segments of the data; however, there was no clear statistical evidence that these R Squares were truly different.

While there is less than $95 \%$ confidence that the R Squares are statistically different, the segmented data suggests that the model may have better fit in companies that are publicly held with higher revenue and are in more structured industries such as the financial sector and defence. While this needs further study, it may imply that the model is a better fit in companies that have the resources and structure to carry out formal strategic planning. The model may not fit smaller privately held companies quite as well because some percentage of these companies may not have the resources or expertise necessary to create strategy in a more formal and deliberate fashion. In such a case, the 
starting point for the model which is the intended strategic plan may not exist in a formal, detailed and documented fashion.

The better model fit for respondents with more than 18 years experience (i.e. the survey mean is 18.4 years) may suggest a similar finding. The executives with higher experience levels may be more prone to create and document strategic plans. Another possibility is that more experienced executives may be better able to understand the transformation of strategy that occurs during implementation and the reasons for such a transformation.

When the data was segmented, the sample size for each regression was considerably reduced. This may be the reason that the $\mathrm{R}$ Squares did not prove statistically significant. Alternatively, the results with the segmented data may indicate that the model has wide general applicability. Only further research with sufficient sample sizes for segmented groups will provide clear evidence as to the model's applicability. These sample groups could include companies in different industries, companies having larger versus smaller revenue sizes and companies with higher versus lower levels of executive experience. 


\subsection{CONCLUSIONS}

"No battle plan survives first contact with the enemy"

German Field Marshal Helmuth Karl Bernhard Graf von Moltke (1800 - 1891).

\subsection{Summary}

Central to the organizational strategy formation literature since the 1970 s, is the debate over how strategy can most effectively be formulated (Andrews, 1971; Ansoff, 1991; Mintzberg, 1977; Mintzberg \& Waters, 1985). This debate over the relative merits of deliberate versus emergent strategy formation has not yet reached consensus (Boyd, 1991; Brews \& Hunt, 1999; Greenley, 1994; Holloway, 2004; Miller \& Cardinal, 1994; Schäffer \& Willauer, 2003) and has resulted in dozens of empirical studies designed to shed light on the issue (e.g., Falshaw, Glaister, \& Tatoglu, 2006; Hopkins \& Hopkins, 1997; Slater, Olson, \& Hult, 2006; Thune \& House, 1970). These organizational planning versus performance studies have not provided consistent results. A series of literature reviews and meta-analyses have been conducted in an effort to find significant results (e.g., Greenley, 1994) but here too the results have been mixed. However, some authors have come to recognize that it may be more realistic to envision a synthesis whereby deliberately developed strategic plans are modified during their implementations through an emergent strategy formation process (e.g., Andersen, 2004; Grant, 2003).

Part of the issue may be the lack of theory that would explain any link between strategy formation, implementation and organizational results. In general, the current literature tends to portray the simplistic view of trying to relate performance to whether or not deliberate strategic planning has occurred, oblivious to the contextual situations that exist inside and outside a firm at the time. This would insinuate that contextual 
factors have no significant impact on strategy implementation or eventual performance. This simplistic perspective does not reflect the considerable complexity of the relationship between strategy and context, and is probably responsible for much of the mixed results of planning-performance studies. Further, a comprehensive understanding of this process cannot be attained without understanding the impact of internal and external context. The need to recognize the impact of context in the study of all aspects of management theory is now gaining acceptance (Bamberger, 2008).

This work has attempted to contribute to the literature by taking a first step toward adding the complexity of context to our understanding of how strategies are formulated and implemented. In 1985, Mintzberg and Waters proposed the concept that intended strategies are transformed into realized strategies as some of the deliberate components fall away and emergent components are added (Figure 1). In this regard, strategy implementation is part of the strategy formation process because the strategy continues to evolve during implementation as emergent aspects arise (Mintzberg, 1977). It is this evolution that transforms intended strategy into realized strategy.

This research has attempted to develop the Mintzberg and Waters (1985) concept into a model by identifying and testing the contextual factors which impact strategy transformation. Initially, an a priori model (Figure 3) was developed by gathering contextual factors and indicators mentioned in the literature (e.g., Ashill, Frederikson, \& Davies, 2003; Blythe \& Zimmerman, 2004; Depperu \& Gnan, 2006; Harrington, Lemak, Reed, \& Kendall, 2004; Miller, Droge, \& Toulouse, 1988). This model was augmented by adding variables which arose during a qualitative interview study with executives 
regarding examples of strategy transformation with which they were intimately familiar through direct involvement.

The model was tested using 153 responses from a quantitative survey study to gain a better understanding of the impact of the identified variables on intended strategy as it transforms into realized strategy. The quantitative study survey instrument was developed and populated with measures taken from the literature, and added to or modified based on the interviews.

Exploratory factor analysis was used during the data analysis to aid in the development of the Figure 15 Strategy Transformation Model. The model is a step toward our understanding of how strategy transforms during implementation and the factors which most impact this transformation. Further, because of the numerous moderation and mediation interactions between the constructs, it heightens an awareness of the evolving nature of strategy as an implementation proceeds. What becomes clear is that perhaps strategy should not be thought of as a noun but rather as a verb. As such, strategy is a living evolving conceptual entity and strategic plans are living documents.

Von Moltke's oft quoted statement is a fundamental assumption drilled into officers who are charged with developing campaign or battle plans. "No battle plan survives first contact with the enemy" is simply a concise phrasing of the concept of strategy transformation. It means that the enemy will take unexpected actions during contact and plans will always have to be adjusted accordingly. That is the key reason that military commanders keep formations in reserve during engagements, it allows them the flexibility to react. 
Flexibility is a central concept in the Strategy Transformation Model. Flexibility inherent in the plans, approach and culture of organizations and leadership teams allows them to appropriately react to the impacts of contextual factors during implementations. Based on the survey, some level of strategy transformation is the norm for most organizations. It may be that flexibility is the factor which allows leadership teams to have a level of control over how this transformation proceeds.

Chapter 1 of this thesis starts with a quote from Dwight Eisenhower where he opines that "plans are nothing, planning is everything" (Blythe \& Zimmerman, 2004). It may be that important inherent flexibility is built and developed during planning sessions as leaders explore concepts and develop new mental models (Schaffer and Willauer, 2003) which are later used in the to-and-fro between contextual inputs and organizations' reactions in the form of strategy transformation. This may be the link which helps explain why scenario based planning can be effective (De Geus, 1988). It accelerates the acquisition of new mental models and thereby increases flexibility.

Beinhocker and Kaplan have determined that strategic planning can be effective if it has as an objective to "make sure that decision makers have a solid understanding of the business, its strategy, and the assumptions behind that strategy, thereby making it possible for executives to respond swiftly to challenges and opportunities as they occur in real time" (2002 p. 51). The flexibility which can result from effective planning may be at the heart of the ability to guide strategy transformation in a positive direction for a firm. 


\subsection{Contributions to the Strategy Literature}

This doctoral thesis has endeavoured to contribute to theory relative to the deliberate and emergent strategy formation methodologies, and specifically, the factors which transform deliberate (i.e. intended) strategy into realized strategy (i.e. the strategy that is actually implemented). Numerous conceptual papers exist which propose the importance of either deliberate or emergent strategy formation, and recent literature contains papers which suggest that both mechanisms often work together in operating firms (Andersen, 2004; Grant, 2003; Harrington, Lemak, Reed, \& Kendall, 2004). Specifically, they indicate that deliberate strategy changes or transforms during implementations due to the influence of internal and external contextual factors. However, there is a gap in the literature as to the identification of which contextual factors play this influential role, the relative impacts of the factors and how these factors impact each other, whether through mediating or moderating roles. Given the dearth of theory in this area, there has also been virtually no empirical research to validate theory and quantify its elements.

A theory has been constructed and tested which gives an initial understanding of how contextual factors impact the transformation of intended strategy into realized strategy. This model contributes to academic literature by helping close the gap in our knowledge of how strategy is formulated and implemented, and the transformation that occurs through this process. The model includes validated survey items which will allow researchers to extent this work and enhance the Strategy Transformation Model.

This study provides an empirical basis for judging how various contextual factors in the internal and external environment impact the strategic plans of organizations 
during their implementations. It has also refined and provided an estimate of the relative importance of the factors, providing an empirical base which has altered the theoretical approach. It provides an enhanced and tested model to aid our understanding of the transformation of strategy from what is envisioned during the planning phase to the actual results of implementation.

This work has developed a theoretical foundation for future study into this important facet of strategy research. It is hoped that future research will further inform the intricacy of the relationship between intended and realized strategy.

\subsection{Implications for Practicing Managers}

This research contributes to managers' understanding of strategy formation and implementation in their complex and dynamic environments. Although the study focuses on the private sector, the results may also be useful to managers in the not-for-profit and government sectors.

As noted in the interview narratives, it seems to be the evolving relationship between the internal and external variables during implementation that results in the transformation of strategy. While the interview sample is small, the results point to the importance of leadership teams building flexibility into their strategies, culture and

implementations. Further, the importance of leaders fostering a culture of organizational learning also seems to be highlighted, as is the importance of having a feasible intended strategy. One of the themes that emerged from this small sample qualitative study is that while almost all strategies transform, it may be the flexibility in the internal environment that impacts whether the transformation leads to a positive or negative result. As noted in Section 12.3, this was indicated by the quantitative data analysis as well. 
The quantitative survey results echo the interview results in showing the importance of flexibility in strategy transformation. The Strategy Transformation Model displays the visual impact of flexibility as it interacts with other factors. Whether companies are publicly or privately owned, large or small, it is clear that managers should place a high level of significance on flexibility. However, this may not currently be the case. It is hoped that this research will highlight the dynamic nature of strategy and the importance of flexibility in guiding strategy transformation in a direction which would be considered positive by a firm.

This work will give operating companies a better understanding of how their planned strategies are changed by the environments within and outside their companies. This should allow them to better anticipate strategy evolution as their environments change, thereby giving them an opportunity to potentially guide the changes in their strategies as opposed to being led by them.

\subsection{Limitations}

The key limitation in this study is the non-random character of the sample. This inhibits the generalizability of the findings of the research. However, given the difficulties encountered when researchers attempt to gather data from executives, this is considered acceptable given the exploratory nature of this study. Further, given the number of industries and geographic areas from which the data has come, some level of generalizability may be appropriate.

The snowball sampling technique used in this research can sometimes have a bias toward particular professional or social networks due to the nature of the referral of one 
informant to another. In this study, the first tier of informants was taken from a number of different groups from various industries so this should not present a major problem.

As with any research in the social sciences where human responses form the data, there is always the potential for bias. This was particularly possible during the interviews where some of the interviewees might have skewed the narratives to portray their positions in a more positive light. In addition, they may have employed retrospective rationality to make sense of the decisions they made or actions they took during strategy implementation. However, in reading the narratives, this did not seem to be a significant problem. In fact, several of the interviewees offered examples where they wished they had made different decisions or indicated that they had made mistakes.

This work was exploratory in nature and therefore there will be considerable opportunity in future to refine the survey items, potentially add new factors and indicators, or in other ways improve the model and theory. This is expected and welcomed as it will further our understanding of this complex and important strategy transformation process.

\subsection{Future Research}

Future studies will be able to leverage this work to investigate the process by which strategy transformation occurs and the mechanisms by which the contextual factors impact the transformation. As this is the first data in this area, both the qualitative and quantitative studies could be repeated with larger, more diverse or more specific data sets in an effort to reproduce, expand or enhance the results.

The qualitative study was used in this work to validate the factors found in the literature and to add any indicators and factors which came up during the interviews. A 
larger qualitative study could be undertaken to test the Strategy Transformation Model. Using the model as a guide, the important role of flexibility could be explored in a more in-depth fashion and a better understanding gained of its interactions with the other factors.

The qualitative study could be repeated with executives from single industries to understand if the model's factors vary from industry to industry. Further, it would be interesting to know if the model's factors vary for business-to-business versus businessto-consumer firms, or for privately versus publicly owned firms.

One of the surprises which arose from the quantitative data analysis was the lack of a moderating role of the external environment upon customers' actions. This could be the focus of a series of interviews to understand why this might be the case.

From a quantitative perspective, the survey could be repeated with specific target groups to see if the model shows different results for different countries, public versus private ownership or different industries. Section 11.10 attempted to segment the data to look for different results but the differences in R Squares did not prove to be statistically significant. This may have been because once segmented, the number of survey responses for each data segment was not large enough. Alternatively, it may indicate that the model has wide applicability. The data segments should be definitively tested using larger samples for each segment to answer this question.

During Interview 2, the interviewee noted the emotional elements of the situation that Company $B$ found itself it when the first acquisition attempt failed. It was clear that there was a sense of failure at an emotional level. While senior leaders and organizations in general are often viewed as operating in an objective or logical manner, this may not 
always be the case. The emotional reactions of decision makers may be responsible for some percentage of decisions and resultant transformation of strategy. A qualitative study whose aim is to test the impact of emotional situational elements on strategy transformation would be interesting. One could imagine some of the applicable emotions of decision makers being anger, embarrassment, envy, pride or stubbornness.

The perception by decision makers that particular factors might have an impact in the future may be enough to cause strategy transformation. If this is the case, it exacerbates the complexity of strategy transformation. For example, Interview 1 related to a risk-taking company in the high tech sector who was experiencing a softening of the market yet did not perceive the extremely negative impact on its strategy until it was too late. In Interview 2, a very conservative company was experiencing a highly profitable market yet was concerned about the impact of a possible future downturn in the economy and changed their strategy. A study into any relationship between the tendency toward risk taking by a management team, how the team perceives strategy transformation factors in a future time, and the impact on strategy transformation may yield interesting results. 


\section{APPENDIX A - INFORMATION SCRIPT FOR INTERVIEW REQUEST}

My name is Wade Rose, a Ph.D. Candidate at the Sprott School of Business, Carleton University. Under the supervision of my Thesis Advisor, Dr, David Cray, Sprott School of Business, I am conducting a study of how planned strategies are transformed by environmental factors during their implementations. This project has been reviewed by and received ethics clearance from the Carleton University Research Ethics Committee.

As you are aware, the strategies that companies develop often change during their implementations due to the impact of numerous factors. In order to help organizations better understand how their planned strategies are affected by the environments within and outside their companies, I am conducting research to identify which factors most influence strategy during implementation and how these factors relate to one another. This research should help companies better anticipate strategy evolution as their environments change, thereby giving them an opportunity to potentially guide the changes in their strategies as opposed to being led by them.

I am calling you to request your participation in this research by agreeing to be interviewed about one example from your professional experience of a strategy planning and implementation cycle. The interview should take about an hour and can be carried out at any site that is convenient for you. If I need to clarify any of the information you provide, I may contact you again for a brief discussion. You should note that the interview will be audio taped to allow me to go over the information in detail to ensure that nothing is missed. You are under no obligation to answer any question with which 
you are uncomfortable and you may withdraw from the interview process at any time and have the right to have any data that you have provided destroyed.

I request that you choose one specific strategy implementation cycle for the discussion. The implementation cycle you choose must be one in which you were intimately involved, both at the planning stage and during the implementation itself. Any information you provide will be treated anonymously, that is to say it will not be attributed to your name or that of your company.

The results of this research should have direct relevance to your company as it goes about the complex cyclical process of strategy implementation. An understanding of how strategy is transformed from the original plan to what is actually implemented may help you to be more proactive as these factors influence your strategy implementation, thereby putting your organization in a better position to achieve its goals.

If you would like a summary of the results of this research, I would be pleased to provide it. Simply provide me with your email address and I will send the summary as soon as the study is completed.

I would be happy to answer any questions you might have about this research. My email address is wrose2@connect.carleton.ca. Any concerns about this research should be directed to my Thesis Advisor, Dr. David Cray, or the Chair of Carleton University's Research Ethics Committee, Dr. Antonio Gualtieri. Their contact information is provided on the interview consent form. 


\section{APPENDIX B - INTERVIEW QUESTIONS}

1. Based on your experiences in various companies where you have been involved in the formation and implementation of strategy, please discuss one specific example with which you are particularly familiar. Specifically, describe in detail:

$\circ$ the planned strategy;

○ how the implementation proceeded;

O any changes in the implementation results relative to what was planned;

$\circ$ if the results of the strategy implementation were not exactly as envisioned, how did any changes occur; and

$\circ$ if the results of the strategy implementation were not exactly as envisioned, why did any changes occur.

2. After the description of the example, the interviewer will ask the interviewee to list the most significant factors which impacted the evolution of the strategy throughout the implementation.

3. Probing questions will be asked throughout the discussion and factor identification to gain required information. Some examples include:

$\circ$ Please provide more detail on that point.

- What do you think caused this to happen?

○ What preceded this change? Was there anything specific? 
- Do you think there was consensus in the organization as to this change or why it happened?

o Other questions will be formed as dictated by the situation.

4. Interviewees will be asked to rate the eight contextual factors developed from the literature against their importance relative to the example they provided. The rating will be on a seven-point Likert-type scale running from highly important to highly unimportant:

1- highly important

2 - important

3- somewhat important

4- neutral

5- somewhat unimportant

6 - unimportant

7 - highly unimportant

5. Interviewees will be asked to rank the factors scored as "Highly Important" from 1 (most "Highly Important") to 'n' (least "Highly Important"). 


\section{APPENDIX C - INTERVIEWEE SCORING OF CONTEXTUAL FACTORS}

1. Please score each of the following factors as to its importance relative to the transformation of strategy in the example you provided.

Note: Indicators in Bold were added during and as a consequence of the interviews.

\begin{tabular}{|c|c|c|c|c|c|c|c|}
\hline Factors & $\begin{array}{l}\text { Completely } \\
\text { Unimportant } \\
\end{array}$ & Unimportant & $\begin{array}{l}\text { Somewhat } \\
\text { Unimportant }\end{array}$ & Neutral & $\begin{array}{l}\text { Somewhat } \\
\text { Important }\end{array}$ & Important & $\begin{array}{l}\text { Highly } \\
\text { Important }\end{array}$ \\
\hline $\begin{array}{l}\text { Environmental } \\
\text { instability. }\end{array}$ & & & & & & & \\
\hline $\begin{array}{l}\text { Competitors' } \\
\text { actions. }\end{array}$ & & & & & & & \\
\hline $\begin{array}{l}\text { Changes in } \\
\text { customer } \\
\text { requirements. }\end{array}$ & & & & & & & \\
\hline $\begin{array}{l}\text { Environmental } \\
\text { complexity. }\end{array}$ & & & & & & & \\
\hline $\begin{array}{l}\text { Leadership } \\
\text { team } \\
\text { characteristics. }\end{array}$ & & & & & & & \\
\hline $\begin{array}{l}\text { Employee } \\
\text { involvement. }\end{array}$ & & & & & & & \\
\hline $\begin{array}{l}\text { Organizational } \\
\text { learning } \\
\text { ability. }\end{array}$ & & & & & & & \\
\hline $\begin{array}{l}\text { Flexibility of } \\
\text { the intended } \\
\text { strategy. }\end{array}$ & & & & & & & \\
\hline $\begin{array}{l}\text { Feasibility of } \\
\text { the intended } \\
\text { strategy. }\end{array}$ & & & & & & & \\
\hline $\begin{array}{l}\text { Ambitiousness } \\
\text { of the } \\
\text { intended } \\
\text { strategy. }\end{array}$ & & & & & & & \\
\hline $\begin{array}{l}\text { Availability of } \\
\text { Resources. }\end{array}$ & & & & & & & \\
\hline $\begin{array}{l}\text { Changes in } \\
\text { key personnel. }\end{array}$ & & & & & & & \\
\hline $\begin{array}{l}\text { Government } \\
\text { regulatory } \\
\text { requirements. }\end{array}$ & & & & & & & \\
\hline
\end{tabular}


2. To what level were the primary goals of the strategic plan implemented and achieved as originally planned?

- $0-25 \%$

- $26-50 \%$

- $51-75 \%$

- $76-100 \%$

3. To what level were the secondary goals of the strategic plan implemented and achieved as originally planned?

- $0-25 \%$

- $26-50 \%$

- $51-75 \%$

- $76-100 \%$

4. Indicate, by circling a number, your level of agreement with the following statement: "The actions that formed the process of implementing the strategy were carried out exactly as planned".

1 - strongly agree

2 - agree

3- somewhat agree

4- neutral

5- somewhat disagree

6 - disagree

7 - strongly disagree

5. Please return to question 1 and rank the factors scored as "Highly Important" from ' 1 ' (most "Highly Important") to ' $n$ ' (least "Highly Important"). 


\section{APPENDIX D - LETTER OF INFORMATION (I.E. COVERING EMAIL FOR SURVEY)}

Subject: Carleton University Research Study - Strategy Implementation

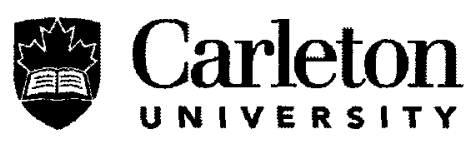

Dear

My name is Wade Rose, a Ph.D Candidate at the Sprott School of Business, Carleton University. Under the supervision of my Thesis Advisor, Dr, David Cray, Sprott School of Business, I am conducting a study of how planned strategies are transformed by environmental factors during their implementations. This project has been reviewed by and received ethics clearance from the Carleton University Research Ethics Committee.

As you are aware, the strategies that companies develop often change during their implementations due to the impact of numerous factors. In order to help organizations better understand how their planned strategies are affected by the environments within and outside their companies, I am conducting research to identify which factors most influence strategy during implementation and how these factors relate to one another. This research should help companies better anticipate strategy evolution as their environments change, thereby giving them an opportunity to potentially guide the changes in their strategies as opposed to being led by them. 
I am writing to request two things: first, your participation in this research by completing a questionnaire. The questionnaire should only take about 15 minutes to complete and can be accessed by clicking on the following web link:

. Please note that the questionnaire pertains to only one

example from your professional experience of a strategy planning and implementation cycle. Second, I would greatly appreciate if you could send this email along to at least three of your colleagues at the senior manager or executive levels so that they too might participate by completing the questionnaire. Your help in this regard will enable the number of responses required to provide statistically significant results. Any information you provide will be treated anonymously, that is to say it will not be attributed to your name or that of your company.

The results of this research should have direct relevance to your company as it goes about the complex cyclical process of strategy implementation. An understanding of how strategy is transformed from the original plan to what is actually implemented may help you to be more proactive as these factors influence your strategy implementation, thereby putting your organization in a better position to achieve its goals.

If you would like a summary of the results of this research, I would be pleased to provide it. Simple enter your email address in the location indicated at the end of the questionnaire and I will send the summary as soon as the study is completed.

I would be happy to answer any questions you might have about this research. My email address is wrose2@connect.carleton.ca. Any concerns about this research should be directed to my Thesis Advisor, Dr. David Cray, or the Chair of the Carleton 
University Research Ethics Committee, Dr. Antonio Gualtieri. Their contact information appears below.

Please note that as this is a web-hosted questionnaire and therefore a non-secure form of communication, we have not requested any confidential information in the questionnaire.

Thank-you for your assistance.

Yours Sincerely,

Wade R. Rose

Ph.D Candidate

Sprott School of Business

Carleton University

Ottawa, Ontario, Canada

\begin{tabular}{|l|l|}
\hline Dr. David Cray & Dr. Antonio Gualtieri \\
Sprott School of Business & Chair, Ethics Committee \\
Carleton University & Carleton University \\
$613-520-7802$ & $613-520-2517$ \\
david cray@carleton.ca & ethics@ carleton.ca \\
\hline
\end{tabular}




\section{APPENDIX E - SURVEY INSTRUMENT}

Survey questions have been composed of indicators which align with the eight hypotheses which were devised based on the literature. The survey instrument appears below. The questions are formatted in the form of a seven-point Likert-type scale from strongly agree to strongly disagree. Although the answer choices in the actual survey instrument appeared in one column on the left below the questions, most of the answers in this appendix have been formatted into two lines below the questions to save space.

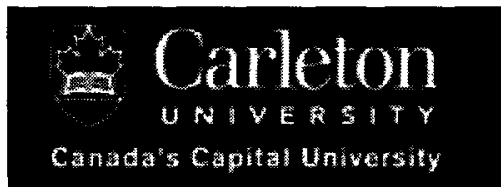

\section{Sprott School of Business Research Project: The Role of Context in the Transformation of Planned Strategy into Implemented Strategy}

Please choose ONE SPECIFIC STRATEGY IMPLEMENTATION CYCLE from your business experience to answer the questions below. The questions all relate to your ONE EXAMPLE of a particular strategic plan and its implementation. Assuming that the final implementation was not exactly as envisioned in the original strategic plan, the questions are designed to gauge the impact that a defined set of factors had in terms of causing any differences between the original strategic plan and what the organization actually did. Please note that the factors in the questions could potentially all have an impact on strategic plans in general; however, the questions should be answered with respect to your ONE SPECIFIC STRATEGY IMPLEMENTATION EXAMPLE ONLY.

Please note: Questions 1-31 differ only with respect to the items in quotations. If the item in quotations (e.g. "Competitiveness of the Environment") caused a change in the strategy in your example, you would answer 'somewhat agree', 'agree' or 'strongly agree'. If the item does not apply to your example, you would answer 'somewhat disagree', 'disagree' or 'strongly disagree' because the item did not lead to a change in your strategy. 
Please answer all questions.

1. The "Competitiveness of the Environment" led to a difference between your organization's original strategic plan and what was actually implemented.

$O$ Strongly Agree $O$ Agree $O$ Somewhat Agree $O$ Neutral

$O$ Somewhat Disagree $O$ Disagree $O$ Strongly Disagree

2. "Senior Management Flexibility" led to a difference between your organization's original Cstrategic plan and what was actually implemented.

$\bigcirc$ Strongly Agree $O$ Agree $O$ Somewhat Agree $\bigcirc$ Neutral

$O$ Somewhat Disagree $O$ Disagree $O$ Strongly Disagree

3. "Volatility of Sales Growth" led to a difference between your organization's original strategic plan and what was actually implemented.

$O$ Strongly Agree $\bigcirc$ Agree $O$ Somewhat Agree $O$ Neutral

$O$ Somewhat Disagree $O$ Disagree $O$ Strongly Disagree

4. The "Authority of Lower Level Managers to Make Decisions and Take Initiative" led to a difference between your organization's original strategic plan and what was actually implemented.

O Strongly Agree $\bigcirc$ Agree $O$ Somewhat Agree $O$ Neutral

$O$ Somewhat Disagree $O$ Disagree $O$ Strongly Disagree

5. The "Tendency Towards Opportunity Taking by your Firm" led to a difference between your organization's original strategic plan and what was actually implemented.

O Strongly Agree $O$ Agree $O$ Somewhat Agree $O$ Neutral

$\bigcirc$ Somewhat Disagree $O$ Disagree $O$ Strongly Disagree

6. The "Complexity of your Firm's Relationships with its Distributors, Customers and Suppliers" led to a difference between your organization's original strategic plan and what was actually implemented.

$O$ Strongly Agree $O$ Agree $O$ Somewhat Agree $O$ Neutral

$O$ Somewhat Disagree $O$ Disagree $O$ Strongly Disagree

7. "Leadership Team Support of the Strategy" led to a difference between your organization's original strategic plan and what was actually implemented.

$O$ Strongly Agree $O$ Agree $O$ Somewhat Agree $O$ Neutral

$O$ Somewhat Disagree $O$ Disagree $O$ Strongly Disagree

8. "Communication by your Firm of its Strategic Goals and Priorities to the Whole Firm" led to a difference between your organization's original strategic plan and what was actually implemented.

$\bigcirc$ Strongly Agree $\bigcirc$ Agree $\bigcirc$ Somewhat Agree $\bigcirc$ Neutral

$O$ Somewhat Disagree $O$ Disagree $O$ Strongly Disagree 
9. The "Unpredictability of the Environment in Which your Firm Operates" led to a difference between your organization's original strategic plan and what was actually implemented.

$O$ Strongly Agree $O$ Agree $O$ Somewhat Agree $\bigcirc$ Neutral

O Somewhat Disagree $O$ Disagree O Strongly Disagree

10. "Speed of Change in Customer Demand Trends" led to a difference between your organization's original strategic plan and what was actually implemented.

$O$ Strongly Agree $O$ Agree $O$ Somewhat Agree $O$ Neutral

O Somewhat Disagree $O$ Disagree O Strongly Disagree

11. The "Tendency of Individuals to Pursue the Goals of their Position or Group Instead of the Goals of the Whole Organization" led to a difference between your organization's original strategic plan and what was actually implemented.

$O$ Strongly Agree $O$ Agree $O$ Somewhat Agree $O$ Neutral

O Somewhat Disagree $O$ Disagree O Strongly Disagree

12. The "Tendency of your Firm to Develop Contingency Plans for Alternate Possible Futures" led to a difference between your organization's original strategic plan and what was actually implemented.

O Strongly Agree $O$ Agree $O$ Somewhat Agree $O$ Neutral

$O$ Somewhat Disagree $O$ Disagree $O$ Strongly Disagree

13. The "Rate of New Product Introduction by your Firm's Competitors" led to a difference between your organization's original strategic plan and what was actually implemented.

Strongly Agree $O$ Agree $O$ Somewhat Agree $\bigcirc$ Neutral

$O$ Somewhat Disagree $O$ Disagree $O$ Strongly Disagree

14. The "Flexibility Inherent in the Planned Strategy" led to a difference between your organization's original strategic plan and what was actually implemented.

$O$ Strongly Agree $O$ Agree $O$ Somewhat Agree $O$ Neutral

O Somewhat Disagree $O$ Disagree O Strongly Disagree

15. "Customer Demand for Innovation in your Firm's Market" led to a difference between your organization's original strategic plan and what was actually

implemented.

O Strongly Agree $O$ Agree $O$ Somewhat Agree $\bigcirc$ Neutral

O Somewhat Disagree O Disagree O Strongly Disagree

16. "Managers Sharing a Detailed and Consistent Understanding of the Business" led to a difference between your organization's original strategic plan and what was actually implemented.

O Strongly Agree $O$ Agree $O$ Somewhat Agree $O$ Neutral

$O$ Somewhat Disagree $O$ Disagree $O$ Strongly Disagree 
17. "Instability of the Environment in Which your Firm Operates" led to a difference between your organization's original strategic plan and what was actually implemented.

O Strongly Agree $\bigcirc$ Agree $\bigcirc$ Somewhat Agree $O$ Neutral

O Somewhat Disagree $O$ Disagree $O$ Strongly Disagree

18. "Diversity of the Customers and Markets Served by your Firm" led to a difference between your organization's original strategic plan and what was actually implemented.

O Strongly Agree O Agree O Somewhat Agree O Neutral

O Somewhat Disagree $O$ Disagree O Strongly Disagree

19. "Participation of Low and Mid-Level Managers in the Strategic Planning Process" led to a difference between your organization's original strategic plan and what was actually implemented.

O Strongly Agree O Agree $O$ Somewhat Agree $O$ Neutral

O Somewhat Disagree $O$ Disagree O Strongly Disagree

20. The "Rate of Change of Customer Needs" led to a difference between your organization's original strategic plan and what was actually implemented.

O Strongly Agree O Agree O Somewhat Agree O Neutral

O Somewhat Disagree O Disagree O Strongly Disagree

21. The "Ability of Senior Managers to Quickly Develop and Share New

Perspectives" led to a difference between your organization's original strategic plan and what was actually implemented.

O Strongly Agree O Agree O Somewhat Agree O Neutral

O Somewhat Disagree O Disagree O Strongly Disagree

22. The "Rigidity of the Planned Strategy" led to a difference between your organization's original strategic plan and what was actually implemented.

O Strongly Agree O Agree O Somewhat Agree O Neutral

O Somewhat Disagree $O$ Disagree O Strongly Disagree

23. "Managers' Use of Previously Acquired Experiential Knowledge during Strategy Implementation" led to a difference between your organization's original strategic plan and what was actually implemented.

O Strongly Agree $O$ Agree $O$ Somewhat Agree $O$ Neutral

O Somewhat Disagree O Disagree O Strongly Disagree

24. The "Rate of Response of your Firm's Competitors to Changing Market

Conditions" led to a difference between your organization's original strategic plan and what was actually implemented.

O Strongly Agree O Agree O Somewhat Agree O Neutral

$O$ Somewhat Disagree $O$ Disagree $O$ Strongly Disagree 
25. "Resistance to Change in your Organization" led to a difference between your organization's original strategic plan and what was actually implemented.

$O$ Strongly Agree $O$ Agree $O$ Somewhat Agree $O$ Neutral

$\bigcirc$ Somewhat Disagree $O$ Disagree $O$ Strongly Disagree

26. The "Complexity of the Operating Environment of your Firm" led to a difference between your organization's original strategic plan and what was actually implemented.

Strongly Agree $O$ Agree $O$ Somewhat Agree $\bigcirc$ Neutral

$O$ Somewhat Disagree $O$ Disagree $O$ Strongly Disagree

27. The "Feasibility of the Planned Strategy" led to a difference between your organization's original strategic plan and what was actually implemented.

O Strongly Agree $O$ Agree $O$ Somewhat Agree $O$ Neutral

$O$ Somewhat Disagree $O$ Disagree $O$ Strongly Disagree

28. "Government Regulatory Requirements" led to a difference between your organization's original strategic plan and what was actually implemented.

O Strongly Agree O Agree O Somewhat Agree O Neutral

$O$ Somewhat Disagree $O$ Disagree $O$ Strongly Disagree

29. The "Ambitiousness of the Planned Strategy" led to a difference between your organization's original strategic plan and what was actually implemented.

O Strongly Agree $O$ Agree $O$ Somewhat Agree $O$ Neutral

$O$ Somewhat Disagree $O$ Disagree $O$ Strongly Disagree

30. "Unavailability of Resources" Ied to a difference between your organization's original strategic plan and what was actually implemented.

$O$ Strongly Agree $O$ Agree $O$ Somewhat Agree $O$ Neutral

$O$ Somewhat Disagree $O$ Disagree $O$ Strongly Disagree

31. "Changes in Key Personnel" led to a difference between your organization's original strategic plan and what was actually implemented.

$O$ Strongly Agree $\bigcirc$ Agree $O$ Somewhat Agree $O$ Neutral

$O$ Somewhat Disagree $O$ Disagree $O$ Strongly Disagree

* Please note that questions 32 through 34 refer to the same particular strategic plan implementation example used to answer the previous questions.

32. To what level were the primary goals of your organization's strategic plan implemented and achieved as originally planned?

O $0 \%-25 \%$

O26\%- 50\%

O $51 \%-75 \%$

$76 \%-100 \%$ 
33. To what level were the secondary goals of your organization's strategic plan implemented and achieved as originally planned?
O $0 \%-25 \%$
O $26 \%-50 \%$
O $51 \%-75 \%$
O $76 \%-100 \%$

34. Indicate your level of agreement with the following statement: "The process of implementing the strategy was carried out exactly as planned".

$O$ Strongly Agree $O$ Agree $O$ Somewhat Agree $O$ Neutral

O Somewhat Disagree $O$ Disagree $O$ Strongly Disagree

35. Choose the title which most closely reflects your current position?

$O$ Senior Manager $O$ Director $O$ Vice President $O$ General Manager $O$ President

$\mathrm{O}$ CEO

O Board of Directors Member O Owner O Partner O Consultant

36. What is the approximate size of the company used in your example in annual revenue?

O Under $\$ 10$ million

O $\$ 10$ million to $\$ 50$ million

O $\$ 50$ million to $\$ 100$ million

O $\$ 100$ million to $\$ 500$ million

O $\$ 500$ million to $\$ 1$ billion

$O \$ 1$ billion to $\$ 10$ billion

O Greater than $\$ 10$ billion

37. In which area is the company used in your example headquartered?

$O$ Canada $O$ The United States O Europe

$O$ Asia O Oceania O Other

38. In which area is your position located in the company used in your example?

O Canada $O$ The United States O Europe

O Asia O Oceania O South America O Other

39. In which industry is the company used in your example predominately focused?

O Telecom O Biotech O Computer Hardware or Software O Defence

O Commercial Aerospace O Financial O Automotive O Retail O Natural

Resources

$O$ Food $O$ General Manufacturing $O$ Engineering $O$ Logistics $O$ Other

40. Which of the following describes the firm used in your example?

O Privately owned

O Publicly owned 
41. How many years experience do you have in the industry used in your example?

42. If you have any further comments, please type them into the space provided.

Note: If you would like to receive a summary of the results of this study, please send an email to wrose2@connect.carleton.ca with the subject line "Request Summary of Results". 
APPENDIX F - SURVEY RESPONSES PER DAY

\begin{tabular}{|c|c|c|c|}
\hline $\begin{array}{c}\text { Release } \\
\text { Day }\end{array}$ & Cum Total & $\begin{array}{l}\text { Responses } \\
\text { For the Day }\end{array}$ & Weekday \\
\hline D & 12 & 12 & Friday \\
\hline $\mathrm{D}+1$ & 19 & 7 & Saturday \\
\hline $\mathrm{D}+2$ & 24 & 5 & Sunday \\
\hline $\mathrm{D}+3$ & 37 & 13 & Monday \\
\hline$D+4$ & 43 & 6 & Tuesday \\
\hline $\mathrm{D}+5$ & 49 & 6 & Wednesday \\
\hline$D+6$ & 62 & 13 & Thursday \\
\hline $\mathrm{D}+7$ & 66 & 4 & Friday \\
\hline $\mathrm{D}+8$ & 75 & 9 & Saturday \\
\hline $\mathrm{D}+9$ & 77 & 2 & Sunday \\
\hline$D+10$ & 86 & 9 & Monday \\
\hline $\mathrm{D}+11$ & 90 & 4 & Tuesday \\
\hline $\mathrm{D}+12$ & 94 & 4 & Wednesday \\
\hline $\mathrm{D}+13$ & 104 & 10 & Thursday \\
\hline $\mathrm{D}+14$ & 117 & 13 & Friday \\
\hline $\mathrm{D}+15$ & 118 & 1 & Saturday \\
\hline$D+16$ & 122 & 4 & Sunday \\
\hline $\mathrm{D}+17$ & 129 & 7 & Monday \\
\hline $\mathrm{D}+18$ & 131 & 2 & Tuesday \\
\hline$D+19$ & 133 & 2 & Wednesday \\
\hline $\mathrm{D}+20$ & 134 & 1 & Thursday \\
\hline $\mathrm{D}+21$ & 136 & 2 & Friday \\
\hline $\mathrm{D}+22$ & 137 & 1 & Saturday \\
\hline $\mathrm{D}+23$ & 139 & 2 & Sunday \\
\hline $\mathrm{D}+24$ & 140 & 1 & Monday \\
\hline $\mathrm{D}+25$ & 141 & 1 & Tuesday \\
\hline $\mathrm{D}+26$ & 143 & 2 & Wednesday \\
\hline $\mathrm{D}+27$ & 144 & 1 & Thursday \\
\hline $\mathrm{D}+28$ & 145 & 1 & Friday \\
\hline $\mathrm{D}+29$ & 146 & 1 & Saturday \\
\hline $\mathrm{D}+30$ & 146 & 0 & Sunday \\
\hline $\mathrm{D}+31$ & 147 & 1 & Monday \\
\hline $\mathrm{D}+32$ & 148 & 1 & Tuesday \\
\hline $\mathrm{D}+33$ & 148 & 0 & Wednesday \\
\hline $\mathrm{D}+34$ & 148 & 0 & Thursday \\
\hline $\mathrm{D}+35$ & 148 & 0 & Friday \\
\hline $\mathrm{D}+36$ & 149 & 1 & Saturday \\
\hline $\mathrm{D}+37$ & 149 & 0 & Sunday \\
\hline $\mathrm{D}+38$ & 149 & 0 & Monday \\
\hline $\mathrm{D}+39$ & 150 & 1 & Tuesday \\
\hline $\mathrm{D}+40$ & 155 & 5 & Wednesday \\
\hline $\mathrm{D}+41$ & 157 & 2 & Thursday \\
\hline $\mathrm{D}+42$ & 158 & 1 & Friday \\
\hline $\mathrm{D}+43$ & 158 & 0 & Saturday \\
\hline $\mathrm{D}+44$ & 159 & 1 & Sunday \\
\hline$D+45$ & 160 & 1 & Monday \\
\hline $\mathrm{D}+46$ & 160 & 0 & Tuesday \\
\hline $\mathrm{D}+47$ & 161 & 1 & Wednesday \\
\hline $\mathrm{D}+48$ & 161 & 0 & Thursday \\
\hline $\mathrm{D}+49$ & 161 & 0 & Friday \\
\hline
\end{tabular}


APPENDIX G - DESCRIPTIVE STATISTICS OF SAMPLE DATA IN

DESCENDING ORDER OF THE MEANS

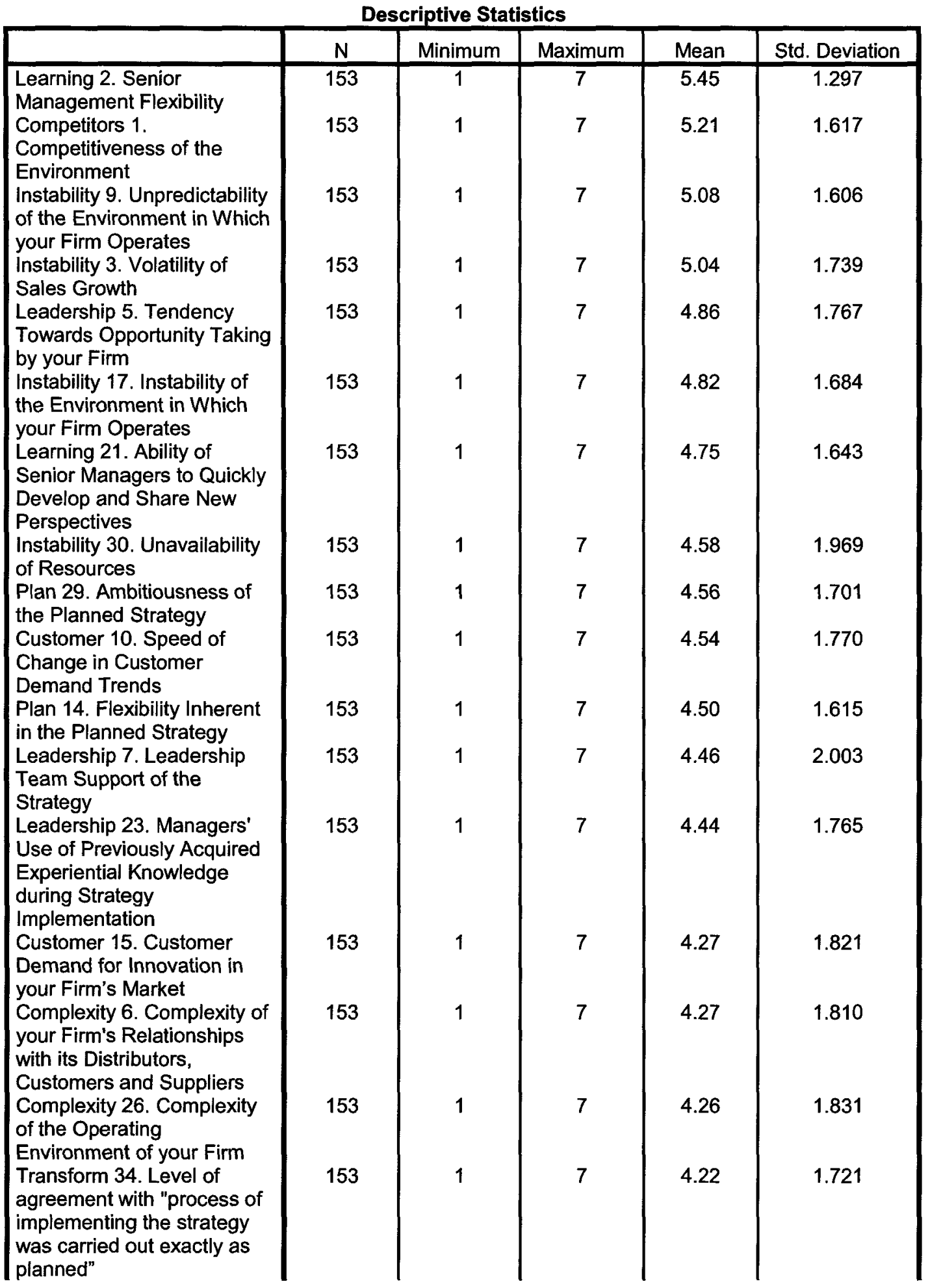


Plan 27. Feasibility of the Planned Strategy

Employee 4. Authority of Lower Level Managers to Make Decisions and Take Initiative

Customer 20. Rate of Change of Customer Needs Complexity 18 . Diversity of the Customers and Markets Served by your Firm Leadership 16. Managers Sharing a Detailed and Consistent Understanding of the Business

Competitors 24. Rate of

Response of your Firm's

Competitors to Changing Market Conditions

Leadership 31. Changes in Key Personnel

Learning 12. Tendency of your Firm to Develop Contingency Plans for Alternate Possible Futures Employee 8.

Communication by your

Firm of its Strategic Goals and Priorities to the Whole Firm

Complexity 28. Government Regulatory Requirements Employee 11. Tendency of Individuals to Pursue the Goals of their Position or Group Instead of the Goals of the Whole Organization Employee 25. Resistance to Change in your

Organization

Competitors 13. Rate of

New Product Introduction by your Firm's Competitors Employee 19. Participation of Low and Mid-Level Managers in the Strategic Planning Process

Plan 22. Rigidity of the

Planned Strategy

Transform 33. Level of achievement of secondary goals

Transform 32. Level of achievement of primary goals

Valid N (listwise)

\begin{tabular}{|c|c|c|c|c|}
\hline 153 & 1 & 7 & 4.21 & 1.894 \\
\hline 153 & 1 & 7 & 4.17 & 1.915 \\
\hline 153 & 1 & 7 & 4.14 & 1.721 \\
\hline 153 & 1 & 7 & 4.08 & 1.830 \\
\hline 153 & 1 & 7 & 4.05 & 1.817 \\
\hline 153 & 1 & 7 & 4.05 & 1.691 \\
\hline 153 & 1 & 7 & 3.93 & 1.927 \\
\hline 153 & 1 & 7 & 3.87 & 1.742 \\
\hline 153 & 1 & 7 & 3.87 & 1.972 \\
\hline 153 & 1 & 7 & 3.80 & 1.948 \\
\hline 153 & 1 & 7 & 3.79 & 2.051 \\
\hline 153 & 1 & 7 & 3.78 & 1.974 \\
\hline 153 & 1 & 7 & 3.58 & 1.750 \\
\hline 153 & 1 & 7 & 3.41 & 1.823 \\
\hline 153 & 1 & 7 & 3.10 & 1.667 \\
\hline 153 & 1 & 4 & 2.30 & .946 \\
\hline 153 & 1 & 4 & 2.05 & .934 \\
\hline 1 & & & & \\
\hline
\end{tabular}




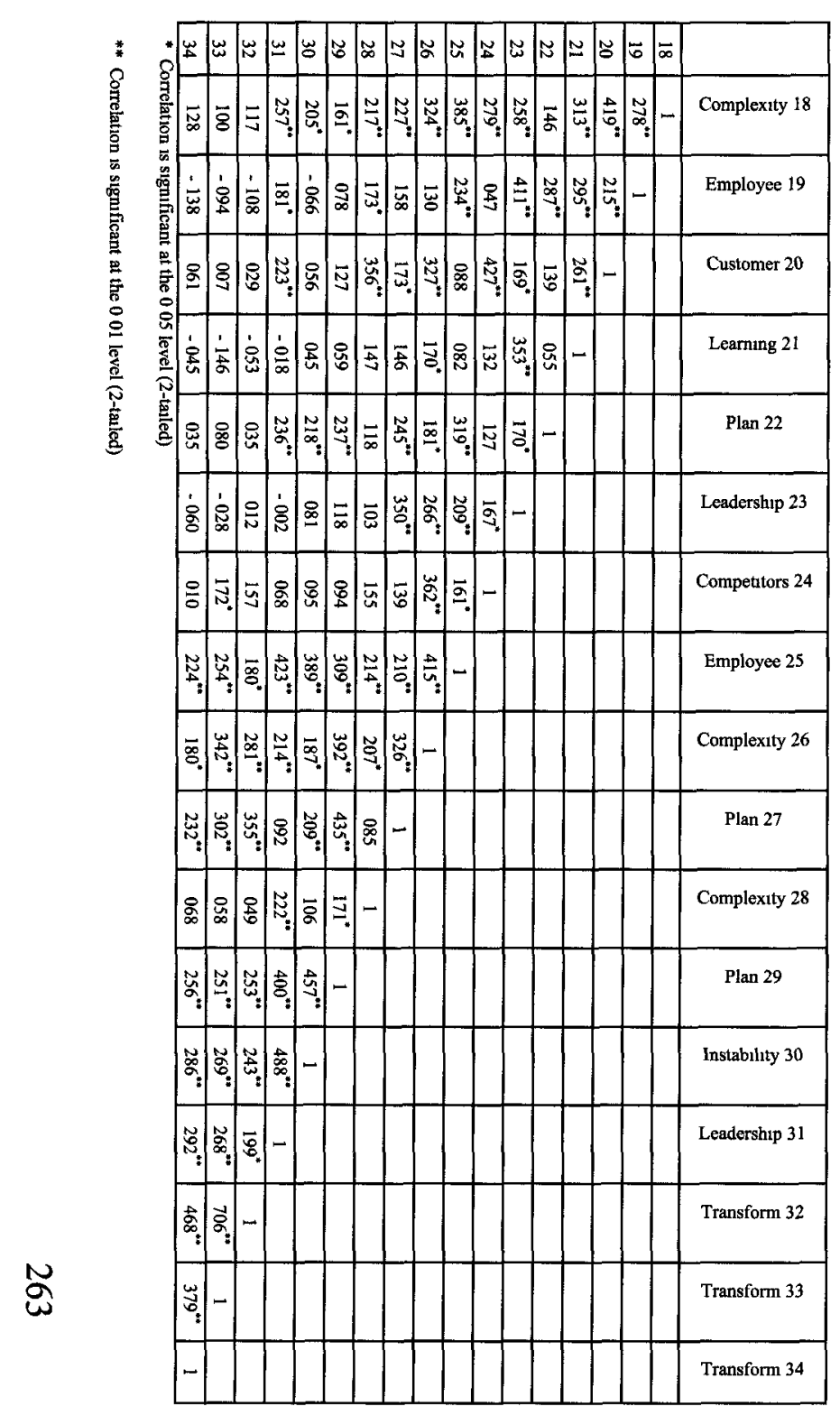

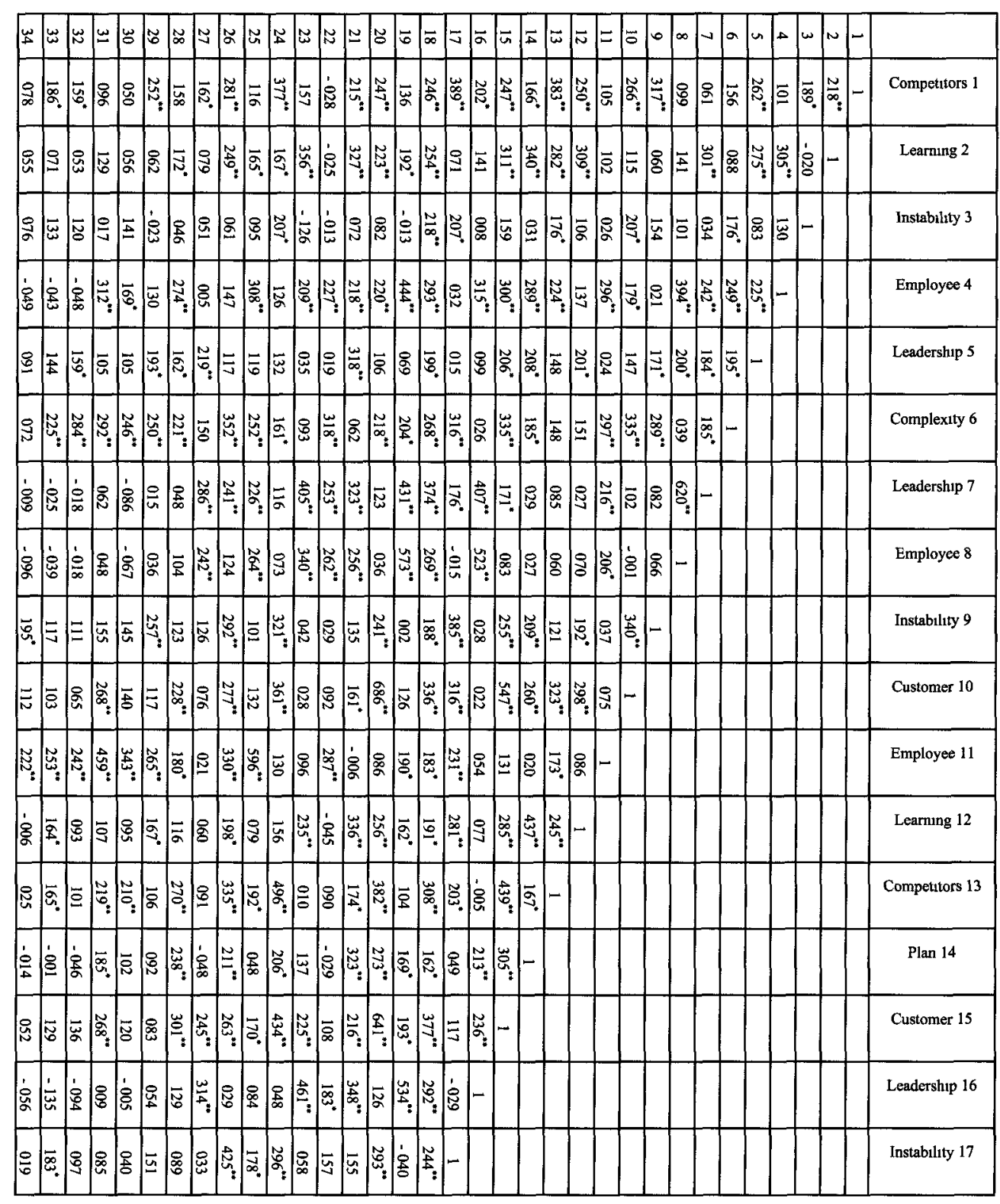




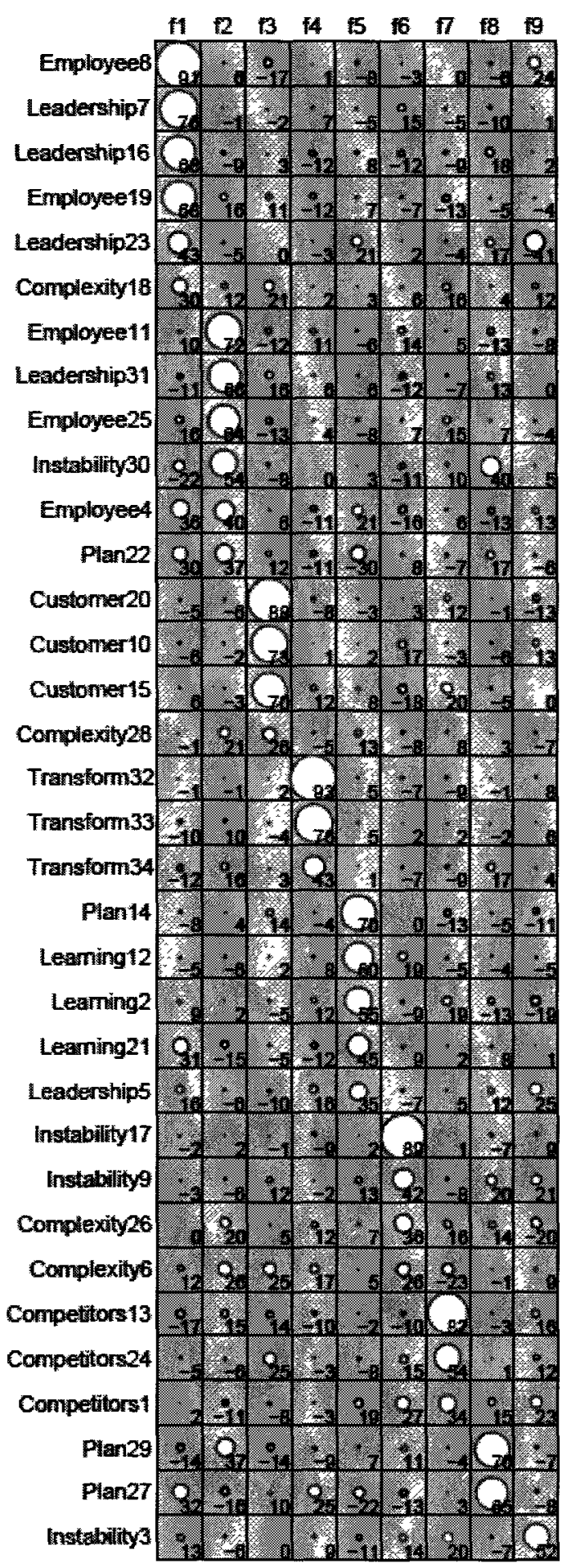




\section{REFERENCES}

Alinsky, S. D. (1971). Rules for radicals; a practical primer for realistic radicals (1st ed.). New York: Random House.

Andersen, T. J. (2004). Integrating decentralized strategy making and strategic planning processes in dynamic environments. Journal of Management Studies, 41, 1271-1299.

Anderson, P. (1999). Complexity theory and organization science. Organization Science, $10(3), 216-232$.

Andrews, K. R. (1971). The concept of corporate strategy. Homewood, Ill.: Dow JonesIrwin.

Andrews, R., Boyne, G. A., Law, J., Walker, R. M. (2009). Strategy formulation, strategy content and performance. Public Management Review, 11(1), 1-22.

Ansoff, H. I. (1964). A quasi-analytic approach to the business strategy problem. Management Technology, 4(1), 67-77.

Ansoff, H. I. (1965). Corporate strategy; An analytic approach to business policy for growth and expansion. New York: McGraw-Hill.

Ansoff, H. I. (1991). Critique of Henry Mintzberg's 'the design school: Reconsidering the basic premises of strategic management'. Strategic Management Journal, 12(6), 449461.

Armstrong, J. S. (1982). The value of formal planning for strategic decisions: Review of empirical research. Strategic Management Journal, 3(3), 197-211.

Ashill, N. J., Frederikson, M., \& Davies, J. (2003). Strategic marketing planning: A grounded investigation. European Journal of Marketing, 37(3/4), 430-460.

Bain and Co. (2003, 4 September). Bain study reveals how firms are using three main analytical tools. Financial Times.

Bamberger, P. (2008). Beyond contextualization: Using context theories to narrow the micro-macro gap in management research. Academy of Management Journal, 51(5), 839-846.

Baron, R. M., \& Kenny, D. A. (1986). The moderator-mediator variable distinction in social psychological research: Conceptual, strategic, and statistical considerations. Journal of Personality and Social Psychology, 51(6), 1173-1182. 
Barth, M. M. (2008). Deciphering student evaluations of teaching: A factor analysis approach. Journal of Education for Business, 84(1), 40-46.

Beinhocker, E. D., \& Kaplan, S. (2002). Tired of strategic planning? McKinsey Quarterly, 48.

Blythe, J., \& Zimmerman, A. (2004). Strategic planning for global markets. Marketing Review, 4, 369-384.

Boal, K. B., \& Bryson, J. M. (1987). Representation, testing and policy implications of planning processes. Strategic Management Journal, 8, 211-231.

Boyd, B. K. (1991). Strategic planning and financial performance: A meta-analytic review. Journal of Management Studies, 28(4), 353-374.

Boyd, B. K., \& Reuning-Elliott, E. (1998). A measurement model of strategic planning. Strategic Management Journal, 19, 181.

Brews, P. J., \& Hunt, M. R. (1999). Learning to plan and planning to learn: Resolving the planning school/learning school debate. Strategic Management Journal, 20(10), 889913.

Burt, D. N. (1978). Planning and performance in Australian retailing. Long Range Planning, 11(3), 62-66.

Crawford, L., Cooke-Davis, T., Hobbs, B., Labuschagne, L., Remington, K., \& Chen, P. (2008). Governance and support in the sponsoring of projects and programs. Project Management Journal, 39, S43-S55.

Cronbach, L. J. (1951). Coefficient alpha and the internal structure of tests. Psychometrika, 16, 297-334.

Cycyota, C. S., \& Harrison, D. A. (2006). What (not) to expect when surveying executives: A meta-analysis of top manager response rates and techniques over time. Organizational Research Methods, 9(2), 133-160.

Daake, D., Dawley, D. D., \& Anthony, W. P. (2004). Formal data use in strategic planning: An organizational field experiment. Journal of Managerial Issues, 16, 232247.

De Geus, A. P. (1988). Planning as learning. Harvard Business Review, 66(2), 70-74.

Depperu, D., \& Gnan, L. (2006). The role of the competitive context in the business strategy-formation process. International Studies of Management \& Organization, $36,110-130$.

Dess, G. G., \& Priem, R. L. (1995). Consensus-performance research: Theoretical and empirical extensions. Journal of Management Studies, 32(4), 401-417. 
Eisenhardt, K. M. (1989). Building theories from case study research. Academy of Management Review, 14(4), 532-550.

Entrekin, L., \& Court, M. (2001). Human resource management practice: Adaptation and change in an age of globalization. Geneva: International Labour Office.

Falshaw, J. R., Glaister, K. W., \& Tatoglu, E. (2006). Evidence on formal strategic planning and company performance. Management Decision, 44(1), 9-30.

Forbes, D. P. (1999). Cognition and corporate governance: Understanding boards of directors as strategic decision-making groups. Academy of Management Review, $24(3), 489-505$.

Frederickson, H. G., Rainey, H. G., Backoff, R. W., \& Levine, C. H. (1976). Comparing public and private organizations. Public Administration Review, 36(2), 233-244.

Ganco, M, \& Agarwal, R. (2009). Performance differentials between diversifying entrants and entrepreneurial start-ups: A complexity approach. Academy of Management Review, 34(2), 228-252.

Ginter, P. M., Ruck, A. C., \& Duncan, W. J. (1985). Planners' perceptions of the strategic management process. Journal of Management Studies, 22(6), 581.

Glaister, K. W., \& Hughes, J. F. (2008). Corporate strategy formation and taxation: Evidence from UK firms. British Journal of Management, 19(1), 33-48.

Grant, R. M. (1995). Contemporary strategy analysis: Concepts, techniques, applications (2nd ed.). Cambridge: Blackwell.

Grant, R. M. (2003). Strategic planning in a turbulent environment: Evidence from the oil majors. Strategic Management Journal, 24, 491.

Greenley, G. E. (1994). Strategic planning and company performance: An appraisal of the empirical evidence. Scandinavian Journal of Management, 10(4), 383-396.

Grinyer, P. H., \& Norburn, D. (1977). Planning for existing markets: An empirical study. International Studies of Management \& Organization, 7(3), 99-122.

Gujarati, D. N., \& Porter, D. C. (2009). Basic econometrics (5ed). New York, New York: McGraw-Hill Irwin.

Guth, W. D., \& MacMillan, I. C. (1986). Strategy implementation versus middle management self-interest. Strategic Management Journal, 7(4), 313-327.

Hambrick, D. C., \& Fredrickson, J. W. (2001). Are you sure you have a strategy? Academy of Management Executive, 15(4), 48-59. 
Harrington, R. J., Lemak, D. J., Reed, R., \& Kendall, K. W. (2004). A question of fit: The links among environment, strategy formation, and performance. Journal of Business \& Management, 10, 15-38.

Hogarth, R. M. (1987). Judgement and choice: The psychology of decision (2nd ed.). Chichester West Sussex; New York: Wiley.

Holloway, D. A. (2004). Strategic planning and habermasian informed discourse: Reality or rhetoric. Critical Perspectives on Accounting, 15(4-5), 469-483.

Hopkins, W. E., \& Hopkins, S. A. (1997). Strategic planning-financial performance relationships in banks: A causal examination. Strategic Management Journal, 18(8), 635-652.

Hutcheson, G., \& Sofroniou, N. (1999). The multivariate social scientist: Introductory statistics using generalized linear models. Thousand Oaks, CA: Sage.

Jennings, D., \& Disney, J. (2006). The strategic planning process and its context: The role of psychological type. Journal of General Management, 31, 75-93.

Jung, C. G. (1923). Psychological types; Or, the psychology of individuation [Psychologische Typen.]. London: Routledge \& K. Paul.

Kaplan, S. (2008). Framing contests: Strategy making under uncertainty. Organization Science, 19(5), 729-752.

Kaplan, S., \& Beinhocker, E. D. (2003). The real value of strategic planning. MIT Sloan Management Review, 44(2), 71-76.

Ketokivi, M., \& Castañer, X. (2004). Strategic planning as an integrative device. Administrative Science Quarterly, 49, 337-365.

Kim, K. S. (2004). Strategic planning for value-based management: An empirical examination. Management Decision, 42(8), 938-948.

Kjaergaard, A. L. (2009). Organizational identity and strategy. International Studies of Management and Organization, 39(1), 50-69.

Kotey, B., \& Meredith, G. G. (1997). Relationships among owner / manager personal values, business strategies, and enterprise performance. Journal of Small Business Management, 35(2), 37-64.

Kotter, J. P. (1982). The general managers. New York; London: Free Press; Collier Macmillan.

Kudla, R. J. (1980). The effects of strategic planning on common stock returns. Academy of Management Journal, 23(1), 5-20. 
Kwan, E., Lu, I. R. R., \& Friendly, M. (2009). Tableplot: A new tool for assessing precise predictions. Zeitschrift fur Psychologie / Journal of Psychology, 217, 38-48.

Levy, D. (1994). Chaos theory and strategy: Theory, application, and managerial implications. Strategic Management Journal, 15, 167-178.

Lichtenthaler, U. (2009). Absorptive capacity, environmental turbulence, and the complementarity of organizational learning processes. Academy of Management Journal, 52(4), 822-846.

Liedtka, J. (2008). Strategy making and the search for authenticity. Journal of Business Ethics, 80(2), 237-248.

Lindblom, C. E. (1977). Politics and markets: The world's political economic systems. New York: Basic Books.

Michael, I. (2006). Motivators for Australian consumers to search and shop online. Electronic Journal of Business Research Methods, 4(1), 47-55.

Miles, R. E., \& Snow, C. C. (1978). Organizational strategy, structure and process. New York: McGraw-Hill.

Miller, C. C., \& Cardinal, L. B. (1994). Strategic planning and firm performance: A synthesis of more than two decades of research. Academy of Management Journal, $37(6), 1649$.

Miller, D., Friesen, P. H., \& Mintzberg, H. (1984). Organizations: A quantum view. Englewood Cliffs, N.J.: Prentice-Hall.

Mintzberg, H. (1972). Research on strategy-making. Academy of Management Proceedings, 90-94.

Mintzberg, H. (1977). Strategy formation as a historical process. International Studies of Management \& Organization, 7, 28-40.

Mintzberg, H. (1979). An emerging strategy of "direct" research. Administrative Science Quarterly, 24, 582-589.

Mintzberg, H. (1987). Crafting strategy. Harvard Business Review, 65, 66-75.

Mintzberg, H. (1990). The design school: Reconsidering the basic premises of strategic management. Strategic Management Journal, 11, 171-195.

Mintzberg, H. (1994). The fall and rise of strategic planning. Harvard Business Review, $72,107-114$.

Mintzberg, H., \& Lampel, J. (1999). Reflecting on the strategy process. MIT Sloan Management Review, 40, 21-30. 
Mintzberg, H., \& Waters, J. A. (1985). Of strategies, deliberate and emergent. Strategic Management Journal, 6, 257-272.

Nunnally, J. C. (1967). Psychometric theory. 1st edition. New York: McGraw-Hill.

Nunnally, J. C. (1978). Psychometric theory. $2^{\text {nd }}$ edition. New York: McGraw-Hill.

Oliver, J. (2008). Action learning enabled strategy making. Action Learning: Research and Practice, 5(2), 149-158.

Oliver, D.G., Serovich, J. M., \& Mason, T. L. (2005). Constraints and opportunities with interview transcription: towards reflection in qualitative research. Social Forces, $84(2), 1273-1289$.

Parnell, J. A., \& Lester, D. L. (2003). Towards a philosophy of strategy: Reassessing five critical dilemmas in strategy formation and change. Strategic Change, 12, 291-303.

Pearce II, J. A., Freeman, E. B., \& Robinson Jr., R. B. (1987). The tenuous link between formal strategic planning and financial performance. Academy of Management Review, 12(4), 658-675.

Peng, M.W., Sun, S.L., Pinkham, B., \& Chen, H. (2009). The institution-based view as a third leg for a strategy tripod. Academy of Management Perspectives, 23(3), 63-81.

Peterson, Robert A. (1994). A meta-analysis of Cronbach's coefficient alpha. The Journal of Consumer Research, 21(2), 381-391.

Pinto, M. B., Pinto, J. K., \& Prescott, J. E. (1993). Antecedents and consequences of project team cross-functional cooperation. Management Science, 39(10), 1281-1297.

Poland, Blake (2002). Transcription Quality. In J. Gubrium \& Holstein (Ed), Handbook of Interview Research. Thousand Oaks, California: Sage.

Porter, M. E. (1980). Competitive strategy: Techniques for analyzing industries and competitors. New York: Free Press.

Prahalad, C. K., \& Hamel, G. (1994). Strategy as a field of study: Why search for a new paradigm? Strategic Management Journal, 15, 5-16.

Preacher, K. J., \& MacCallum, R. C. (2003). Repairing Tom Swift's Electric Factor Analysis Machine. Understanding Statistics, 2(1), 13-43.

Ring, P. S., \& Perry, J. L. (1985). Strategic management in public and private organizations: Implications of distinctive contexts and constraints. Academy of Management Review, 10(2), 276-286. 
Robinson Jr., R. B., \& Pearce II, J. A. (1988). Planned patterns of strategic behavior and their relationship to business-unit performance. Strategic Management Journal, 9(1), 43-60.

Rudd, J. M., Greenley, G. E., Beatson, A. T., \& Lings, I. N. (2008). Strategic planning and performance: Extending the debate. Journal of Business Research, 61(2), 99108.

S\&T Encyclopaedia. (2007). McGraw-hill Encyclopaedia of Science and Technology Online, 2007, from http://connect.carleton.ca/cp/tag.f394e61f9e7ba7f8.render.userLayoutRootNode.uP? uP_root=root\&uP_sparam $=$ activeTab\&activeTab=u1111 $154 \& u P$ tparam $=$ frm\&frm $=$ frame

Schäffer, U., \& Willauer, B. (2003). Strategic planning as a learning process. Schmalenbach Business Review (SBR), 55, 86-107.

Schegloff, Emanuel (1997). Whose text? Whose context? Discourse and Society, 8, $165-$ 187.

Schoemaker, P. J. H. (1995). Scenario planning: A tool for strategic thinking. Sloan Management Review, 36(2), 25-40.

Selznick, P. (1957). Leadership in administration; a sociological interpretation. Evanston, Ill.: Row, Peterson.

Shay, J. P., \& Baack, S. A. (2004). Expatriate assignment, adjustment and effectiveness: An empirical examination of the big picture. Journal of International Business Studies, 35(3), 216-232.

Simon, H. A. (1957). Administrative behavior: A study of decision-making processes in administrative organization (2d). New York: Macmillan.

Slater, S. F., Olson, E. M., \& Hult, G. T. (2006). The moderating influence of strategic orientation on the strategy formation capability-performance relationship. Strategic Management Journal, 27(12), 1221-1231.

Sminia, H. (2009). Process research in strategy formation: Theory, methodology and relevance. International Journal of Management Reviews, 11(1), 97-125.

Smircich, L., \& Stubbart, C. (1985). Strategic management in an enacted world. Academy of Management Review, 10(4), 724-736.

Snow, C. C., \& Thomas, J. B. (1994). Field research methods in strategic management: Contributions to theory building and testing. Journal of Management Studies, 31(4), 457-480. 
Stevens, J. (2002). Applied multivariate statistics for the social sciences (4th ed.). Mahwah, N.J.: Lawrence Erlbaum Associates.

Thune, S. S., \& House, R. J. (1970). Where long-range planning pays off. Business Horizons, 13(4), 81.

Thurstone, L. L. (1935). The vectors of mind. Chicago: University of Chicago Press.

Vancil, R. F., \& Lorange, P. (1975). Strategic planning in diversified companies. Harvard Business Review, 53(1), 81-90.

Vilà, J., \& Canales, J. I. (2008). Can strategic planning make strategy more relevant and build commitment over time? The case of RACC. Long Range Planning, 41(3), 273290.

Walsh, J. P., \& Fahey, L. (1986). The role of negotiated belief structures in strategy making. Journal of Management, 12(3), 325.

Welch, S. (1975). Sampling by referral in a dispersed population. Public Opinion Quarterly, 39(2), 237.

Weston, C., Gandell, T., Beauchamp, J., McAlpine, L., Wiseman, C., \& Beauchamp, C. (2001). Analyzing interview data: The development and evolution of a coding system. Qualitative Sociology, 24(3), 381.

White, J. C., Conant, J. S., \& Echambadi, R. (2003). Marketing strategy development styles, implementation capability, and firm performance: Investigating the curvilinear impact of multiple strategy-making styles. Marketing Letters, 14(2), 111124.

Wolfle, D. (1940). Factor analysis to 1940. Psychometric Monographs (No. 3). Chicago: University of Chicago Press.

Yin, R. K. (2003). Case study research: Design and methods, ( $3^{\text {rd }}$ Edition), Thousand Oakes, California: Sage. 